Air Pollutant Penetration through Airflow Leaks into Buildings

by

De-Ling Liu

B.S. (National Taiwan University, Taiwan) 1993

M.S. (National Taiwan University, Taiwan) 1995

A dissertation submitted in partial satisfaction of the

requirements for the degree of

Doctor of Philosophy

in

Engineering-Civil and Environmental Engineering

in the

GRADUATE DIVISION

of the

UNIVERSITY OF CALIFORNIA, BERKELEY

\author{
Committee in Charge: \\ Professor William W Nazaroff, Chair \\ Professor James R. Hunt \\ Professor Catherine P. Koshland
}

Fall 2002 


\section{Air Pollutant Penetration through Airflow Leaks into Buildings}

Copyright $\odot 2002$

by

De-Ling Liu 


\author{
ABSTRACT \\ Air Pollutant Penetration through Airflow Leaks into Buildings \\ by \\ De-Ling Liu \\ Doctor of Philosophy in Civil and Environmental Engineering \\ University of California, Berkeley \\ Professor William W Nazaroff, Chair
}

The penetration of ambient air pollutants into the indoor environment is of concern owing to several factors: (1) epidemiological studies have shown a strong association between ambient fine particulate pollution and elevated risk of human mortality; (2) people spend most of their time in indoor environments; and (3) most information about air pollutant concentration is only available from ambient routine monitoring networks. A good understanding of ambient air pollutant transport from source to receptor requires knowledge about pollutant penetration across building envelopes. Therefore, it is essential to gain insight into particle penetration in infiltrating air and the factors that affect it in order to assess human exposure more accurately, and to further prevent adverse human health effects from ambient particulate pollution.

In this dissertation, the understanding of air pollutant infiltration across leaks in the building envelope was advanced by performing modeling predictions as well as experimental investigations. The modeling analyses quantified the extent of airborne particle and reactive gas (e.g., ozone) penetration through building cracks and wall cavities using engineering analysis that incorporates existing information on building leakage characteristics, knowledge of pollutant transport processes, as well as pollutant- 
surface interactions. Particle penetration is primarily governed by particle diameter and by the smallest dimension of the building cracks. Particles of $0.1-1 \mu \mathrm{m}$ are predicted to have the highest penetration efficiency, nearly unity for crack heights of $0.25 \mathrm{~mm}$ or higher, assuming a pressure differential of $4 \mathrm{~Pa}$ or greater and a flow path length of $3 \mathrm{~cm}$ or less. Supermicron and ultrafine particles (less than $0.1 \mu \mathrm{m}$ ) are readily deposited on crack surfaces by means of gravitational settling and Brownian diffusion, respectively. The fraction of ozone penetration through building leaks could vary widely, depending significantly on its reactivity with the adjacent surfaces, in addition to the crack geometry and pressure difference. Infiltrating air can also travel through wall cavities, where the penetration of particles and ozone is predicted to vary substantially, depending mainly on whether air flow passes through fiberglass insulation. For ozone, its reactivity with the insulation materials is also an important factor. The overall pollutant penetration factor is governed by the flow-weighted average from all air leakage pathways. Large building leaks would strongly influence the overall penetration factor, because they permit much larger flow.

The penetration of particles was also evaluated experimentally for three building leakage components that reflect different physical scales — individual building cracks, windows, and an entire house. Rectangular single straight-through cracks made of a variety of common building materials were used as building leak surrogates to examine particle penetration in the laboratory. The experimental results agree well with model predictions, suggesting nearly complete penetration for particles of $0.02-7 \mu \mathrm{m}$ when the crack height is $\geq 1 \mathrm{~mm}$, and for particle diameters of $0.1-1 \mu \mathrm{m}$ when the crack height is $\geq$ $0.25 \mathrm{~mm}$, assuming that the pressure difference is $\geq 4 \mathrm{~Pa}$. The experimental data also 
reveal that particle penetration can be reduced if the inner crack surface roughness is large or the crack geometry is irregular.

In the laboratory-based window experiments, more than $80 \%$ of $0.2-3 \mu \mathrm{m}$ particles penetrated through two different windows at $\Delta \mathrm{P}$ of $1 \mathrm{~Pa}$, and significantly less penetration was observed for particles larger or smaller than this size range. Both windows exhibited similar performance in terms of the extent of particle penetration as a function of particle size, regardless of the installation of weatherstripping. The window air leakage rate, which is commonly reported for air tightness characterization, provides inadequate information to predict particle penetration.

The particle penetration factor with respect to a whole building was finally examined in a residence, which represents a typical modern house in the United States. With a blower door technique, a uniform pressure difference was established across the entire building envelope during depressurization to evaluate particle penetration loss through the air leakage pathways. Particle penetration factors of 0.5-0.9 were found for particles ranging from 0.02 to $2 \mu \mathrm{m}$, indicating that significant particle loss occurred as they were transported from outdoors into the indoor environment. One plausible explanation for the loss is that a fraction $(\sim 25 \%)$ of the infiltrating air passed through fiberglass insulation in wall cavities, effectively filtering ambient particles. An alternative hypothesis is that the evaporative loss of volatile constituents on particles might play a role to yield lower values of penetration factors than observed in the laboratory. To provide a quantitative estimate for the second hypothesis, four scenarios were simulated, assuming volatile species with various mixing characteristics. The resulting particle penetration factors are found to approach unity for $0.2-2 \mu \mathrm{m}$ particles 
after adjusting for evaporative loss, while penetration factors remain nearly unchanged and significantly below unity for particles $<0.2 \mu \mathrm{m}$. 
Dedicated to

Mom, Dad, and Simon 


\section{CONTENTS}

Abstract 1

Contents $\quad$ ii

List of Tables vi vi vi vis

List of Figures viii

List of Symbols $\quad$ xiv

Acknowledgements xvii

1 Introduction 1

1.1 Background 1

1.1.1 Significance of the Research 1

1.1.2 Previous Studies 2

1.1.3 Air Exchange between Outdoors and Building Interiors 4

1.1.4 Some Notes about Penetration 5

1.2 Dissertation Overview 6

1.3 Outline of Dissertation Contents 7

1.4 References 10

\section{Modeling Air Pollutant Penetration Across Building Envelopes}

2.1 Abstract 21

2.2 Introduction 22

2.3 Methods 24

2.3.1 Building Cracks 24

2.3.1.1 Airflow Characterization in Cracks 25

2.3.1.2 Characterization of Building Cracks and their Dimensions 25

2.3.1.3 Particle Penetration through Cracks 27

2.3.1.4 Penetration of Reactive Gases through Cracks 29

2.3.2 Wall Cavity 31

2.3.2.1 Wall Cavity Characterization 31

2.3.2.2 Fiberglass Insulation in Wall Cavities 32 
2.3.2.3 Particle Penetration Analysis 33

2.3.2.4 Ozone Penetration Analysis 34

2.4 Results and Discussion 35

2.4.1 Building Cracks 35

2.4.1.1 Airflow Characteristics 35

2.4.1.2 Particle Penetration 35

2.4.1.3 Overall Particle Penetration for a Building Shell with Variable Crack Heights 37

2.4.1.4 Ozone Penetration 38

2.4.2 Wall Cavity 39

2.4.2.1 Particle Penetration 39

2.4.2.2 Ozone Penetration 41

2.5 Conclusions 41

2.6 References 43

3 Measuring Particle Penetration through Building Cracks

3.1 Abstract 58

3.2 Introduction 59

3.3 Methods 61

3.3.1 Crack Apparatus and the Chamber 61

3.3.2 Experimental Setup 63

3.4 Results and Discussion 65

3.4.1 Cracks of Uniform Geometry 65

3.4.2 Penetration through a Broken Brick 69

3.5 Conclusions 70

3.6 References 72

4 Measuring Particle Penetration through Windows

4.1 Abstract 87

4.2 Introduction 88

4.3 Methods 90 
4.3.1 Experimental Setup 90

4.3.2 Experimental Protocol 92

4.4 Results and Discussion 94

4.4.1 Particle Loss Rates 94

4.4.2 Penetration Factor 95

4.4.3 Window Leakage 100

4.5 Conclusions 101

4.5 References 102

5 Measuring Particle Penetration into a Single-family House

5.1 Abstract 113

5.2 Introduction 114

5.2.1 Indoor Particle Dynamics 114

5.2.2 Highlights of Previous Studies 116

5.3 Methods 8

5.3.1 The Principle 118

5.3.2 Data Interpretation 120

5.3.3 The Study House 121

5.3.4 Instrumentation 121

5.4 Results and Discussion 124

5.4.1 Concentration Profiles of Indoor/Outdoor Aerosols 124

5.4.2 Air Exchange Rate and Pressure Difference 126

5.4.3 House Air Leakage Characterization 128

5.4.4 Particle Deposition Coefficients 129

5.4.5 Particle Penetration Assuming Nonvolatile Composition 131

5.4.6 Particle Penetration Assuming Semi-Volatile Components 133

5.4.7 Ozone Penetration 140

5.5 Conclusions 142

5.6 References 145 
6.1 Summary 174

6.2 Implications of this Research 178

6.3 Future Research Directions 179

6.3.1 Characterization of Building Leakage Distribution 179

6.3.2 Advances in Building Technology 180

6.3.3 Thermodynamic Aspects of Particle Phase Transformation 181

6.3.4 Pollutant-Surface Interactions 183

\subsection{References 184}

\section{Appendices}

Appendix A Penetration Factor Derived from Mass Balance in a Rectangular Crack

Appendix B Transport-Limited Deposition Velocity Derived from Particle Filtration Theory

Appendix C Particle Penetration Modeling Program

Appendix D Making the Concrete Crack Sample

Appendix E Construction of a Custom-Built Supermicron Aerosol Atomizer193

Appendix F Working Principles of Aerosol Instruments used in this Study

F.1 Differential Mobility Analyzer (DMA) 195

F.2 Electrical Aerosol Analyzer (EAA) 196

F.3 Aerodynamic Particle Sizer (APS) 198

F.4 Laser Aerosol Spectrometer (LAS-X) 199

F.5 Condensation Nuclei Counter (CNC) 200

Appendix G Penetration Factors Measured for Cracks Made of Aluminum, 201 Six Building Materials, and a Broken Brick

Appendix H Surface Roughness Measurement For Two Crack Samples 212

Appendix I Derivation of Particle Deposition Coefficients and Penetration 214 Factors in the Time-Integrated and Transient Analysis 


\section{LIST OF TABLES}

Table 1.1 Summary of previous studies on the relationship of indoor/outdoor 16 particle concentrations ( $\mathrm{I} / \mathrm{O}$ ratios).

Table 2.1 Reaction probability $(\gamma)$ for sarin, $\mathrm{SO}_{2}$, and ozone on selected building materials.

Table 2.2 Airflow parameters as a function of crack height for selected conditions.

Table 3.1 Estimated particle boundary layer thickness in the well-developed airflow for the $0.25 \mathrm{~mm}$ crack height at $\Delta \mathrm{P}=4 \mathrm{~Pa}$.

Table 4.1 Particle deposition loss rates and air exchange rates determined in 104 the concentration decay experiments.

Table 4.2 Penetration factors estimated by the least-squares approximation in 105 the Monte Carlo simulations for the two test windows (Wc' and Wr).

Table 5.1 Summary of previous field studies reporting particle penetration measurements.

Table 5.2 Summary of the monitoring durations and measured air-exchange rates for the pressurization and depressurization experiments in the Clovis study house.

Table 5.3 (a) Particle deposition coefficients, determined from the EAA measurements, as a function of particle size from each pressurization experiment.

Table 5.3 (b) Particle deposition coefficients, determined from the APS measurements, as a function of particle size from each pressurization experiment.

Table 5.4 The parameters of the lognormal distributions used for fitting the outdoor and indoor particle size distribution at noon, January 30, 2001.

Table 5.5 The parameters of the lognormal distributions used for fitting the outdoor and indoor particle size distributions determined from January 30 morning data.

Table G.1 Experimental particle penetration factors for cracks made of aluminum. 
Table G.2 Experimental particle penetration factors for cracks made of six 205 building materials $(z=4.5 \mathrm{~cm}, \Delta \mathrm{P}=4 \mathrm{~Pa})$.

Table G.3 Experimental particle penetration factors for cracks created by naturally broken bricks $(\Delta \mathrm{P}=4 \mathrm{~Pa}$ and the nominal flow path length $z=4.5 \mathrm{~cm}$ ).

Table H.1 Results of surface roughness measurement for brass (surrogate for 213 aluminum) and strand board. 


\section{LIST OF FIGURES}

Figure 1.1 Schematic of airborne particle dynamics in the indoor environment (modified from Thatcher and Layton, 1995). In this disseration, the ventilation pathway of interest for air pollutant penetration into indoor environments is infiltration.

Figure 1.2 Illustration of the potential sources of air infiltration for a typical house.

Figure 2.1 $\quad$ (a) Configuration of three types of idealized cracks through building envelopes, and (b) three-dimensional view of postulated straight-through crack.

Figure 2.2 Total crack width versus crack height (assumed uniform) necessary to support an infiltration rate of $150 \mathrm{~m}^{3} \mathrm{~h}^{-1}$, which is typical for a single-family residence.

Figure 2.3 Schematic of airflow paths through wall cavities in wood-frame construction; (a) uninsulated wall cavity; (b) wall cavity filled with fiberglass insulation; and (c) fiberglass-insulated wall cavity with airflow bypass.

Figure 2.4 Particle penetration factor as a function of particle diameter, crack height, and pressure difference for a straight-through crack with flow length $z=3 \mathrm{~cm}$.

Figure 2.5 Particle penetration factor as a function of particle diameter, crack height, and flow length at a fixed pressure drop of $\Delta P=10$ $\mathrm{Pa}$.

Figure 2.6 Overall particle penetration factor for a building with crack area distributed uniformly with respect to crack height. Results are presented for three different ranges of crack sizes.

Figure 2.7

Ozone penetration factor through a single crack as a function of reaction probability, crack height, and pressure difference for two flow path lengths (a) $z=3 \mathrm{~cm}$ and (b) $z=9 \mathrm{~cm}$.

Figure 2.8 Ozone penetration factor for airflow through a fiberglass blanket as a function of ozone-fiber reaction probability.

Figure 3.1 Configuration of crack apparatus (not to scale).

Figure 3.2 Schematic illustration of the crack apparatus and the aluminum mixing chamber. 
Figure 3.3 Experimental schematic for measuring particle penetration through the crack apparatus for particle diameter $d_{p}>0.6 \mu \mathrm{m}$.

Figure 3.4 Experimental schematic for measuring particle penetration through the crack apparatus for particle size $d_{p}<1 \mu \mathrm{m}$.

Figure 3.5 Experimental schematic for measuring particle penetration through the crack apparatus for particle diameter $d_{p}<0.1 \mu \mathrm{m}$ (monodisperse aerosols generated in this setup).

Figure 3.6 Comparison of model predictions with experimental data for aluminum cracks. Results are presented for four sets of crack dimensions (crack heights of 0.25 and $1.0 \mathrm{~mm}$ and crack flow lengths of 4.3 and $9.4 \mathrm{~cm}$ ), with an applied pressure difference, $\Delta \mathrm{P}=4 \mathrm{~Pa}$.

Figure 3.7 Comparison of model predictions with experimental data for aluminum cracks. Results are presented for four sets of crack dimensions (crack heights of 0.25 and $1.0 \mathrm{~mm}$ and crack flow lengths of 4.3 and $9.4 \mathrm{~cm}$ ), with an applied pressure difference, $\Delta \mathrm{P}=10 \mathrm{~Pa}$.

Figure 3.8 Experimental particle penetration factors for six crack materials at crack heights of 0.25 and $1 \mathrm{~mm}$ and with $\Delta \mathrm{P}=4 \mathrm{~Pa}$, as compared with model predictions. The flow path distance is 4.5 $\mathrm{cm}$.

Figure 3.9 Schematic illustration of concentration boundary layers for particles of (a) $0.03 \mu \mathrm{m}$ and (b) $0.3 \mu \mathrm{m}$. Surface roughness is also illustrated, with rms referring to the standard deviation of the height of the test surface, and PV representing the height difference from peak to valley.

Figure 3.10 Schematic drawing of the naturally broken brick apparatus.

Figure 3.11 Photographs of the naturally broken brick tested in this study.

Figure 3.12 Comparison of model calculations and experimental results for 86 the broken brick with crack heights of 0.25 and $1 \mathrm{~mm}$. The nominal flow path distance is $4.5 \mathrm{~cm}$.

Figure 4.1 Schematic illustration of the detachable window panel and the 106 two chambers that were employed to measure particle penetration through the window component. 
Figure 4.2 Schematic of the system for submicron particle generation and measurement in window penetration experiments. For measuring particle deposition, the generated particles are introduced into chamber 2 and particle-free air is supplied into chamber 1 .

Figure 4.3 Schematic of the system for supermicron particles generation and 108 measurement in window penetration experiments. For measuring particle deposition, the generated particles are introduced into chamber 2 and particle-free air is supplied into chamber 1 .

Figure 4.4

Air-exchange rate in chamber 2 determined simultaneously by concentration decay of $\mathrm{CO}_{2}$ and $\mathrm{SF}_{6}$. The parameter $\mathrm{CO}_{2}{ }^{*}$ is background corrected: $\mathrm{CO}_{2}{ }^{*}=\left[\left(\mathrm{CO}_{2}(\mathrm{t})-\mathrm{CO}_{2, \mathrm{~b}}\right) /\left(\mathrm{CO}_{2}(0)-\mathrm{CO}_{2, \mathrm{~b}}\right)\right]$, where $\mathrm{CO}_{2, \mathrm{~b}}$, the background $\mathrm{CO}_{2}$ concentration in air supply, is $\sim 450 \mathrm{ppm}$. The test window is Wr.

Figure 4.5 Particle concentration decay with time in the deposition experiments with an air exchange rate of $1.5 \mathrm{~h}^{-1}$. The particle concentration in chamber $2, C_{2}$, is normalized by $C_{r e f}\left(1 \mathrm{~cm}^{-3}\right)$. The test window was $\mathrm{Wr}$, and the generated submicron particles were measured by the EAA.

Figure 4.6 Measured particle concentration for mean particle diameter 0.24 $\mu \mathrm{m}$ in both chambers, as well as the simulated aerosol concentration in chamber 2 as a function of time in the concentration growth method. The test window is $\mathrm{Wr}$.

Figure 4.7 Particle penetration factors obtained for the two test windows from the steady state method, and the dynamic concentration growth approach. Airflow through the window unit was induced by means of a steady pressure drop of $1 \mathrm{~Pa}$.

Figure 5.1 Floor plan of the Clovis study residence.

Figure 5.2(a) Outdoor and indoor particle concentration profiles measured by the EAA for mean particle diameters of 0.024, 0.042, 0.075, and $0.133 \mu \mathrm{m}$ during the sampling period (Jan. 27 to 31 ). Periods of pressurization (p) and depressurization (dp) of the house are indicated on the top.

Figure 5.2(b) Outdoor and indoor particle concentration profiles measured by the EAA for mean particle diameters of $0.24,0.42$, and $0.75 \mu \mathrm{m}$ during the sampling period (Jan. 27 to 31). Periods of pressurization (p) and depressurization (dp) of the house are indicated on the top.

Figure 5.2(c) Outdoor and indoor particle concentration profiles measured by 
the APS for particle diameters of $0.9,1.2,1.6$, and $2.1 \mu \mathrm{m}$ during the sampling period (Jan. 27 to 31). Periods of pressurization (p) and depressurization (dp) of the house are indicated on the top.

Figure 5.2(d) Outdoor and indoor particle concentration profiles measured by the APS for particle diameters of 2.6,3.3, and $4.4 \mu \mathrm{m}$ during the sampling period (Jan. 27 to 31). Periods of pressurization (p) and depressurization (dp) of the house are indicated on the top.

Figure 5.3 Particle concentration profiles for (a) the unusual indoor particle 159 concentration rise at the first pressurization test; (b) the elevated submicron particle concentration outdoors at night; (c) the supermicron outdoor particle concentration peaks during the morning rush hours.

Figure 5.4 The $\mathrm{SF}_{6}$ concentration profiles versus time for various zones in 160 the study house during (a) pressurization and (b) depressurization on January 30,2001 . The $\mathrm{SF}_{6}$ removal rates correspond to the absolute value of the slope and correlation coefficients $\left(\mathrm{R}^{2}\right)$ are indicated.

Figure 5.5 Comparison of particle deposition coefficients determined from this study to past investigations, as represented with various symbols in the lower left.

Figure 5.6 Particle penetration factors based on particle deposition 162 coefficients presented in Table 5.3; (a) solid symbols represent average penetration factors from combined time-integrated and transient analysis with error bars of one standard deviation; (b) the open symbols and the error bars represent the average values of penetration factor and one standard deviation from timeintegrated analysis; (c) comparison of the average penetration factors from the two approaches.

Figure 5.7 Comparison of penetration factors obtained in this study to 163 previous investigations, as indicated with various symbols. The predicted penetration factors from Chapter 2 are also presented for reference.

Figure 5.8 Measured indoor/outdoor PM2.5 nitrate concentration profiles from Jan. 28 to Jan. 31, 2001

Figure 5.9 Curve fitting from the superposition of three log-normal 165 distributions for outdoor and indoor particles sampled at noon, when outdoor PM nitrate was at its peak concentration on January 30, 2001. 
Figure 5.10(a) The outdoor/indoor particle concentrations were taken from the measurements at noon, January 30, 2001, and the corresponding best indoor/outdoor curve fits were obtained based on the measured particle concentrations. The other three curves, with nitrate only, nitrate $+5 \%$ water, and nitrate $+10 \%$ water, represent the expected indoor particle size distribution assuming no evaporative loss. The insert provides a close-up illustration of the adjusted particle size distribution for indoor fitting and three different water contents in the particle size range of 0.02-0.2 $\mathrm{mm}$. (a) The simulated indoor PM concentration for Scenario 1, in which the particle size distributions were adjusted assuming complete dissociation of $20 \%$ externally mixed particulate nitrate that is distributed uniformly across particle sizes accompanied by various water content (0-10\%) evaporation.

Figure 5.10(b) Simulated indoor PM concentration for Scenario 2, in which the 167 particle size distributions were adjusted assuming complete dissociation of $20 \%$ internally mixed particulate nitrate that is distributed uniformly across particle sizes accompanied by various water content $(0-10 \%)$ evaporation.

Figure 5.10(c) Simulated indoor PM concentration for Scenario 3, in which the 168 particle size distributions were adjusted assuming complete dissociation of $20 \%$ externally mixed particulate nitrate that was distributed as a function of particle size, as indicated. Various water content (0-10\%) evaporation was also considered in the analysis.

Figure 5.10(d) Simulated indoor PM concentration for Scenario 4, in which the particle size distributions were adjusted assuming complete dissociation of $20 \%$ internally mixed particulate nitrate that was distributed as a function of particle size, as indicated. Various water content (0-10\%) evaporation was also considered in the analysis.

Figure 5.11 Curve fitting from the superposition of three log-normal distributions for outdoor and indoor particles sampled in the morning on January 30, 2001.

Figure 5.12 Adjusted indoor particle deposition coefficients accounting for 171 the evaporative loss for four hypothesized scenarios, as described in page 136. Determined from the January 30 pressurization experiment, the particle deposition coefficients before revision are represented by the open symbols. 
Figure 5.13 Comparison of the particle deposition coefficients before adjustments and those accounting for 5-15\% evaporative loss in Scenario 2, where the volatile constituents within particles were assumed to be internally mixed and uniformly distributed across particle size.

Figure 5.14 Comparison of particle penetration factors for noon on January 30 calculated from the four simulated scenarios, in which $20 \%$ particulate nitrate was assumed to be completely dissociated under various mixing characteristics as well as different levels of water evaporation $(0-10 \%)$.

Figure A.1 Illustration of a differential slice within a crack.

Figure B.1 Configuration of a differential slice of fiberglass blanket within a wall cavity.

Figure E.1 Schematic illustration of the custom-built supermicron aerosol atomizer.

Figure F.1 Schematic of the Differential Mobility Analyzer, Model 3071.

Figure F.2 Schematic diagram of the Electrical Aerosol Analyzer, Model 3030 .

Figure F.3 Schematic illustration of the Aerodynamic Particle Sizer, Model 3320 .

Figure F.4 Schematic of the LAS-X light scattering aerosol optical counter system.

Figure F.5 Schematic drawing of the Condensation Nuclei Counter system. 


\section{LIST OF SYMBOLS}

$C_{1}$

$C_{2}$

$C_{d}$

$C_{i}$

$\bar{C}_{i}$

$C_{o}$

$\bar{C}_{o}$

D

G

H

$H_{c}$

$L$

$L_{n}$

$N_{i}$

Pe

$\Delta P$

$Q$

$Q_{f}$

$R$

Re

$R e_{z}$

$S$

St effective (or equivalent) leakage area $\left(\mathrm{m}^{2}\right)$

the effective leakage area at reference pressure difference of $4 \mathrm{~Pa}\left(\mathrm{~m}^{2}\right)$

cross-sectional area of fiberglass blanket $\left(\mathrm{cm}^{2}\right)$

the floor area of a house $\left(\mathrm{m}^{2}\right)$

a parameter used in Equation (2.1) to approximate air flow rate through a leakage path; $C=1.5+n_{b}(-)$

particle number concentration in chamber $1\left(\mathrm{~cm}^{-3}\right)$

particle number concentration in chamber $2\left(\mathrm{~cm}^{-3}\right)$

discharge coefficient for the leakage openings (-)

indoor particle number concentration $\left(\mathrm{cm}^{-3}\right)$

time-averaged concentrations of indoor particles $\left(\mathrm{cm}^{-3}\right)$

outdoor particle number concentration $\left(\mathrm{cm}^{-3}\right)$

time-averaged number concentrations of outdoor particles $\left(\mathrm{cm}^{-3}\right)$

particle or molecular diffusion coefficient $\left(\mathrm{m}^{2} \mathrm{~s}^{-1}\right)$

indoor aerosol generation rate $\left(\operatorname{mass} \mathrm{h}^{-1}\right)$

the reference ceiling height of a test house (m), usually use $2.5 \mathrm{~m}$

the ceiling height of a test house (m)

the flow path length through the fiberglass blanket (m)

normalized leakage (-)

the particle number concentration of the $i^{\text {th }}$ mode $\left(\mathrm{cm}^{-3}\right)$

Peclet number $\left(=U_{o} d_{f} / D\right.$ in Chapter 2$)$

pressure difference across the crack openings or building envelopes

air flow rate through the leakage path, or infiltration air flow rate through the test house $\left(\mathrm{m}^{3} \mathrm{~h}^{-1}\right)$

filtration rate $\left(\mathrm{m}^{3} \mathrm{~h}^{-1}\right)$

particle resuspension rate $\left(\right.$ mass $\left.\mathrm{h}^{-1}\right)$

Reynolds number $(=U d N)$ of crack airflow (-)

Reynolds number $(=U z / N)$ based on flow path distance (-)

house interior surface area $\left(\mathrm{m}^{2}\right)$

particle Stokes number (-) 


\begin{tabular}{|c|c|}
\hline$U$ & average air velocity in the crack $\left(\mathrm{m} \mathrm{s}^{-1}\right)$ \\
\hline$U_{o}$ & freestream air speed approaching a fiber $\left(\mathrm{m} \mathrm{s}^{-1}\right)$ \\
\hline$V$ & house or chamber volume $\left(\mathrm{m}^{3}\right)$ \\
\hline$V_{s}$ & particle settling velocity $\left(\mathrm{m} \mathrm{s}^{-1}\right)$ \\
\hline$W(d)$ & distribution function of crack widths \\
\hline$d$ & crack height, the smallest dimension of a crack $(\mathrm{mm})$ \\
\hline$d_{f}$ & fiber diameter of fiberglass insulation material $(\mu \mathrm{m})$ \\
\hline$d_{p}$ & particle diameter $(\mu \mathrm{m})$ \\
\hline$\overline{d_{p i}}$ & geometric mean particle diameter in a particle size distribution $(\mu \mathrm{m})$ \\
\hline$k_{d}$ & particle deposition loss coefficient $\left(\mathrm{h}^{-1}\right)$ \\
\hline$n_{b}$ & the number of right-angle bends in the leakage path (-) \\
\hline$n_{N}^{\mathrm{o}}\left(\log d_{p}\right)$ & particle number distribution as a function of $\log d_{p}$ \\
\hline$p$ & particle penetration factor \\
\hline$p_{d}$ & particle penetration factor due to Brownian diffusion alone \\
\hline$p_{f}$ & overall penetration fraction through the fiberglass blanket \\
\hline$p_{g}$ & particle penetration factor due to gravitational settling alone \\
\hline$p_{o_{3}}$ & ozone penetration factor through a fiberglass blanket or a crack \\
\hline$p_{i}$ & particle penetration factor due to impaction alone \\
\hline$t$ & time $(\min$ or $\mathrm{h})$ \\
\hline$v_{d}$ & species deposition velocity $\left(=k_{d} V / S\right.$ in Chapter $\left.5 ; \mathrm{cm} \mathrm{s}^{-1}\right)$ \\
\hline$v_{o}$ & species overall deposition velocity $\left(\mathrm{cm} \mathrm{s}^{-1}\right)$ \\
\hline$v_{s}$ & deposition velocity in the limit of control by surface uptake $\left(\mathrm{cm} \mathrm{s}^{-1}\right)$ \\
\hline$v_{t}$ & $\begin{array}{l}\text { deposition velocity in the limit of control by gas-phase mass transport (cm } \\
\mathrm{s}^{-1} \text { ) }\end{array}$ \\
\hline$\langle v\rangle$ & Boltzmann velocity of gas molecules $\left(\mathrm{cm} \mathrm{s}^{-1}\right)$ \\
\hline$w$ & crack width, the largest dimension in the crack configuration $(\mathrm{cm})$ \\
\hline$x_{e}$ & flow entrance length along the leakage path $(\mathrm{cm})$ \\
\hline$z$ & flow path distance (or length) along the leakage path $(\mathrm{cm})$ \\
\hline$\alpha$ & solidity of fiberglass blanket (-) \\
\hline$\delta_{p}$ & boundary layer thickness of particles $(\mu \mathrm{m})$ \\
\hline$\phi$ & $=4 D z / d^{2} U ;$ a parameter used in Equation (2.4) \\
\hline
\end{tabular}


$\gamma \quad$ reaction probability, the ratio of the removal rate to the collision rate of the species on the surface (-)

$\eta$

$\eta_{d}$

$\eta_{\Sigma}$

$\lambda_{v}$

$\mu$

v

$\rho$

$\tau_{\exp }$

$\sigma_{i}$ filtration efficiency (-)

single fiber efficiency due to diffusion alone (-)

total single fiber efficiency (-)

air-exchange rate $\left(\mathrm{h}^{-1}\right)$

dynamic viscosity of air $\left(\mathrm{g} \mathrm{cm}^{-1} \mathrm{~s}^{-1}\right)$

kinematic viscosity of air $\left(\mathrm{cm}^{2} \mathrm{~s}^{-1}\right)$

air density $\left(\mathrm{kg} \mathrm{m}^{-3}\right)$

duration of pressurization or depressurization experiment (h)

geometric standard deviation of particle size distribution (-) 


\section{ACKNOWLEDGEMENTS}

It now remains for me to remember, with both pleasure and gratitude, all those who have helped me during my doctoral career at Cal. In particular, I would like to thank my research advisor, Professor Bill Nazaroff, for his intellectual stimulation, guidance, and support over the years. Bill has showed me how to explore and define the important issues in research, and has helped me step back and take a broader picture. Bill's meticulous review and revision of the manuscripts have inspired me what it takes to convey an idea concisely and gracefully.

Needless to say, this dissertation reflects contributions from many people. I am most indebted to Professor Chiu-sen Wang in National Taiwan University for his generous loan of the Electrical Aerosol Analyzer, making the experimental work conducive to completion. I am also greatly thankful to Professors Cathy Koshland and James Hunt for taking their time in summer to carefully review and improve this dissertation, as well as to Professor Rob Harley for his insightful comments to my talks in the airhead seminar, and for lending the Ozone Analyzer. My special thank goes to Tracy Thatcher for her generosity of sharing her valuable experiences with the aerosol instruments, which gave me a good start in the lab. I appreciate having Alvin Lai's companion in my mid-graduate student days, and I know I can always count on Alvin whenever I need a hand. I would like to thank Glenn Morrison's assistance, during his busy days of dissertation writing, in measuring ozone reaction probability on glass fibers. Thanks to Doug Sullivan, Doug Black, Mike Apte, Darryl Dickerhoff, and David Faulkner for their generosity regarding the instrument use and loan. I have also greatly benefited from the technical support from the skilled staffs in the shop: Mark Troxler, Jeff 
Higginbotham, Doug Zulaica, Dick Parsons, Lev Stepanov, Frank Lotora, and Chris Moy. Furthermore, I would like to acknowledge Steve Irick in the Optical Metrology Laboratory at Lawrence Berkeley National Laboratory, who offered invaluable assistance in the surface roughness measurement of crack samples. I also wish to express my appreciation to Ashok Gadgil and Rich Sextro for their assistance both intellectually and financially over the years.

Certainly I had a good fortune enjoying a neat work environment for Mark Sippola's good housekeeping habits. Jeff Siegel was always ready to lend a hand when it came to borrowing stuff from the hill. It wouldn't be possible for me to meet Kim Rannala and Elif Pehivanoglu, whom I'd like to thank for their warm friendship, had I decided not to come to Berkeley.

Additionally, the work in this dissertation could not have been possible without the financial support from Department of Energy via the Indoor Environment Program at Lawrence Berkeley National Laboratory, and from UC Toxic Substances Research and Training Program.

Last but not the least, I thank my Family for their unconditional love, faith, and encouragement throughout these years. I have been fortunate to enjoy the greatest freedom in pursuing the path I am taking, while my Parents, with their enormous understanding and support, are always there for me at every turn. Most of all, I would like to thank Simon, my understanding and loving husband, for his patience and unreserved love that I, with my entire life, will never have as much as his in return. 


\section{INTRODUCTION}

\subsection{BACKGROUND}

\subsubsection{Significance of the Research}

Building envelopes were once considered to be able to provide sufficient protection against ambient air pollutants, such as episodes of urban photochemical smog, intermittent exhaust emission from vehicles, abrupt emanations from wildfires and volcano eruptions, or accidental release due to operation failure of industrial facilities. Once pollutants are released, they are transported with prevailing air movements, advecting downwind and spreading by turbulent dispersion. During the journey, their concentrations are diluted in the atmosphere, and they may be lost either by atmospheric transformation or by deposition. Air contaminants that contact the outer boundary of a building may enter through the air intake of the ventilation system, or through building air leakage pathways. A portion of air contaminants may be lost as they travel across the building envelopes. The pollutants that remain airborne in indoor environments can potentially contribute to adverse human health effects.

Recent epidemiological studies have shown a strong correlation between ambient particulate pollution and adverse human health effects (Schwartz, 1994; Thurston et al., 1994; Pope, 2000; Pope et al., 2002). Since people spend a large fraction of time indoors (Jenkins et al., 1992; Klepeis et al., 2001), most exposure is expected to occur in the indoor environment. As a result, the penetration of ambient particles into buildings is an important component in the sequence of events necessary for such an association to indicate a causal relationship. The effectiveness of particle penetration is expected to vary with particle properties such as size and chemical composition. Exposure of building occupants to pollutants of outdoor origin can occur 
through inhalation, or through dermal contact of contaminants that have been deposited in the indoor environment. Resuspension of previously deposited particles may also play a role.

In addition, concerns have been raised with respect to material damage owing to the deposition of airborne particles in the indoor environment, such as soiling of artworks (Nazaroff et al., 1990), and contamination in high purity environments such as semiconductor and biotechnology facilities (Cooper, 1986; Schroth, 1996). Efforts have been made to reduce the particle levels in such locations by operating air filtration devices, increasing the fraction of air recirculation, frequent housekeeping activities, avoiding particle generation activities, etc. Nevertheless, the intrusion of outdoor particles through unintentional building openings may contribute significantly to the indoor particle levels, particularly when the ambient air is heavily polluted.

Among indoor particles of ambient origin that are inhaled by humans or are deposited onto indoor surfaces, a substantial proportion passes through building envelopes in their transit between source and receptor. All of these issues underline the importance of studying the penetration process of airborne particles through building envelopes, and physical factors that affect such transport.

\subsubsection{Previous Studies}

Indoor airborne particle levels in comparison to outdoor particle concentrations were first measured by Gruber and Alpaugh (1954). In subsequent decades, people began to realize that most exposure to air pollutants actually occurred inside buildings, which pointed to the importance of characterizing indoor air pollution. The relationship of indoor and outdoor airborne particle levels (I/O ratios) has since been explored extensively with the major 
investigations summarized chronologically in Table 1.1. These results indicated no clearly consistent correlations for the I/O ratios owing to the activities that caused indoor particle generation (smoking, for example) and because of indoor removal mechanisms such as filtration in air-conditioning systems. Although the measured I/O ratio offers helpful information for personal exposure, it cannot identify the individual physical factors that lead to such $\mathrm{I} / \mathrm{O}$ results. Since indoor particles can be generated and removed through various mechanisms (as shown schematicaly in Figure 1.1; see §5.2.1 for more discussion), the evaluation of I/O ratios, for which the contributions from each factor collapse into one value, is not adequate to provide insight into the transport of ambient particles into the indoor environments across the building envelopes.

Attention has been raised with respect to the penetration of ambient particles into the indoor environment since the mid 1950s, largely owing to the concerns over the shielding effect of a building against radiation in the case of nuclear accidents (Stewart et al., 1955). Subsequent investigations that followed the same line have focused on the study of the protection factor - the ratio of dose (time-integrated concentration) that would result from exposure to outdoor concentrations to that accumulated indoors (Megaw, 1962; Alzona et al., 1979; Cederwall, et al., 1976; Cohen and Cohen, 1980; Cristy and Chester, 1981; Engelmann, 1992; Engelmann et al., 1992; Lewis, 1995). Recently, as the interest of human exposure to indoor particles of outdoor origin has grown, greater effort has been undertaken in evaluating particle penetration factors based mainly on field experimental evidence (Thatcher and Layton, 1995; Özkaynak et al., 1996; Long et al.; 2001, Lunden et al., 2001; Vette et al., 2001). Laboratory-based experiments of particle penetration through leakage paths have also been reported (Lewis, 1995; Mosely et al., 2001). More details of these studies will be mentioned in 
the following chapters.

\subsubsection{Air Exchange between Outdoors and Building Interiors}

To understand how ambient air pollutants are transported across a building envelope, a mechanistic view of air exchange between outdoors and indoors is required. Buildings are ventilated by three major mechanisms: mechanical ventilation, natural ventilation, and infiltration (ASHRAE, 1993). Mechanical ventilation, i.e. air exchange induced by fans, is designed to provide sufficient outdoor air to the buildings and remove contaminants generated indoors. The proper design and operation of a ventilation system provides for control of the air-exchange rate, air distribution within a building, and acceptable thermal comfort. Mechanical ventilation is generally mandatory for large buildings, and is advisable for places where optimal air supply and distribution is a concern. Many residences and small buildings are not equipped with mechanical ventilation systems, and instead are primarily ventilated by natural ventilation and infiltration. Natural ventilation refers to air exchange through designed openings, such as open doors and windows. Air exchange by natural ventilation is expected to be dominant in mild climate zones, where many residences and small buildings have open windows to provide adequate ventilation. Infiltration is the uncontrolled flow of air through unintentional building cracks and leaks in the building envelope. Air exchange by infiltration becomes the primary mode of ventilation for buildings without mechanical ventilation during cooling and heating seasons when doors and windows are closed. The potential sites of building leaks for air infiltration are illustrated in Figure 1.2. Both natural ventilation and infiltration can be caused by wind, buoyancy induced flow, and appliance operation, such as the use of bathroom fans, kitchen hoods, and fireplaces. 
For large buildings, the penetration of ambient particles into the indoor environment can be strongly influenced by the performance of filters in the air handling system (Hanley et al., 1994). Nevertheless, substantial infiltration can occur even in mechanically ventilated buildings ${ }^{1}$ (Grot and Persily, 1986); thus the study of pollutant penetration is relevant in many circumstances. In buildings where natural ventilation dominates air exchange, particle penetration should be almost complete because the airflow openings are large. Particle penetration in infiltration-dominated buildings is expected to depend on building air leakage characteristics, the pressure difference that induces air flow, and particle transport properties.

\subsubsection{Some Notes about Penetration}

Infiltrating air enters the indoor environment through building leakage paths. Assume that pollutant removal from infiltrating air is a steady, first-order loss process. Then, the average pollutant concentration in air at egress is proportional to the concentration as it enters the leakage path. The ratio of these two concentrations is called the penetration factor, denoted $p$. Therefore, the rate of pollutant entry through a leakage path can be expressed as $p Q C_{o}$, where $Q$ is the volumetric airflow rate through that path and $C_{o}$ is the species concentration in outdoor $\mathrm{air}^{2}$. The penetration factor is a function of the pollutant species. It also depends on the leakage geometry, surface materials, and pressure drop along the leakage path. When considering all the air that enters a building by infiltration, the overall penetration factor for the entire envelope is the flow-weighted average of the penetration factors over all building leakage paths.

1 Under windy conditions, the average infiltration rates were found to constitute $23-61 \%$ of the building design heating load from the measurements of eight federal buildings.

2 Strictly, this expression requires an adjustment for expansion or contraction if the air temperature changes along the flow path. 
Note that the penetration factor may vary with time or with environmental conditions such as temperature or relative humidity. Also, penetration may not be well described by a simple proportionality constant. It may depend on the nature of pollutant-surface interactions or on properties of the pollutant per se, such as reversible sorption of volatile organic compounds, or the volatility of semi-volatile inorganic constituents. These potentially important subtleties will be explored in Chapter 5 of this dissertation.

\subsection{DISSERTATION OVERVIEW}

The objective of this dissertation is to advance our understanding of the proportion of ambient air pollutants that penetrate into indoor environments through unintentional openings in building envelopes, with a special emphasis on the physical behavior of airborne particles. This aspect is of particular concern since elevated ambient fine particle levels have been shown to be strongly linked with enhanced mortality and morbidity related to respiratory and cardiopulmonary diseases. People spend a majority of their time indoors, and so inhalation exposures to particles of outdoor origin is influenced by the extent to which ambient particles penetrate into and persist in buildings. The research addressed in this dissertation is important for assessing the contribution to exposure of indoor particles of ambient origin, as well as for providing insights into the physical factors that affect the extent of particle penetration in infiltrating air. The objectives of the research were accomplished through engineering analysis, model calculations, and experimental studies of leakage components on three distinct scales individual cracks, window assemblies, and a whole house.

Assuming idealized building leakage geometry, a model was formulated to predict the fractional penetration of airborne particles through building cracks and wall cavities. As an 
extension based on the same modeling framework, the penetration of reactive gases (e.g., ozone) was modeled by incorporating existing knowledge of pollutant-surface interactions. For

the experimental studies, the physical scale and system complexity increased in each succeeding phase. Particle penetration across building cracks, using rectangular slots as surrogates, was determined as the ratio of particle concentration downstream to that upstream of the slot in a specially constructed laboratory apparatus. Particle penetration through windows, which were installed in a two-chamber system, was inferred by analyzing data on the dynamic relationship of particle concentrations in both chambers. A field study, in a single-family house, located in Clovis, California (near Fresno), was conducted to evaluate particle penetration through the entire building envelope. Throughout the experimental research, the modeling results serve as a baseline for comparison to the data obtained in the experimental studies.

\subsection{OUTLINE OF DISSERTATION CONTENTS}

This dissertation explores air pollutant penetration into buildings through air infiltration pathways by means of both model analysis and experimental studies. In Chapter 2, a modeling exploration aims to quantitatively characterize the fractional pollutant penetration as air infiltrates through building cracks and wall cavities. Three idealized crack configurations — straightthrough, L-shaped, and double-bend — were postulated to evaluate the extent of particle penetration, assuming uniform crack geometry, smooth inner crack surface and steady airflow. The calculations were performed for crack heights of 0.25 and $1 \mathrm{~mm}$, flow-path lengths of 3 and $9 \mathrm{~cm}$ and under pressure difference less than $10 \mathrm{~Pa}$. Two major particle deposition mechanisms, gravitational settling and Brownian diffusion, were incorporated into the analysis, which was applied for particle diameters ranging from 0.001 to $100 \mu \mathrm{m}$. For wall cavities, the 
calculation of particle penetration with respect to three different insulation practices was performed utilizing filtration theory (Hinds, 1982). Built on the same modeling framework for particles, the analysis of reactive gas (specifically considering ozone) penetration through building cracks and wall cavities was conducted, by incorporating the kinetics of pollutantsurface reactions, as parameterized by reaction probability $(\gamma)$. For a given crack geometry and pressure difference, the fractional penetration was predicted as a function of particle size or reaction probability, respectively. The overall particle penetration factor into a building, computed from the flowrate-weighted average penetration for each crack, was also evaluated based on hypothetical distributions of building cracks.

One of the objectives of the laboratory-based experimental work in Chapter 3 was to validate the modeling calculations for particle penetration through a single crack, as predicted in Chapter 2. Therefore, a rectangular single-crack apparatus, as a surrogate of air leakage paths in building envelopes, was constructed with crack heights of $0.25 \mathrm{~mm}$ and $1 \mathrm{~mm}$ from a variety of building materials, including aluminum, brick, concrete, plywood, redwood lumber, pine lumber, and strand board. Nonvolatile particles were generated and introduced into a wellmixed chamber to which the crack apparatus was mounted. Air was drawn at a constant airflow rate through the slot from the chamber at a pressure difference of 4 or $10 \mathrm{~Pa}$. Sizeresolved particle penetration was measured, for particle diameters of 0.02-7 $\mu \mathrm{m}$, as the ratio of particle concentration downstream of the crack to that in the chamber. The effect of surface roughness and irregular crack geometry on particle penetration was also explored, shedding light on the physical factors that can be potentially exploited as control tools to manipulate particle penetration.

Based on the foundations built in Chapters 2 and 3, Chapter 4 extended the physical 
scale of leakage paths to a building component, i.e., a window assembly. This represents a building subsystem with more complicated air leakage paths compared to a straight-through crack. The extent of particle penetration through two aluminum-framed sliding windows, one with weatherstripping and the other without, was measured in the laboratory. Mounted in a plywood panel, the finished window was inserted to separate two well-mixed chambers of identical volumes. The design of the two-chamber system was intended to offer optimal control of particle concentrations on both sides of the test window. The typical experimental scheme involved measuring the growth of particle concentration in one chamber from a negligible level, with particle-laden air flowing through the window leaks at a fixed air flow rate from the other chamber. Particle loss rate due to air exchange and deposition onto the chamber surface was determined in a separate experiment. The particle penetration factor was then inferred from the dynamic relationship of concentrations in both chambers. The window performance with respect to particle penetration was compared to the measured air leakage rate, which is commonly reported for assessing window air tightness as part of window quality certification in the fenestration industry.

In Chapter 5, field experiments were performed to study the transport of ambient particles infiltrating into a full scale, single-family house. Although the particle penetration process had been studied by other researchers, we have developed and applied a distinct experimental approach, and have proposed a new model for data analysis to further explore particle penetration across the building envelope. The experiments involved the use of a blower door to pressurize or depressurize the entire house to decouple the effects of particle deposition and penetration. Particle deposition in the house was determined during pressurization, in which ambient air was moved through the blower door fan, leading to complete particle penetration 
into the house. Particle penetration could be determined when the house was depressurized, in which ambient particles were brought in through unintentional building leakage paths. The pressure difference across the building envelope was constantly monitored. Both indoor and outdoor particle concentrations, as well as tracer gas decay at six locations in the house were measured continuously when the blower door was in use. The evaporative loss of particulate volatile constituents was taken into account, in order to provide better estimates of the particle penetration factor.

Chapter 6 highlights the major findings from this dissertation and outlines potential future research directions. The dissertation ends with nine Appendices that provide details in support of some fine points of the dissertation.

\subsection{REFERENCES}

Abt, E., Suh, H.H., Catalano, P., and Koutrakis, P. (2000) Relative contribution of outdoor and indoor particle sources to indoor concentrations, Environmental Science and Technology, 34: 3579-3587.

Alzona, J., Cohen B.L., Rudolph, H., Jow, H.N., and Frohliger, J.O. (1979) Indoor-outdoor relationships for airborne particulate matter of outdoor origin, Atmospheric Environment, 13: $55-60$.

Andersen, I. (1972) Relationships between outdoor and indoor air pollution, Atmospheric Environment, 6: 275-278.

ASHRAE (1993) ASHRAE Handbook: 1993 Fundamentals. American Society of Heating, Refrigerating, and Air-Conditioning Engineers, Atlanta, Chapter 23.

Biersteker, K., de Graaf, H., and Nass, Ch.A.G. (1965) Indoor air pollution in Rotterdam 
homes, International Journal of Air and Water Pollution, 9: 343-350.

Cederwall, R.T., Meyers, R.E., and Polk, J.D. (1976) Note on the effectiveness of indoor shelter as a countermeasure to achieve reduced radionuclide inhalation in the event of a nuclear accident, Water, Air, and Soil Pollution, 5: 501-505.

Cohen, A.F. and Cohen, B.L. (1980) Protection from being indoors against inhalation of suspended particulate matter of outdoor origin, Atmospheric Environment, 14: 183-184.

Colome, S.D., Kado, N.Y., Jaques, P., and Kleinman, M. (1992) Indoor-outdoor air pollution relations: Particulate matter less than $10 \mu \mathrm{m}$ in aerodynamic diameter (PM10) in homes of asthmatics, Atmospheric Environment, 26A: 2173-2178.

Cooper, D.W. (1986) Particulate contamination and microelectronics manufacturing: An introduction, Aerosol Science and Technology, 5: 287-299.

Christy G.A., and Chester, C.V. (1981) Emergency protection from aerosols, ORNL-5519, Oak Ridge National Laboratory, Oak Ridge, TN.

Engelmann, R.J. (1992) Sheltering effectiveness against plutonium provided by buildings, Atmospheric Environment, 26A: 2037-2044.

Engelmann, R.J., Pendergrass, W.R., White, J.R., and Hall, M.E. (1992) The effectiveness of stationary automobiles as shelters in accidental releases of toxic materials, Atmospheric Environment, 26A: 3119-3125.

Grot, R.A., and Persily, A.K. (1986) Measured air infiltration and ventilation rates in eight large office buildings, Measured Air Leakage of Buildings, ASTM STP 904, American Society for Testing and Materials, Philadelphia, pp 151-183.

Gruber, C.W., and Alpaugh, E.L. (1954) The automatic filterpaper sampler in an air pollution measurement program, Air Repair, 4: 143-146. 
Hanley, J.T., Ensor, D.S., Smith, D.D. and Sparks, L.E. (1994) Fractional aerosol filtration efficiency of in-duct ventilation air cleaners, Indoor Air, 4: 169-178.

Hinds, W.C. (1982) Aerosol Technology, Wiley, New York.

Jenkins, P.L., Phillips T.J., Mulberg, E.J. and Hui, S.P. (1992) Activity patterns of Californians: Use of and proximity to indoor pollutant sources, Atmospheric Environment, 26A: 2141-2148.

Klepeis, N.E., Nelson, W.C., Ott, W.R., Robinson, J. P., Tsang, A.M., Switzer, P., Behar, J.V., Hern, S.C. and Engelmann, W.H. (2001) The National Human Activity Pattern Survey (NHAPS): A resource for assessing exposure to environmental pollutants, Journal of Exposure Analysis and Environmental Epidemiology, 11: 231-252.

Koutrakis, P., Briggs, S.L.K., and Leaderer, B.P. (1992) Source apportionment of indoor aerosols in Suffolk and Onondaga counties, New York, Environmental Science and Technology, 26: 521-527.

Lee, R.E. Jr. (1972) The size of suspended particulate matter in air, Science, 178: 567-575. Lefcoe, N.M, Inculet, I.I. (1975) Particulates in domestic premises II. Ambient levels and indoor-outdoor relationships, Archives of Environmental Health, 30: 565-570.

Lewis, S. (1995) Solid particle penetration into enclosures, Journal of Hazardous Materials, 43: $195-216$.

Ligocki, M.P., Salmon, L.G., Fall, T., Jones, M.C., Nazaroff, W.W., Cass, G.R. (1993) Characteristics of airborne particles inside southern California museums, Atmospheric Environment, 27A: 697-711.

Long, C.M., Suh, H.H., Catalano, P.J., and Koutrakis, P. (2001) Using time- and size- 
resolved particulate data to quantify indoor penetration and deposition behavior, Environmental Scence and Technology, 35: 2089-2099. (See also errata, p. 4584) Lunden, M.M., Thatcher, T.L., Littlejohn, D., Fisher, M.L., Kirchstetter, T.W., Hering, S.V., Stolzenburg, M., and Brown, N.J. (2001) Building a predictive model of indoor concentrations of outdoor PM-2.5 in Homes, LBNL-48929, Lawrence Berkeley National Laboratory, Berkeley, CA.

Megaw, W.J. (1962) The penetration of iodine into buildings, International Journal of Air and Water Pollution, 6: 121-128.

Mosley, R.B., Greenwell, D.J., Sparks, L.E., Guo, Z., Tucker, W.G., Fortmann, R., Whitfield, C., (2001) Penetration of ambient fine particles into the indoor environment, Aerosol Science and Technology, 34: 127-136.

Nazaroff, W.W., Salmon L.G., and Cass, G.R. (1990) Concentration and fate of airborne particles in museums, Environmental Science and Technology, 24: 66-77.

Özkaynak, H., Xue, J., Weker, R., Butler D., and Spengler, J. (1993) The Particle TEAM (PTEAM) study: Analysis of the data, Volume III, Draft Final Report, Contract \#68-024544, Research Triangle Park, NC, US EPA.

Özkaynak, H., Xue, J., Spengler, J., Wallace, L., Pellizzari, E., and Jenkins, P. (1996) Personal exposure to airborne particles and metals: Results from the Particle TEAM study in Riverside, California, Journal of Exposure Analysis and Environmental Epidemiology, 6: $57-78$.

Pope, C.A. III. (2000) Review: Epidemiological basis for particulate air pollution health standards, Aerosol Science and Technology, 32: 4-14.

Pope, C.A., Burnett, R.T., Thun, M.J., Calle, E.E., Krewski, D., Ito, K., and Thurston, G.D. 
(2002) Lung cancer, cardiopulmonary mortality, and long-term exposure to fine particulate air pollution, Journal of American Medical Association, 287: 1132-1141.

Schroth, T. (1996) New HEPA/ULPA filters for clean-room technology, Filtration and Separation, 33: 245-250.

Schwartz, J. (1994) Air pollution and daily mortality: A review and meta analysis, Environmental Research, 64: 36-52.

Spengler, J.D., Dockery, D.W., Turner, W.A., Wolfson, J.M., and Ferris, B.G. Jr. (1981) Long-term measurements of respirable sulfates and particles inside and outside homes, Atmospheric Environment, 15: 23-30.

Spengler, J.D., Treitman, R.D., Tosteson T.D., Mage, D.T., and Soczek, M.L. (1985) Personal exposures to repirable particulates and implications for air pollution epidemiology, Environment Science and Technology, 19: 700-707.

Stewart, N.G., Chisholm, J.M., Crooks, R.N., and Gale, H.J. (1955) The shielding provided by a brick house against gamma radiation from a uniformly distributed source, Atomic Energy Research Establishment, HP/R 1782.

Suh, H.H., Koutrakis, P., and Spengler, J.D. (1994) The relationship between airborne acidity and ammonia in indoor environments, Journal of Exposure Analysis and Environmental Epidemiology, 4: 1-22.

Thatcher, T.L. and Layton, D.W. (1995) Deposition, resuspension, and penetration of particles within a residence, Atmospheric Environment, 29: 1487-1497.

Thompson, C.R., Hensel, E.G., and Kats, G. (1973) Outdoor-indoor levels of six air pollutants, Journal of Air Pollution Control Association, 23: 881-886.

Thurston, G.D., Ito, K., Hayes, C.G., Bates, D.V., and Lippmann, M. (1994) Respiratory 
hospital admissions and summertime haze air pollution in Toronto, Ontario: Consideration of the role of acid aerosols, Environmental Research, 65: 271-290.

Vette, A.F., Rea, A.W., Lawless, P.A., Rodes, C.E., Evans, G., Highsmith, V.R. and Sheldon, L. (2001) Characterization of indoor-outdoor aerosol concentration relationships during the Fresno PM exposure studies, Aerosol Science and Technology, 34: 118-126.

Weatherley, M.L. (1966) The effect of buildings, International Journal of Air and Water Pollution, 10: 404-409.

Williams, R., Suggs, J., Creason, J., Rodes, C., Lawless, P., Kwok, R., Zweidinger R., and Sheldon L. (2000) The 1998 Baltimore particulate matter epidemiology exposure study: Part 2. Personal exposure assessment associated with an elderly study population, Journal of Exposure Analysis and Environmental Epidemiology, 10: 533-543.

Yocom, J.E., Clink, W.L., and Cote, W.A. (1971) Indoor/outdoor air quality relationships, Journal of Air Pollution Control Association, 21: 251-259. 


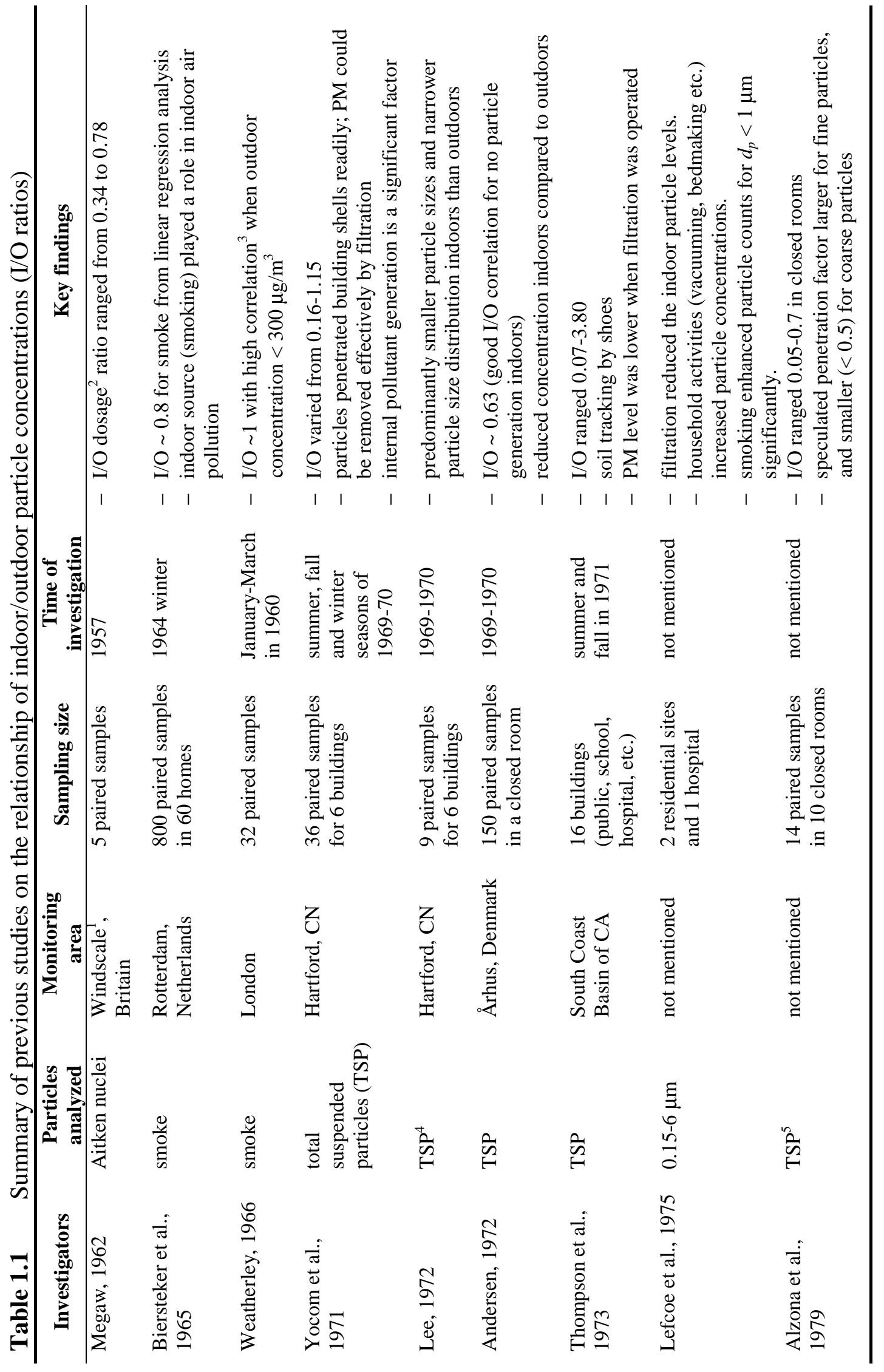




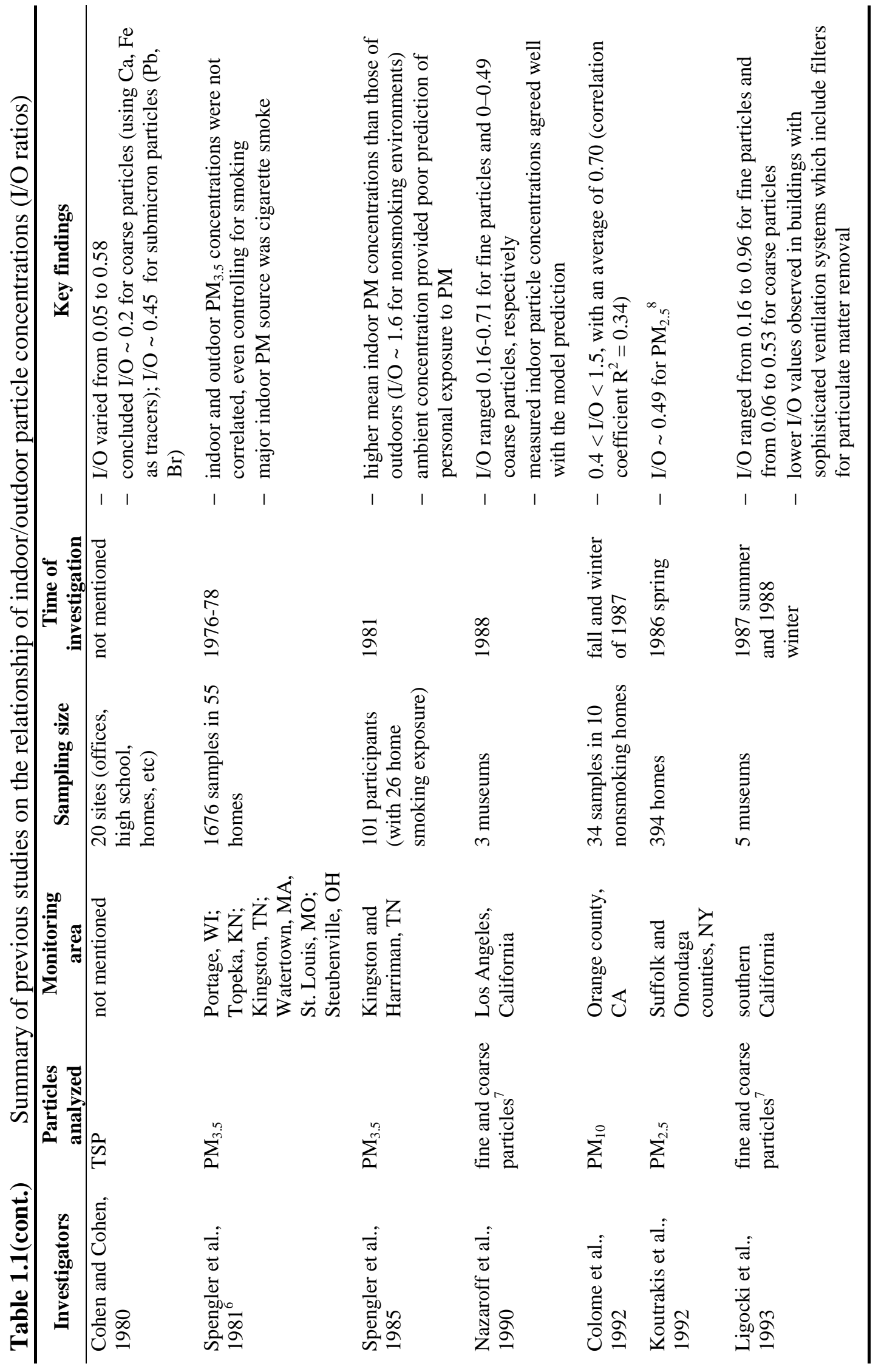




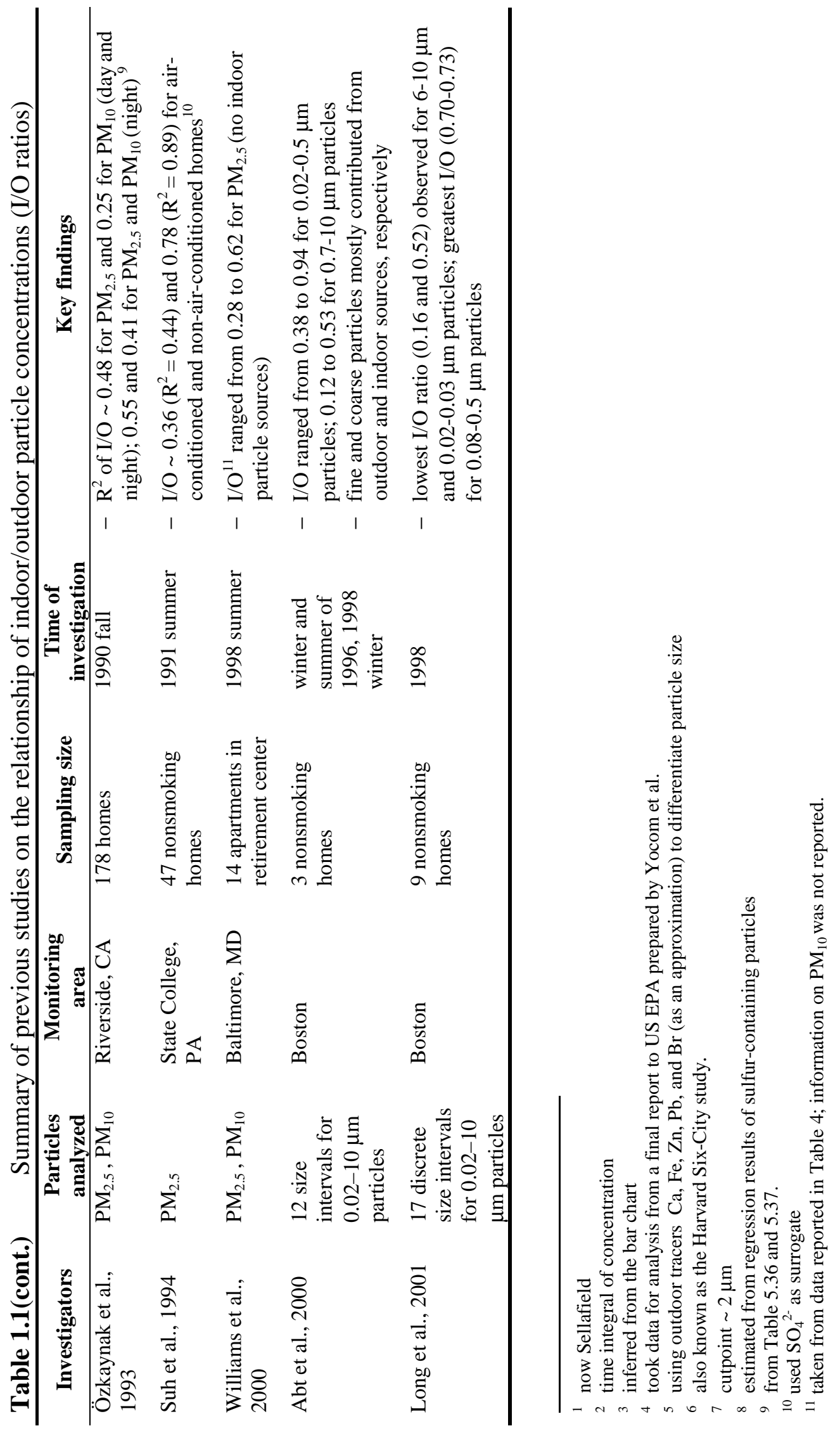




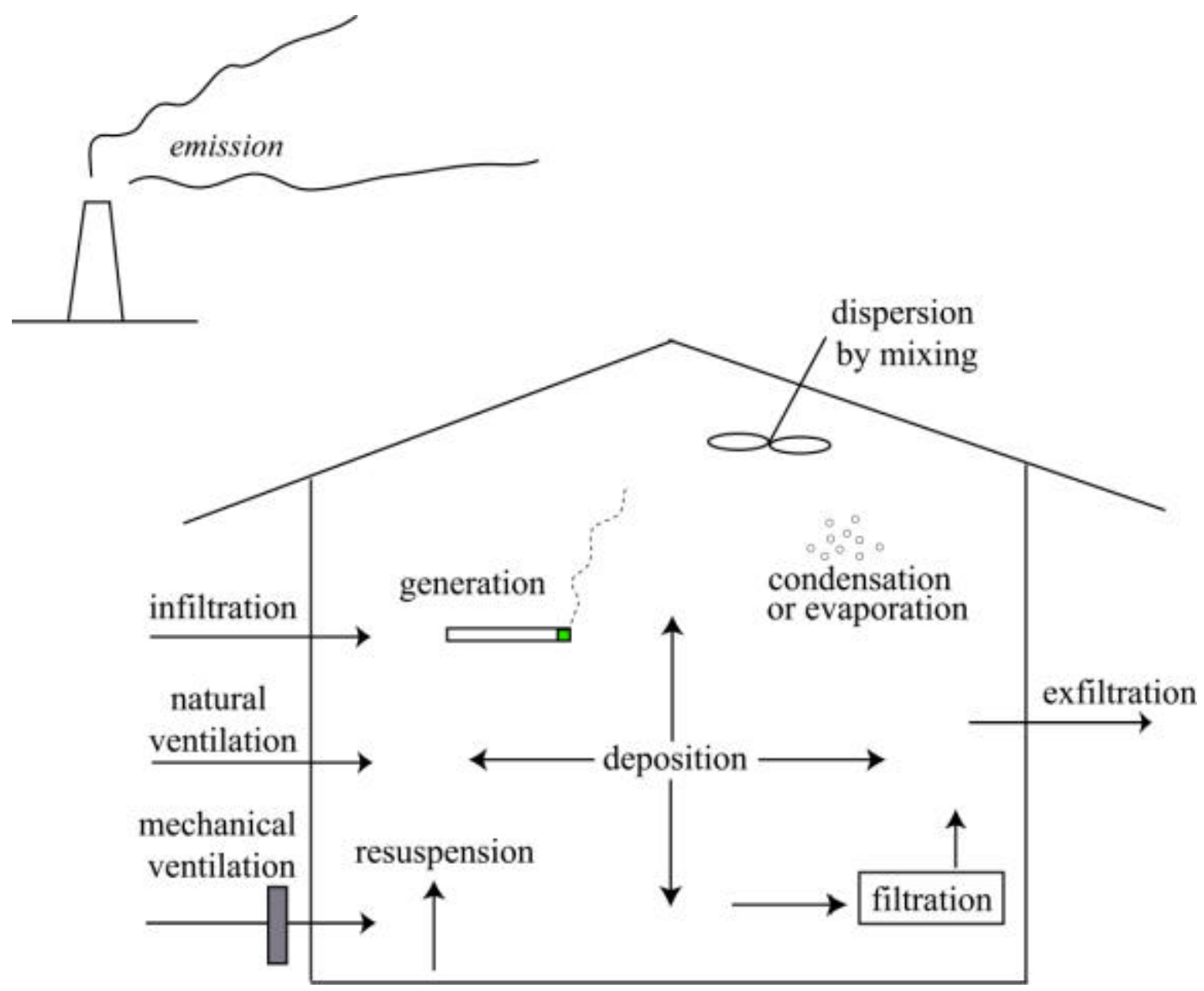

Figure 1.1 Schematic of airborne particle dynamics in the indoor environment (modified from Thatcher and Layton, 1995). In this disseration, the ventilation pathway of interest for air pollutant penetration into indoor environments is infiltration. 


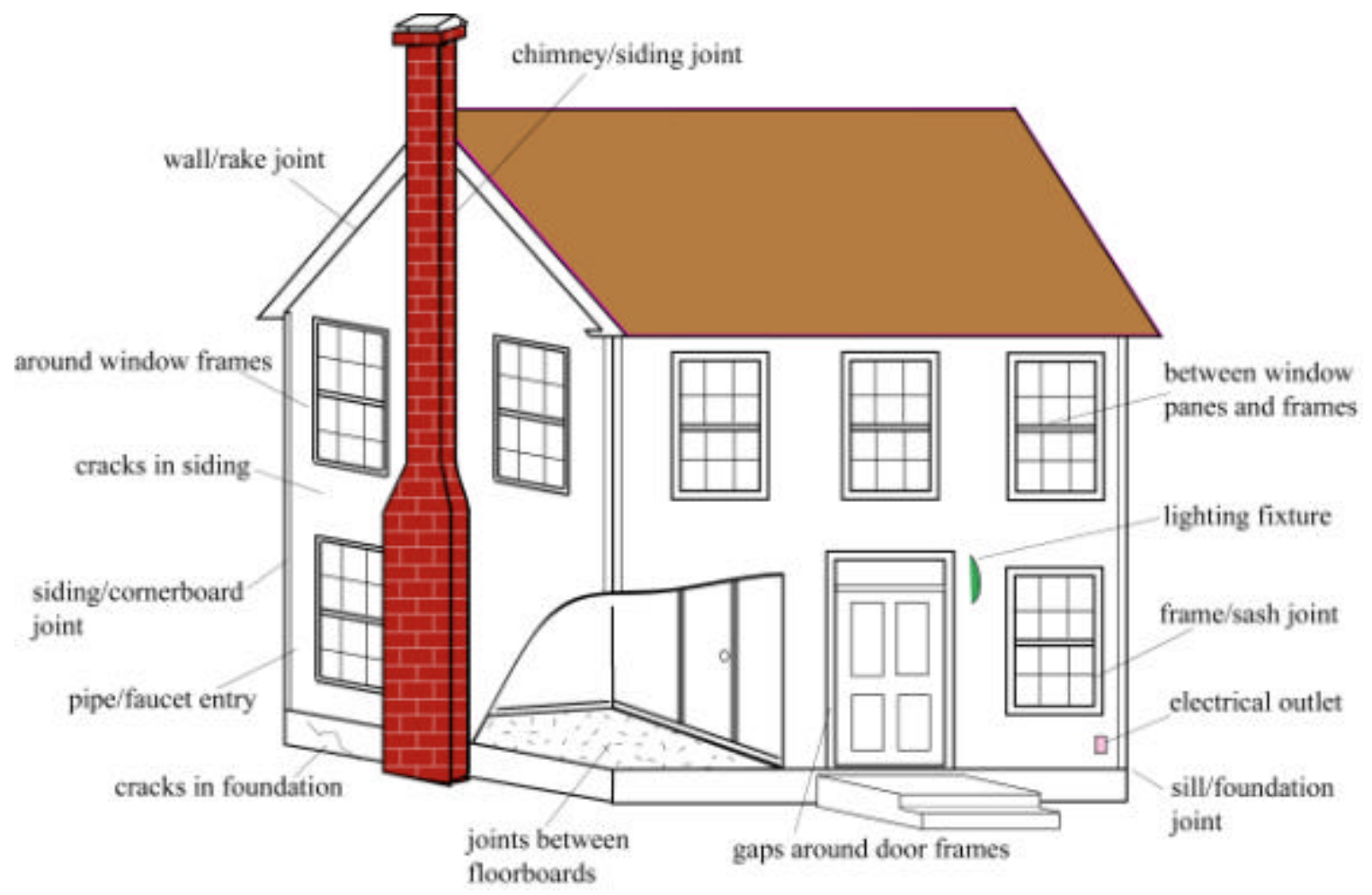

Figure 1.2 Illustration of the potential sources of air infiltration for a typical house. 


\section{Modeling Air Pollutant Penetration ACROSS BUILDING ENVELOPES*}

\subsection{ABSTRACT}

The primary objective for the research reported in this chapter is to quantify, through modeling and engineering analysis, the extent to which ambient pollutants penetrate through unintentional openings in building envelopes and enter indoor environments. As air infiltrates through building leakage paths, interactions between pollutants and adjacent surfaces can alter indoor human exposure to air pollutants of ambient origin. This chapter presents modeling explorations of the fraction of particles and reactive gases (e.g., ozone) that penetrate building envelopes and remain suspended as air enters through cracks and wall cavities. Assuming regular geometry, smooth inner crack surface and steady airflow, idealized rectangular slots are used to represent building cracks. Particles of 0.1-1.0 $\mu \mathrm{m}$ diameter are predicted to have the highest penetration efficiency, nearly unity for crack heights of $0.25 \mathrm{~mm}$ or larger, assuming a pressure difference of $4 \mathrm{~Pa}$ or greater and a flow path length of $3 \mathrm{~cm}$ or less. Supermicron and ultrafine (diameter $\leq 0.1 \mu \mathrm{m}$ ) particles are significantly removed by gravitational settling and Brownian diffusion, respectively. In addition to crack geometry, ozone penetration is governed by its reactivity with crack surfaces, as parameterized by the reaction probability. For reaction probabilities less than $\sim 10^{-5}$, complete penetration is predicted for cracks heights greater than $\sim 1 \mathrm{~mm}$. However, penetration through mm scale cracks can be small if the reaction probability is $\sim 10^{-4}$ or greater. For wall cavities, fiberglass

\footnotetext{
* This chapter is largely based on the following paper: Liu, D.-L. and Nazaroff, W.W. (2001) Modeling pollutant penetration across building envelopes, Atmospheric Environment, 35: 4451-4462.
} 
insulation can remove particles effectively. However, particles might penetrate efficiently if infiltrating air flows through uninsulated wall cavities or through insulated cavities with significant airflow bypass. The ozone reaction probability on fiberglass fibers was measured to be $10^{-7}$ for fibers with prolonged ozone exposure and $6 \times 10^{-6}$ for unexposed fibers. Over this range, ozone penetration through fiberglass insulation is predicted to vary from $\sim 10-40 \%$ to $>90 \%$. Thus, ozone penetration can be high under some conditions. There are, however, realistic circumstances in which building envelopes can provide substantial pollutant removal from infiltrating air.

\subsection{INTRODUCTION}

Because people spend a large proportion of their time in buildings, most exposure to air pollutants of outdoor origin occurs indoors. However, evidence has shown that the concentrations of indoor air pollutants are not necessary well correlated to those outdoors, even in the absence of indoor emissions. Pollutants may be lost or transformed as ambient air flows through building envelopes. Once indoors, the concentration of air pollutants may change owing to deposition onto indoor surfaces, homogeneous transformations, or removal by filters and other air cleaning devices.

Among these potential mechanisms that alter indoor air pollutant concentrations, one aspect that has not been well studied is the penetration loss as ambient air infiltrates into buildings through air leakage pathways. The significance of this issue is established by the fact that all building envelopes leak. A large proportion of buildings, including most residences in the United States, are not equipped with mechanical ventilation systems. When doors and windows are closed, e.g., during heating and cooling seasons, 
ventilation mainly relies on infiltration, i.e., air exchange driven by pressure difference across the building shell through unintentional air leakage pathways. Therefore, exposure of building occupants to air pollutants of outdoor origin is influenced by the extent to which those pollutants penetrate along with infiltrating air.

The transport of ambient pollutants across building envelopes can be quantified in terms of penetration factors, the fraction of pollutants that remain airborne as air enters indoor environments. The value of the penetration factor may vary depending on the nature and strength of pollutant-surface interactions, or on environmental conditions (e.g., change in temperature and relative humidity). For modeling purpose in this chapter, the rate of airborne pollutant removal in air leakage pathways was treated as a first-order process, a reasonable approximation for air pollutants with nonvolatile constituents under roughly constant temperature and relative humidity along the leakage paths.

Pollutants of concern include airborne particles and reactive gases. These may be urban air pollutants such as diesel soot or the constituents of photochemical smog. They may also be fly ash from coal-burning power plants or accidental releases from industrial facilities. Additional concerns have been raised regarding chemical and biological agents released by terrorists or through military action. Airborne pollen grains released from outdoor vegetation may penetrate into buildings and cause respiratory allergies. The analyses in this chapter are also relevant for assessing exposure to bioaerosols associated with certain indoor moisture problems (Miller, 1992). Moisture condensation and structural water leaks can lead to mold growth in wall cavities. The release of spores and microbial volatile organic compounds from molds can pose significant human health threats if the contaminants are subsequently transported into the occupied space.

Several studies have evaluated penetration factors for airborne particles based 
mainly on experimental evidence (Thatcher and Layton, 1995; Özkaynak et al., 1996;

Mosley et al., 2001, Long et al., 2001; Vette et al., 2001). Prior to this study, no work had been published concerning experimental investigation of reactive gas penetration through leaks in building envelopes. However, this phenomenon has been studied by Karlsson (1994) using a modeling approach in the context of assessing exposure in buildings in the case of an accidental release of toxic gases or attacks with chemical warfare agents.

The objective of this study is to explore airborne particle and reactive gas penetration through leakage paths in building envelopes from a modeling perspective. Based on mechanistic knowledge of pollutant transport processes and building leakage characteristics, mathematical models are applied to seek quantitative estimates of penetration factors, as well as an understanding of the variables that affect them. These models are used to analyze airflow and pollutant penetration through idealized representations of building leakage paths.

\subsection{METHODS}

\subsubsection{Building Cracks}

We considered three configurations — straight-through, L-shaped, and doublebend — that represent cracks commonly found in buildings (Figure 2.1a). The smallest dimension of the crack (known here as "crack height") is denoted $d$. The crack dimension parallel to airflow ("crack length") is denoted $z$, with the three-dimensional view illustrated in Figure 2.1b. It was assumed that the crack geometry is uniform throughout the channel, that the inner surface is perfectly smooth, and that airflow through the crack is steady. It was also assumed that the extent of the crack in the third 
dimension ("crack width"), denoted $w$, is much larger than crack height, so that airflow can be reasonably modeled as two-dimensional.

\subsubsection{Airflow Characterization in Cracks}

The flow of air through a crack is driven by a small pressure difference $(\Delta P$, typically less than $10 \mathrm{~Pa}$ ), which in turn may be induced by wind, indoor/outdoor temperature difference, or unbalanced fan-driven flow. The relationship between the airflow rate, $Q$, and pressure difference, $\Delta P$, is well approximated by this quadratic expression (Baker et al., 1987):

$$
\Delta P=\frac{12 \mu z}{w d^{3}} Q+\frac{\rho C}{2 d^{2} w^{2}} Q^{2}
$$

Here, $\mu$ is the dynamic viscosity of air and $\rho$ is the air density. The parameter $C$ is well approximated by $C=1.5+n_{b}$ where $n_{b}$ is the number of right-angle bends in the crack. Equation (2.1) reflects the key physical processes that control drag. When the flow channel is long and thin, viscous resistance dominates and the flow rate varies in direct proportion to $\Delta P$, as described by the first term on the right. For cracks that have a large height but are not long, inertial resistance associated with air density dominates, and the flow rate varies in proportion to $\Delta P^{0.5}$, as described by the rightmost term.

\subsubsection{Characterization of Building Cracks and their Dimensions}

The dimensions of air leakage cracks in buildings have not been well characterized. One investigation on air infiltration through gaps around closed windows suggested that crack heights were normally less than $2.5 \mathrm{~mm}$ (Thomas and Dick, 1953). Another study reported that crack heights of 0.5 to $7.5 \mathrm{~mm}$ represent the range commonly 
found in buildings (Hopkins and Hansford, 1974).

Interest in ventilation and energy use has spurred studies of the leakage characteristics of buildings. These studies have focused on quantifying the effective leakage area of whole buildings and of building components (Reinhold and Sonderegger, 1983). As is appropriate for air infiltration, this information is expressed in terms of an effective leakage area without specifying the crack dimensions. Unfortunately, pollutant penetration through cracks is very sensitive to the minimum crack dimension. The lack of detailed information on the distribution of crack sizes in buildings limits the ability to extend the modeling results presented in this chapter to real buildings. Nevertheless, information on the overall air-leakage characteristics of single-family residences can be used to constrain the domain of practical interest.

For example, assume that all cracks in a building have the same height, $d$, and length, $z$. Then, the total crack width $W$ can be estimated as the ratio of the leakage area to crack height:

$$
W=\frac{\text { total leakage area } A}{\text { crack height } d}=\frac{1}{d} \frac{Q}{C_{d}(d) \sqrt{2 \Delta P / \rho}}
$$

where $C_{d}(d)$ refers to the discharge coefficient for crack height $d$. Equation (2.2) is based on a standard formula linking air infiltration to leakage area and pressure drop (ASHRAE, 1993). Figure 2.2 illustrates the dependence of $W$ on $d$ and $\Delta P$ for a postulated residential building with an infiltration rate of $150 \mathrm{~m}^{3} \mathrm{~h}^{-1}$, typical of US housing (Murray and Burmaster, 1995). For a medium-sized US house (volume 300 $\mathrm{m}^{3}$ ), the perimeter of the exterior walls and the doors and windows is on the order of hundreds of meters. Figure 2.2 shows that it is plausible for air leaking into such a building to pass mostly through cracks whose height is on the order of $\sim 0.5 \mathrm{~mm}$ or 
larger. However, the predominant flow must pass through cracks with $d \geq \sim 0.2 \mathrm{~mm}$. Otherwise, an unrealistically high value of total crack width would be required to yield the observed total building leakage.

In the analysis presented here for pollutant penetration through cracks, the flow path length $(z)$ was fixed at one of two values: 3 or $9 \mathrm{~cm}$. Various crack heights were considered $(d=0.05,0.10,0.25$, and $1.0 \mathrm{~mm})$. Although the smaller values are unlikely to represent dominant flow paths, they were included to investigate how small a crack must be to prevent penetration of $\sim 0.1-1 \mu \mathrm{m}$ particles.

\subsubsection{Particle Penetration through Cracks}

Particle penetration through building cracks was estimated by considering the effects of three major particle deposition mechanisms: Brownian diffusion, gravitational settling, and inertial impaction. Particles were assumed to be spherical with a density of 1 $\mathrm{g} \mathrm{cm}^{-3}$ and with diameters ranging from 0.001 to $100 \mu \mathrm{m}$. The lower bound reflects the growing interest in the effects of ultrafine particles on human health (Oberdörster, et al., 1995). The largest particle sizes in this range are of concern for human exposure to nonrespirable particles, such as large pollen grains.

It was assumed that airflow within a crack is uniform and steady, and that the particle concentration at the inlet is equal to that of the incoming airflow. The penetration factor due to gravitational settling alone $\left(p_{g}\right)$ is computed from the results of trajectory analysis (Fuchs, 1964):

$$
p_{g}=1-\frac{V_{s} z}{d U} \quad \text { valid for } 0 \leq p_{g} \leq 1
$$

where $V_{s}$ is the particle settling velocity and $U$ is the mean air speed in the crack. For the 
case of $V_{s} z \geq d U, p_{g}=0$ and there is no particle penetration.

Small particles may diffuse to the walls of a crack and adhere to the surfaces by means of van der Waals forces. The penetration factor through a crack considering Brownian diffusion alone $\left(p_{d}\right)$ is approximated from a result by De Marcus and Thomas (1952):

$$
p_{d}=0.915 \exp (-1.885 \phi)+0.0592 \exp (-22.3 \phi)+0.026 \exp (-152 \phi)+\ldots
$$

where $\phi$ is given by:

$$
\phi=\frac{4 D z}{d^{2} U}
$$

Here, $D$ is the particle diffusion coefficient computed according to the Stokes-Einstein relation with the Cunningham slip correction factor (Hinds, 1999, pp. 152-153). Equation (2.4) was derived by means of solving the equation of mass conservation, assuming well-developed parabolic flow with particle transport via advection and Brownian diffusion. The equation has been experimentally validated for particles smaller than $0.3 \mu \mathrm{m}$ (Thomas, 1955).

Particle deposition caused by impaction is a function of the Stokes number $(S t)$, which is the ratio of the particle stopping distance to the characteristic dimension associated with flow acceleration (Hinds, 1999, p. 121). The greater the Stokes number (i.e., owing to increased particle inertia or a sharper bending of fluid streamlines), the higher the likelihood of particle impaction at crack bends. The system considered here has similarities to particle-sampling impactors. Since impactor performance has been well characterized, the results from rectangular impactor nozzles (Marple and Willeke, 1976) were used estimate particle deposition at crack bends induced by inertial drift. The 
penetration factor associated with impaction, $p_{i}$, was taken as one minus the fractional loss caused by inertia. The calculation results indicate that impaction was not an important particle deposition mechanism for airflow through building cracks. For any crack with a horizontal component of the flow channel, any particle with enough inertia to be lost by impaction was also likely to be lost by settling.

Based on the approximation that the deposition mechanisms operate independently, the total penetration factor was estimated as the product of the penetration factors for the three processes considered separately:

$$
p=p_{g} \times p_{d} \times p_{i}
$$

Alternative schemes for combining mechanisms to estimate overall particle penetration have been formulated (e.g., Chen and Yu, 1993). For the situation considered here, where generally only one mechanism is important for a given particle size, differences among approaches are small.

\subsubsection{Penetration of Reactive Gases through Cracks}

The loss of a gaseous pollutant on crack surfaces was considered to occur by a first-order, irreversible process. The species removal rate is parameterized in terms of a mass-transfer coefficient known as the deposition velocity, which is defined as the net pollutant flux to a surface divided by the freestream airborne concentration. In general, the deposition of reactive gases is governed by two mechanisms acting in series: (1) mass transport to surfaces, and (2) subsequent uptake by the surface. Following Cano-Ruiz et al. (1993), the overall mass transfer process is modeled as two resistances in series, such that the overall deposition velocity $\left(v_{o}\right)$ is expressed as follows: 


$$
v_{o}=\left(\frac{1}{v_{s}}+\frac{1}{v_{t}}\right)^{-1}=\frac{v_{s} v_{t}}{v_{s}+v_{t}}
$$

Here, $v_{s}$ and $v_{t}$ refer to the species deposition velocity in the limit of control by surface uptake and control by gas-phase mass transport, respectively. From the kinetic theory of gases, the value of $v_{s}$ is estimated as

$$
v_{s}=\gamma \frac{\langle v\rangle}{4}
$$

where $\langle v\rangle$ is the Boltzmann velocity of the species. For ozone, for example, $\langle v\rangle$ is $\sim 360$ $\mathrm{m} \mathrm{s}^{-1}$ at $293 \mathrm{~K}$. The dimensionless parameter, $\gamma$, is the reaction probability, the ratio of the removal rate to the collision rate of the species on the surface. When $\gamma$ is sufficiently small (such that $v_{s}<<v_{t}$ ), the deposition velocity is controlled by the rate of surface uptake $\left(v_{o} \sim v_{s}\right)$. Table 2.1 summarizes the reaction probabilities for three gases ozone, sarin and $\mathrm{SO}_{2}$ - on materials found in building envelopes, based on experimental data reported in the literature.

The transport-limited deposition velocity, $v_{t}$, is a function of the air flow field and the species molecular diffusivity. The overall deposition velocity $v_{o}$ approaches the transport-limited value $\left(v_{o} \sim v_{t}\right)$ when the surface resistance is small compared to the gasphase mass-transfer resistance $\left(v_{s}>>v_{t}\right)$. For specific flow conditions, the estimate of the transported-limited deposition velocity was made by a two-step process. First, equations (2.4) and (2.5) were applied to determine the pollutant penetration factor, accounting for pollutant transport by means of molecular diffusion and advection, and assuming no surface resistance. Second, an idealized model was applied to link the penetration factor to its deposition velocity. The model is derived by writing a species material balance over a differential slice normal to the direction of flow. It was assumed that flow is 
uniform and that the surface pollutant flux is equal to the product of the deposition velocity and the average species concentration in the slice. This expression is obtained for the penetration factor in the case of mass-transport-limited uptake:

$$
p_{d}=\exp \left(-\frac{2 v_{t} z}{U d}\right)
$$

Given $p_{d}$ from equation (2.4), equation (2.9) can be solved for $v_{t}$. This result is then combined with equations (2.7) and (2.8) to determine the overall species deposition velocity, including the combined effects of mass transfer and surface uptake. The detailed derivation is shown in Appendix A. Finally, the overall penetration factor is computed using an equation that is analogous to equation (2.9):

$$
p=\exp \left(-\frac{2 v_{o} z}{U d}\right)
$$

For the examples considered in this chapter, ozone was selected as a specific example of a reactive gas. The approach is applicable to other reactive gases.

\subsubsection{Wall Cavity}

\subsubsection{Wall Cavity Characterization}

Some air that leaks into buildings passes through wall cavities. In the U.S., most residential buildings are built with a wood frame. Wall cavities are bounded by the framing lumber and by the inner and outer wall materials. Typical dimensions for a single cavity are $10-15 \mathrm{~cm}($ thick $) \times 35 \mathrm{~cm}($ wide $) \times 2.5 \mathrm{~m}$ (high). For old houses in areas with mild climate, the wall cavities are commonly unfilled. Modern homes contain insulation materials in the wall cavity to save energy by reducing the rate of heat transfer through the building envelope. Three wall cavity configurations were considered in the 
analysis: uninsulated (Figure 2.3a), filled with insulation (Figure 2.3b), and insulated but with air leakage paths that bypass the insulation (Figure 2.3c).

\subsubsection{Fiberglass Insulation in Wall Cavities}

Fiberglass is a widely used insulation material because it is inexpensive, easily installed, and versatile. Fiberglass insulation is commonly installed in the form of a fibrous blanket, cut to fit into the space between wall studs. Both the thickness and solidity of the fiberglass materials govern the insulation performance. In the U.S., commercial products are rated by an "R-value," which is a measure of thermal resistance, in units of $\mathrm{ft}^{2}-{ }^{\circ} \mathrm{F}-\mathrm{h} / \mathrm{BTU}$. Because it is fibrous, fiberglass insulation in wall cavities might serve as a pollutant filter. Modeling tools were used to explore the penetration factor for particles and reactive gases through wall cavities filled with fiberglass insulation.

For the analyses reported here, a fiberglass blanket of 8.9-cm thickness (R-11) was considered, accounting for two flow path lengths through the fiberglass blanket: $L=$ $8.9 \mathrm{~cm}$ (horizontal flow) and $L=2.3 \mathrm{~m}$ (vertical flow). (See Figure 2.3b.) Based on microscopic examination of a sample purchased at a local hardware store, fibers were modeled as uniform cylinders with a $10 \mu \mathrm{m}$ diameter. The solidity of the blanket $(\alpha)$ was estimated to be 0.003 , on the basis of a weight measurement and assuming that the fiber density was the same as bulk glass $\left(\sim 2.5-2.8 \mathrm{~g} \mathrm{~cm}^{-3}\right)$.

Air speed through the fiberglass blanket was computed by assuming a fixed pressure drop (4-10 $\mathrm{Pa}$ ) across the flow path length and applying a theoretical expression linking air flow to pressure drop for fibrous filters (Hinds, 1999, pp. 200-202). At a pressure drop of $4 \mathrm{~Pa}$ across an 8.9-cm thickness of R-11 fiberglass, the air speed would 
be $2.4 \mathrm{~cm} \mathrm{~s}^{-1}$. The total infiltrating flow of $150 \mathrm{~m}^{3} \mathrm{~h}^{-1}$ into a typical residence would be generated by such a speed applied across a face area of $1.7 \mathrm{~m}^{2}$. Since the total exterior wall area of a residence is on the order of $100 \mathrm{~m}^{2}$, it is plausible that a significant fraction of infiltrating air passes follows pathway (1) as illustrated in Figure 2.3b. On the other hand, a pressure difference of $4 \mathrm{~Pa}$ applied across a 2.3-m length of fiberglass blanket would only induce an air speed of $0.2 \mathrm{~cm} \mathrm{~s}^{-1}$. If air flowed in this manner through all exterior wall cavities, the total infiltration rate would only be on the order of $10 \mathrm{~m}^{3} \mathrm{~h}^{-1}$, much smaller than observed infiltration rates. Therefore, pathway (2) in Figure 2.3b was excluded from further consideration of pollutant penetration.

\subsubsection{Particle Penetration Analysis}

Filtration theory, as summarized below, was applied to calculate particle penetration through fiberglass insulation in wall cavities (Hinds, 1999, pp. 190-196). These deposition mechanisms were included in the analysis: interception, impaction, Brownian diffusion, and gravitational settling. Total single fiber efficiency $\left(\eta_{\Sigma}\right)$ was estimated by summing the collection efficiencies determined separately for each

mechanism. Applying an approximation that all fibers have the same diameter $\left(d_{f}\right)$, the overall penetration fraction through the fiberglass blanket, $p_{f}$, is related to single-fiber efficiency by this expression:

$$
p_{f}=\exp \left(\frac{-4 \alpha \eta_{\Sigma} L}{\pi d_{f}}\right)
$$




\subsubsection{Ozone Penetration Analysis ${ }^{1}$}

Ozone penetration through a fiberglass blanket was analyzed in an analogous manner to penetration through cracks. The transport-limited deposition velocity $\left(v_{t}\right)$ was estimated from particle filtration theory, accounting for only two transport mechanisms: advection and molecular diffusion. The transport-limited deposition velocity is related to the single-fiber efficiency by means of the following equation:

$$
v_{t}=\frac{\eta_{d}}{\pi} U_{o}
$$

where the single fiber efficiency due to diffusion alone is given by $\eta_{d}=2 P e^{-2 / 3}$ (Hinds, 1999, p. 194), $P e$ is the Peclet number $\left(=U_{o} d_{f} / D\right)$, and $U_{o}$ is the freestream air speed approaching a fiber. The molecular diffusivity of ozone was taken to be $1.82 \times 10^{-5} \mathrm{~m}^{2} \mathrm{~s}^{-1}$ (Cano-Ruiz et al., 1993).

The overall ozone deposition velocity to a single fiber was determined by equation (2.7). The surface reaction probability $(\gamma)$ was measured, as described in $§ 2.4 .2 .2$. Given $\gamma$, equation (2.8) was applied to determine $v_{s}$. The fractional ozone penetration through the fiberglass blanket was estimated by applying a variation of filtration theory:

$$
P_{o_{3}}=\exp \left[-\frac{4 v_{o} \alpha L}{U_{o} d_{f}}\right]
$$

\footnotetext{
${ }^{1}$ The detailed derivation for the analysis is provided in Appendix B.
} 


\subsection{RESULTS AND DISCUSSION}

\subsubsection{Building Cracks}

\subsubsection{Airflow Characteristics}

Air speeds through cracks were found to depend on crack height $(d)$, crack length $(z)$, and pressure difference $(\Delta P)$, but to be independent of crack configuration. Selected results are presented in Table 2.2. For crack dimensions of practical interest, the flow is always laminar. For crack heights smaller than about $1 \mathrm{~mm}$ and crack lengths greater than about $3 \mathrm{~cm}$, the airflow is well described as laminar and fully developed. On the other hand, for cracks with a greater crack height or shorter flow length, the entrance length may approach a significant fraction of the flow length. In this case, the flow will be developing from a flat profile at the inlet toward the well-developed parabolic profile. Because developing flow has a component of velocity that is normal to and away from the crack surfaces, pollutant deposition by diffusion will be reduced somewhat in developing flow conditions. This effect is not included in the analyses reported here.

\subsubsection{Particle Penetration ${ }^{2}$}

Figure 2.4 shows predicted particle penetration factors $p$ as a function of particle diameter, crack height, and pressure difference for straight-through cracks with $z=3 \mathrm{~cm}$. The results indicate that accumulation mode particles $(0.1-1 \mu \mathrm{m}$ diameter) have the highest penetration efficiency across the whole particle-size spectrum. This is expected, since larger and smaller particles are readily removed in cracks under the influences of gravitational settling and Brownian diffusion, respectively. As indicated in Figure 2.4,

\footnotetext{
${ }^{2}$ See Appendix $\mathrm{C}$ for details of the computer program used to compute particle penetration.
} 
the penetration factor is predicted to be approximately one for accumulation mode particles when $d \geq 0.25 \mathrm{~mm}$.

For crack height $d=1 \mathrm{~mm}$, the particle fractional penetration is more than $90 \%$ for 0.01 to $7 \mu \mathrm{m}$ particles. When $d$ is smaller than $1 \mathrm{~mm}$, penetration varies significantly with crack height, even within this particle size range. At $d=0.25 \mathrm{~mm}$, for example, particles of diameter $0.1-1.0 \mu \mathrm{m}$ have penetration factors greater than 0.85. At $d=0.1$ $\mathrm{mm}$, only about half of $0.3-\mu \mathrm{m}$ particles penetrate. Particle penetration becomes negligible $(<2 \%)$ for $d=0.05 \mathrm{~mm}$, regardless of particle size.

Figure 2.5 presents the predicted penetration factor as a function of crack length, $z$ (3 and $9 \mathrm{~cm}$ ), for straight-through cracks with various crack heights at $\Delta \mathrm{P}=10 \mathrm{~Pa}$. Penetration is significantly reduced in the longer cracks for many particle sizes. For instance, the penetration factor of $0.03 \mu \mathrm{m}$ particles with $d=0.25 \mathrm{~mm}$ is about $70 \%$ at $z=$ $3 \mathrm{~cm}$, but only about $10 \%$ at $z=9 \mathrm{~cm}$. On the other hand, for $d=1 \mathrm{~mm}$, penetration is nearly complete ( $p \geq 95 \%$ ) for both crack lengths for particle diameters between 0.02 and $4 \mu \mathrm{m}$.

Entrance effects on particle penetration were not included in the analyses. Although potentially significant, it is believed that they are unlikely to have important effects on the results. For example, aspiration efficiency, which measures the particle concentration at the inlet of a flow channel divided by the average concentration in the approaching airflow, was not included in this analysis. Aspiration efficiency is expected to be close to one for particles of small Stokes numbers, because they are able to follow air streamlines well. The Stokes numbers were small for most conditions considered in this study. For the largest particles, where the Stokes number may be large, predicted 
penetration is small because of gravitational settling within the crack.

Perhaps greater limitations of the analyses are related to the assumptions that crack geometry is regular and that crack surfaces are smooth. In real cracks, irregular geometry and surface roughness might increase particle deposition significantly. This issue is best explored by laboratory-based experimental studies, as will be presented in Chapter 3.

\subsubsection{Overall Particle Penetration for a Building Shell with Variable Crack Heights}

In any real building, air leaks through many cracks with a distribution of dimensions. The overall particle penetration factor for the building is the flow-weighted average penetration for each crack. There are no data on the distribution of leak sizes within buildings. Nevertheless, some insight into the effects of distributed crack sizes can be gained by analyzing a hypothetical distribution. Although the postulated distribution might not be representative of crack-size distributions in real buildings, it is useful to illustrate the relative contributions of large and small cracks in influencing pollutant penetration.

Here, the crack size distribution was postulated to have the following properties. The crack length is constant at $z=3 \mathrm{~cm}$. The crack height has a fixed upper and lower bound, $d_{\max }$ and $d_{\min }$, respectively. The fraction of crack area $(d \times w)$ between any two crack heights is proportional to the difference between those two crack heights. Mathematically, the total area of leaks can be related to such a crack-size distribution in this manner: 


$$
A=\int_{d_{\min }}^{d_{\max }} d \times W(d) \times \mathrm{d}(d) \quad W(d) \propto \frac{1}{d}
$$

where $W(d)$ is the distribution function of crack widths.

The overall particle penetration factors for three pairs of $d_{\max }$ and $d_{\min }$ values are shown in Figure 2.6. A change in the lower bound of crack size $\left(d_{\min }\right)$ from 0.05 to 0.5 $\mathrm{mm}$ has an insignificant effect on the results. However, changing the upper bound from 1 to $2 \mathrm{~mm}$ changes the penetration factor for the particle sizes near the outer edges of the size distribution. These results indicate that overall penetration is influenced more by the largest cracks than by the smallest cracks in a building. The result is not surprising, since airflow rates increase strongly as crack height increases (Table 2.2).

\subsubsection{Ozone Penetration}

The predicted penetration factor for ozone as a function of reaction probability $(\gamma)$, crack height $(d)$, and pressure difference $(\Delta P)$ is illustrated in Figure 2.7a for $z=3 \mathrm{~cm}$ and in Figure $2.7 \mathrm{~b}$ for $z=9 \mathrm{~cm}$. Since the penetration factor decays exponentially with flow path lengths for fixed $\gamma$, much less ozone penetration is predicted for $z=9 \mathrm{~cm}$ than for $z=$ $3 \mathrm{~cm}$.

Broadly, the relationship of ozone penetration and reaction probability can be divided into three regimes. For the following discussion, consider the example of a crack height of $d=1 \mathrm{~mm}$, a pressure difference of $\Delta P=10 \mathrm{~Pa}$, and a crack flow length of $z=3$

$\mathrm{cm}$. For high reaction probability $\left(\gamma>\sim 10^{-3}\right)$, ozone penetration is small and becomes independent of $\gamma$. In this region uptake is mass-transport limited. Reactions on the crack surfaces are sufficiently fast that the overall rate of uptake is governed by the rate at 
which ozone molecules reach the surface from the bulk air. For reaction probabilities in the intermediate range $\left(\sim 10^{-5}<\gamma<\sim 10^{-3}\right)$, ozone penetration varies strongly with $\gamma$. In this part of the domain, surface uptake and gas-phase mass transfer both contribute significantly to uptake resistance. In the third regime, where ozone-surface reactivity is small $\left(\gamma<\sim 10^{-5}\right)$, ozone penetration becomes large. Uptake is governed entirely by surface kinetics in this case. For all combinations of crack height, pressure difference, and flow length, the curves exhibit the same general shape. However, the values of $\gamma$ at which inflection points occur vary.

As shown in Table 2.1, the reaction probability of ozone is low on some building materials, such as glass and aluminum. On these surfaces, where typically $\gamma<\sim 10^{-6}$, ozone penetration is likely to be complete through cracks with height of $\sim 1 \mathrm{~mm}$ or larger, provided the crack flow length is less than approximately $9 \mathrm{~cm}$. Ozone reactivity is higher on other materials, such as concrete and brick. For these materials, where $\gamma \sim(0.4-$ 2) $\times 10^{-4}$, significant ozone loss may occur by reaction on surfaces through cracks with heights of as much as 1-2 mm.

\subsubsection{Wall Cavity}

\subsubsection{Particle Penetration}

\section{(1) Uninsulated wall cavity}

In a typical single-family residence, the total air volume in the exterior wall cavities would be on the order of $10 \mathrm{~m}^{3}$ (estimated from the back-of-envelope calculation based on the dimension of a single wall cavity, as described in $§ 2.3 .2 .1$ ). If a significant fraction of infiltrating air passes through wall cavities, then the characteristic residence 
time of air in the cavity would be of the order of 5-10 minutes. Applying results from studies of deposition onto room surfaces (Nazaroff et al., 1993; Lai and Nazaroff, 2000), particle loss during this short residence time is expected to be insignificant, except for the smallest ultrafine and the largest coarse particles. These particles are likely to be lost during airflow through cracks into or out of the wall cavity. Therefore, it is unlikely that particle loss in an uninsulated wall cavity is important in understanding particle penetration.

\section{(2) Wall cavity insulated with a fiberglass blanket}

When fiberglass insulation is properly installed, without airflow bypass, infiltrating air that enters a wall cavity must pass through the fibrous materials. Using particle filtration theory, the predicted particle penetration factor was found to be zero for flow path (1) in Figure 2.3b. This result applies for all particle sizes, regardless of pressure difference. The work by Taylor et al. (1999) also reported similar particle filtration performance with respect to air permeable walls, in which fibrous materials were used in the analysis. Fiberglass insulation acts as an effective particle filter to the extent that infiltrating air passes through it. This result is consistent with anecdotal observations of soot-stained fiberglass insulation in the walls of residences undergoing retrofit.

However, airflow paths through a wall cavity may bypass the insulation, as depicted in Figure 2.3c. On the basis of our analysis of particle penetration through idealized cracks, particle penetration through an insulated wall cavity would be large if the air flows through bypass channels with minimum dimensions larger than a few $\mathrm{mm}$. 


\subsubsection{Ozone Penetration}

To evaluate the fractional ozone penetration through fiberglass insulation, the reaction probability $(\gamma)$ for ozone on fiberglass fibers has to be examined. The apparatus used by Morrison and Nazaroff (2000) was employed to measure ozone uptake on fiberglass fibers. The reaction probability for ozone on fiberglass was determined to be 6 $\times 10^{-6}$ for freshly exposed fibers. The reaction probability dropped to about $10^{-7}$ after exposure to an elevated ozone level (1000 ppb) for 1 day. Over this range of values for $\gamma$, surface uptake kinetics represent the rate-limiting step for ozone deposition in a fiberglass blanket. Figure 2.8 shows the predicted ozone penetration according to equation (2.13) for airflow through a fiberglass blanket along pathway (1) in Figure 2.3b. For $\gamma \sim 10^{-7}$, ozone penetration is predicted to exceed $95 \%$. On the other hand, for $\gamma \sim 6 \times 10^{-6}$, ozone penetration is much smaller, in the range of $10-40 \%$. These results indicate that scavenging by fiberglass insulation may affect ozone penetration into modern houses.

\subsection{CONCLUSIONS}

The infiltration of pollutants from outdoors into buildings has been examined by applying tools from engineering analysis, incorporating data on building leakage characteristics and information on pollutant-surface interactions. For relatively large cracks (height $>\sim 1 \mathrm{~mm}$ ), particle penetration is complete, except for the largest (diameter $>\sim 10 \mu \mathrm{m}$ ) and smallest (diameter $<\sim 0.01 \mu \mathrm{m}$ ) particles. Gas penetration is also complete for large cracks unless the pollutant-surface reaction probability $(\gamma)$ exceeds $\sim 10^{-5}$. For air that flows through fiberglass insulation in a wall cavity, particle penetration drops to zero and gaseous pollutant penetration is also less than one when the 
pollutant-surface reaction probability exceeds $\sim 10^{-7}$.

Existing information about the leakage characteristics of buildings provides important clues, but is not yet sufficient to reliably predict pollutant penetration into real buildings from models. Two important issues are required to improve our knowledge of air pollutant penetration into buildings. First, it is essential to understand how air leakage into buildings is distributed with respect to crack dimensions. A small number of large cracks would produce high penetration factors. The same total leakage distributed among a large number of small cracks could produce much lower penetration factors. Secondly, we need to know to what extent the air that flows into buildings passes through insulation rather than around it. Pollutant penetration into buildings depends substantially on whether or not a large portion of the airflow passes through fiberglass insulation blankets.

The modeling calculations presented here have provided important insight into the expected values of pollutant penetration and the physical factors that affect them. To compare to the model calculations, experimental studies are required on several scales, including penetration through single cracks, penetration through building components, and penetration across entire building shells, as will be presented in the successive chapters. Improved knowledge in this area of study will permit more reliable prediction of human exposure to particles and gaseous pollutants of outdoor origin. Advances in building technology based on these findings may also hold the promise of reducing pollutant penetration into indoor environments. 


\subsection{REFERENCES}

ASHRAE (1993) ASHRAE Handbook: 1993 Fundamentals. American Society of Heating, Refrigerating, and Air-Conditioning Engineers, Atlanta, Chapter 23.

Baker, P.H., Sharples, S. and Ward, I.C. (1987) Air-flow through cracks, Building and Environment, 22: 293-304.

Cano-Ruiz, J.A., Kong, D., Balas, R.B., and Nazaroff, W.W. (1993) Removal of reactive gases at indoor surfaces: Combining mass transport and surface kinetics, Atmospheric Environment, 27A: 2039-2050.

Chen, Y.K. and Yu, C.P. (1993) Particle deposition from duct flows by combined mechanisms, Aerosol Science and Technology, 19: 389-395.

Cox, R.A. and Penkett, S.A. (1972) Effect of relative humidity on disappearance of ozone and sulfur dioxide in contained systems, Atmospheric Environment, 6: 365-368.

De Marcus, W. and Thomas, J.W. (1952) Theory of a diffusion battery, U. S. Atomic Energy Commission, Oak Ridge National Laboratory, Oak Ridge, Tennessee.

Fuchs, C.N. (1964) The Mechanics of Aerosols, Pergamon Press, Oxford.

Hinds, W.C. (1999) Aerosol Technology, second edition, Wiley, New York.

Hopkins, L.P. and Hansford, B. (1974) Air flow through cracks, Building Services Engineer, 42: 123-131.

Karlsson, E. (1994) Indoor deposition reducing the effect of toxic gas clouds in ordinary buildings, Journal of Hazardous Materials, 38: 313-327.

Karlsson, E. and Huber, U. (1996) Influence of desorption on the indoor concentration of toxic gases, Journal of Hazardous Materials, 49: 15-27.

Lai, A.C.K. and Nazaroff, W.W. (2000) Modeling indoor particle deposition from 
turbulent flow onto smooth surfaces, Journal of Aerosol Science, 31: 463-476.

Long, C.M., Suh, H.H., Catalano, P.J., and Koutrakis, P. (2001) Using time- and sizeresolved particulate data to quantify indoor penetration and deposition behavior, Environmental Science and Technology, 35: 2089-2099. (See also errata, p. 4584)

Marple, V.A. and Willeke, K. (1976) Impactor design, Atmospheric Environment, 10: 891-896.

Miller, J.D. (1992) Fungi as contaminants in indoor air, Atmospheric Environment, 26: 2163-2172.

Morrison, G.C., Nazaroff, W.W., Cano-Ruiz, J.A., Hodgson, A.T., and Modera, M.P. (1998) Indoor air quality impacts of ventilation ducts: Ozone removal and emissions of volatile organic compounds, Journal of the Air and Waste Management Association, 48: 941-952.

Morrison, G.C., and Nazaroff, W.W. (2000) The rate of ozone uptake on carpets: Experimental studies, Environmental Science and Technology, 34: 4963-4968.

Mosley, R.B., Greenwell, D.J., Sparks, L.E., Guo, Z., Tucker, W.G., Fortmann, R., and Whitfield, C., (2001) Penetration of ambient fine particles into the indoor environment, Aerosol Science and Technology, 34: 127-136.

Mueller, F.X., Loeb, L., and Mapes, W.H. (1973) Decomposition rates of ozone in living areas, Environmental Science and Technology, 7: 342-346.

Murray, D.M. and Burmaster, D.E. (1995) Residential air exchange rates in the UnitedStates - Empirical and estimated parametric distributions by season and climatic region, Risk Analysis, 15: 459-465.

Nazaroff, W.W., Gadgil, A.J., and Weschler, C.J. (1993) Critique of the use of deposition 
velocity in modeling indoor air quality, edited by Nagda, N.L., Modeling of Indoor Air Quality and Exposure, ASTM STP 1205, American Society for Testing and Materials, Philadelphia, pp. 81-104.

Oberdörster, G., Gelein, R.M., Ferin, J., and Weiss, B. (1995) Association of particulate air pollution and acute mortality: Involvement of ultrafine particles, Inhalation Toxicology, 7: 111-124.

Özkaynak, H., Xue, J., Spengler, J., Wallace, L., Pellizzari, E., and Jenkins, P. (1996) Personal exposure to airborne particles and metals: Results from the Particle TEAM study in Riverside, California, Journal of Exposure Analysis and Environmental Epidemiology, 6: 57-78.

Reinhold, C., and Sonderegger, R. (1983) Component leakage areas in residential buildings, Report LBL-16221, Lawrence Berkeley Laboratory, Berkeley, California.

Reiss, R., Ryan, P.B., and Koutrakis, P. (1994) Modeling ozone deposition onto indoor residential surfaces, Environmental Science and Technology, 28: 504-513.

Sabersky, R.H., Sinema, D.A., and Shair, F.H. (1973) Concentrations, decay rates, and removal of ozone and their relation to establishing clean indoor air, Environmental Science and Technology, 7: 347-353.

Simmons, A., and Colbeck, I. (1990) Resistance of various building materials to ozone deposition, Environmental Technology, 11: 973-978.

Spedding, D.J. (1972) Sorption of sulphur dioxide by indoor surfaces. IV. Flooring materials, Journal of Applied Chemistry and Biotechnology, 22: 1-8.

Sutton, D.J., Nodolf, K.M., Makino, K.K. (1976) Predicting ozone concentrations in residential structures, ASHRAE Journal, 18: 21-26. 
Taylor, B.J., Webster, R., and Imbabi, M.S. (1999) The building envelope as an air filter, Building and Environment, 34: 353-361.

Thatcher, T.L., and Layton, D.W. (1995) Deposition, resuspension, and penetration of particles within a residence, Atmospheric Environment, 29: 1487-1497.

Thomas, D.A., and Dick, B.A. (1953) Air infiltration through gaps around windows, Journal of the Institution of Heating and Ventilating Engineers, 21: 85-97.

Thomas, J.W. (1955) The diffusion battery method for aerosol particle size determination, Journal of Colloid Science, 10: 246-255.

Vette, A.F., Rea, A.W., Lawless, P.A., Rodes, C.E., Evans, G., Highsmith, V.R. and Sheldon, L. (2001) Characterization of indoor-outdoor aerosol concentration relationships during the Fresno PM exposure studies, Aerosol Science and Technology, 34: 118-126. 
Table 2.1 Reaction probability $(\gamma)$ for sarin, $\mathrm{SO}_{2}$, and ozone on selected building materials.

\begin{tabular}{|c|c|c|c|}
\hline Species & Material & $\gamma^{\mathrm{a}}$ & Reference \\
\hline Sarin & $\begin{array}{l}\text { Silanized glass, } 0-60 \% \text { RH } \\
\text { Plastic coated wallpaper } \\
\text { Rough spruce, } 50-60 \% \text { RH } \\
\text { Chalking paint on concrete }\end{array}$ & $\begin{array}{l}1.6 \times 10^{-8} \\
2.1 \times 10^{-8} \\
1.9 \times 10^{-8} \\
5.1 \times 10^{-7}\end{array}$ & Karlsson and Huber, $1996^{\mathrm{b}}$ \\
\hline $\mathrm{SO}_{2}$ & $\begin{array}{l}\text { Gloss paint, } 32 \% \mathrm{RH} \\
84 \% \mathrm{RH} \\
\text { Aluminum, } 78 \% \mathrm{RH}\end{array}$ & $\begin{array}{l}1.5 \times 10^{-7} \\
5.0 \times 10^{-6} \\
5.7 \times 10^{-6}\end{array}$ & Cox and Penkett, $1972^{c}$ \\
\hline & $\begin{array}{l}\text { Softwood } \\
\text { Hardwood, } 65 \% \mathrm{RH} \\
\text { PVC wall covering, } 60 \% \mathrm{RH}\end{array}$ & $\begin{array}{l}3.1 \times 10^{-4} \\
6.2 \times 10^{-4} \\
3.9 \times 10^{-5}\end{array}$ & Spedding, $1972^{\mathrm{d}}$ \\
\hline Ozone & $\begin{array}{l}\text { Dirty glass } \\
\text { Clean glass } \\
\text { Bricks (new and old) } \\
\text { Outdoor concrete } \\
\text { Concrete slab } \\
\text { Gravel } \\
\text { Red tiles (new) } \\
\text { Gray tiles (new) }\end{array}$ & $\begin{array}{l}2.9 \times 10^{-6} \\
5.5 \times 10^{-6} \\
2.2 \times 10^{-4} \\
4.4 \times 10^{-5} \\
7.9 \times 10^{-5} \\
4.8 \times 10^{-5} \\
4.5 \times 10^{-5} \\
3.8 \times 10^{-5}\end{array}$ & Simmons and Colbeck, $1990^{\mathrm{e}}$ \\
\hline & $\begin{array}{l}\text { Polyethylene sheet } \\
8 \% \mathrm{RH} \\
70 \% \mathrm{RH}\end{array}$ & $\begin{array}{c}7 \times 10^{-7} \\
1.4 \times 10^{-6}\end{array}$ & Sutton et al., 1976 \\
\hline & $\begin{array}{l}\text { Plywood }^{\mathrm{f}} \\
\text { Plate glass }^{\mathrm{f}} \\
\text { Aluminum }^{\mathrm{f}} \\
\text { Polyethylene sheet } \\
\text { Lucite }\end{array}$ & $\begin{array}{c}4.7 \times 10^{-6}-5.8 \times 10^{-7} \\
1.1 \times 10^{-7}-5.5 \times 10^{-8} \\
1.1 \times 10^{-6}-5.5 \times 10^{-8} \\
3.5 \times 10^{-6}-1.2 \times 10^{-6} \\
7 \times 10^{-7}-5.5 \times 10^{-8}\end{array}$ & Sabersky et al., $1973^{\mathrm{e}}$ \\
\hline & $\begin{array}{l}\text { Aluminum, 5\% RH } \\
40-50 \% \mathrm{RH} \\
87 \% \mathrm{RH} \\
\text { Stainless steel }\end{array}$ & $\begin{array}{c}4.9 \times 10^{-8} \\
7.0 \times 10^{-7}-1.3 \times 10^{-7} \\
2.4 \times 10^{-6} \\
1.7 \times 10^{-6}-9 \times 10^{-7}\end{array}$ & Mueller et al., $1973^{\mathrm{e}}$ \\
\hline & $\begin{array}{l}\text { Aluminum, 32\% RH } \\
83 \% \text { RH }\end{array}$ & $\begin{array}{l}7.7 \times 10^{-8} \\
2.3 \times 10^{-7}\end{array}$ & Cox and Penkett, $1972^{\mathrm{e}}$ \\
\hline & $\begin{array}{l}\text { Latex paint, }<10 \% \mathrm{RH}^{\mathrm{f}} \\
\sim 80 \% \mathrm{RH}^{\mathrm{f}} \\
\text { Glass } \\
\text { Vinyl wallpaper } \\
\text { Paper wallpaper }\end{array}$ & $\begin{array}{c}2 \times 10^{-6}-7 \times 10^{-7} \\
2 \times 10^{-5}-1 \times 10^{-6} \\
<1 \times 10^{-6} \\
5 \times 10^{-6} \\
1 \times 10^{-6}\end{array}$ & Reiss et al., 1994 \\
\hline
\end{tabular}


Table 2.1 (cont.) Reaction probability $(\gamma)$ for sarin, $\mathrm{SO}_{2}$, and ozone on selected building materials.

\begin{tabular}{llcl}
\hline Species & Material & $\gamma^{\mathrm{a}}$ & Reference \\
\hline Galvanized sheet steel & $1.1 \times 10^{-6}$ & Morrison et al., 1998 \\
Duct liners (new) & $0.8 \times 10^{-5}-3.2 \times 10^{-5}$ & \\
Duct liners (used) & $4.8 \times 10^{-5}$ & \\
& & \\
& & & \\
Carpet (whole) $^{\mathrm{g}}$ & $3.1 \times 10^{-5}-6.3 \times 10^{-6}$ & Morrison and Nazaroff, 2000 \\
Carpet (fibers) $^{\mathrm{g}}$ & $4.8 \times 10^{-7}-5.0 \times 10^{-8}$ & \\
Carpet (backing) $^{\mathrm{g}}$ & $2.8 \times 10^{-5}-1.0 \times 10^{-5}$ & \\
\hline
\end{tabular}

a Italicized values were inferred from the reference; others are directly quoted.

b The $\gamma$ values were estimated from reported first-order decay rate and surface/volume ratios.

$c$ Both first-order decay constant and deposition velocity were reported.

${ }^{\mathrm{d}}$ Estimated from deposition velocity reported in the reference.

e As cited by Cano-Ruiz et al., 1993.

f Range of values reflect the decrease in uptake with prolonged ozone exposure.

${ }^{g}$ Reaction probability determined after 48-hour exposure. 
Table 2.2 Airflow parameters as a function of crack height for selected conditions ${ }^{\mathrm{a}}$.

\begin{tabular}{cccc}
\hline Crack height, $\mathrm{mm}$ & Air speed, $\mathrm{cm} \mathrm{s}^{-1}$ & Reynolds number $^{\mathrm{b}}$ & Entrance length $^{\mathrm{c}}$ \\
\hline 0.05 & 0.4 & 0.01 & $1.1 \times 10^{-6}$ \\
0.10 & 1.4 & 0.08 & $1.6 \times 10^{-5}$ \\
0.25 & 9.6 & 1.3 & $6.7 \times 10^{-4}$ \\
1.00 & 131 & 73 & $1.5 \times 10^{-1}$ \\
\hline
\end{tabular}

a Conditions: flow path length $(z)=3 \mathrm{~cm}$ and pressure drop $(\Delta P)=10 \mathrm{~Pa}$.

b Reynolds number, $R e=U d / v$, where $U$ is the air speed and $v$ is the kinematic viscosity of air.

${ }^{c}$ Dimensionless entrance length, $x_{e} / z$, estimated as $0.06 d R e=0.06 U d^{2} / \mathrm{N}$. 


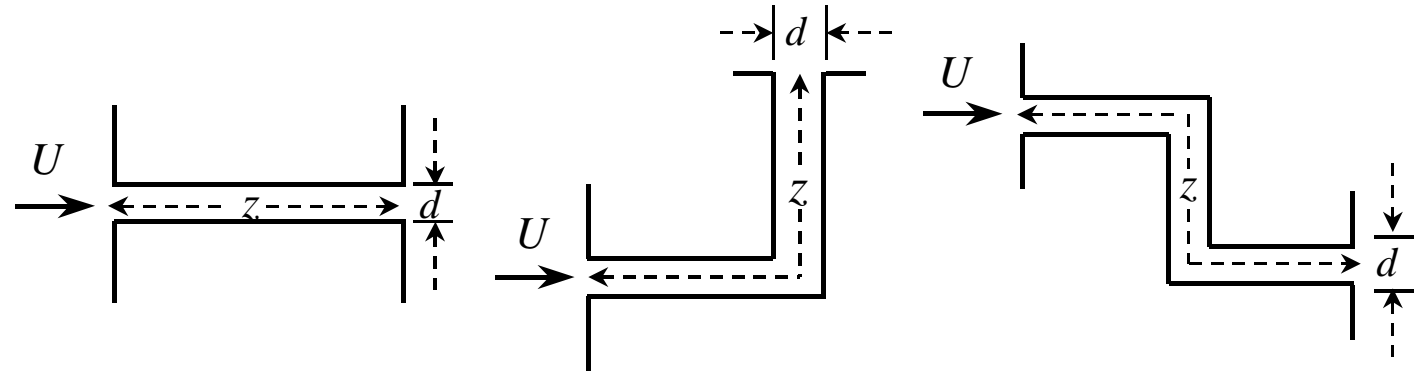

straight-through L-shaped double-bend

(a)

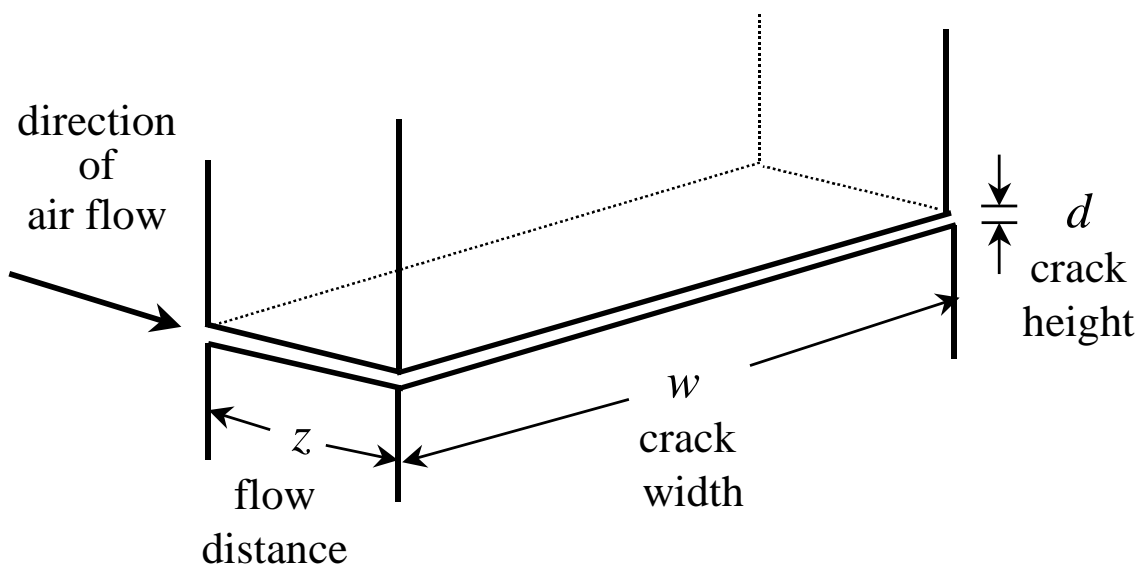

(b)

Figure 2.1 (a) Configuration of three types of idealized cracks through building envelopes, and (b) three-dimensional view of postulated straight-through crack. 


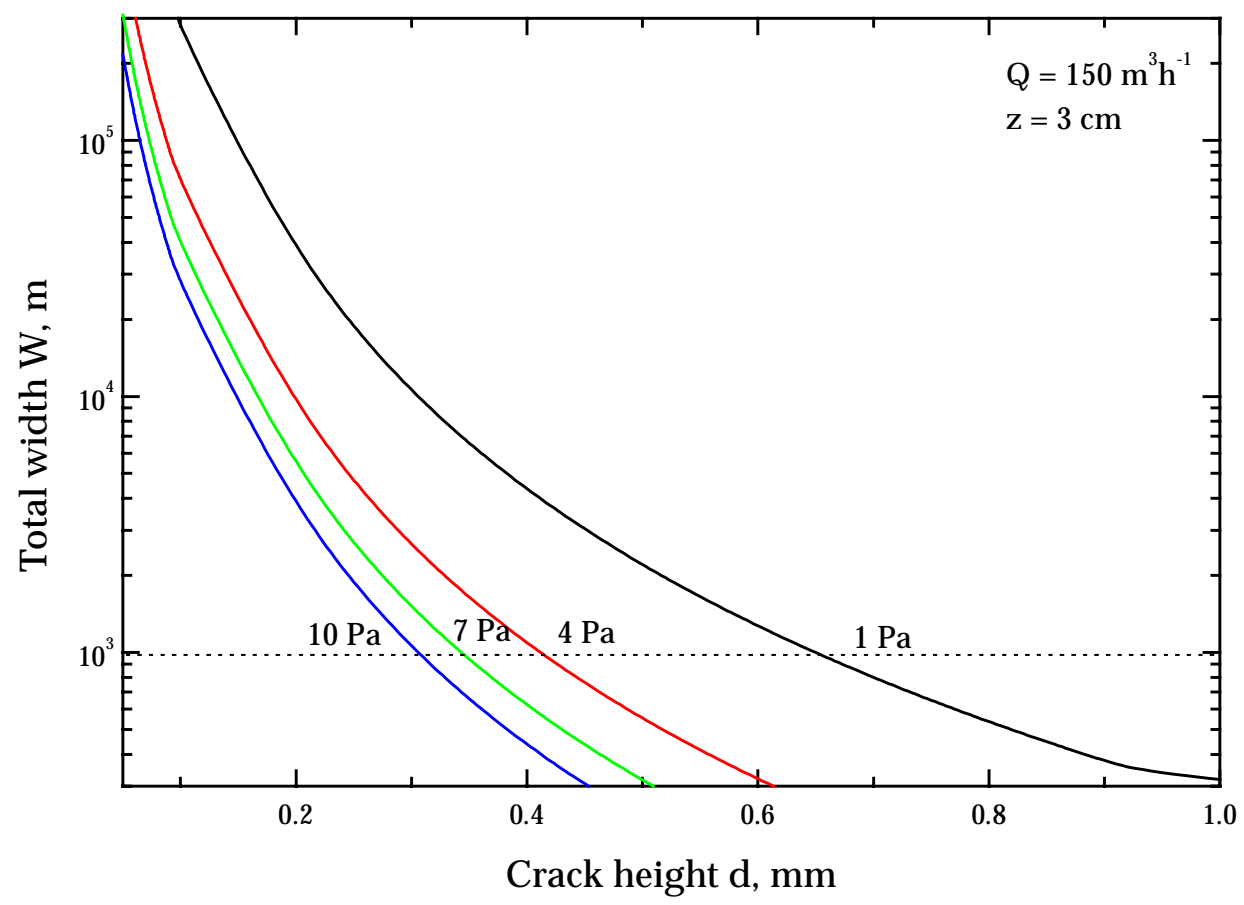

Figure 2.2 Total crack width versus crack height (assumed uniform) necessary to support an infiltration rate of $150 \mathrm{~m}^{3} \mathrm{~h}^{-1}$, which is typical for a singlefamily residence. 


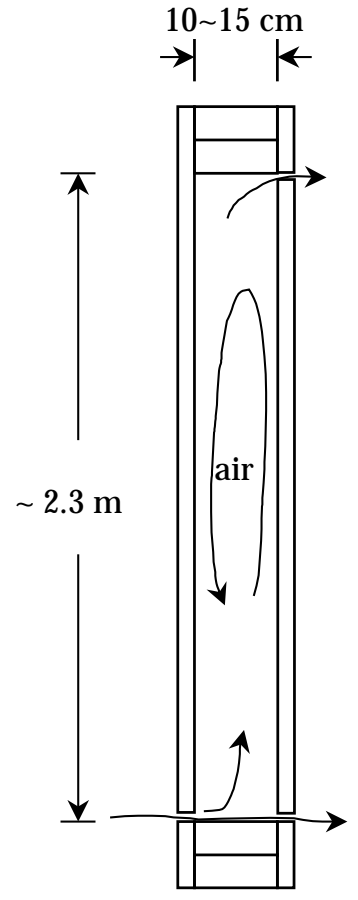

(a)

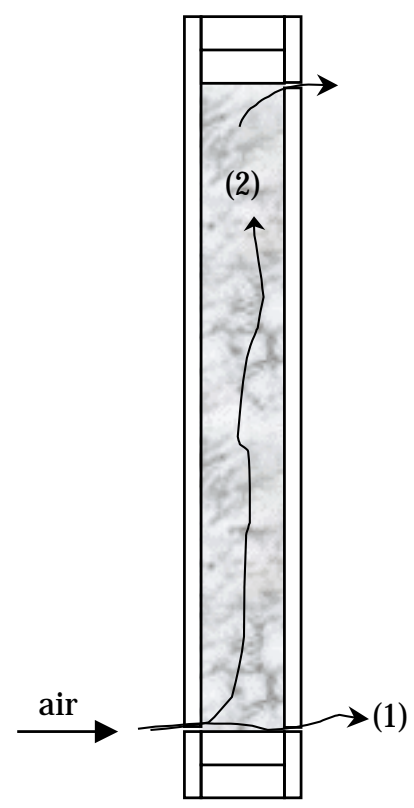

(b)

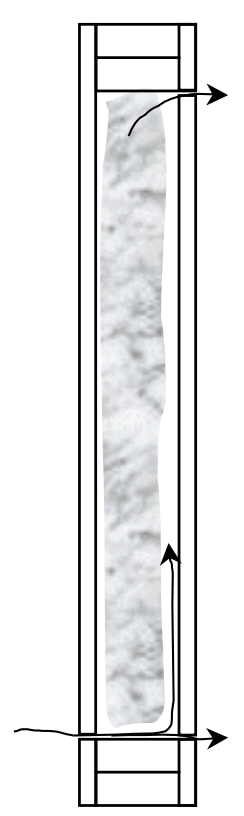

(c)

Figure 2.3 Schematic of airflow paths through wall cavities in wood-frame construction; (a) uninsulated wall cavity; (b) wall cavity filled with fiberglass insulation; and (c) fiberglass-insulated wall cavity with airflow bypass. 


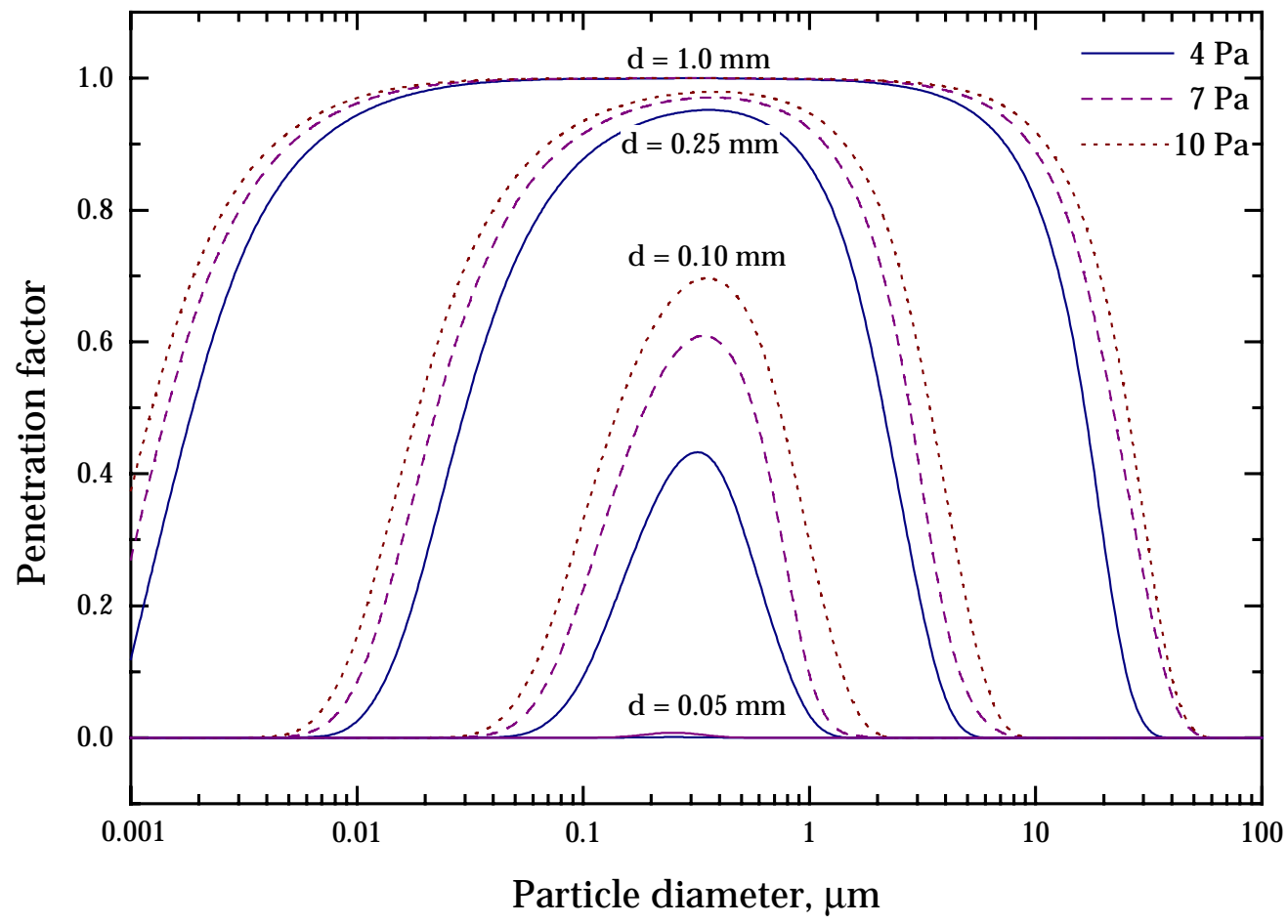

Figure 2.4 Particle penetration factor as a function of particle diameter, crack height, and pressure difference for a straight-through crack with flow length $z=3$ $\mathrm{cm}$. 


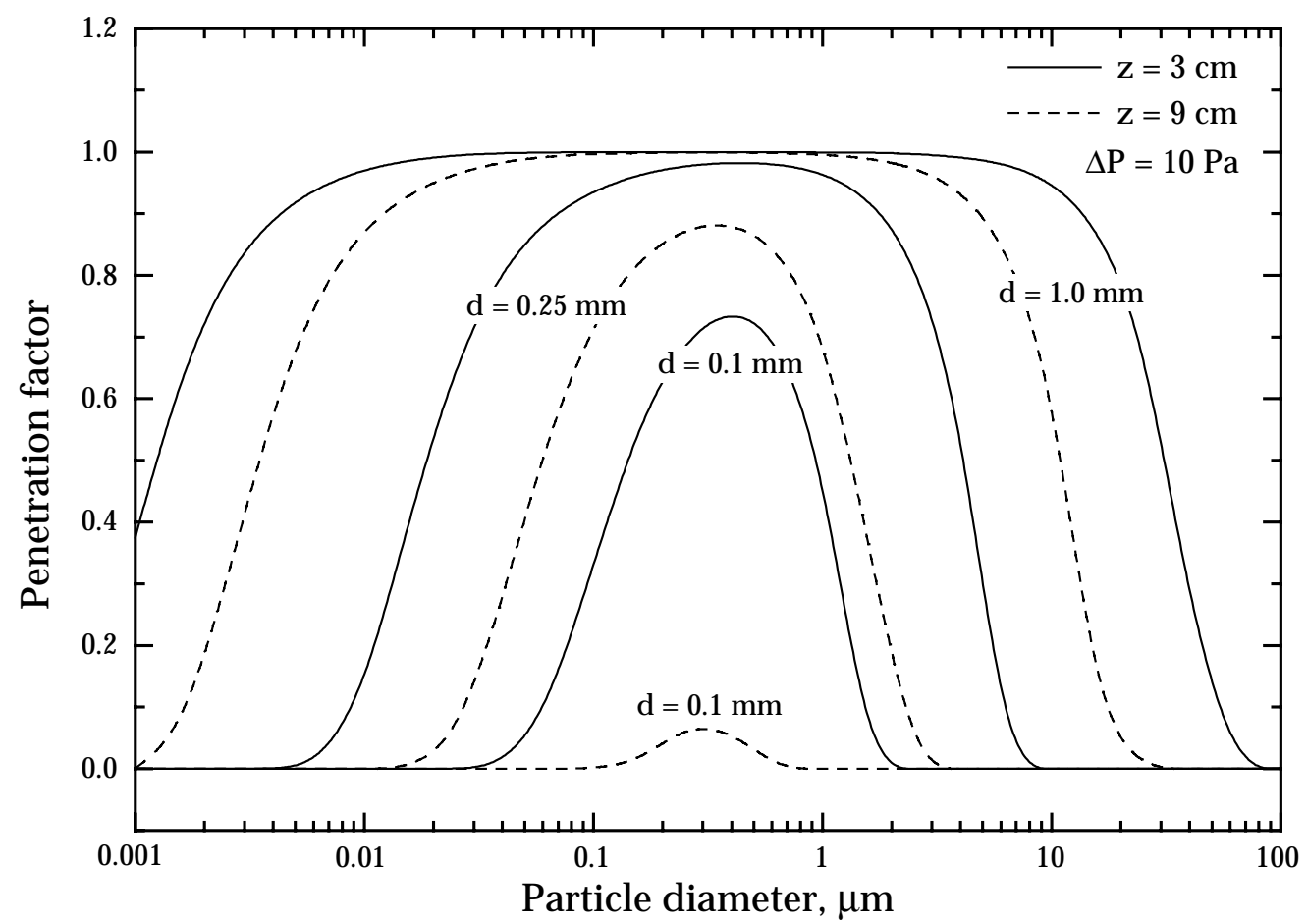

Figure 2.5 Particle penetration factor as a function of particle diameter, crack height, and flow length at a fixed pressure drop of $\Delta \mathrm{P}=10 \mathrm{~Pa}$. 


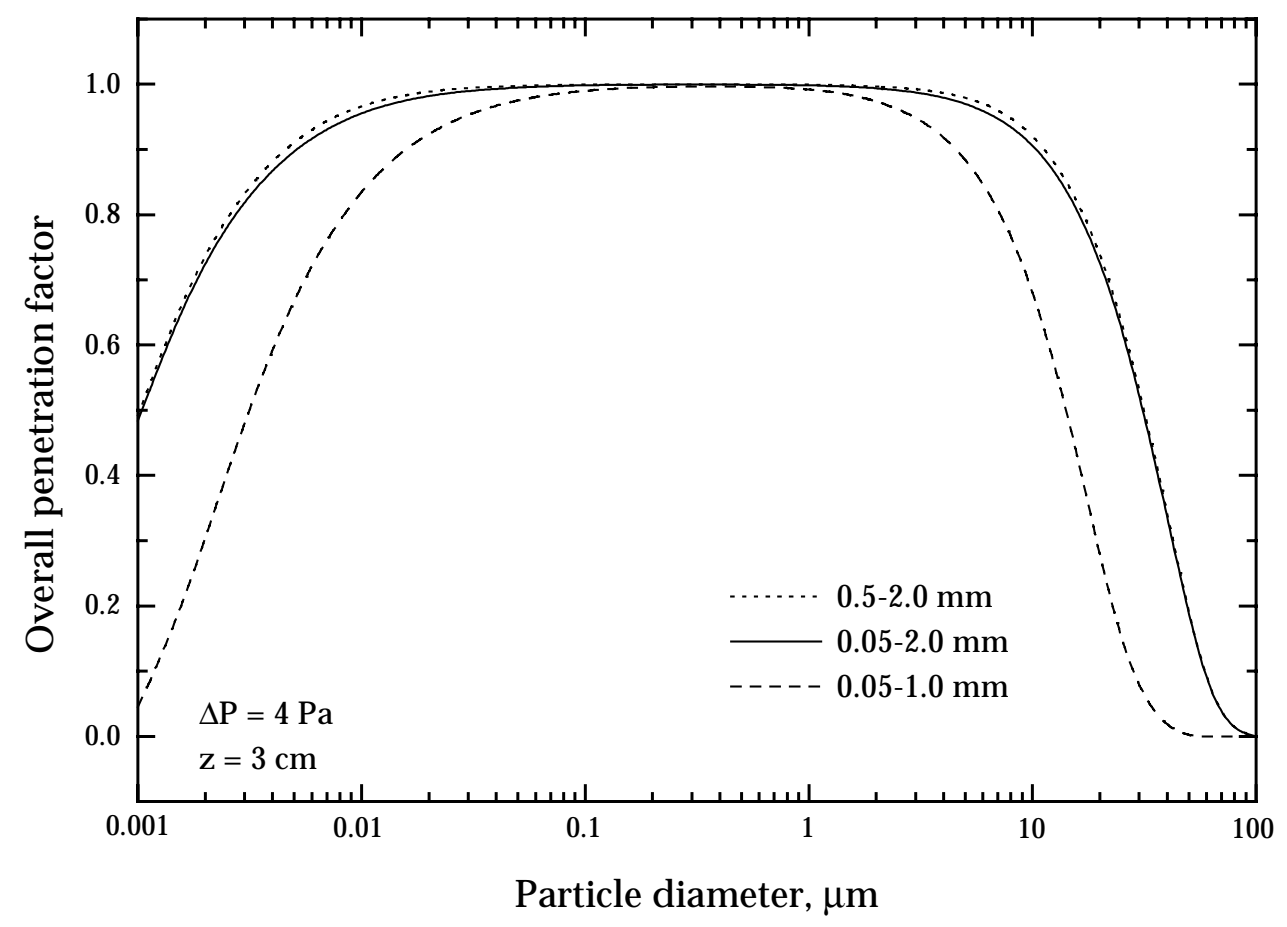

Figure 2.6 Overall particle penetration factor for a building with crack area distributed uniformly with respect to crack height. Results are presented for three different ranges of crack sizes. 

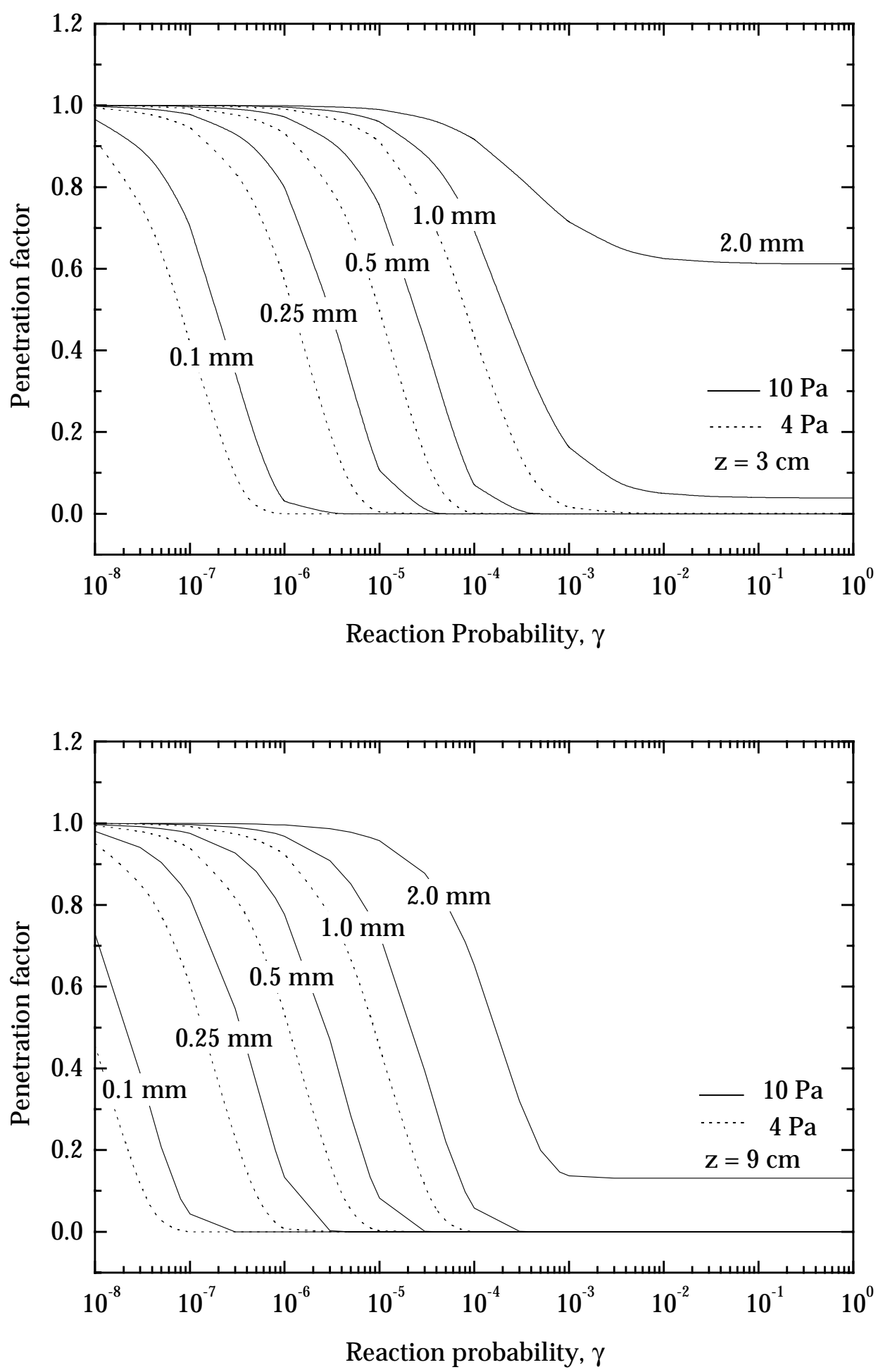

Figure 2.7 Ozone penetration factor through a single crack as a function of reaction probability, crack height, and pressure difference for two flow path lengths (a) $z=3 \mathrm{~cm}$ and (b) $z=9 \mathrm{~cm}$. 


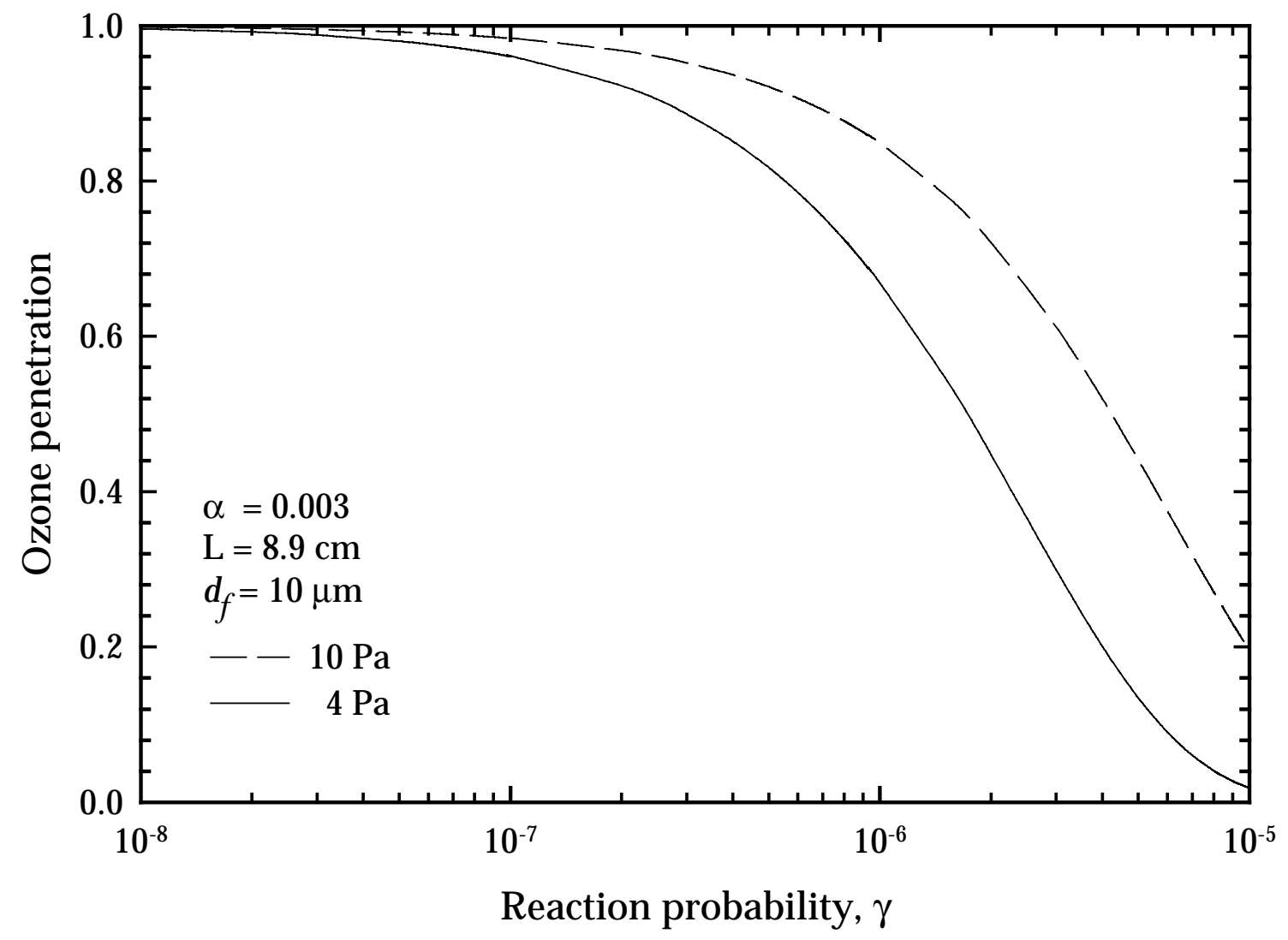

Figure 2.8 Ozone penetration factor for airflow through a fiberglass blanket as a function of ozone-fiber reaction probability. 


\section{Measuring Particle Penetration through BUILDING CRACKS *}

\subsection{ABSTRACT}

Ambient aerosol penetration through building envelopes contributes to human exposure to particles of outdoor origin. In this chapter, experimental results are presented for particle penetration through single rectangular slots of uniform geometry, a surrogate of leakage paths in building envelopes. Cracks with heights of $0.25 \mathrm{~mm}$ and $1 \mathrm{~mm}$ were prepared using several different building materials: aluminum, brick, concrete, plywood, redwood lumber, pine lumber, and strand board. The crack apparatus was coupled to a well-mixed aluminum chamber. Fixed pressure differences $(\Delta \mathrm{P})$ of 4 and $10 \mathrm{~Pa}$ across the crack were established by withdrawing air at constant flow rates out of the chamber, through the crack apparatus. Nonvolatile, electrically neutralized particles were generated and introduced into the chamber. Air was sampled from the chamber and from downstream of the crack by aerosol measuring instruments. The particle penetration factor was determined, for particle sizes of 0.02-7 $\mu \mathrm{m}$, as the ratio of the particle concentration downstream of the slot to that in the chamber. Particle size and crack height were the two main factors that governed fractional particle penetration. Consistent with modeling results presented in Chapter 2, the penetration factor was nearly unity for particles of diameter $0.1-1.0 \mu \mathrm{m}$ at $\quad 0.25 \mathrm{~mm}$ crack height and $\Delta \mathrm{P}$ of $\quad 4 \mathrm{~Pa}$. Particle penetration diminished for larger and smaller particles due to gravitational settling and Brownian diffusion, respectively. Particle penetration less than predicted values was

\footnotetext{
* This chapter is closely related to the following manuscript: D.-L. Liu, and W.W. Nazaroff, Particle penetration through building cracks, submitted to Aerosol Science and Technology.
} 
observed for cracks that exhibit significant surface roughness and irregular crack geometry.

\subsection{INTRODUCTION}

Particulate matter (PM) is one of the criteria air pollutants regulated by the US EPA. Inhalation of airborne particles also presents an important pathway of human exposure to certain toxic compounds and elements. With increasing awareness that personal PM exposure mostly occurs indoors, more attention has been directed to understand the presence of indoor particles of outdoor origin (Riley et al., 2002). Air infiltration, driven by the pressure difference across building shells, is a primary mode of ventilation in many residential settings. Through unintentional building openings, such as building cracks and window gaps, ambient pollutants may enter indoor environments along with infiltrating air. Consequently, human inhalation exposure to particles of outdoor origin is influenced by the degree to which such particles can penetrate the building envelope and remain suspended in indoor air.

Little was known about particle penetration into buildings until the mid 1990s. Since then, several studies have been published that infer overall particle penetration rates into residences on the basis of model fits to field data on indoor and outdoor particle levels (Thatcher and Layton, 1995; Özkaynak et al., 1996; Long et al., 2001; Vette et al., 2001). More discussion of these studies is presented in Chapter 5. Other investigators have reported on laboratory-based experiments of particle penetration (Lewis, 1995; Mosley et al., 2001). In Lewis's study, for instance, a test facility was built to house aerosol generation/dissemination and measurement instruments, as well as an exposure 
chamber that was attached with a horizontal perspex test slit (0.1 mm high). By blowing airborne particles to the vicinity of the crack from one end of the facility, the ratio of aerosol concentration in the chamber to that of the challenge dust cloud was determined as the "total transport fraction". The fraction of airborne particles transported through the slit therefore accounted for particle loss not only in the leakage path, but also particle loss within the chamber. In a separate study, Mosley et al. performed experiments that involved transporting particles through an array of 140 slits constructed with aluminum plates from one compartment to another. The fraction of particle penetration through the slits was evaluated so that it took into account of particle loss in the compartments. One crack height of $0.508 \mathrm{~mm}$ (with the flow path distance of $10.2 \mathrm{~cm}$ ) was investigated against pressure differentials of 2, 5, 10,20 $\mathrm{Pa}$, and the particle sizes evaluated ranged from 0.08 to $5 \mu \mathrm{m}$.

While these studies have advanced our knowledge, they have not fully elucidated the extent to which particles penetrate building envelopes. This chapter complements and extends the previously published investigations by greatly increasing the quantity of empirical data from laboratory-based experiments. Measurement results are reported for particle penetration through slots designed to be surrogates of real infiltration pathways in buildings. Most of the slots tested had regular, rectangular geometry, and were made from common building materials. In addition, to explore the effects of irregular crack geometry, particle penetration through a broken brick was investigated. The slot dimensions and the applied pressure differences were chosen to be representative of conditions in buildings. The design of our experimental apparatus has the advantage of versatility, allowing various crack heights and different crack materials to be tested. 
Penetration was measured over a broad range of particle diameters, 0.02-7 $\mu \mathrm{m}$. The results were compared against model predictions as reported in Chapter 2.

\subsection{METHODS}

\subsubsection{Crack Apparatus and the Chamber}

Cracks were prepared using seven different materials: aluminum, brick, concrete, plywood, redwood lumber, pine lumber, and strand board. The aluminum plates were machined so that the inner wall surfaces of the crack were smooth. This represents an idealized case in which surface roughness is expected to have minimal effect on particle deposition. Rectangular slots or cracks were configured from the other six materials by cutting them with conventional methods. Some of the natural surface roughness of these materials was retained to approximately simulate the texture of building cracks. Brick, redwood lumber, and pine lumber were cut to the desired size directly from the original bulk materials. To imitate the coarse surface texture of building gaps made of plywood and strand board, the inner wall of the crack was created from the cut faces of several layers of boards that had been previously glued together. The concrete plates were made by pouring a mixture of Portland cement, sand, and water into a plywood form, so that the surface texture resembled closely that of realistic concrete walls (see Appendix D for details). Additionally, for wood materials, polyurethane paint and caulking agents were applied on the exterior surface of the crack apparatus to seal the pores, ensuring that air passed through the crack only, and not through the material pores.

The crack apparatus is illustrated in Figure 3.1. The main component consists of two plates of identical size and materials. Two crack heights, $0.25 \mathrm{~mm}$ and $1 \mathrm{~mm}$, were 
created by inserting metal shims of the appropriate thickness between the two plates. The crack length, i.e., the dimension parallel to the airflow direction, was 4.3 and $9.4 \mathrm{~cm}$ for aluminum cracks, and $4.5 \mathrm{~cm}$ for the other materials. For crack heights of $1 \mathrm{~mm}$, the crack width, perpendicular to the flow direction, was shortened by inserting shims of greater width so that the crack air flow rate corresponding to a given $\Delta \mathrm{P}$ could be accommodated by the aerosol measuring instruments.

The specific crack heights of $0.25 \mathrm{~mm}$ and $1 \mathrm{~mm}$ were selected to represent dimensions of interest for real building leakage paths. The smaller value represents a lower bound of the crack height through which significant infiltration airflow could occur in buildings. For crack heights larger than $1 \mathrm{~mm}$, penetration is expected to be large over a broad range of particle sizes, according to modeling prediction presented in Chapter 2 .

The crack apparatus was assembled and mounted with a gasket to an aluminum cover that allowed sampling of aerosols flowing through the crack by the measuring instruments. The whole apparatus was coupled to a slot in the wall of an aluminum chamber $(50 \times 40 \times 40 \mathrm{~cm})$ into which particles were introduced. A glazing compound was applied to seal leaks at the junction between the crack apparatus and the chamber so that the designed leakage path was the only aerosol flow pathway. The schematic drawing of the crack apparatus and the chamber is depicted in Figure 3.2.

Since the aerosol concentration in the chamber was used to represent that of upstream of crack apparatus, it is important to provide a uniform particle concentration throughout the chamber. A small fan was positioned in the center, and a diffuser was installed beneath the aerosol inlet inside the chamber to promote good mixing of air and particles. In addition, a pleated HEPA (high efficiency particulate air) filter was located 
at the bottom, as shown in Figure 3.2, to create equal flow resistance prior to the exit of air, preventing short-circuiting airflow. The uniformity of the particle concentration was confirmed by sampling ammonium fluorescein particles on filters ( $26 \mathrm{~mm}$ cellulous membrane, Osmonics Inc.) at five locations in the chamber with pumps of known flow rates and sampling time. After the particles were extracted by soaking the filters into fixed volumes of buffer solution (sodium bisulphate, $0.05 \mathrm{M}$ ), the collected particulate mass on filters were determined by analyzing the buffer fluorescent concentrations (Fluorometer TD-700, Turner Designs, Sunnyvale, CA). Consistent particle concentrations were found, indicating good mixing in the chamber.

\subsubsection{Experimental Setup}

The experimental configurations are illustrated schematically in Figures 3.3-3.5. Since no single aerosol instrument can measure particles of all sizes, different arrangements were required for different particle size ranges. In each case, particles were generated and continuously supplied to the aluminum chamber. Air was extracted at a constant flow rate from the chamber through the crack apparatus. Particles were measured upstream and downstream of the crack. The penetration factor was evaluated as the ratio of the downstream to upstream concentration.

For particles larger than $0.6 \mu \mathrm{m}$ in diameter (Figure 3.3), polydisperse droplets were generated by supplying a highly concentrated aqueous $\mathrm{KCl}$ solution under high pressure into the nozzle of the custom-built atomizer (see Appendix E for details). The spray particles were dried and electrically neutralized before being introduced into the aluminum chamber. For submicron particles (Figure 3.4), a dilute aqueous $\mathrm{KCl}$ solution 
was supplied to a constant output atomizer (TSI, Inc. Model 3075), and the droplets were then passed through a diffusion dryer and a Kr-85 neutralizer (TSI, Inc. Model 3077). To examine submicron particle penetration with greater precision, experiments were also conducted with monodisperse particles that were generated by means of an atomizer coupled to a differential mobility analyzer (DMA, TSI, Inc. Model 3071), as illustrated in Figure 3.5. The DMA is a device that allows the separation of a narrow range of particle electrical mobility, which corresponds to certain particle sizes, from among all particles introduced into the instrument. The particle diameters used with this approach were 0.02 , $0.03,0.05$, and $0.09 \mu \mathrm{m}$.

A pump was employed in conjunction with the aerosol measurement instruments to maintain the desired pressure difference $(\Delta \mathrm{P}=4$ or $10 \mathrm{~Pa})$ across the crack, withdrawing air at fixed flow rates out of the chamber. For the crack sizes and pressure differences that were investigated in this study, the airflow within the crack was laminar. Furthermore, the airflow rate exhibited a linear relationship with pressure difference, indicating that flow resistance was dominated by viscosity (Baker et al., 1987; Chastain et al., 1987). Before each run, the relationship between crack airflow rate and pressure difference was measured. Then during an experiment, the airflow rate was established at the value necessary to achieve the target value of $\Delta \mathrm{P}$. Depending on the crack geometry and pressure difference, additional particle-free air was added downstream of the crack apparatus in some cases to augment the crack air and thereby ensure appropriate aerosol flow rate for each instrument.

The particle penetration experiments were performed for particle diameters ranging from 0.02 to $7 \mu \mathrm{m}$. Particles were sampled through copper tubing. Two 
identical tubes $(28.4 \mathrm{~cm}$ long with an inner diameter of $0.5 \mathrm{~cm}$ ) were used to connect the chamber and the crack apparatus to a three-way ball valve (Swagelok Inc.). During experiments, the valve was switched to alternately direct the upstream or downstream aerosol flow to one of the measuring instruments (Aerodynamic Aerosol Sizer, APS, TSI, Inc. Model 3320; Electrostatic Aerosol Analyzer, EAA, TSI, Inc. Model 3030; and Condensation Nuclei Counter, CNC, TSI, Inc. Model 3022 or 3022A), as shown in Figures 3.3-3.5. The EAA was used to measure particle number concentrations in seven size ranges, which had mean particle diameters of $0.024,0.042,0.075,0.13,0.24,0.42$, and $0.75 \mu \mathrm{m}$, respectively. The APS was used to measure size-resolved particle number concentrations for particles larger than $0.6 \mu \mathrm{m}$ in diameter. For the experiments involving monodisperse particles, the $\mathrm{CNC}$ was used to measure particle number concentrations. The operation principles of these aerosol measurement instruments are summarized in Appendix F.

Particle concentration data were collected only after the levels in the chamber reached an apparent steady state. Sufficient flushing intervals were used between crack and chamber samples to ensure that the measurements accurately reflected the intended conditions.

\subsection{RESULTS AND DISCUSSION}

\subsubsection{Cracks of Uniform Geometry}

Figures 3.6 and 3.7 present the experimental results for particle penetration through aluminum cracks under $\Delta \mathrm{P}$ of 4 and $10 \mathrm{~Pa}$, respectively. The aluminum crack with smooth inner surfaces was meant to simulate an idealized crack as postulated in 
Chapter 2. The lines in the figures represent the predictions of particle penetration associated with the given crack heights and crack lengths, based on the model for idealized cracks in Chapter 2. Each symbol in the figures represents the mean value of many measurements for a given particle size. The error bars correspond to ninety-five percent confidence intervals on the mean, based on fluctuations in the measured concentrations. Three data sets are illustrated, with different symbols distinguishing among the three particle generation and measurement methods. To make these experimental data available for future use, the measured values of particle penetration factors for all cracks examined in this chapter are tabulated in Appendix G.

For a given crack height, the highest particle penetration factors were predicted to occur for particles of 0.1 to $1 \mu \mathrm{m}$ in diameter. Particles outside of this size range should exhibit lower penetration factors as they are expected to deposit on crack surfaces by means of gravitational settling or Brownian diffusion. The model predictions generally conform well to the experimental results, except for the EAA results of the lowest crack flow rate $-d=0.25 \mathrm{~cm}$ and $z=9.4 \mathrm{~cm}$ at $4 \mathrm{~Pa}$ - while the APS and $\mathrm{CNC}$ results appear to be in good agreement with the predictions. The discrepancy between the model and experiment in this EAA measurement may be attributable to the fluctuation of air flow rate through the crack, which resulted from the EAA aerosol flow rate uncertainty $\left(\sim 50 \mathrm{~cm}^{3} \mathrm{~min}^{-1}\right)$.

Figure 3.8 displays the experimental results for cracks made of the six other building materials. Model predictions based on the assumption of smooth crack surfaces are also shown. Among the six tested materials, the inner surface of strand board and concrete cracks appeared the roughest, based on direct observation. A small piece $(\sim 1 \mathrm{x}$ 
$1 \mathrm{~cm}^{2}$ ) of the strand board crack surface was characterized for roughness (Micromap 570 Profiler). The results revealed that the root mean square (rms) height variation along a $200 \mu \mathrm{m}$ line was $\sim 15 \mu \mathrm{m}$ and peak to valley difference was $\sim 70 \mu \mathrm{m}$. If a larger area were sampled, these roughness parameters would probably be larger. Appendix $\mathrm{H}$ provides more information pertinent to the surface roughness measurement.

At a crack height of $1.0 \mathrm{~mm}$, the experimental data presented in Figure 3.8 show essentially complete penetration for all six materials across the full range of particle sizes tested, in good agreement with the predictions. For $0.25 \mathrm{~mm}$ crack height, penetration was significantly lower, especially for ultrafine (diameter $\quad 0.1 \mu \mathrm{m}$ ) and supermicron particles. Most materials showed moderately good agreement with the modeling predictions.

For redwood and concrete with a crack height of $0.25 \mathrm{~mm}$, deviations are exhibited between model and measurement for particle sizes less than $0.1 \mu \mathrm{m}$. This is believed to be attributable to deformation of the cracks over time for these two samples as these experiments were undertaken much later than were the others. The deformation of the redwood and concrete samples caused uneven crack height; the $0.25 \mathrm{~mm}$ feeler gauge could not penetrate all the way through the crack slots.

Less particle penetration than predicted was observed in the particle size range of 0.1-1 $\mu \mathrm{m}$ for cracks made of strand board and concrete. For instance, at a $0.25 \mathrm{~mm}$ crack height, for particles in the size range $0.1-0.4 \mu \mathrm{m}$, the measured particle penetration factors for these two cracks were less than the predicted values by $\sim 20 \%$. In this size range, Brownian diffusion is an important transport mechanism contributing to deposition in the crack, whereas for larger particles, gravitational settling controls. The discrepancy 
between model and measurement may be a consequence of roughness elements protruding into the particle concentration boundary layer. The boundary layer is thinner for larger diffusive particles, and so roughness is expected to play a greater role in enhancing deposition for 0.1-0.4 $\mu \mathrm{m}$ particles than for ultrafine particles.

Scale analysis (Bejan, 1984) was used to estimate the particle concentration boundary layer thickness $\left(\delta_{p}\right)$ within the crack, which can be approximated by

$$
\delta_{p} \sim z P e^{-\frac{1}{3}} \operatorname{Re}_{z}^{-\frac{1}{6}}
$$

where $P e$ is the Peclet number $(=U z / D)$, and $R e_{z}$ is the Reynolds number $(=U z / N)$ based on flow path distance $z$. Table 3.1 provides the estimated boundary layer thickness corresponding to some particle sizes of interest in this analysis.

As indicated in Table 3.1, when the pressure difference was $4 \mathrm{~Pa}$ and the crack height was $0.25 \mathrm{~mm}$, the thickness of the particle concentration boundary layer for particles of $0.03 \mu \mathrm{m}$ and $0.3 \mu \mathrm{m}$ was $\sim 370$ and $100 \mu \mathrm{m}$, respectively. This suggests that the protruding elements on the rough surface (e.g., strand board) are likely to be contained well below the particle concentration boundary layer for ultrafine particles, as illustrated in Figure 3.9, but to extend well into the boundary layer for the case of 0.1-0.4 $\mu \mathrm{m}$ particles. Therefore for diameter less than $0.1 \mu \mathrm{m}$, no significant change is expected for particle deposition from Brownian diffusion in the presence of surface roughness. For particles of 0.1-0.4 $\mu \mathrm{m}$, the boundary layer thickness is comparable to the dimension of roughness elements on the crack surfaces, leading to enhanced particle deposition owing to inertial impaction or interception onto the local protrusions. For particles larger than $0.4 \mu \mathrm{m}$, where gravity begins to control deposition, roughness appears to be relatively unimportant, and the smooth-surface model generally conforms well to the experimental 
data.

\subsubsection{Penetration through a Broken Brick}

Apart from surface roughness, the irregular geometry of real cracks may affect particle penetration. To investigate this issue, a real crack, created by breaking a brick, was studied using the same experimental approach applied to the rectangular slots.

Figure 3.10 depicts a schematic of the naturally broken-brick crack apparatus, in which a micrometer (Mitutoyo, Japan) was installed so that the test crack height could be adjusted and confirmed as well. The irregular crack channel, as well as the surface characteristics within the cracks are illustrated in Figure 3.11. The nominal flow-path length was 4.5 $\mathrm{cm}$. Two crack heights of 0.25 and $1 \mathrm{~mm}$ were examined under a pressure difference of 4 Pa. In addition to the experimental configurations shown in Figures 3.3-3.5, for the crack height of $0.25 \mathrm{~mm}$, a supplementary approach was required because the aerosol flow rate needed for the target pressure differential was too low to be accurately sampled by the EAA. Instead, a Laser Aerosol Spectrometer (LAS-X, Particle Measurement Systems, Inc. Boulder, $\mathrm{CO}$ ) was used to determine penetration for 0.1-1 $\mu \mathrm{m}$ diameter particles. Also, to confirm the experimental results measured with the APS, monodisperse particles $(\sim 0.9 \mu \mathrm{m})$ generated by a vibrating orifice aerosol generator (VOAG, TSI, Inc. Model 3450) were introduced into the chamber in one experimental run. Particle concentrations from the chamber and downstream of the crack apparatus were measured using a CNC (TSI, Inc. Model 3030).

The experimental results, as presented in Figure 3.12, show general consistency among the different measurement techniques. The experimental data for the rough, 
irregular crack, and the model predictions for a smooth, regular-geometry channel show good agreement for particles smaller than $\sim 0.3 \mu \mathrm{m}$ diameter. For most larger particle sizes, less penetration was observed than predicted.

Note that at a particle diameter of $\sim 2 \mu \mathrm{m}$, the measured penetration did not go abruptly to zero as predicted by the model. A similar result was observed for concrete cracks (see Figure 3.8), for which the slot openings were not sharp-edged as were other crack samples. A possible explanation for this phenomenon is that certain portions of these irregular flow channels have larger crack heights than the $0.25 \mathrm{~mm}$ base value. In the zones with larger crack height, penetration would be more effective than predicted by the model.

For a crack height of $1.0 \mathrm{~mm}$, evident deviations of the experimental data from the idealized predictions occur for supermicron particles. The enhanced deposition of bigger particles might be caused by non-uniform crack geometry that gives rise to local flow irregularity, which in turn leads to impaction or interception when particles hit the protruding elements associated with the rough surfaces. For ultrafine particles, on the other hand, the experimental data show good agreement with the predictions, suggesting neither nonuniform crack geometry nor surface roughness has significant influence on particle deposition for this size range.

\subsection{CONCLUSIONS}

The penetration of airborne particles through building envelopes can influence inhalation exposure to particles of ambient origin and therefore contribute to the risk of adverse human health effects. A sound understanding of airborne particle penetration 
through rectangular single cracks, a surrogate of leakage paths in building envelopes, provides insight into the phenomenon of particle penetration into buildings and the physical factors that affect it. This chapter has presented experimental measurements of particle penetration through air leakage paths made of aluminum and a variety of other building materials, and has compared the results with model predictions formulated for idealized crack configurations. For most cracks with uniform geometry, the experimental particle penetration factors show good agreement with the model predictions, regardless of crack materials. Particle penetration is essentially complete for particles of 0.02 - 7 $\mu \mathrm{m}$ when the crack height is $1 \mathrm{~mm}$, and for particle diameters of $0.1-1 \mu \mathrm{m}$ when the crack height is $0.25 \mathrm{~mm}$, assuming that the pressure difference is $4 \mathrm{~Pa}$. The experimental data also indicate that some deviations occur for cracks that exhibit significant surface roughness or irregular channel geometries as illustrated by the strand board, concrete, and natural broken brick.

The work reported here contributes to the base of information about penetration through building envelopes, but additional investigations are needed to fill in important gaps. For example, it would be worth studying particle penetration through real building components, such as windows, which possess a variety of non-uniform leakage paths. Additional studies in well-characterized single buildings are also needed. Some experimental results for larger scale leakage components will be presented in the following two chapters. Continued developments on this topic would advance our understanding of how ambient particle sources might affect human health. Knowledge improvement on particle penetration through building envelopes would be potentially 
helpful to develop state-of-the-art building design and technology for reducing human exposure to ambient aerosols.

\subsection{REFERENCES}

Baker, P.H., Sharples, S. and Ward, I.C. (1987) Airflow through cracks, Building and Environment, 22: 293-304.

Bejan, A. (1984) Convection Heat Transfer, Wiley, New York.

Chastain, J.P., Colliver, D.G. and Winner, P.W.Jr. (1987) Computation of discharge coefficients for laminar flow in rectangular and circular opening, ASHRAE Transactions, 27: 2259-2283.

Lewis, S. (1995) Solid particle penetration into enclosures, Journal of Hazardous Materials, 43: 195-216.

Long, C.M., Suh, H.H., Catalano, P.J., and Koutrakis, P. (2001) Using time- and sizeresolved particulate data to quantify indoor penetration and deposition behavior, Environmental Science and Technology, 35: 2089-2099. (See also errata, p. 4584)

Mosley, R.B., Greenwell, D.J., Sparks, L.E., Guo, Z., Tucker, W.G., Fortmann, R. and Whitfield, C. (2001) Penetration of ambient fine particles into the indoor environment, Aerosol Science and Technology, 34: 127-136.

Özkaynak, H., Xue, J., Spengler, J., Wallace, L., Pellizzari, E. and Jenkins, P. (1996) Personal exposure to airborne particles and metals — Results from the particle TEAM study in Riverside, California. Journal of Exposure Analysis and Environmental Epidemiology, 6: 57-78.

Riley, W.J., McKone, T.E., Lai, A.C.K., and Nazaroff, W.W. (2002) Indoor particulate 
matter of outdoor origin: Importance of size-dependent removal mechanisms, Environmental Science and Technology, 36: 200-207. (See also errata, p. 1868)

Thatcher, T.L., and Layton, D.W. (1995) Deposition, resuspension, and penetration of particles within a residence, Atmospheric Environment, 29: 1487-1497.

Vette, A.F., Rea, A.W., Lawless, P.A., Rodes, C.E., Evans, G., Highsmith, V.R. and Sheldon, L. (2001) Characterization of indoor-outdoor aerosol concentration relationships during the Fresno PM exposure studies, Aerosol Science and Technology, 34: 118-126. 
Table 3.1 Estimated particle boundary layer thickness in well-developed airflow for a $0.25 \mathrm{~mm}$ crack height at $\Delta \mathrm{P}=4 \mathrm{~Pa}^{*}$

\begin{tabular}{cccc}
\hline $\begin{array}{c}\text { Particle diameter } \\
d_{p}, \mu \mathrm{m}\end{array}$ & $\begin{array}{c}\text { Diffusion coefficient } \\
D, \mathrm{~cm}^{2} \mathrm{~s}^{-1}\end{array}$ & $\begin{array}{c}\text { Peclet number } \\
P e\end{array}$ & $\begin{array}{c}\text { Boundary layer thickness } \\
\delta_{p}, \mu \mathrm{m}\end{array}$ \\
\hline 0.02 & $1.4 \times 10^{-4}$ & $9.0 \times 10^{4}$ & 480 \\
0.03 & $6.4 \times 10^{-5}$ & $2.0 \times 10^{4}$ & 369 \\
0.04 & $3.7 \times 10^{-5}$ & $3.4 \times 10^{5}$ & 308 \\
0.1 & $6.9 \times 10^{-6}$ & $1.8 \times 10^{6}$ & 176 \\
0.2 & $2.2 \times 10^{-6}$ & $5.6 \times 10^{6}$ & 122 \\
0.3 & $1.2 \times 10^{-6}$ & $1.0 \times 10^{7}$ & 99 \\
0.4 & $8.3 \times 10^{-7}$ & $1.5 \times 10^{7}$ & 87 \\
1.0 & $2.7 \times 10^{-7}$ & $4.6 \times 10^{7}$ & 60 \\
\hline
\end{tabular}

* Based on the flow path distance $z=4.5 \mathrm{~cm}$, and air flow velocity in the crack $U=2.8 \mathrm{~cm} \mathrm{~s}^{-1}$, giving $R e_{z}$ $\sim 84$. 


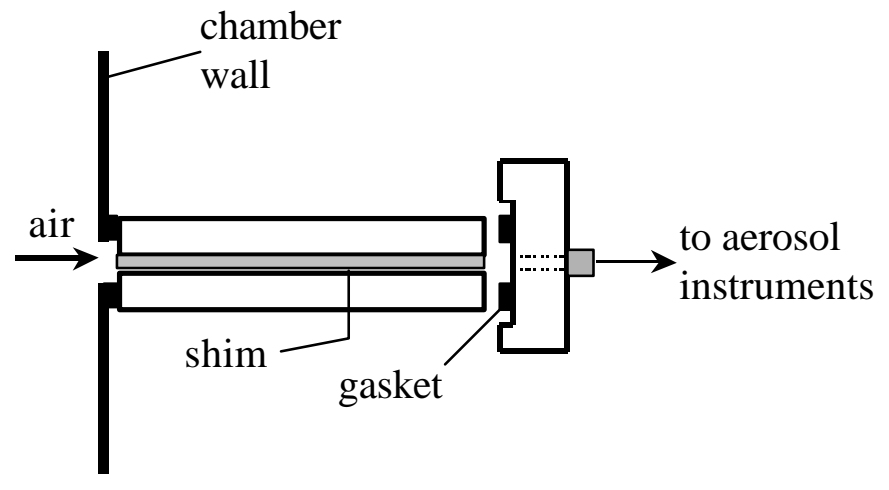

side view

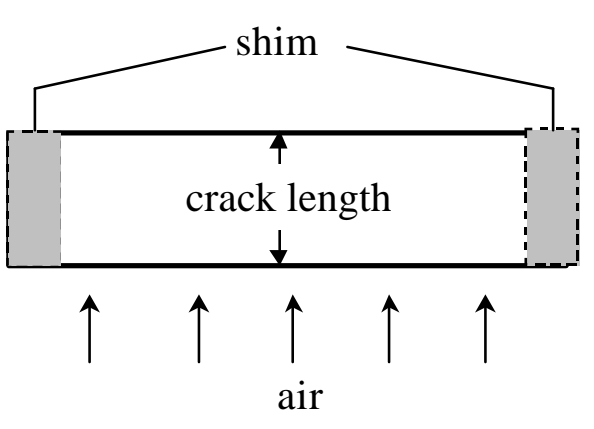

top view

Figure 3.1 Configuration of crack apparatus (not to scale). 


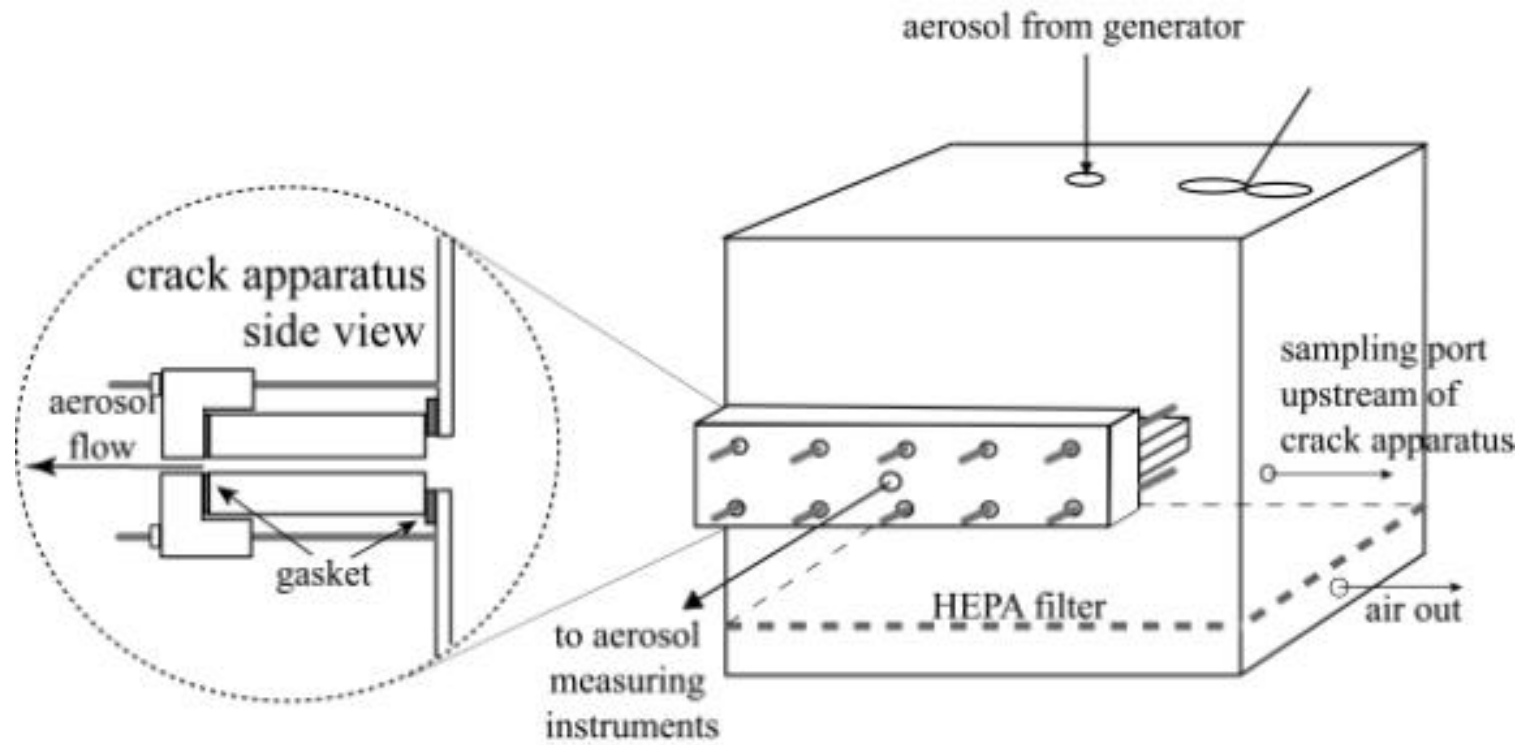

Figure 3.2 Schematic illustration of the crack apparatus and the aluminum mixing chamber. 


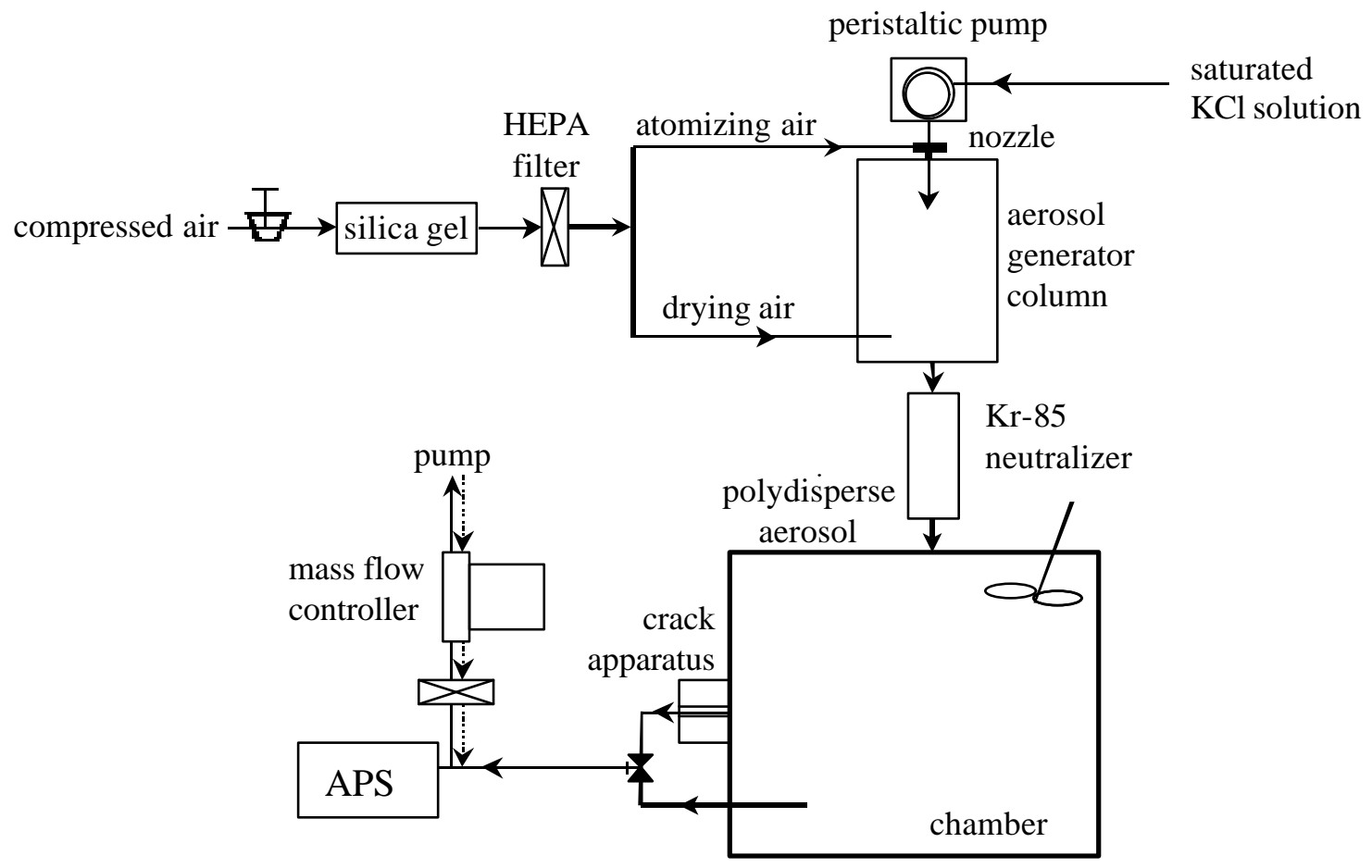

Figure 3.3 Experimental schematic for measuring particle penetration through the crack apparatus for particle diameter $d_{p}>0.6 \mu \mathrm{m}$. 


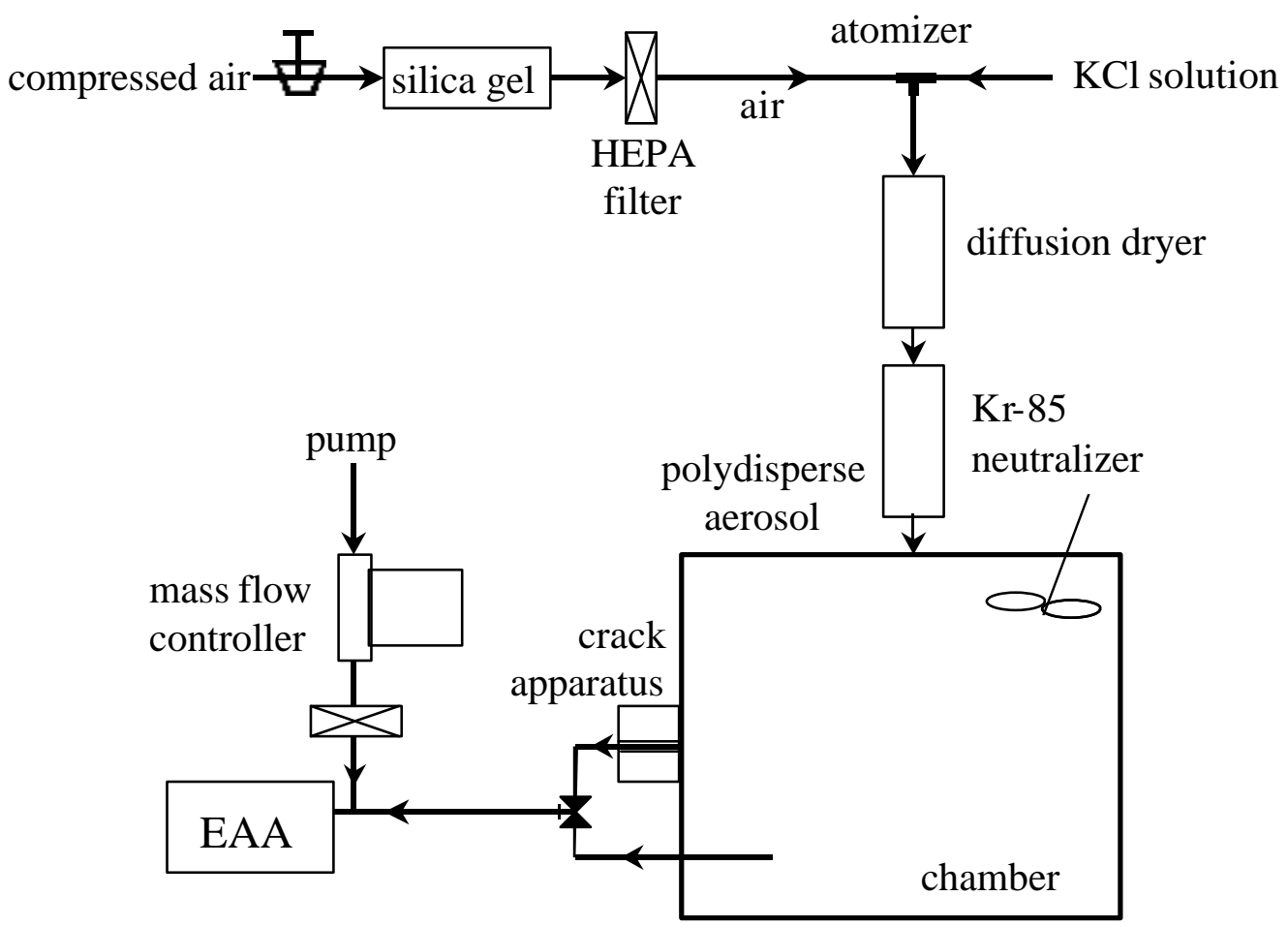

Figure 3.4 Experimental schematic for measuring particle penetration through the crack apparatus for particle size $d_{p}<1 \mu \mathrm{m}$. 


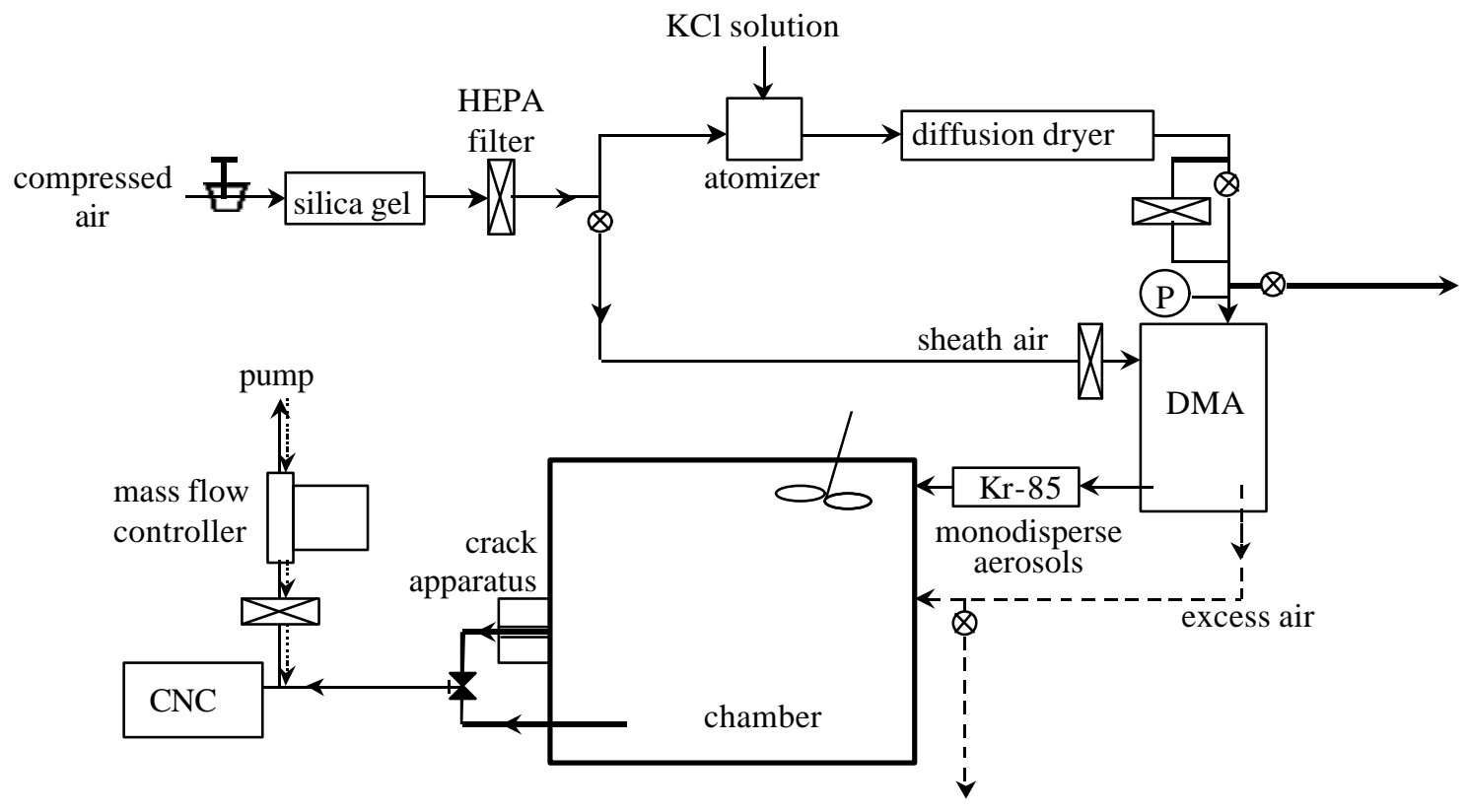

Figure 3.5 Experimental schematic for measuring particle penetration through the crack apparatus for particle diameter $d_{p}<0.1 \mu \mathrm{m}$ (monodisperse aerosols generated in this setup). 

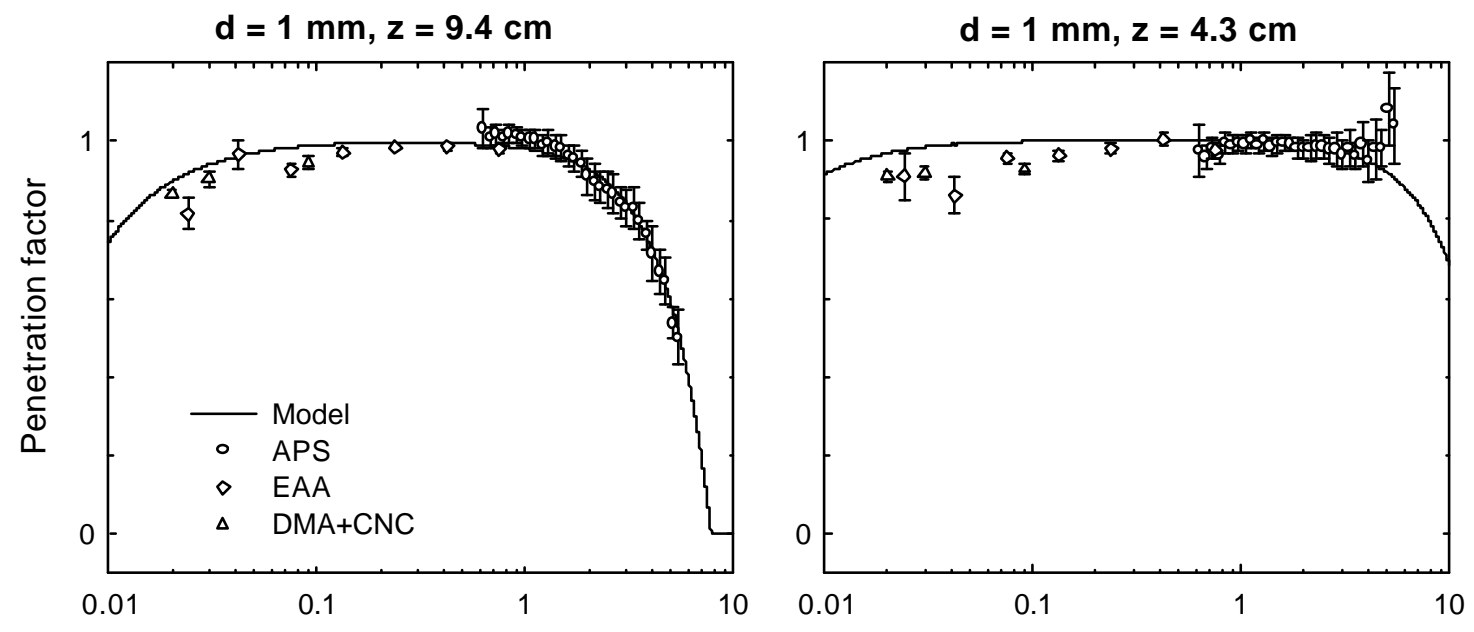

Particle diameter, $\mu \mathrm{m}$

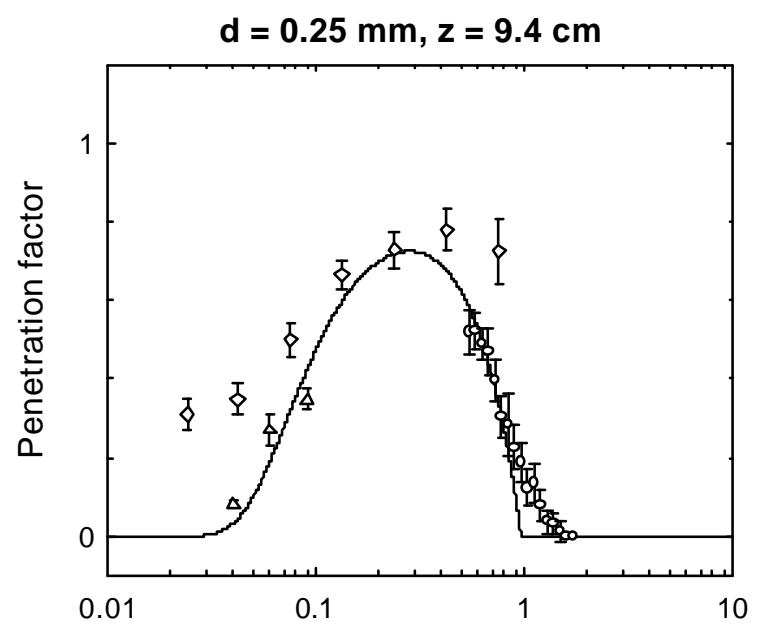

Particle diameter, $\mu \mathrm{m}$

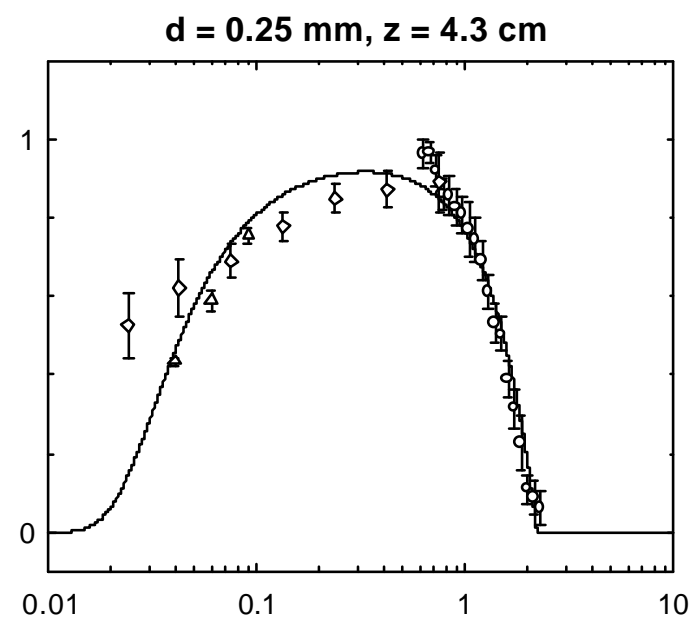

Particle diameter, $\mu \mathrm{m}$

Figure 3.6 Comparison of model predictions with experimental data for aluminum cracks. Results are presented for four sets of crack dimensions (crack heights of 0.25 and $1.0 \mathrm{~mm}$ and crack flow lengths of 4.3 and $9.4 \mathrm{~cm}$ ), with an applied pressure difference, $\Delta \mathrm{P}=4 \mathrm{~Pa}$. 


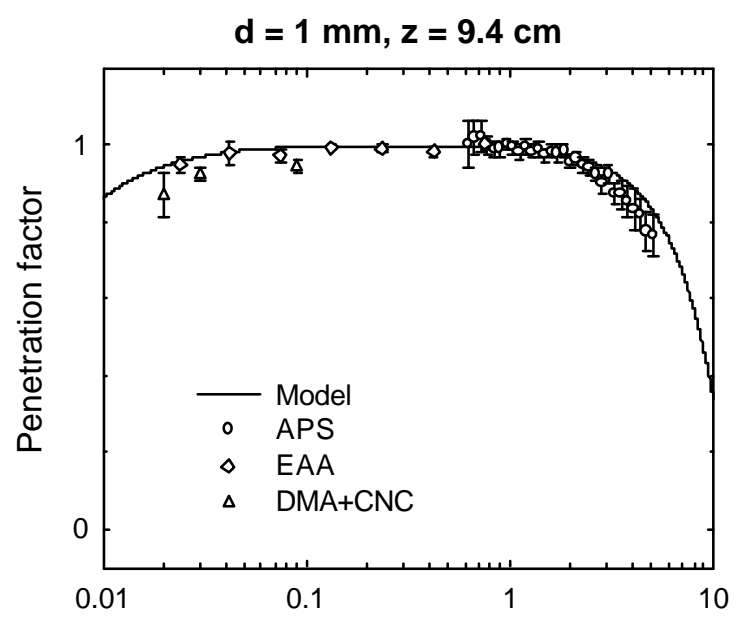

Particle diameter, $\mu \mathrm{m}$

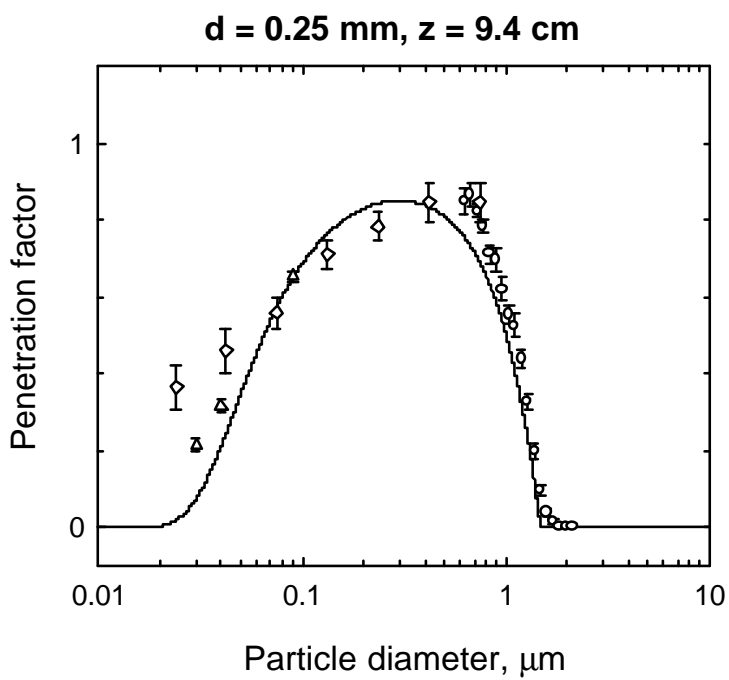

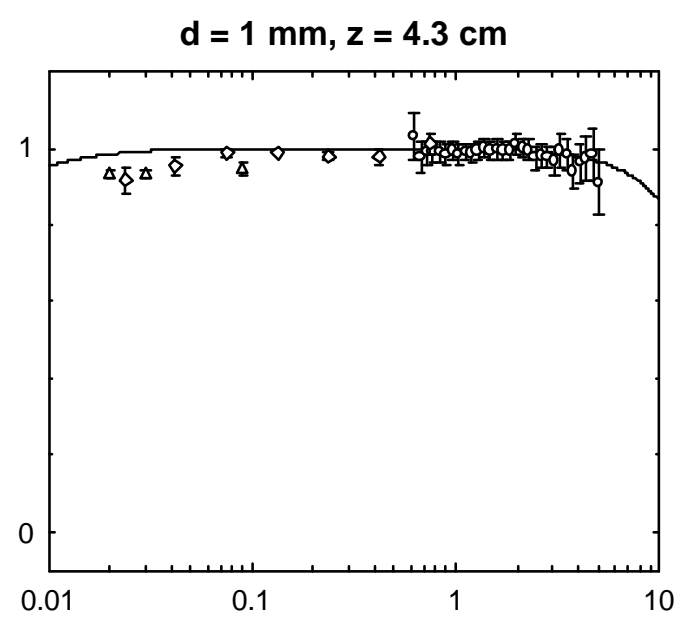

Particle diameter, $\mu \mathrm{m}$

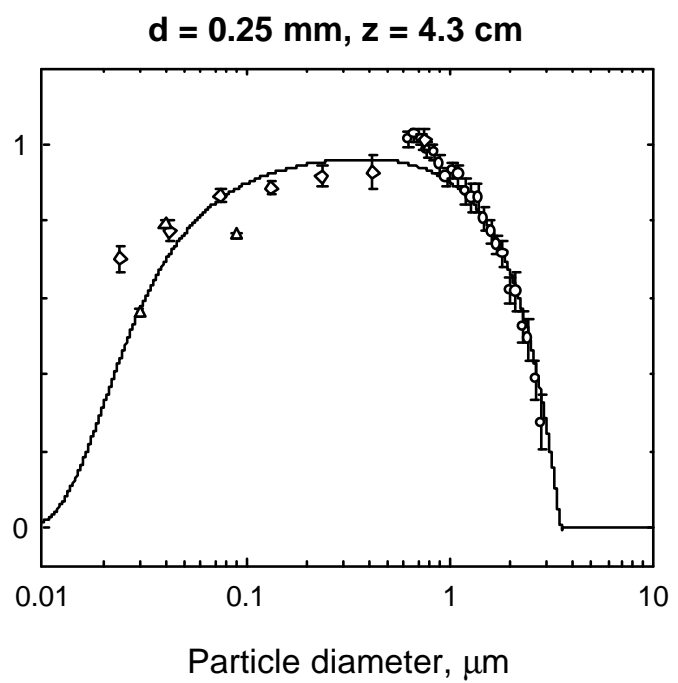

Figure 3.7 Comparison of model predictions with experimental data for aluminum cracks. Results are presented for four sets of crack dimensions (crack heights of 0.25 and $1.0 \mathrm{~mm}$ and crack flow lengths of 4.3 and $9.4 \mathrm{~cm}$ ), with an applied pressure difference, $\Delta \mathrm{P}=10 \mathrm{~Pa}$. 


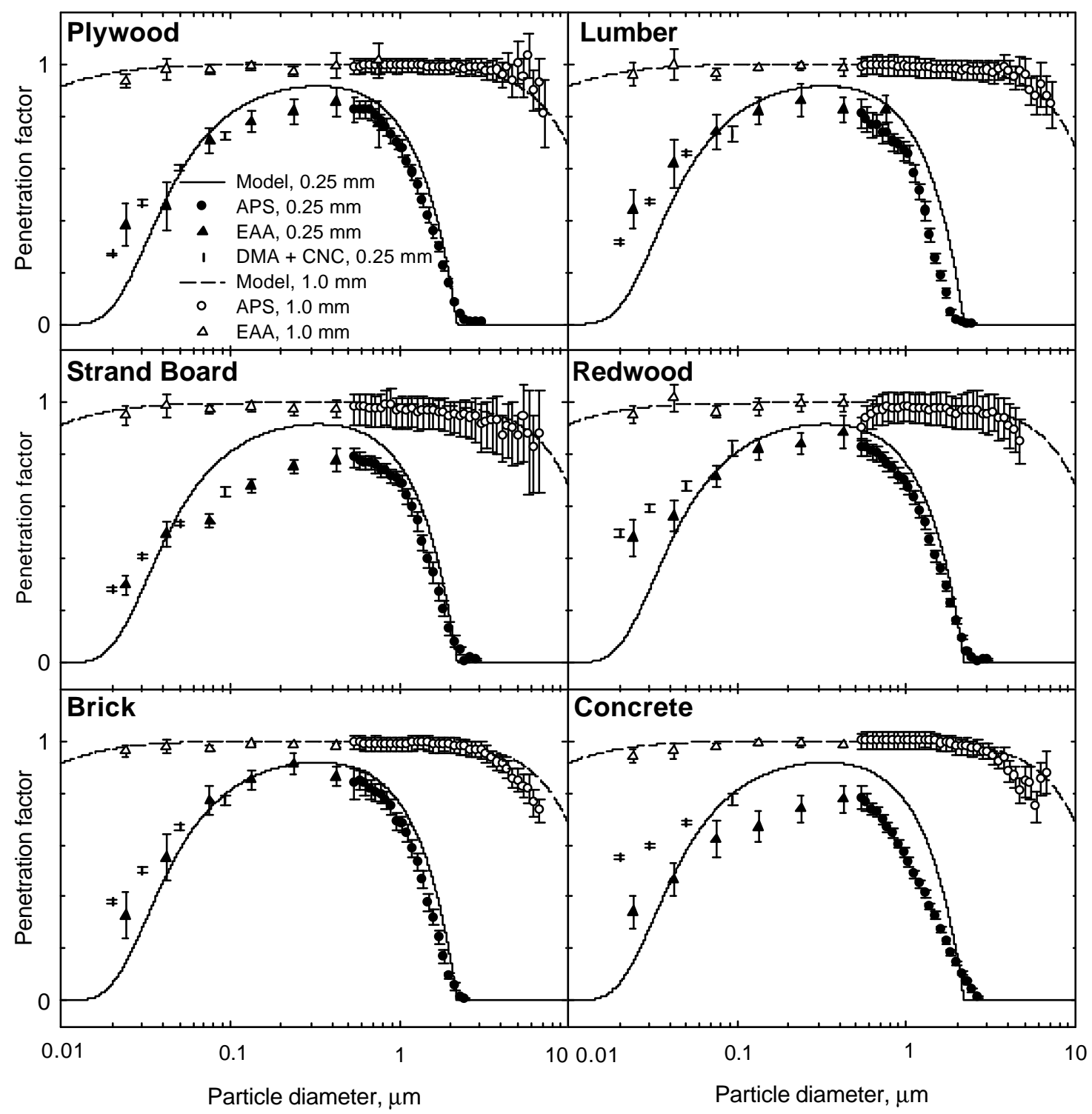

Figure 3.8 Experimental particle penetration factors for six crack materials at crack heights of 0.25 and $1 \mathrm{~mm}$ and with $\Delta \mathrm{P}=4 \mathrm{~Pa}$, as compared with model predictions. The flow path distance is $4.5 \mathrm{~cm}$. 


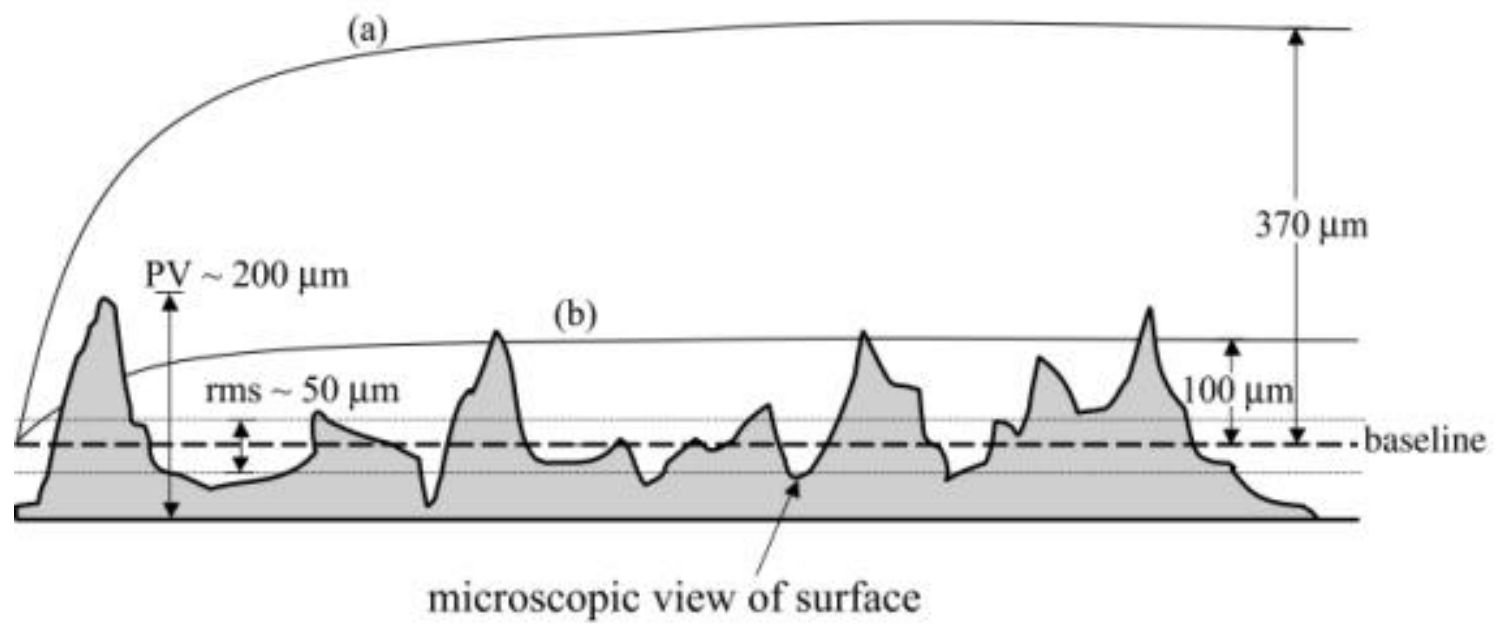

Figure 3.9 Schematic illustration of concentration boundary layers for particles of (a) $0.03 \mu \mathrm{m}$ and (b) $0.3 \mu \mathrm{m}$. Surface roughness is also illustrated, with rms referring to the standard deviation of the height of the test surface, and PV representing the height difference from peak to valley. 


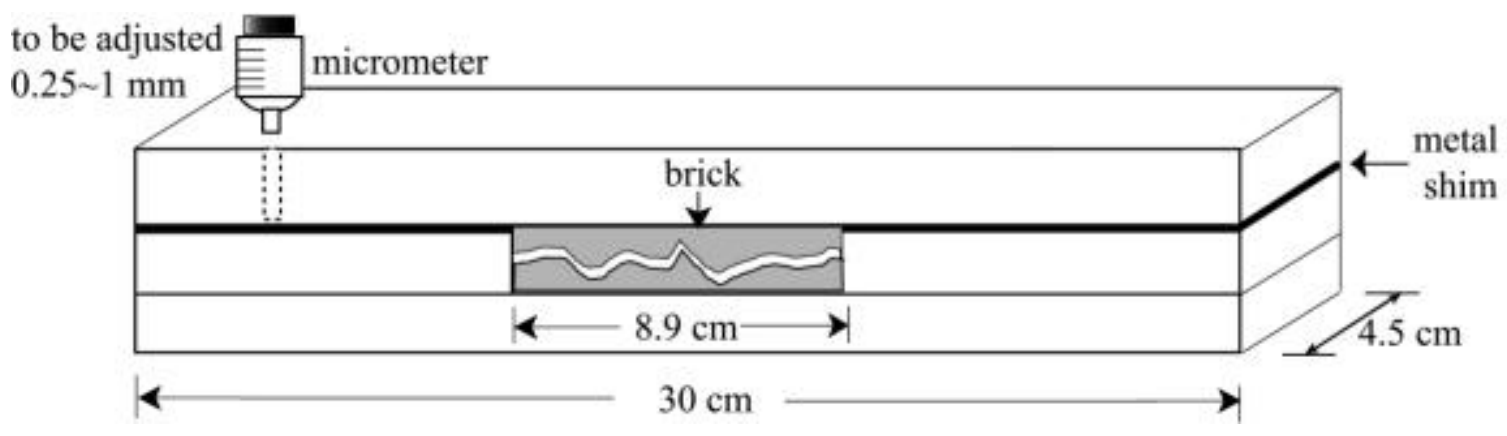

Figure 3.10 Schematic drawing of the naturally broken brick apparatus (not to scale). 
(a) side view of the irregular channel

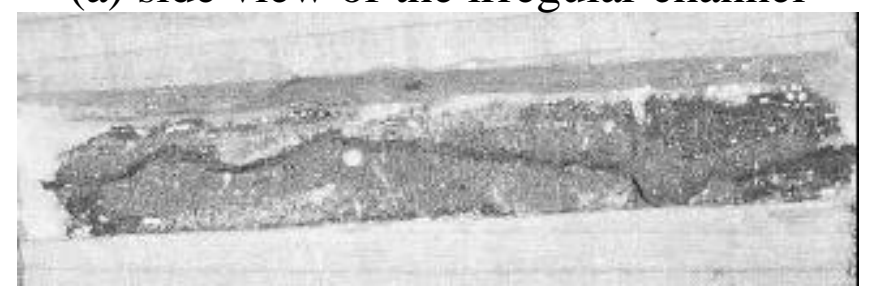

(b) inside view of the surface texture of the inner walls

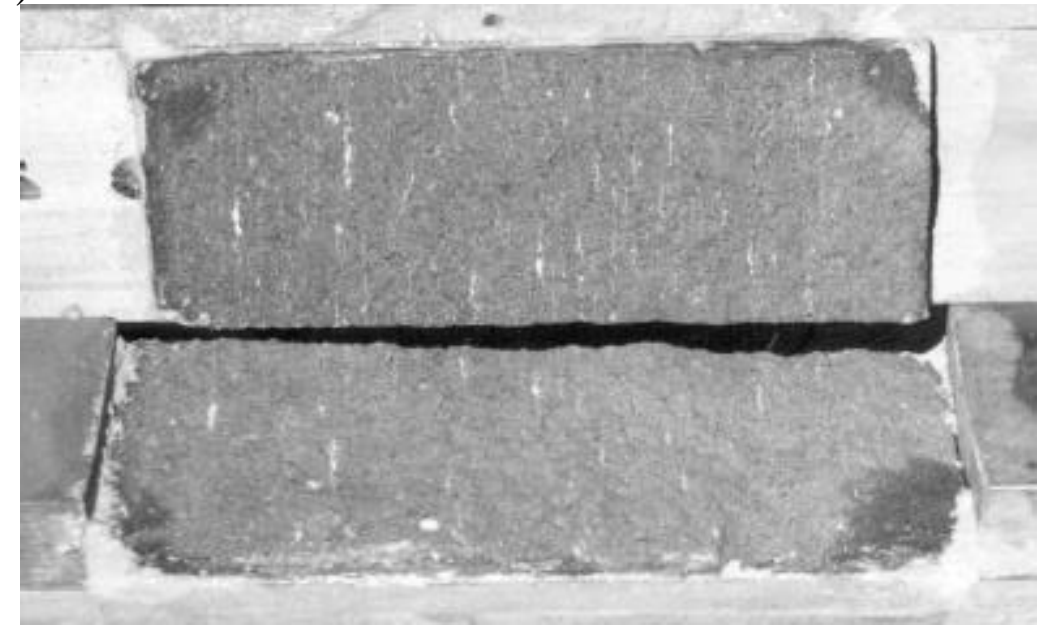

Figure 3.11 Photographs of the naturally broken brick tested in this study. 


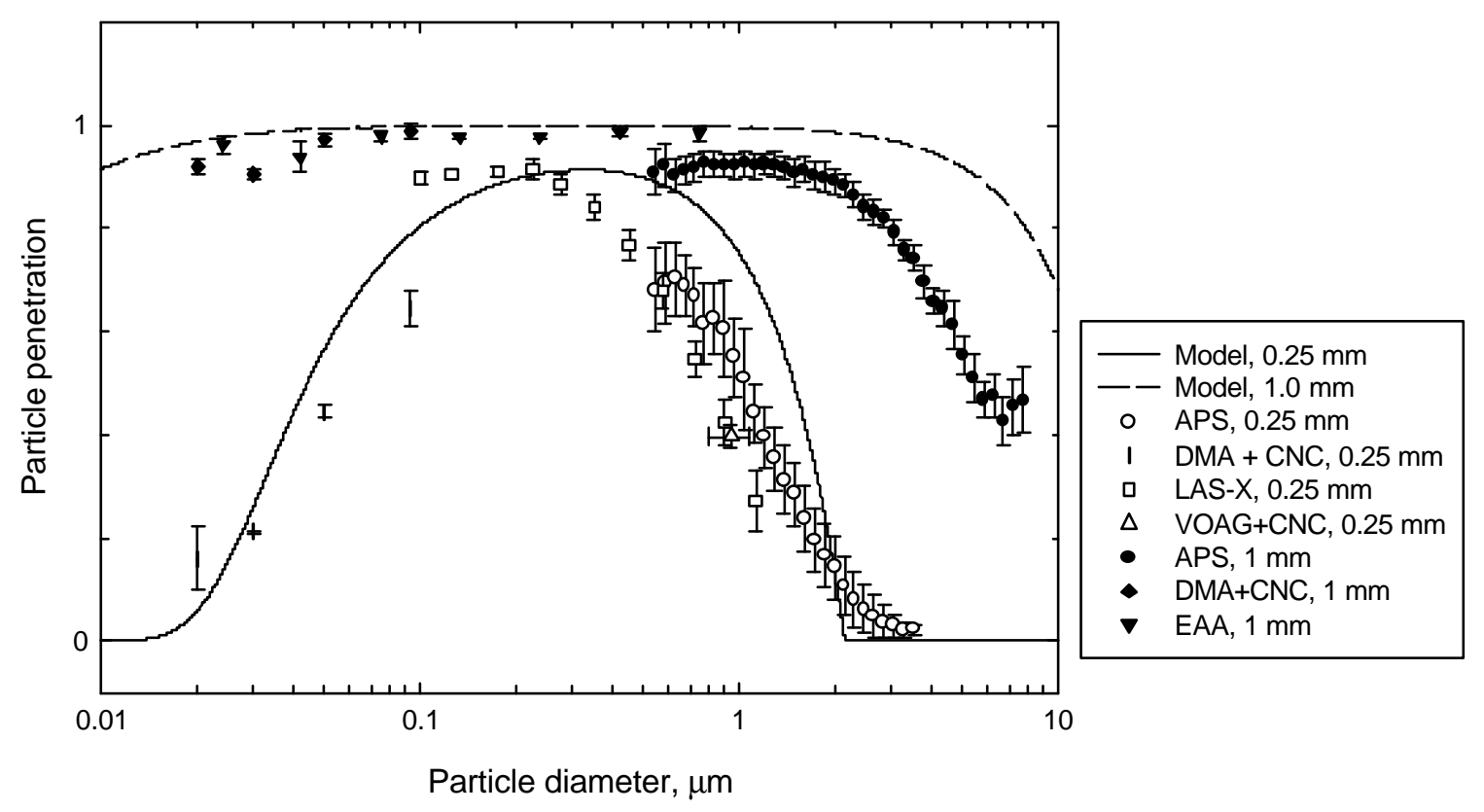

Figure 3.12 Comparison of model calculations and experimental results for the broken brick with crack heights of 0.25 and $1 \mathrm{~mm}$. The nominal flow path distance is $4.5 \mathrm{~cm}$. 


\section{Measuring Particle Penetration through WINDOWS*}

\subsection{ABSTRACT}

The research reported in this chapter aims to characterize the fractional penetration of airborne particles through windows, one of the important sites of air leakage through building envelopes. The performance of two aluminum sliding windows was evaluated, one with weatherstripping and one without. A finished window was mounted in a plywood panel so that all gaps between the window and the plywood were sealed to prevent extraneous air leakage. The window panel was inserted so that it separated the volumes of two identical plywood chambers. A small pressure difference (1 Pa) was established between the compartments to induce a constant rate of airflow through leakage paths in the window. Two methods were employed to evaluate particle penetration as a function of particle size. In one method, the penetration was inferred by measuring the steady-state size-resolved particle concentrations in both chambers in response to a constant supply of polydisperse particles to chamber 1 . In the second method, the particle concentration in chamber 2 was first lowered to a negligible concentration by supplying particle-free air. Then, the increase of particle concentration was measured as a polydisperse aerosol, supplied to chamber 1, penetrated through the window. Particle concentrations in both well-mixed chambers were continuously measured using an Aerodynamic Particle Sizer (APS, TSI 3320) and an Electrical

\footnotetext{
* Part of the work in this chapter was presented at the Indoor Air 2002, The $9^{\text {th }}$ International Conference on Indoor Air Quality and Climate, Monterey, CA, June 30-July 5, and published in the proceedings, Vol I, pp. 862-867.
} 
Aerosol Analyzer (EAA, TSI 3030). The air-exchange rate in chamber 2 was measured during the experiments using tracer gases. The measurement of particle deposition loss rate was conducted in a separate experiment. The results indicate that airborne particles of 0.2 to $3 \mu \mathrm{m}$ penetrate through both test windows fairly effectively ( $\geq 80 \%$ ), while significant particle losses were observed for particles smaller and larger than this size range.

\subsection{INTRODUCTION}

Windows are important contributors to air leakage in building envelopes.

Research on window air leakage has been of interest as a result of concerns such as reduced thermal comfort from cold drafts, increased energy consumption, and condensation problems. Less studied is the concern that air leakage through windows can also permit ambient airborne particles to penetrate into the indoor environment, causing exposures that may have adverse human health effects or contribute to material soiling problems. For low-rise buildings, studies have indicated that the most air leakage arises from openings in ceilings and walls; window and door components contribute about twenty percent to total air infiltration (Tamura, 1975; Reinhold and Sonderegger, 1983; ASHRAE, 1993). In Chapter 2, modeling results have been presented to characterize the extent of particle penetration through cracks of well-defined geometry and through wall cavities. An experimental study using building-material cracks of idealized geometry has shown generally good agreement with model predictions, as presented in Chapter 3. For building components possessing complicated leakage paths, such as windows and other fenestration products, it seems necessary to develop an understanding of particle 
penetration by conducting experiments in the laboratory or in the field. This chapter seeks to extend the physical scale from the single crack studies of Chapter 3 to examine particle penetration through windows in laboratory-based experiments. The methods presented here can be applied to study particle penetration through other fenestration products (doors, curtain walls, etc), and also certain other leaky building components, such as exterior light fixtures and interior electrical outlets.

Air can infiltrate windows not only through the joints between the sash and frame, but also through leakage paths between window perimeters and wall cavities around the sides of windows. The latter is known as extraneous air leakage. Extraneous air leakage can be identified and determined in experiments where windows are installed in a wall. Significant extraneous air leakage associated with windows can result from inappropriate installation (Carpenter, 1991; Louis and Nelson, 1995). The study presented in this chapter is restricted to leakage within the window unit.

Measurements of air leakage through windows, or air tightness characterizations, are commonly conducted in accordance with American Society for Testing and Materials test standards E283 and E783 in laboratory settings and in the field, respectively (ASTM, 2001; Daoud et al., 1991; Henry and Patenaude, 1998). It is also part of the window performance and quality test procedures specified by American Architectural Manufactures Association (ANSI, 1999). For these standard tests, the main concern is the total volumetric flow rate of air infiltrating through the window in response to a certain applied pressure difference. In contrast to the widely accepted practice of air infiltration rate measurement, little is known about window performance pertinent to the infiltration of ambient particles. Depending on the size distribution of leakage paths and 
on details of the air flow channels, it is possible for windows to exhibit high or low particle penetration whether they are leaky or tight with respect to air flow.

In this chapter, two aluminum windows available on the market were tested in the laboratory for their performance regarding particle penetration as a function of particle size. The two windows tested in these experiments are considered reasonably representative of the ones commonly installed in residential and commercial buildings. The experimental apparatus consisted of a detachable window panel and two chambers. Two methods were employed to evaluate particle penetration as a function of particle size. The first method involved the measurement of the steady-state size-resolved particle concentrations in both chambers in response to a constant supply of polydisperse particles to one of the chambers. In the second method, the particle concentration in one chamber was measured, starting from a negligible level, as it rose with time in response to leakage of particle-laden air from the other chamber. Air exchange was measured for each experiment, and particle deposition loss in the chamber was also determined in a separate experiment. The experimental results of the study, albeit limited to the window types examined, provide important insights into particle penetration through windows.

\subsection{METHODS}

\subsubsection{Experimental Setup}

Two operable, used aluminum-framed sliding windows were obtained for the experiments. One window was equipped with tubular gasket weatherstripping between the moving sash and the bottom frame (commercial class; designated as Wc), and the other was not weatherstripped (residential; Wr). Both windows have bristles between the 
sash and the frame to reduce air leakage. In addition, Wc has a wooden case that surrounds the aluminum perimeter frame closely. The commercial window was also tested with the joints between the wooden case and aluminum frame sealed by tape (this test is designated as Wc'). The frame sizes of $\mathrm{Wc}$ and $\mathrm{Wr}$ are $48.7 \times 63.8 \mathrm{~cm}$ and $58.9 \times$ $58.6 \mathrm{~cm}$, respectively.

The finished window to be tested was mounted in a plywood panel $(101.6 \times 101.6$ $\mathrm{cm})$ so that all gaps between the window perimeter and the plywood were well sealed. Thus, the leakage paths within the window unit were the only air leakage pathways in these experiments. The window panel was inserted so that it separated the volumes of two identical plywood chambers $(101.6 \times 101.6 \times 76.2 \mathrm{~cm})$, as illustrated in Figure 4.1 . Gasket material was put around the chamber openings in contact with the window panel, and the chambers and the window panel were secured by tight-fitting bungee cords. A pressure difference $(\Delta \mathrm{P})$ of $1 \mathrm{~Pa}$ was created across the window by supplying air to chamber 1 , some of which leaked into chamber 2 . Both chambers were maintained at a net positive pressure with respect to the laboratory to prevent uncontrolled particle infiltration into the chambers. During the experiments, the pressure difference between the chambers, $\Delta \mathrm{P}$, was monitored with a digital micromanometer (The Energy Conservatory, Minneapolis, MN, USA), which had been calibrated with a manometer (Microtector®, Model 1430, Dwyer Instruments Inc., IN, USA). The pressure tap was located adjacent to the joint between the sashes and frames on each side of the window. The pressure fluctuations caused by the supply air was found to be negligible. A small fan, used to mix the air in the chamber, was installed in the center position and located $\sim 15 \mathrm{~cm}$ down from the top in each compartment. 


\subsubsection{Experimental Protocol}

The experimental scheme typically involved continuously introducing nonvolatile, polydisperse particles into chamber 1, and monitoring the concentration change with time in both chambers. The change of particle concentration in chamber 2 with time $\left(d C_{2} / d t\right)$ can be represented by the following equation:

$$
\frac{d C_{2}}{d t}=p \lambda_{v} C_{1}-\left(\lambda_{v}+k_{d}\right) C_{2}
$$

where $C_{1}$ and $C_{2}$ are the particle number concentrations in chambers 1 and 2, respectively $\left(\mathrm{cm}^{-3}\right), p$ is particle penetration factor (dimensionless) through the test window, $\lambda_{\mathrm{v}}$ and $k_{\mathrm{d}}$ are the air-exchange rate $\left(\mathrm{h}^{-1}\right)$ and particle deposition coefficient $\left(\mathrm{h}^{-1}\right)$ in chamber 2 , respectively. Equation (4.1) states that the change of particle concentration in chamber 2 with time depends on the input from chamber 1 and the two particle removal mechanisms. Note that $C_{1}$ and $C_{2}$ are measured as a function of particle diameter $\left(d_{p}\right)$. It is evident from Equation (4.1) that particle penetration factors can be inferred from $C_{1}(t)$,

$C_{2}(t), \lambda_{\mathrm{v}}$, and $k_{d}$ once these parameters are obtained. Particle penetration is determined as a function of particle diameter through the appropriate application of Equation (4.1) to experimental data, as will be discussed in $\S 4.4 .2$.

Figures 4.2 and 4.3 show the experimental schematics. Submicron particles were generated by feeding a dilute aqueous $\mathrm{KCl}$ solution to a constant output atomizer (TSI 3075, St. Paul, MN). The airborne particles were dried and electrically neutralized by a diffusion dryer and Kr-85 radioactive source (TSI 3077, St. Paul, MN), respectively (Figure 4.2). For supermicron particle generation, a saturated $\mathrm{KCl}$ aqueous solution and air under high pressure were supplied into the nozzle of a custom-built atomizer, where particles were desiccated by upward dry air in the column and neutralized (TSI 3012, St. 
Paul, MN) prior to entering the chamber, as shown in Figure 4.3. Aerosol concentrations in both well-mixed chambers were continuously measured using an Aerodynamic Particle Sizer (APS, TSI 3320, St. Paul, MN) and an Electrical Aerosol Analyzer (EAA, TSI 3030, St. Paul, MN). Two sampling lines of identical length and tube diameter (outer diameter $0.63 \mathrm{~cm}$ ) from chambers 1 and 2 were connected to a three-way valve, which was used to alternate the aerosol flow to the EAA or the APS.

The air-exchange rate in chamber 2 was evaluated for each experiment by monitoring tracer gas concentration decay with time. $\mathrm{SF}_{6}$ was used and the concentration was measured with a multi-gas monitor (Type 1302, Brüel \& Kjær, Denmark). When the multi-gas monitor was not available in the laboratory, $\mathrm{CO}_{2}$ was used as a tracer gas instead. $\mathrm{CO}_{2}$ was generated in chamber 2 by immersing dry ice in a beaker filled with water. The $\mathrm{CO}_{2}$ concentration was monitored with a $\mathrm{CO}_{2}$ monitor (Telaire 7001, Engelhard, USA) connected to a datalogger (HOBO, Onset Computer Corporation, MA, USA).

To summarize, a typical experimental run involved the following steps: (1) assemble and secure the test window panel and the two chambers, and turn on both fans for mixing the air in each chamber; (2) supply particle-free air into chamber 2 to reduce the particle level to a negligible value, which is checked using the EAA or the APS; (3) continuously generate and supply ploydisperse particles into chamber 1 while step (2) is in process concurrently, and make sure no particles from chamber 1 flow across the window unit by establishing higher pressure in chamber 2 than chamber 1; (4) while maintaining particle generation into chamber 1, establish the desired $\Delta \mathrm{P}$ across the window (1 Pa higher in chamber 1 than in chamber 2 in the experiments), and monitor 
the particle concentrations in both chambers by the EAA or the APS; (5) tracer gas $\mathrm{SF}_{6}$ $(\sim 3 \mathrm{~mL})$ in syringe is injected into chamber 2 , and the concentration is sampled and analyzed by the Brüel \& Kjær multi-gas monitor. If $\mathrm{CO}_{2}$ is used as the tracer gas, dry ice in a water-filled beaker is put in chamber 2 before the window apparatus is assembled. The sublimation of dry ice was found to be a small source of submicron particles. Thus, the experiment can only be conducted after the particle concentration is reduced to a negligible level by ventilation, but while the $\mathrm{CO}_{2}$ concentration is still sufficient for the air-exchange rate determination. When $\mathrm{CO}_{2}$ is used for the air-exchange rate calculations, the background ambient concentration is subtracted from the measured values prior to evaluating the decay rate. Consistent air-exchange rate results were obtained when either tracer gas was used. Good mixing of air and aerosols in chamber 2 was indicated by the clearly linear relationship of the logarithmic values of tracer gas concentration versus time, as demonstrated by Figure 4.4 .

\subsection{RESULTS AND DISCUSSION}

\subsubsection{Particle Loss Rates}

As shown in Equation (4.1), air exchange and particle deposition onto chamber surface are the only two particle removal mechanisms in chamber 2. To determine the size-resolved particle loss rates from the chamber under the same airflow conditions at $\Delta \mathrm{P}$ of $1 \mathrm{~Pa}$, a separate experiment was performed that relies on measurement of sizespecific particle concentration change with time after a deliberate concentration increase. After the particle concentration in chamber 2 was raised to a sufficiently high level, particle generation was stopped and the concentration decay was monitored as particles 
were flushed out by particle-free air from chamber 1. Mathematically, the particle concentration change with time in chamber 2 during this experiment can be written as:

$$
\frac{d C_{2}}{d t}=-\left(\lambda_{v}+k_{d}\right) C_{2}
$$

Therefore, the overall particle loss rate, $\lambda_{v}+k_{d}$, was determined by the slope of logarithmic values of $C_{2}$ versus time. For example, Figure 4.5 shows the particle concentration change with time in the deposition experiments for Wr. Excellent linear relationships were obtained for most particle diameters, except for the two smallest particle size ranges: 0.024 and $0.042 \mu \mathrm{m}$. The concentration fluctuations at these two size ranges probably resulted from the incomplete charging for the small particles within the EAA instrument (Liu and Pui, 1975).

Similarly, the air-exchange rate can be determined from the slope using the same concentration decay approach, where tracer gas concentration was used instead of particle concentration. When conducting the particle deposition rate experiments, concentrations of particles and tracer gas in chamber 2 were measured simultaneously.

Table 4.1 displays the measured air-exchange rates $\left(\lambda_{v}\right)$ and the particle deposition loss rates $\left(k_{d}\right)$ as a function of particle size in chamber 2. These results were used in subsequent experiments to evaluate particle penetration factors through the test windows.

\subsubsection{Penetration Factor}

Particle penetration factor is defined here to be the fraction of particles that remain airborne as air enters chamber 2 from chamber 1 through leaks in the test window. To evaluate particle penetration as a function of particle size, two methods were employed: a steady-state method and a dynamic approach. The first method assumed that 
a steady-state condition prevails. The penetration factor was inferred by measuring the size-resolved particle concentrations in both chambers in response to a constant supply of polydisperse particles to chamber 1. Solving Equation (4.1) for steady-state conditions, we have

$$
p=\frac{\lambda_{v}+k_{d}}{\lambda_{v}}\left(\frac{C_{2}}{C_{1}}\right)
$$

By measuring $C_{1}$ and $C_{2}$ in this experiments and using previously determined values of $\lambda_{v}$ and $k_{d}$, the penetration factor can be evaluated as a function of particle size.

In the second method, the aerosol level in chamber 2 was first reduced to a negligible value by supplying particle-free air. Then, the increase of particle concentration was measured as polydisperse aerosols, continuously supplied to chamber 1, penetrate through the window. The particle concentration in chamber 2 is expected to grow until it reaches the steady state, so the second approach is called the dynamic, concentration-growth method. The dynamic aerosol concentrations in both chambers are illustrated in Figure 4.6.

Based on the time-dependent particle concentration profiles in both chambers, the concurrently measured air-exchange rate, as well as the particle deposition loss coefficient determined in a separate experiment, the only unknown — penetration factor for the test window — can be inferred from Equation (4.1) by a numerical approach. This was done by replacing the differential term in Equation (4.1) with an algebraic approximation:

$$
\frac{d C_{2}}{d t} \approx \frac{C_{2}(t+\Delta t)-C_{2}(t)}{\Delta t}
$$

Substituting and solving for $C_{2}$ at time $t+\Delta t$ yields 


$$
C_{2}(t+\Delta t) \approx C_{2}(t)+\Delta t\left[p \lambda_{v} C_{1}(t)-\left(\lambda_{v}+k_{d}\right) C_{2}(t)\right]
$$

Assuming that the values of $p, \lambda_{v}$, and $\lambda_{v}+k_{d}$ change only by small fractional amounts during the interval $\Delta t$, Equation (4.5) was solved iteratively by selecting an appropriate time step $\Delta t^{1}$. As a starting point, the source and loss terms $-p \lambda_{v} C_{1}$ and $\left(\lambda_{v}\right.$ $\left.+k_{d}\right) C_{2}$ - were evaluated by choosing a value for $p$ at $t=t_{0}$, and these two terms were summed to evaluate $C_{2}\left(t_{0}+\Delta t\right)$, which in turn was compared to the measured value of $C_{2}\left(t_{0}+\Delta t\right)$. The square of the difference between the measured and computed values of $C_{2}\left(t_{0}+\Delta t\right)$ was obtained as part of least-squares error approximation. Next, the source and loss terms were evaluated at the new time, $t_{0}+\Delta t$, and the new values along with $C_{2}\left(t_{0}+\Delta t\right)$ from the first iteration were substituted into the right-hand side of Equation (4.5) to evaluate $C_{2}\left(t_{0}+2 \Delta t\right)$. A new value of the square of the difference between the measured and computed values of $C_{2}\left(t_{0}+2 \Delta t\right)$ was again incorporated into the leastsquares error calculation. This numerical process was successively repeated for the entire measurement data with the $p$ value properly adjusted. The penetration factor was best evaluated as the least-squares error was minimized, with the simulated $C_{2}$ concentration closest to that measured from the experiment. For example, the simulated $C_{2}$ concentrations of $0.24 \mu \mathrm{m}$ particles generated from the numerical fitting process, as shown in Figure 4.6, tracked closely with the measurement data.

Because of the limited number of experiments performed for each window, it is important to characterize the uncertainty associated with the penetration factors determined experimentally. A Monte Carlo approach was applied to perform the

1 This time interval was selected to be $\sim 3$ minutes, the sampling interval of the particle concentration for either chamber. 
simulations, with the input parameters randomly sampled from normal distributions. The distribution means were designated as the experimentally determined values of airexchange rate, particle deposition rate, and the measured particle concentrations in both chambers, and the standard deviations were assigned ${ }^{2}$ so that the errors associated with the measurements were reasonably described. The penetration factors were inferred from the least-squares approximation method, as described previously, with the measured particle concentrations $C_{2}(t), C_{1}(t)$, as well as $\lambda_{v}$ and $\lambda_{v}+k_{d}$ fitting each transient state analysis at various time steps. In the study, thirty-two simulations were conducted for the uncertainty analysis in each experiment, and these penetration factors are reported numerically in Table 4.2 .

Figure 4.7 presents the calculated penetration factors from the simulations for $\mathrm{Wr}$ and $\mathrm{Wc}^{\prime 3}$. The solid symbols and the error bars indicate the average value of penetration factors and the ninety-five percent confidence interval of the measurements, as determined by means of the dynamic, concentration growth method. The steady-state penetration factors, as obtained from Equation (4.3), are designated by the open circles ${ }^{4}$. As suggested in Figure 4.7, particle penetration exceeds $80 \%$ for $0.2-3 \mu \mathrm{m}$ in $\mathrm{Wr}$, while

2 The uncertainty for the measurement of air-exchange rate $\left(\lambda_{v}\right)$ was determined to be $\sim \pm 0.5 \%$, and the uncertainties for the total particle loss rates $\left(\lambda_{v}+k_{d}\right)$ were estimated to be $\sim \pm 5 \%, \pm 3 \%, \pm 1 \%, \pm 0.5 \%$, $\pm 0.5 \%, \pm 1.5 \%, \pm 3 \%, \pm 2 \%, \pm 2 \%, \pm 1 \%$, and $\pm 1 \%$, for the mean particle diameters of $0.024,0.043,0.075$, $0.13,0.24,0.43,0.75,1.2,2.4,4.2$, and $7.5 \mu \mathrm{m}$, respectively (Taylor, Chapter 8,1982 ). For $C_{1}(t)$ and $C_{2}(t)$, the uncertainty was estimated to be less than $15 \%$ (Armendariz and Leith, 2002).

3 The results for Wc agree closely with those for Wc'

4 The uncertainty for the penetration factors determined in the steady-state method was estimated to be less than $\pm 20 \%$, which was derived by an error propagation analysis of Equation (4.3) that incorporated the uncertainties of $\lambda_{v}, \lambda_{v}+k_{d}, C_{1}(t)$, and $C_{2}(t)$ (Taylor, Chapter 3,1982 ). 
complete penetration is observed for $0.2-3 \mu \mathrm{m}$ in Wc'. This indicates that the airborne particles in these size ranges penetrate through the windows fairly effectively. For particles larger or smaller than these sizes, significant particle losses arise, probably as a result of gravitational settling and Brownian diffusion, respectively (Chapter 2). The bristles between the frame/sash joint are likely to play a role in removing particles.

As shown in Figure 4.7, the penetration factors estimated from steady state method agree generally well with those determined from the dynamic, concentration growth method for each test window. In terms of experimental reliability, it is reassuring that the penetration factors estimated from the two methods agree. In the experiments, the condition of steady state did not always prevail for each particle size range examined. Although the steady-state method may not be the most precise way to evaluate the penetration factor, it provides an adequate approximation when experiments that require more sophisticated design and control are not feasible.

In addition, for the smaller particles tested, the residential class window without weatherstripping examined in this study appears to allow proportionately fewer particles to penetrate through the unit than the commercial class window with weatherstripping. This is confirmed by running a $t$-test, which reveals that the penetration factors for $\mathrm{Wr}$ are statistically significantly lower than for Wc' (at the 0.05 probability level) for particles smaller than $0.4 \mu \mathrm{m}$ and larger than $2 \mu \mathrm{m}$. For particles between 0.4 and $2 \mu \mathrm{m}$, penetration through the two windows exhibits no statistically significant difference.

The $t$-test was also used to compare the penetration factors of submicron particles for the commercial window with an unsealed frame (Wc) and a tape-sealed frame (Wc'); no significant difference was found. This indicates that any additional air leakage 
between the aluminum perimeter and the wooden frame does not play a role in fractional particle penetration. For experiments using supermicron particles, only Wr and Wc' were tested since similar results were expected for Wc and Wc'. Note that air flows through a variety of window leakage paths, which possess a distribution of geometrical dimensions. The overall penetration factors for a window unit are attributed to the flow-averaged penetration for each opening. Consequently, it is the distribution of window leakage dimensions that determines the overall performance of particle penetration, rather than the leakage area per se. In addition, since particle penetration also results from air infiltrating through leaks of window/wall joints and adjacent wall cavities, the extent of particle penetration would depend on the overall wall construction quality. Based on these insights, to minimize ambient particle penetration into buildings, improvements are needed in all elements: window design, manufacturing, installation quality, and maintenance. Reductions in particle penetration through building component systems, such as windows, can serve to reduce human exposure to ambient particles.

\subsubsection{Window Leakage}

The notion of effective leakage area, used to evaluate the air tightness of building components, was applied to characterize the windows tested in these experiments. The effective leakage area can be calculated from the following expression (ASHRAE, 1993):

$$
A=\frac{Q}{C_{d}}\left[\frac{\rho}{2 \Delta P}\right]^{1 / 2}=\frac{\lambda_{v} V}{C_{d}}\left[\frac{\rho}{2 \Delta P}\right]^{1 / 2}
$$

where $A$ is the effective (or equivalent) leakage area $\left(\mathrm{m}^{2}\right), \rho$ is air density $\left(\mathrm{kg} \mathrm{m}^{-3}\right), Q$ is the air flow rate through the unit $\left(\mathrm{m}^{3} \mathrm{~h}^{-1}\right), C_{d}$ is the discharge coefficient for the leakage 
openings (dimensionless), and $V$ is the chamber volume $\left(\mathrm{m}^{3}\right)$. The value of $C_{d}$ is usually taken as 0.6 (as for a sharp-edged rectangular opening), although it might vary in the range of 0.6-1, depending on leakage characteristics (Heiselberg et al., 2000). Since the window perimeter is well sealed with the surrounding panel in these experiments, air leakage is expected to occur only through the sash/frame joints. The approximate effective leakage areas for $\mathrm{Wr}$ and $\mathrm{Wc}$ ' at $\Delta \mathrm{P}=1 \mathrm{~Pa}$ are 1.1 and $2.2 \mathrm{~cm}^{2} / \mathrm{lms}$ (leakage area per linear meter of sash), respectively. These values appear comparable to the estimated effective leakage area $\left(0.2\right.$ to $\left.2.06 \mathrm{~cm}^{2} / \mathrm{lms}\right)$ reported for single horizontal slider windows with weatherstripping (ASHRAE, 1993). The air leakage rate per unit frame area was also evaluated to compare to the ANSI/AAMA 101/I.S.2 guidelines (ANSI, 1999), and was found to be 2.1 and $4.2 \mathrm{~m}^{3} \mathrm{~h}^{-1} \mathrm{~m}^{-2}$ for $\mathrm{Wr}$ and $\mathrm{Wc}$, respectively. The air leakage performance for both windows appears to be in compliance with the national standard, which specifies an upper bound of $5 \mathrm{~m}^{3} \mathrm{~h}^{-1} \mathrm{~m}^{-2}$.

\subsection{CONCLUSIONS}

Experiments have been performed to investigate particle penetration through two windows in the laboratory. One was equipped with weatherstripping, and the other is not. The penetration factors estimated from the steady-state method agree well with those determined from the dynamic, concentration-growth method. We have shown that more than $80 \%$ of particles in the diameter range $0.2-3 \mu \mathrm{m}$ penetrate through either window, regardless of the presence of weatherstripping. Lower penetration is observed for particles smaller or larger than this range. In addition, the overall particle penetration factor of a window assembly is determined by the distribution of leakage dimensions. 
Neither air-leakage area nor air-leakage rate, as aggregate terms that are commonly reported for assessing window air tightness, are directly helpful in predicting fractional particle penetration. Although the small number of unites tested prevents us from drawing broad conclusions to apply to other window types, the results do provide some insight into expected values of particle penetration, especially when combined with the modeling work presented in Chapter 2. Additional investigations along these same lines could further improve our understanding of the factors that affect human exposure to particles of ambient origin. It is also conceivable that improved fenestration quality could be developed to offer better protection against exposure.

\subsection{REFERENCES}

ANSI (1999) Voluntary specifications for aluminum, vinyl (PVC) and wood windows and glass doors, Standard ANSI/AAMA/NWWDA 101/I.S.2-97, American Architectural Manufactures Association, IL, U.S.A.

Armendariz, A.J. and Leith, D. (2002) Concentration measurement and counting efficiency for the aerodynamic particle sizer 3320, Journal of Aerosol Science, 33: $133-148$.

ASHRAE (1993) ASHRAE Handbook of Fundamentals, Chapter 23, American Society of Heating, Refrigerating, and Air-Conditioning Engineers, Atlanta, U.S.A.

ASTM (2001) Annual Book of ASTM Standards, Vol. 04.11, American Society for Testing and Materials, Philadelphia, U.S.A.

Carpenter, S. (1991) In-situ measurement of window performance, ASHRAE Journal, 33: 14-18. 
Daoud, O., Maheshwari, G., and Al-Shami, H. (1991) Measured field performance of aluminum windows in Kuwait, Energy and Buildings, 17: 75-85.

Heiselberg, P., Svidt, K., and Nielsen, P.V. (2000) Windows - measurements of air flow capacity, Proceedings of the $7^{\text {th }}$ International Conference on Air Distribution in Rooms, Reading, UK, Vol II, pp. 749-754.

Henry, R. and Patenaude, A. (1998) Measurements of window air leakage at cold temperatures and impact on annual energy performance of a house, ASHRAE Transactions, 13: 1254-1260.

Liu, B.Y.H. and Pui, D.Y.H (1975) On the performance of the electrical aerosol analyzer, Journal of Aerosol Science, 6: 249-264.

Louis, M.J. and Nelson, P.E. (1995) Extraneous air leakage from window perimeters, Airflow Performance of Building Envelopes, Components, and Systems, ASTM STP 1225, American Society for Testing and Materials, Philadelphia, pp. 108-122.

Reinhold, C. and Sonderegger, R. (1983) Component leakage areas in residential buildings, Report LBL-16221, Lawrence Berkeley Laboratory, Berkeley, California.

Tamura, G.T. (1975) Measurement of air leakage characteristics of house enclosures, ASHRAE Transactions, 81: 202-211.

Taylor, J.R. (1982) An Introduction to Error Analysis: The Study of Uncertainties in Physical Measurements, University Science Books, Mill Valley, CA. 
Table 4.1 Particle deposition loss rates and air exchange rates determined in the concentration decay experiments

\begin{tabular}{|c|c|c|c|c|c|c|}
\hline & $\begin{array}{l}\text { Mean particle } \\
\text { diameter, } \mu \mathrm{m}\end{array}$ & \multicolumn{2}{|c|}{$\mathrm{Wc}$} & \multicolumn{2}{|c|}{$\mathrm{Wr}$} & $\mathrm{Wc}^{\prime}$ \\
\hline Air-exchange rate, $\lambda_{v}\left(\mathrm{~h}^{-1}\right)$ & & 4.1 & $5.1^{*}$ & 1.5 & $1.5^{*}$ & $3.3^{*}$ \\
\hline \multirow{7}{*}{$\begin{array}{l}\text { Particle deposition } \\
\text { loss rate } k_{d},\left(\mathrm{~h}^{-1}\right)\end{array}$} & 0.024 & 3.38 & 2.98 & 2.23 & 1.93 & 1.84 \\
\hline & 0.043 & 3.12 & 2.39 & 1.21 & 1.66 & 1.61 \\
\hline & 0.075 & 2.57 & 2.02 & 0.83 & 1.15 & 1.25 \\
\hline & 0.133 & 2.04 & 1.50 & 0.59 & 0.58 & 0.80 \\
\hline & 0.237 & 1.73 & 1.25 & 0.53 & 0.31 & 0.69 \\
\hline & 0.44 & 1.54 & 1.14 & 0.58 & 0.25 & 0.69 \\
\hline & 0.75 & 0.68 & 0.68 & 0.54 & 0.11 & 0.58 \\
\hline Air-exchange rate, $\lambda_{v}\left(\mathrm{~h}^{-1}\right)$ & & & & 1.7 & & $3.3^{*}$ \\
\hline Particle deposition & 1.2 & & & 0.48 & & 0.06 \\
\hline \multirow{3}{*}{ loss rate $k_{d},\left(\mathrm{~h}^{-1}\right)$} & 2.4 & & & 1.17 & & 0.95 \\
\hline & 4.2 & & & 2.78 & & 1.25 \\
\hline & 7.5 & & & - & & 0.79 \\
\hline
\end{tabular}

- insufficient data

* air-exchange rate determined by $\mathrm{SF}_{6}$ 
Table 4.2 Penetration factors estimated by the least-squares approximation in the Monte Carlo simulations for the two test windows (Wc' and Wr)

\begin{tabular}{|c|c|c|c|c|c|c|c|c|c|c|c|}
\hline \multicolumn{12}{|c|}{ Penetration factor } \\
\hline $\begin{array}{l}\text { Mean particle } \\
\text { diameter, } \mu \mathrm{m}\end{array}$ & 0.024 & 0.043 & 0.075 & 0.133 & 0.237 & 0.44 & 0.75 & 1.2 & 2.4 & 4.2 & 7.5 \\
\hline \multirow{32}{*}{$\mathrm{Wc}^{\prime}$} & 0.59 & 0.49 & 0.74 & 1.02 & 1.07 & 1.01 & 0.94 & 1.02 & 0.98 & 0.84 & 0.51 \\
\hline & 0.54 & 0.47 & 0.73 & 1.02 & 1.07 & 0.99 & 0.99 & 0.98 & 0.94 & 0.82 & 0.50 \\
\hline & 0.49 & 0.84 & 0.72 & 1.01 & 1.10 & 1.08 & 1.05 & 0.98 & 0.94 & 0.83 & 0.50 \\
\hline & 0.59 & 0.49 & 0.74 & 1.02 & 1.21 & 1.01 & 0.94 & 1.01 & 0.98 & 0.84 & 0.51 \\
\hline & 0.56 & 0.90 & 0.73 & 1.00 & 1.08 & 1.12 & 0.98 & 1.03 & 0.99 & 0.84 & 0.51 \\
\hline & 0.51 & 0.45 & 0.72 & 1.02 & 1.10 & 0.98 & 1.02 & 0.97 & 0.92 & 0.81 & 0.49 \\
\hline & 0.47 & 0.82 & 0.72 & 1.01 & 1.07 & 1.07 & 1.09 & 0.97 & 0.92 & 0.81 & 0.49 \\
\hline & 0.62 & 0.50 & 0.74 & 1.02 & 1.10 & 1.02 & 0.91 & 1.03 & 0.99 & 0.84 & 0.52 \\
\hline & 0.53 & 0.88 & 0.73 & 1.00 & 1.07 & 1.11 & 1.01 & 1.01 & 0.98 & 0.84 & 0.51 \\
\hline & 0.54 & 0.47 & 0.72 & 1.40 & 1.10 & 0.99 & 0.99 & 0.98 & 0.94 & 0.82 & 0.50 \\
\hline & 0.49 & 0.84 & 0.72 & 1.02 & 1.07 & 1.08 & 1.06 & 0.98 & 0.94 & 0.82 & 0.47 \\
\hline & 0.59 & 0.49 & 0.74 & 1.01 & 1.10 & 1.31 & 0.94 & 1.01 & 0.98 & 0.84 & 0.53 \\
\hline & 0.56 & 0.90 & 0.73 & 1.02 & 1.07 & 1.01 & 0.98 & 1.03 & 0.99 & 0.84 & 0.56 \\
\hline & 0.51 & 0.45 & 0.72 & 1.00 & 1.10 & 1.12 & 1.02 & 0.97 & 0.92 & 0.81 & 0.44 \\
\hline & 0.46 & 0.82 & 0.72 & 1.02 & 1.07 & 0.99 & 1.09 & 0.97 & 0.92 & 0.81 & 0.44 \\
\hline & 0.62 & 0.50 & 0.74 & 1.01 & 1.44 & 1.07 & 0.92 & 1.03 & 0.99 & 0.84 & 0.56 \\
\hline & 0.36 & 0.57 & 0.53 & 1.02 & 1.10 & 1.02 & 0.70 & 0.68 & 0.68 & 0.59 & 0.25 \\
\hline & 0.72 & 0.60 & 0.97 & 0.74 & 1.07 & 0.78 & 1.19 & 1.36 & 1.27 & 1.10 & 0.68 \\
\hline & 0.40 & 0.66 & 0.54 & 1.40 & 0.79 & 1.34 & 0.70 & 0.72 & 0.72 & 0.62 & 0.37 \\
\hline & 0.81 & 0.67 & 1.01 & 0.75 & 1.46 & 0.82 & 0.64 & 1.32 & 1.35 & 1.15 & 1.02 \\
\hline & 0.33 & 0.59 & 0.52 & 0.73 & 0.81 & 1.40 & 1.10 & 0.66 & 0.66 & 0.58 & 0.25 \\
\hline & 0.68 & 0.60 & 0.95 & 1.30 & 1.49 & 0.77 & 0.91 & 1.07 & 1.23 & 1.08 & 1.03 \\
\hline & 0.42 & 0.68 & 0.55 & 0.76 & 0.78 & 0.83 & 1.56 & 0.74 & 0.75 & 0.63 & 0.44 \\
\hline & 0.85 & 0.70 & 1.02 & 1.20 & 0.82 & 1.43 & 0.86 & 0.97 & 1.37 & 1.18 & 1.20 \\
\hline & 0.43 & 0.76 & 0.65 & 0.90 & 1.50 & 0.97 & 0.98 & 0.87 & 0.84 & 0.73 & 0.15 \\
\hline & 0.59 & 0.51 & 0.80 & 1.10 & 0.96 & 1.09 & 1.50 & 1.09 & 1.03 & 0.90 & 1.08 \\
\hline & 0.49 & 0.81 & 0.67 & 0.92 & 1.18 & 1.01 & 1.02 & 0.92 & 0.89 & 0.76 & 0.47 \\
\hline & 0.66 & 0.55 & 0.82 & 1.10 & 1.00 & 1.14 & 1.16 & 1.15 & 1.09 & 0.94 & 0.57 \\
\hline & 0.41 & 0.64 & 0.63 & 0.89 & 0.97 & 0.95 & 0.79 & 0.84 & 0.81 & 0.71 & 0.43 \\
\hline & 0.50 & 0.89 & 0.78 & 1.10 & 1.20 & 1.16 & 0.96 & 1.06 & 1.00 & 0.88 & 0.53 \\
\hline & 0.36 & 0.67 & 0.81 & 0.95 & 0.96 & 0.97 & 1.09 & 0.94 & 0.91 & 0.78 & 0.48 \\
\hline & 0.74 & 0.68 & 0.60 & 0.53 & 0.46 & 0.49 & 0.59 & 1.18 & 1.13 & 0.96 & 0.58 \\
\hline \multirow[t]{32}{*}{$\mathrm{Wr}$} & 0.41 & 0.44 & 0.61 & 0.72 & 0.79 & 0.87 & 1.03 & 0.92 & 0.88 & 0.65 & \\
\hline & 0.38 & 0.42 & 0.60 & 0.72 & 0.79 & 0.87 & 1.00 & 0.88 & 0.84 & 0.65 & \\
\hline & 0.37 & 0.42 & 0.60 & 0.71 & 0.79 & 0.87 & 1.01 & 0.88 & 0.84 & 0.65 & \\
\hline & 0.48 & 0.55 & 0.80 & 1.40 & 1.05 & 1.11 & 1.22 & 1.18 & 1.05 & 0.90 & \\
\hline & 0.41 & 0.44 & 0.61 & 0.72 & 0.79 & 0.88 & 1.03 & 0.92 & 0.88 & 0.65 & \\
\hline & 0.42 & 0.45 & 0.61 & 0.72 & 0.79 & 0.88 & 1.04 & 0.94 & 0.90 & 0.65 & \\
\hline & 0.36 & 0.41 & 0.60 & 0.72 & 1.07 & 0.86 & 0.99 & 0.86 & 0.82 & 0.65 & \\
\hline & 0.36 & 0.40 & 0.60 & 0.73 & 0.79 & 0.89 & 1.31 & 0.86 & 0.82 & 0.65 & \\
\hline & 0.42 & 0.45 & 0.61 & 0.72 & 0.79 & 0.88 & 1.00 & 0.94 & 0.90 & 0.66 & \\
\hline & 0.58 & 0.63 & 0.84 & 0.99 & 0.79 & 1.18 & 1.05 & 1.35 & 1.20 & 0.93 & \\
\hline & 0.41 & 0.44 & 0.61 & 0.72 & 1.09 & 0.88 & 1.34 & 0.92 & 0.88 & 0.66 & \\
\hline & 0.38 & 0.42 & 0.60 & 0.72 & 0.79 & 0.87 & 1.04 & 0.88 & 0.84 & 0.64 & \\
\hline & 0.38 & 0.42 & 0.60 & 0.72 & 0.79 & 0.86 & 1.25 & 0.88 & 0.84 & 0.65 & \\
\hline & 0.41 & 0.44 & 0.61 & 0.72 & 0.79 & 0.88 & 1.01 & 1.31 & 0.88 & 0.66 & \\
\hline & 0.42 & 0.45 & 0.61 & 0.72 & 0.79 & 0.88 & 1.01 & 0.92 & 0.90 & 0.65 & \\
\hline & 0.37 & 0.41 & 0.60 & 0.72 & 0.79 & 0.86 & 1.04 & 0.94 & 0.82 & 0.65 & \\
\hline & 0.36 & 0.42 & 0.59 & 0.72 & 0.79 & 0.86 & 1.05 & 0.86 & 0.82 & 0.65 & \\
\hline & 0.42 & 0.45 & 0.62 & 0.72 & 0.79 & 0.88 & 1.00 & 0.86 & 0.89 & 0.65 & \\
\hline & 0.27 & 0.31 & 0.44 & 0.53 & 0.79 & 0.66 & 1.00 & 0.94 & 0.64 & 0.45 & \\
\hline & 0.51 & 0.57 & 0.81 & 0.96 & 0.58 & 1.13 & 1.05 & 0.61 & 1.09 & 0.90 & \\
\hline & 0.30 & 0.33 & 0.45 & 0.54 & 1.05 & 0.68 & 0.82 & 1.28 & 0.68 & 0.46 & \\
\hline & 0.55 & 0.61 & 0.83 & 0.98 & 0.59 & 1.16 & 0.85 & 0.66 & 1.16 & 0.92 & \\
\hline & 0.26 & 0.30 & 0.43 & 0.50 & 0.57 & 0.65 & 0.81 & 0.59 & 0.62 & 0.44 & \\
\hline & 0.32 & 0.34 & 0.46 & 0.68 & 0.59 & 0.69 & 0.87 & 0.68 & 0.70 & 0.46 & \\
\hline & 0.34 & 0.38 & 0.54 & 0.64 & 0.71 & 0.79 & 0.94 & 0.78 & 0.76 & 0.57 & \\
\hline & 0.41 & 0.46 & 0.66 & 0.79 & 0.86 & 0.93 & 1.08 & 1.12 & 0.91 & 0.72 & \\
\hline & 0.37 & 0.41 & 0.55 & 0.66 & 0.72 & 0.81 & 0.97 & 0.96 & 0.81 & 0.58 & \\
\hline & 0.46 & 0.50 & 0.68 & 0.79 & 0.88 & 0.97 & 1.13 & 1.20 & 0.97 & 0.74 & \\
\hline & 0.32 & 0.36 & 0.53 & 0.64 & 0.70 & 0.77 & 0.92 & 0.87 & 0.74 & 0.57 & \\
\hline & 0.39 & 0.45 & 0.65 & 0.78 & 0.85 & 0.93 & 1.06 & 1.08 & 0.88 & 0.71 & \\
\hline & 0.37 & 0.41 & 0.56 & 0.66 & 0.73 & 0.82 & 0.99 & 1.00 & 0.83 & 0.59 & \\
\hline & 0.47 & 0.51 & 0.69 & 0.81 & 0.89 & 0.97 & 1.15 & 1.24 & 1.00 & 0.74 & \\
\hline
\end{tabular}




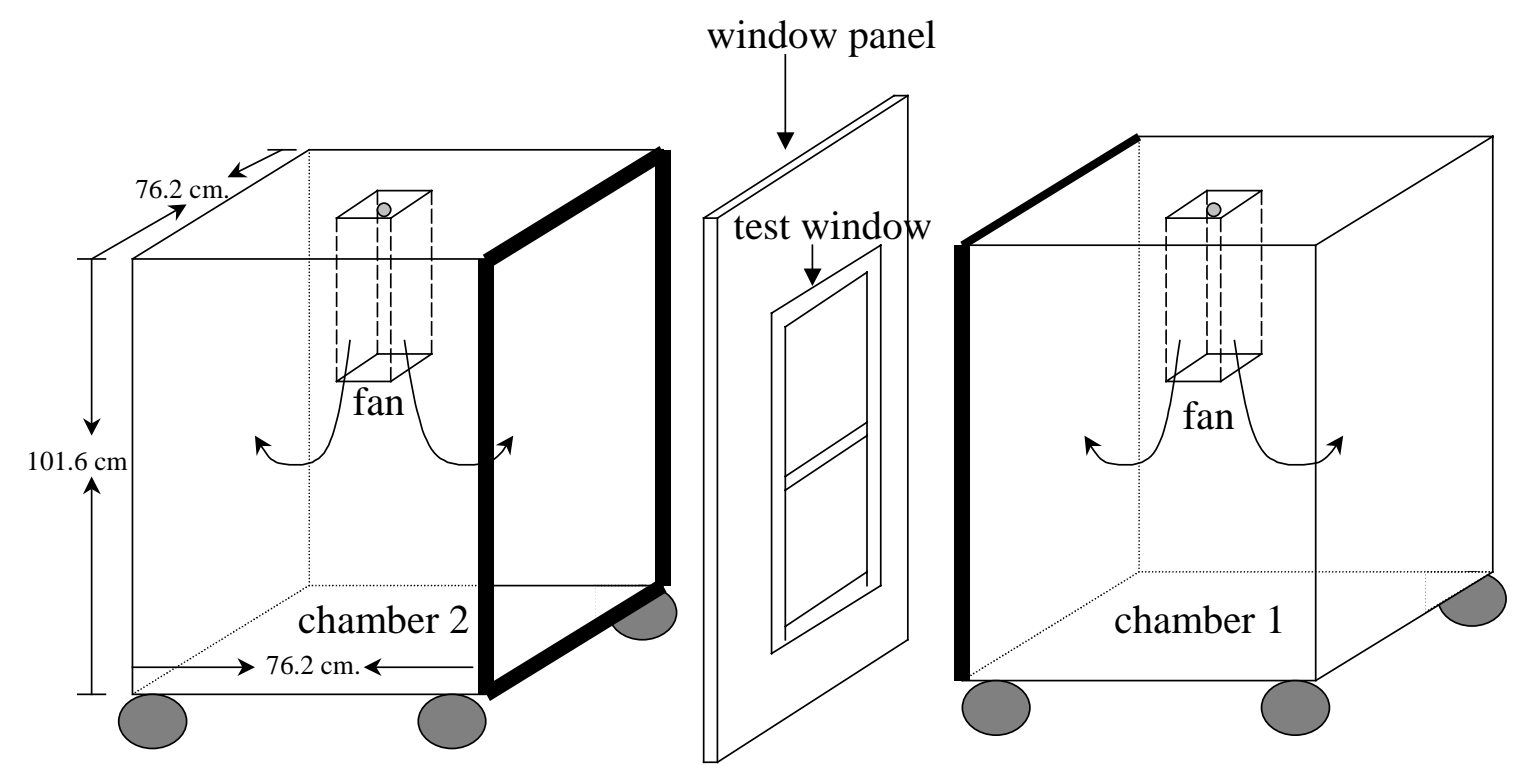

Figure 4.1 Schematic illustration of the detachable window panel and the two chambers that were employed to measure particle penetration through the window component. 


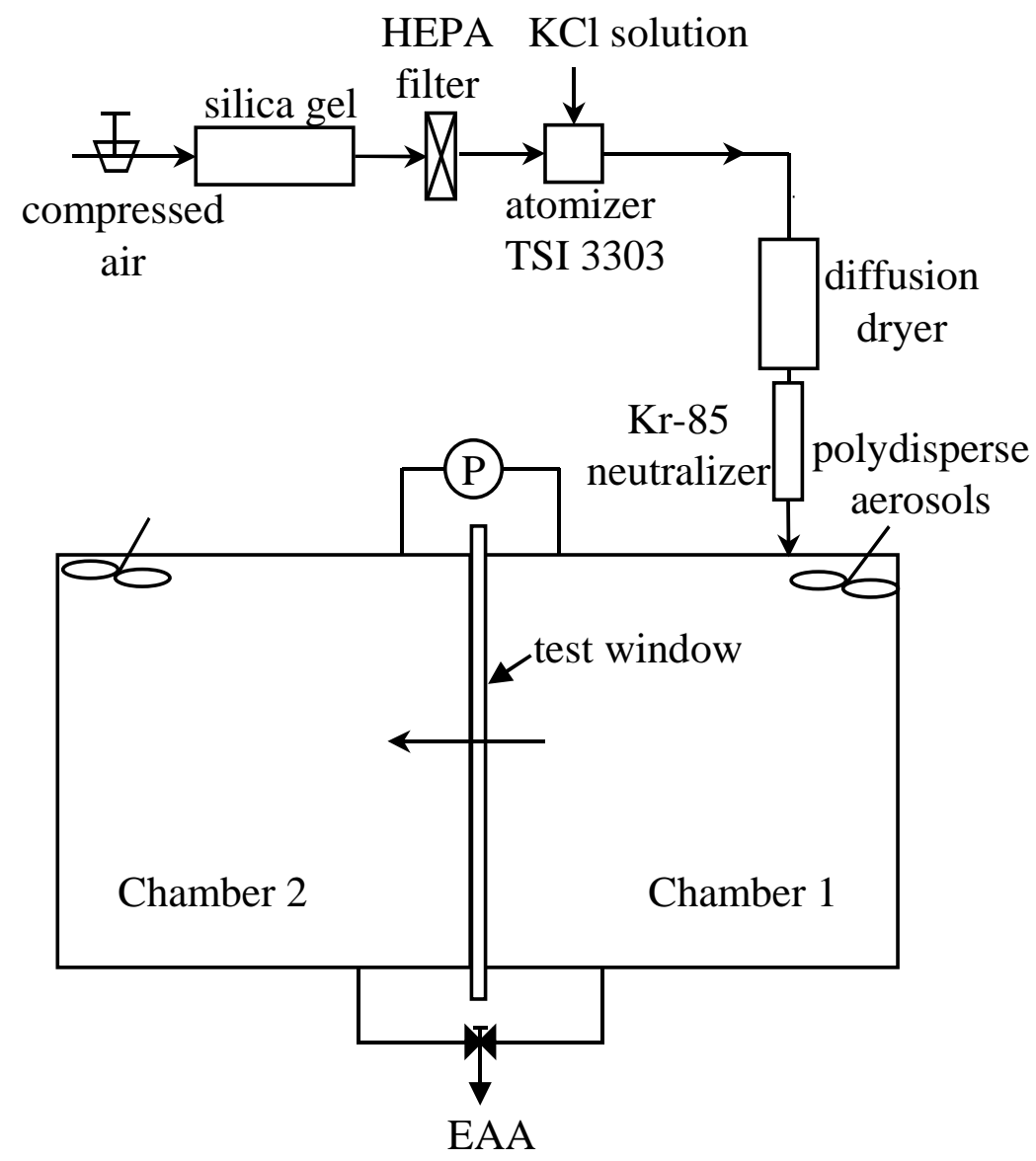

Figure 4.2 Schematic of the system for submicron particle generation and measurement in window penetration experiments. For measuring particle deposition, the generated particles are introduced into chamber 2 and particle-free air is supplied into chamber 1 . 


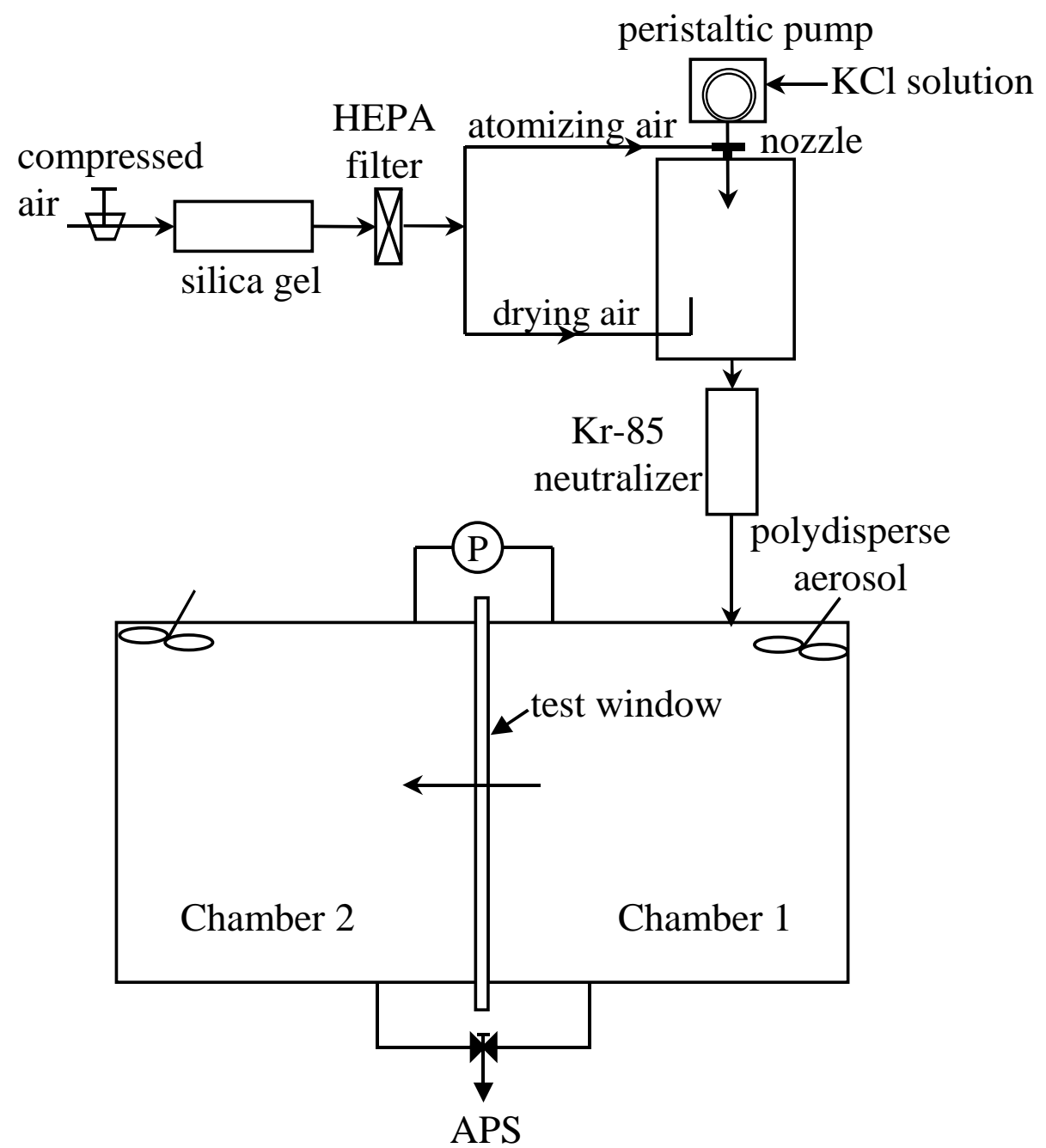

Figure 4.3 Schematic of the system for supermicron particle generation and measurement in window penetration experiments. For measuring particle deposition, the generated particles are introduced into chamber 2 and particle-free air is supplied into chamber 1. 


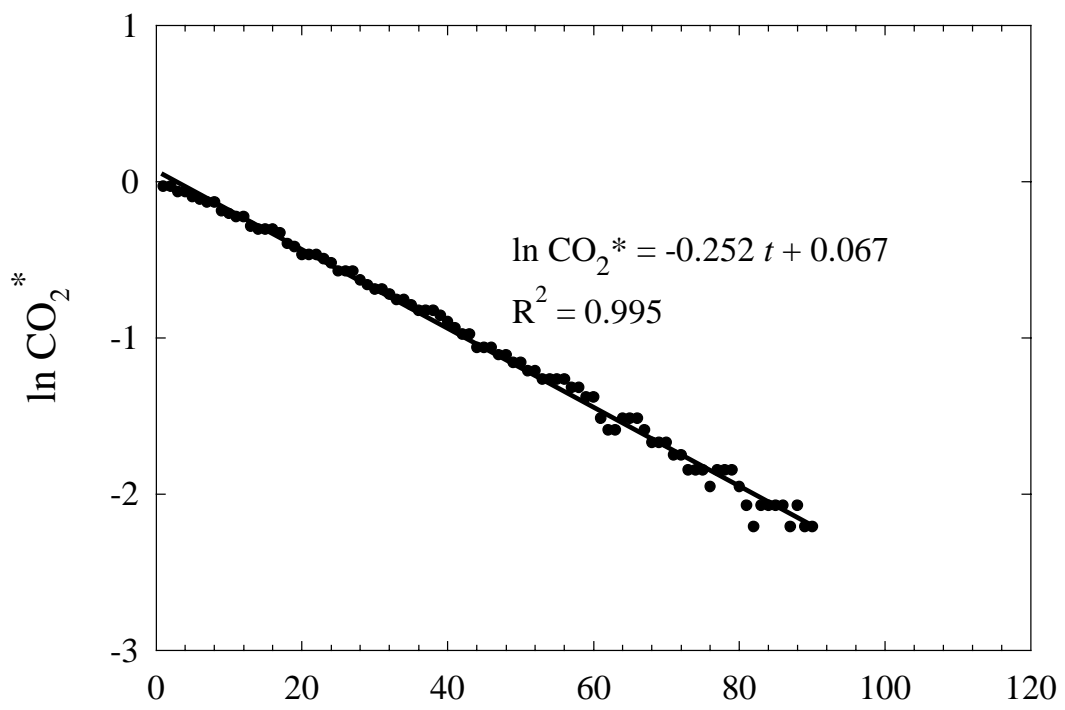

Time $(t), \min$

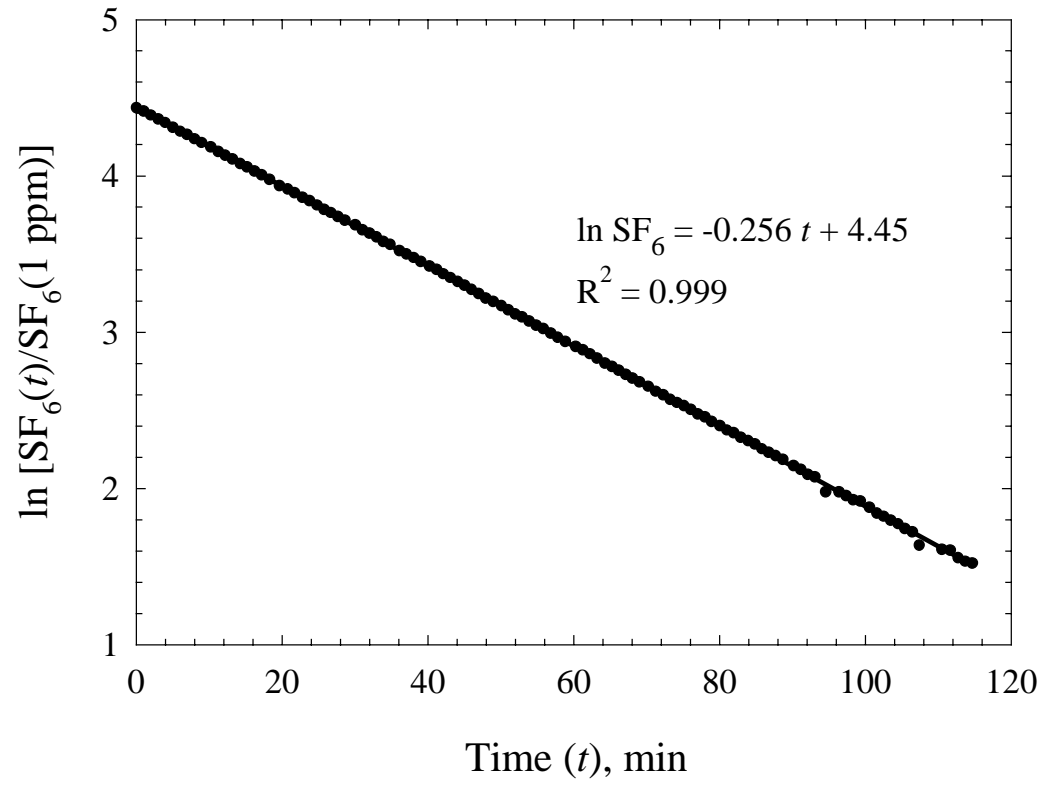

Figure 4.4 Air-exchange rate in chamber 2 determined simultaneously by concentration decay of $\mathrm{CO}_{2}$ and $\mathrm{SF}_{6}$. The parameter $\mathrm{CO}_{2}{ }^{*}$ is background corrected: $\mathrm{CO}_{2}{ }^{*}=\left[\left(\mathrm{CO}_{2}(t)-\mathrm{CO}_{2, \mathrm{~b}}\right) /\left(\mathrm{CO}_{2}(0)-\mathrm{CO}_{2, \mathrm{~b}}\right)\right]$, where $\mathrm{CO}_{2, \mathrm{~b}}$, the background $\mathrm{CO}_{2}$ concentration in air supply, was $\sim 450 \mathrm{ppm}$. The test window is $\mathrm{Wr}$. 


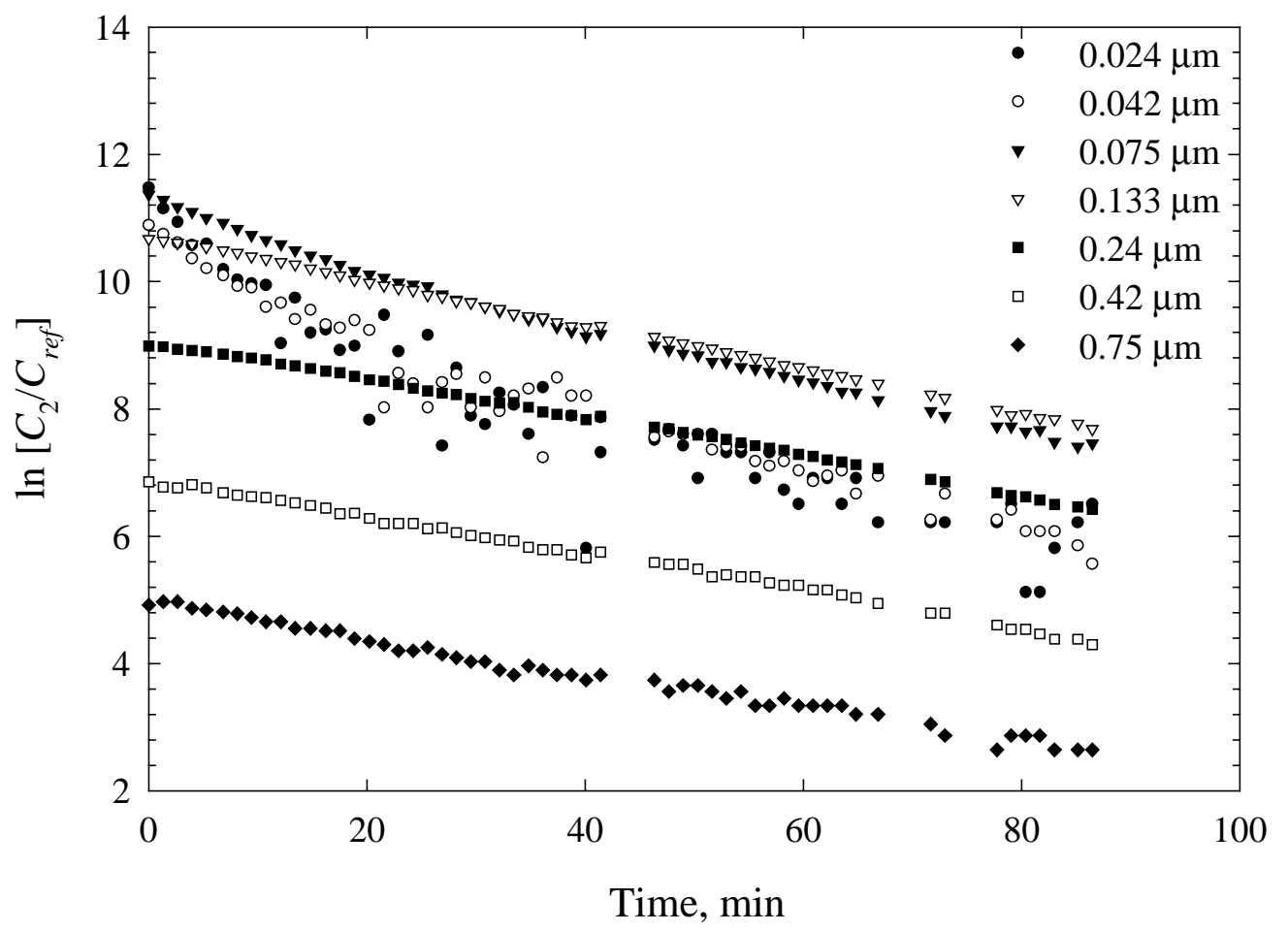

Figure 4.5 Particle concentration decay with time in the deposition experiments with an air-exchange rate of $1.5 \mathrm{~h}^{-1}$. The particle concentration in chamber 2 , $C_{2}$, is normalized by $C_{r e f}\left(1 \mathrm{~cm}^{-3}\right)$. The test window was $\mathrm{Wr}$, and the generated submicron particles were measured by the EAA. 


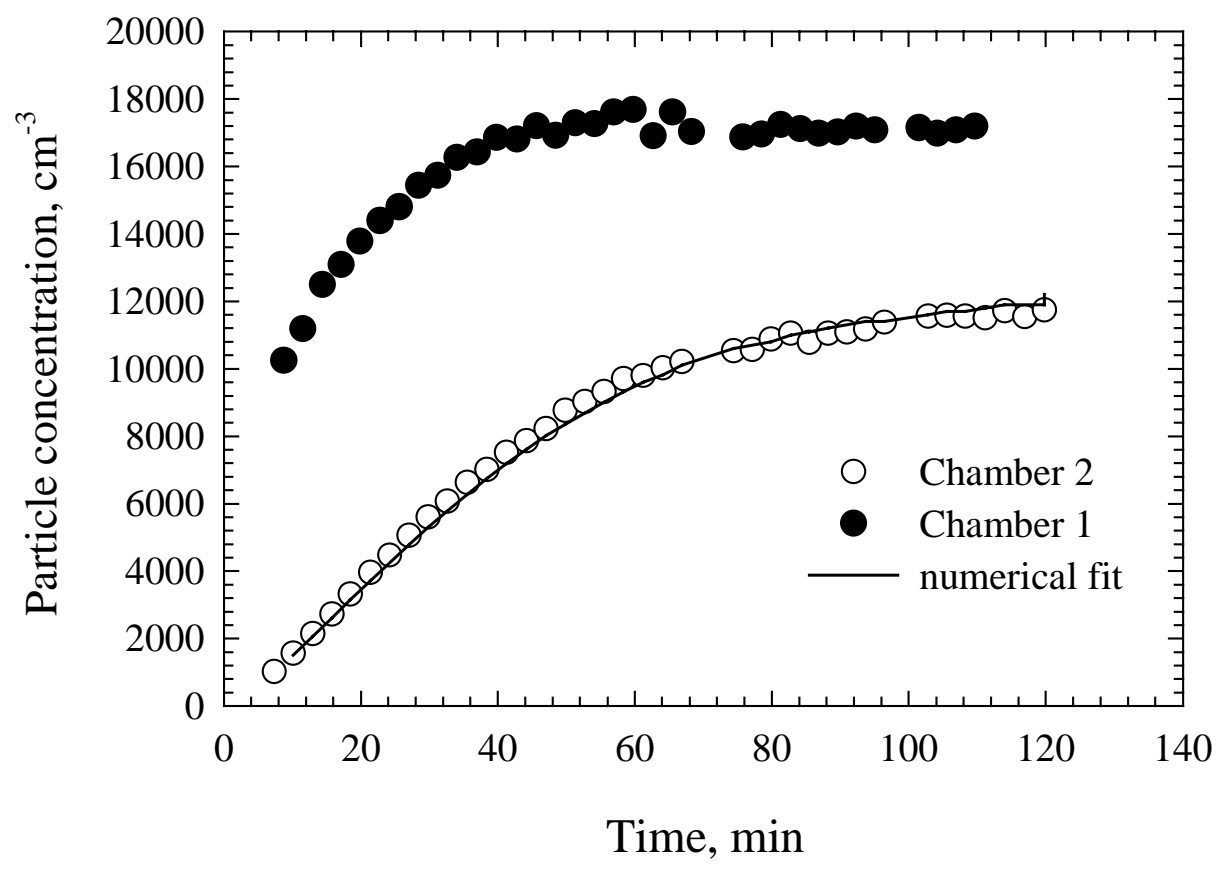

Figure 4.6 Measured particle concentration for mean particle diameter $0.24 \mu \mathrm{m}$ in both chambers, as well as the simulated aerosol concentration in chamber 2 as a function of time in the concentration growth method. The test window is Wr. 


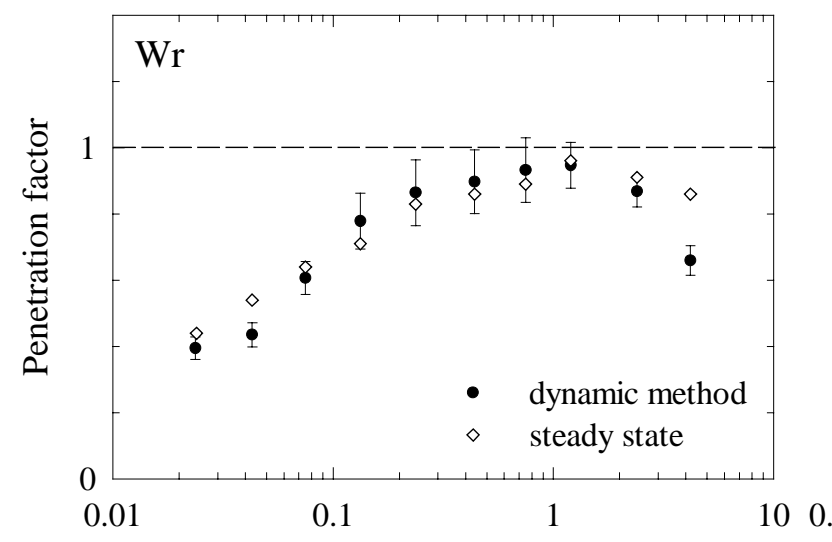

Particle diameter, $\mu \mathrm{m}$

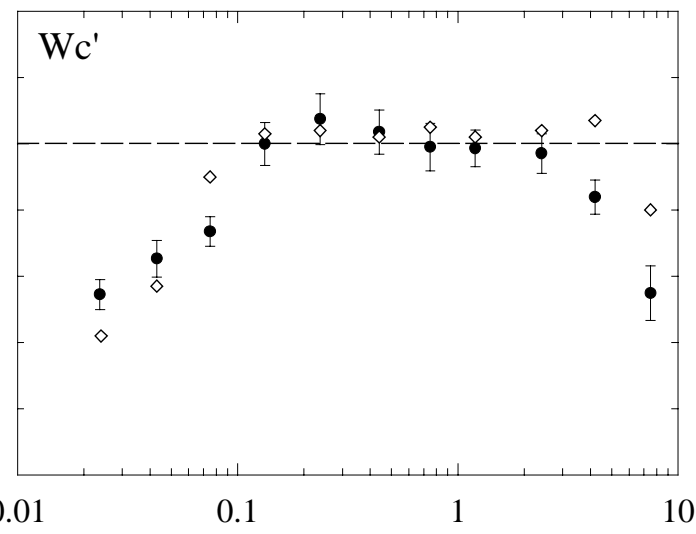

Particle diameter, $\mu \mathrm{m}$

Figure 4.7 Particle penetration factors obtained for the two test windows from the steady-state method, and the dynamic concentration growth approach. Airflow through the window unit was induced by means of a steady pressure drop of $1 \mathrm{~Pa}$. 


\section{5 measuring Particle Penetration into a SINGLE-FAMILY HOUSE}

\subsection{ABSTRACT}

This chapter extends the experimental scale, from a single building crack (Chapter 3) and windows (Chapter 4), to examine particle penetration factors for a whole house. A single-story house in Clovis, in the San Joaquin Valley of California was selected for the study. Continuous indoor and outdoor aerosol concentrations as well as air-exchange rates were measured for four consecutive days, during which the house was unoccupied, and doors and windows were all closed. With a blower door, the house was pressurized to obtain particle deposition coefficients, which in turn were used to determine particle penetration factors from house depressurization experiments. The determined particle deposition coefficients were in a reasonable range $\left(0.4-2 \mathrm{~h}^{-1}\right.$ for $\left.0.02-2 \mu \mathrm{m}\right)$ as compared with previous studies. The resulting whole house penetration factors were in the range 0.5-0.9 for 0.02-2 $\mu \mathrm{m}$ particles, suggesting that significant penetration loss might have occurred in this size range, even though studies of isolated components led to an expectation of higher penetration factors. Two hypotheses were proposed to explain this observation. Lower particle penetration may occur because a certain fraction of infiltrating air flows through well-insulated wall cavities. It is also likely that the phase transition of volatile constituents (such as nitrates and water) on particles upon entry into the house contributed to the lower values of "apparent" particle penetration. For this second hypothesis, quantitative estimates were made for four postulated scenarios, assuming that particles consisted of $20 \%$ nitrate and $0-10 \%$ water content with various mixing characteristics. The results indicate that nearly complete particle penetration may 
have occurred for particle sizes of $0.2-2 \mu \mathrm{m}$ when evaporation of nitrate and water in indoor environments is taken into account. For this field study, nevertheless, not enough is known about the distribution of building leakage pathways and their dimensions, and how these factors affect particle penetration. In addition, indoor and outdoor ozone concentrations were measured concurrently with the particle experiments. Nearly complete ozone penetration was found in this study house.

\subsection{INTRODUCTION}

\subsubsection{Indoor Particle Dynamics}

Exposures to airborne particulate contaminants can cause adverse human health effects. Extensive epidemiological studies have suggested that ambient particulate pollution is an important risk factor for cardiopulmonary diseases and mortality (Pope et al., 2002). Because people spend the majority of their time indoors, a sound understanding of the extent of ambient particle penetration into buildings is crucial to evaluate human exposure to indoor particles of outdoor origin.

To examine the impact on indoor particle levels of ambient particulate matter (PM), it is important to present an overview that accounts for particle generation and removal mechanisms in indoor environments, as shown schematically in Figure 1.1. In an indoor environment where air is assumed to be well-mixed, the size-specific indoor particle level can be characterized by the following mass balance equation:

$$
\frac{d C_{i}}{d t}=p \lambda_{v} C_{o}+\frac{G}{V}+\frac{R}{V}-\lambda_{v} C_{i}-k_{d} C_{i}-\eta \frac{Q_{f}}{V} C_{i}
$$

where $C_{i}$ and $C_{o}$ are indoor and outdoor particle concentrations, $p$ is particle penetration factor, $\lambda_{v}$ is the air-exchange rate owing to infiltration $\left(\mathrm{h}^{-1}\right), G$ is indoor aerosol 
generation rate (mass $\left.\mathrm{h}^{-1}\right), V$ is the house volume $\left(\mathrm{m}^{3}\right), R$ is the particle resuspension rate $\left(\right.$ mass $\left.\mathrm{h}^{-1}\right), k_{d}$ is particle loss coefficient due to deposition onto surfaces $\left(\mathrm{h}^{-1}\right), \eta$ is filtration efficiency, and $Q_{f}$ is the filtration rate $\left(\mathrm{m}^{3} \mathrm{~h}^{-1}\right)$. Equation (5.1) applies for conditions where ventilation occurs entirely by infiltration. It also ignores particle concentration change due to condensation, evaporation, coagulation and chemical transformation, based on an expectation that these processes have minor effects on particle levels under conditions commonly found in residences. Nevertheless, the relative importance of these mechanisms to the change of indoor particle concentrations merits more study in the future.

To experimentally explore the contribution of ambient particulate matter to indoor particle concentrations, it is useful to eliminate interferences from indoor sources (aerosol generation activities) and particle removal processes other than ventilation and deposition (i.e., filtration). In the absence of these mechanisms, the mass balance equation is simplified to the following form:

$$
\frac{d C_{i}}{d t}=p \lambda_{v} C_{o}-\left(\lambda_{v}+k_{d}\right) C_{i}
$$

Particle removal by ventilation occurs at a rate independent of particle size and can be measured, e.g., with tracer gas techniques. Particle penetration and deposition loss, on the other hand, are particle size-dependent processes, which occur simultaneously. The challenge to determine the two parameters is to separate these two effects in the experiments. 


\subsubsection{Highlights of Previous Studies}

A few field investigations have aimed to quantify the proportion of ambient particles that penetrate through residential building envelopes. In these studies, the parameter "penetration factor", or "penetration efficiency" was used to characterize the fraction of indoor particles that remained airborne in infiltrating air. Most of the studies assumed that steady-state conditions prevailed in their data analysis. The experimental approaches in these studies can be categorized into two types: semi-empirical and mechanistic. The former approach is represented by Long et al. (2001) and by the PTEAM (Particle Total Exposure Assessment Methodology) study (Özkaynak et al., 1996). This methodology requires many samples in order to evaluate the particle penetration factors and deposition rates by statistical analysis. For example, 9 nonsmoking homes in Boston area and 178 residences in Riverside, CA were examined, respectively, in these two studies. Derived from the steady-state solution to the mass balance equation, a physical-statistical model was applied to estimate penetration factors and particle loss rate using measured outdoor/indoor PM concentrations and air-exchange rate as inputs. In the PTEAM study, estimates of source strength of indoor particle sources (smoking, cooking, etc.) were also determined in the regression analysis, in addition to $p$ and $k_{d}$. In the PTEAM study, particle size was not highly resolved. Instead, analysis was based on integrated mass concentration measurements for particles smaller than $10 \mu \mathrm{m}\left(\mathrm{PM}_{10}\right)$ and smaller than $2.5 \mu \mathrm{m}\left(\mathrm{PM}_{2.5}\right)$. Penetration factors of very close to unity were found for both size classes in this study.

In the study of Long et al., particle concentration measurements were made for 17 discrete sizes ranging from 0.02 to $10 \mu \mathrm{m}$ in nonsmoking households. Accumulation 
mode particles appeared to exhibit the highest penetration efficiency as compared to ultrafine $\left(d_{p}<0.1 \mu \mathrm{m}\right)$ and coarse particles, indicating strong size-dependent behavior. The findings also showed significantly lower particle penetration factors in winter than in summer seasons (e.g., $0.66-0.80$ vs. $0.88-1.01$ for $0.1-1 \mu \mathrm{m}$ particles). The authors attributed this difference to the fact that the building envelopes were tighter for winter because windows were more commonly open in summer.

For the mechanistic approach, determining particle deposition coefficients is the first step to separate the coupled effects of deposition and penetration on indoor concentrations. This separation can be achieved by assuming that ambient particle infiltration has a negligible contribution during the early stage of experiments after a deliberate increase of indoor concentrations to substantial levels. Then particle loss due to deposition and ventilation is determined by measuring particle concentration decay with time. Subsequently, assuming steady-state holds, the obtained deposition coefficients along with other measured parameters (air exchange rates and indoor/outdoor PM ratio) are incorporated into a mass balance equation to solve for $p$. Two studies adopted this experimental scheme to measure particle penetration factors for supermicron particles (Thatcher and Layton, 1995) and fine particles (Vette et al., 2001) in residential settings. The results from Thatcher and Layton showed essentially complete particle penetration, whereas the study of Vette et al. yielded penetration factors significantly less than one, varying with particle size in the range $0.5-0.9$. A comparison of these studies is provided in Table 5.1. 
Another way to separate the coupling effects is to arrange experimental conditions so as to ensure that particle loss due to deposition is negligible compared to penetration. This can be accomplished by using filtration to make the indoor particle concentration extremely low. After the particle level in the room is reduced to negligible levels, filtration is turned off, and the increase of particle concentration owing to ambient air infiltration is measured. Then particle penetration can be estimated by ignoring the particle loss term in a transient mass-balance analysis. This approach, called the concentration rebound method, has been demonstrated by conducting experiments in a research facility at Richmond Field Station (Lunden et al., 2001). The obtained penetration factors were high; nearly complete penetration was inferred for particles of 0.4-4 $\mu \mathrm{m}$. The authors attributed the high penetration to the leaky building envelope. In this chapter, a different experimental approach was developed and applied to quantify the fractional particle penetration from ambient air through a residential building shell. A blower door was used to pressurize, and sequentially depressurize the house in an attempt to decouple the effects of particle penetration and deposition. The data were examined by considering both time-integrated and transient analysis to evaluate penetration factors and deposition coefficients.

\subsection{METHODS}

\subsubsection{The Principle}

A blower door, a device with a fan that can be mounted in a door or window, is commonly applied to characterize the air tightness of building shells (ASHRAE, 1993). In this study a blower door was employed to create constant pressurization or 
depressurization across the entire building envelope. During pressurization, ambient particles are brought into the house through the fan. Negligible particle loss is assumed to occur in this configuration because of the large openings between the fan blades. Thus, this configuration eliminates the effect of particle penetration loss through the building shell. In the absence of indoor activities, and assuming negligible particle removal processes other than deposition and ventilation, the rate of change of sizeresolved indoor particle concentration can be written as follows:

$$
\frac{d C_{i}}{d t}=\lambda_{v} C_{o}-\left(\lambda_{v}+k_{d}\right) C_{i}
$$

With outdoor/indoor particle concentrations and air-exchange rate measured simultaneously, particle deposition coefficients can be determined by fitting experimental data into Equation (5.3). On the other hand, when the house is depressurized, indoor air is withdrawn through the fan and replenished with outdoor air flowing through leaks in the building envelope. As a consequence, ambient particles may experience penetration loss in the building leaks during depressurization. The mass-balance equation for indoor particles in this case is described by Equation (5.2). Given the measured values of $\lambda_{v}$ and $C_{o}(t)$, and the previously determined values of $k_{d}$, the penetration factor $p$ can be evaluated by fitting Equation (5.2) to the measured values of $C_{i}(t)$. To reiterate, $p$ is the particle penetration factor, the fraction of ambient particles that enter the indoor environment through building leaks and remain airborne. Note that $C_{i}, C_{o}, k_{d}$ and $p$ are all determined as functions of particle diameter.

The goal of manipulating the pressure difference across the building envelope in these experiments is to separate the effects of particle deposition and penetration. A key assumption is that particle deposition coefficients obtained during pressurization and 
depressurization can be reasonably approximated to be the same, since the indoor air experiences similar airflow turbulence intensity ${ }^{1}$. In other words, the size-resolved particle deposition coefficients evaluated from pressurization tests can be used to estimate particle penetration factors in the depressurization tests.

\subsubsection{Data Interpretation}

The first step in the basic analysis scheme involves evaluating particle deposition coefficients for a pressurized house. After integration of Equation (5.3) and some rearrangement, $k_{d}$ is obtained as

$$
k_{d}=\frac{\lambda_{v}}{\bar{C}_{i}}\left(\bar{C}_{o}-\bar{C}_{i}\right)-\frac{1}{\tau_{\exp } \bar{C}_{i}}\left[C_{i}(t)-C_{i}(0)\right]
$$

where $\bar{C}_{i}$ and $\bar{C}_{o}$ are the time-average concentrations of indoor and outdoor particles throughout the experiment, $\tau_{\exp }$ is the duration of experiment, and $C_{i}(0)$ and $C_{i}(t)$, are the indoor particle concentrations at beginning and end of the experiment, respectively.

When the house undergoes depressurization, the particle penetration factor can be solved by integrating Equation (5.2) and rearranging:

$$
p=\left(\frac{k_{d}}{\lambda_{v}}+1\right) \frac{\bar{C}_{i}}{\bar{C}_{o}}+\frac{1}{\lambda_{v} \tau_{\exp }} \frac{C_{i}(t)-C_{i}(0)}{\bar{C}_{o}}
$$

The detailed derivation of Equations (5.4) and (5.5) is provided in Appendix I. Note that the first and second terms on the right-hand sides of Equations (5.4) and (5.5) represent time-integrated and transient terms, respectively. The time-integrated terms tend to remain consistent in magnitude with increasing experimental duration. The transient terms, on the other hand, decrease inversely with $\tau_{\text {exp }}$. Given a sufficient

\footnotetext{
${ }^{1}$ This can be achieved by mixing the indoor air vigorously with the use of fans.
} 
experimental time interval, the transient terms are expected to become negligible in comparison to the time-integrated terms.

\subsubsection{The Study House}

The house used in the study is located in a residential area of Clovis, in the vicinity of Fresno, in central California. The single-story house, built in 1972 with the floor plan shown in Figure 5.1, represents a typical modern house in the US. The floor area is $134 \mathrm{~m}^{2}$ with a ceiling height of $2.4 \mathrm{~m}$, yielding a house volume of $322 \mathrm{~m}^{3}$ (garage excluded). The house is equipped with a forced air heating and cooling system and ceiling fans that were operated to promote air mixing during the experiments reported here. Carpeting covers all floor areas except the kitchen, which has linoleum flooring. The house has a stucco exterior and the windows are made with aluminum frames that slide horizontally to open. Situated in a suburban area, the house is surrounded by houses of similar heights and sizes, resulting in some wind shielding of the study house. The house was monitored from January 27-31, 2001. The house was unoccupied during the sampling period ${ }^{2}$.

\subsubsection{Instrumentation}

The test house was equipped with an APS (Aerodynamic Particle Sizer, TSI 3320, St. Paul, MN) and an EAA (Electrical Aerosol Analyzer, TSI 3030, St. Paul, MN), which were employed to monitor the concentrations of outdoor and indoor airborne particles in the size ranges of 0.54 to $20 \mu \mathrm{m}$, and 0.013 to $1 \mu \mathrm{m}$, respectively. Ambient and indoor

\footnotetext{
${ }^{2}$ The only occupancy in the house occurred between monitoring periods, during which the author entered the house to save sampling data from the previous experimental run, and to prepare for the next measurement.
} 
air samples were sent to the instruments through copper tubes (inner diameter $0.6 \mathrm{~cm}$ ) of identical length and bending angles. The two sampling tubes were connected to a 3-way solenoid valve (ASCO ${ }^{\circledR}$, Automatic Switch Co., Florham Park, NJ), which was operated by a time controller (ChronTrol ${ }^{\circledR}$, ChronTrol Corp., San Diego, CA). Thus, outdoor and indoor air samplings could be programmed, collected, and sent to the aerosol instruments alternatively. Relative particle loss in the copper tubes was evaluated by sampling the indoor air consecutively from the two inlets. The difference was found to be negligible with respect to the measured particle concentrations from the two tubes. This indicates that the sampled indoor/outdoor particle concentrations can be reliably compared without adjusting for particle loss in the sampling lines, even though such loss may have occurred and would influence the determination of absolute particle concentrations. The inlet of indoor air samples, located in the living room, was about $2 \mathrm{~m}$ above the floor and $1 \mathrm{~m}$ from the nearest interior wall. The outdoor air sample, collected $2.4 \mathrm{~m}$ above the ground, was drawn through the copper tube across a plywood window insert. The inlet of outdoor samples was covered with a coarse screen to prevent insects from entering the instruments.

The time controller was synchronized with the instruments prior to each experiment. The sampling cycle was the following: five outdoor air samples were taken during a 380 -second sampling period, followed by a 152 -second purging period. Then 5 indoor air samples were taken for 380 seconds, followed by another 152 -second purging interval.

With all windows and doors closed, the house air-exchange rate of each pressurization or depressurization experiment was determined by monitoring tracer gas 
concentration decay with time. About $90 \mathrm{ml} \mathrm{SF}_{6}$ was injected into the HVAC system with the fan on to mix with air throughout the whole house for the first ten minutes of the measurement. The HVAC fan was off during the rest of the monitoring period. Air in each compartment of the house was vigorously mixed by ceiling and oscillating fans. $\mathrm{SF}_{6}$ samples were collected every 100 110 seconds sequentially from six sampling inlets, deployed about $1.5 \mathrm{~m}$ above the floor in living room, family room, three bedrooms and kitchen, as indicated in Figure 5.1. The $\mathrm{SF}_{6}$ concentrations as a function of time in the six compartments of the house were analyzed by a multi-gas monitor (Type 1302, Brüel \& Kjæ, Denmark), which determined the gas concentration by a non-dispersive infrared technique. The $\mathrm{SF}_{6}$ concentrations were recorded via Tele-tale (Onset Computer Corporation, MA, USA).

The house was pressurized and depressurized with a blower door (Minneapolis Blower Door, Model 3, The Energy Conservatory, Minneapolis, MN) by adjusting the direction and speed of fan rotation. The blower door, facing to the patio in the backyard, was installed against the aluminum frame of the sliding door in the family room. The fan speed was adjusted so that a fixed air-exchange rate in the house was maintained. The air-exchange rate of $\sim 2 \mathrm{~h}^{-1}$ was chosen as a compromise between typical conditions ( $0.5 \mathrm{~h}^{-1}$ ) and the goal of minimizing errors from potentially high variability of $k_{d}$ measurements. The pressure difference relative to outdoors at five locations of the house (master bedroom, bedroom 1, kitchen, living room and attic) was monitored and recorded continuously by the Automated Performance Testing (APT) System ${ }^{\mathrm{TM}}$ (The Energy Conservatory, Minneapolis, MN). 


\subsection{RESULTS AND DISCUSSION}

\subsubsection{Concentration Profiles of Indoor/Outdoor Aerosols}

During the sampling period, the outdoor aerosol concentrations were found to be consistently higher than those indoors. Figures 5.2 (a)-(d) illustrate the concentration profiles $^{3}$ of indoor/outdoor airborne particles for various particle sizes, with periods of pressurization and depressurization indicated on top of the figures. During the first pressurization test, unusually high indoor supermicron particle concentrations were detected, as shown in Figure 5.3 (a). However, since the measured outdoor PM concentrations from the $2.4 \mathrm{~m}$ height sample inlet did not correspond to the elevated indoor particle levels, and because such a phenomenon never occurred again over the entire sampling period, it is likely that this rare event resulted from dust resuspended from the patio and back yard as the blower door fan introduced substantial air flow into the house. Closer correspondence of particle concentrations between indoors and outdoors were typically observed during pressurization than during depressurization, as shown in Figure 5.2, indicating less particle loss through the blower door fan than loss through the building envelope. When outdoor particles were brought into the house through the leaks in the building shell during depressurization, indoor particle levels in the house were found to closely track the ambient particle concentrations over time, but with reduced concentration.

The ambient PM concentration profiles exhibited distinct diurnal patterns. For example, significantly elevated concentrations of submicron aerosols were observed at night (from 6 pm to midnight). Figure 5.3 (b) illustrates the particle concentration

\footnotetext{
${ }^{3}$ Each data point represents the average concentrations of indoor or outdoor particles from five consecutive measurements $(5 \times 76 \mathrm{sec})$.
} 
profiles of $0.13 \mu \mathrm{m}$ mean particle diameter during January 28-30. A similar pattern occurred for other submicron particles, as can be perused in Figures 5.2 (a) and (b). The air exhibited strong smoky smell based on direct personal perception. Wood or vegetative burning activity in the neighborhood combined with weak atmospheric dispersion is likely to be the major contributor to high particle levels at these times. Previous receptor modeling work that used specific organic fingerprints to apportion PM emission sources has identified wood combustion as the largest primary contributor to the fine particles in the San Joaquin Valley during winter (Schauer and Cass, 2000).

During morning rush hours, a pronounced supermicron particle concentration spike was observed, as indicated in Figure 5.3 (c), and this may be a result of contributions from road dust and tire wear. The study house is located in a large residential area with two major freeways (168 and 41) a few kilometers to the west, and state highway 99 is $15 \mathrm{~km}$ further. The wind direction was predominantly from northwest, and wind from that direction was highly likely to bring particles related to traffic activities from the freeways. Note that such elevated coarse particle concentrations were not as evident during evening rush hours, and this might be partly attributed to greater mixing depth in the evening than in the morning, or to a change of wind direction.

The formation of radiation fog is common in the San Joaquin Valley during late night and early morning in wintertime. From the measurement data, the fog droplets $(\geq 10 \mu \mathrm{m})$ seemed to have negligible contribution to the total measured aerosol concentration. For example, the measured outdoor concentration was $\sim 10^{-2} \mathrm{~cm}^{-3}$ or lower for particles $\geq 10 \mu \mathrm{m}$, which was nearly two orders of magnitude lower than the 
concentration for particles $\sim 1 \mu \mathrm{m}$. According to Seinfeld and Pandis (1998, p. 339), the typical fog liquid water content varies from 0.02 to $0.5 \mathrm{~g} \mathrm{~m}^{-3}$, which implies that the fog droplet concentration would range from 5 to $125 \mathrm{~cm}^{-3}$ if all droplets are $\sim 20 \mu \mathrm{m}$ in diameter. The transport loss of fog droplets in the sampling line prior to the solenoid valve was considered negligible since (1) the vertical displacement ${ }^{4}$ was much less than the diameter of the sampling tube, (2) droplet evaporation in the sampling tube was likely to be unimportant in sampled air because of the high relative humidity $(\mathrm{RH} \geq 90 \%)$ and the short residence time of air in the sampling tube ${ }^{5}$, and (3) particle loss as a result of impaction was considered negligible for $S t<1^{6}$. However, it is likely that the APS measuring system failed to sample the fog droplets. The droplets may be lost owing to evaporation at two locations in the system: the solenoid valve (which was slightly heated as a result of electrical current) and the within APS (slightly warm due to the pump operation and the laser source).

\subsubsection{Air Exchange Rate and Pressure Difference}

Air-exchange rate measurements were made during periods of pressurization and depressurization. The value of the air-exchange rate was determined by calculating the slope of a linear regression of the natural logarithm of $\mathrm{SF}_{6}$ concentration versus time.

When the house was pressurized, the family room where the blower door was installed

\footnotetext{
4 This is estimated by the product of residence time in the horizontal sampling tube and the particle settling velocity. The airflow velocity in the sampling tube is $\sim 3 \mathrm{~m} / \mathrm{s}$, and the horizontal tube length is $35 \mathrm{~cm}$. Thus, the vertical displacement is $\sim 0.14 \mathrm{~cm}$ for $20 \mu \mathrm{m}$ particles. The inner diameter of the sampling tube is $\sim 0.6 \mathrm{~cm}$.

${ }^{5}$ It takes $\sim 2.6 \mathrm{sec}$ for pure water droplets of $20 \mu \mathrm{m}$ to evaporate to $1 \mu \mathrm{m}$ at $20^{\circ} \mathrm{C}$ and $50 \%$ relative humidity (Hinds, 1999, Chapter 13). The residence time of air in the sampling tube is only $\sim 0.4 \mathrm{~s}$.

${ }^{6}$ St was estimated to be $\sim 0.6$ for particles of $20 \mu \mathrm{m}$ at air flow speed of $\sim 3 \mathrm{~m} / \mathrm{s}$ and sampling tube diameter of $\sim 0.6 \mathrm{~cm}$.
} 
experienced the highest rates of $\mathrm{SF}_{6}$ removal $^{7}\left(3.6-6.6 \mathrm{~h}^{-1}\right)$, and the adjacent kitchen was the next highest $\left(3.8-5.8 \mathrm{~h}^{-1}\right)$. The $\mathrm{SF}_{6}$ removal rates measured in the other four compartments, however, were fairly close at $\sim 2 \mathrm{~h}^{-1}$. Figure 5.4 (a) shows an example of the $\mathrm{SF}_{6}$ concentration decay with time in the six zones of the house on January 30 . The $\mathrm{SF}_{6}$ concentrations measured in the six zones appear to be fairly uniform in the first ten minutes, indicating that good mixing was achieved with the use of HVAC fan. The good linearity of the data points in each zone clearly indicates the air was well-mixed within each zone; yet different rates of concentration decay indicate that the air in the house as a whole was not well-mixed. In this case, an average air-exchange rate was estimated for the whole house ${ }^{8}$, ranging from 2.1 to $2.7 \mathrm{~h}^{-1}$ (average $2.4 \mathrm{~h}^{-1}$ ).

When the house was depressurized, the overall air-exchange rates were in the range $1.8-2.7 \mathrm{~h}^{-1}$ (average $2.2 \mathrm{~h}^{-1}$ ). Tracer gas concentrations were more uniform throughout the house, as illustrated in Figure 5.4 (b). A slightly greater slope obtained in the master bedroom implied that the mixing between this zone and the rest of the house might not be as rapid as that in other zones. Meanwhile, a stable and uniformly distributed $\Delta \mathrm{P}(\sim 3 \mathrm{~Pa})$ was established across the house envelope throughout the experiment. This suggests that the blower door created a uniform driving force for outdoor air infiltration across the entire building envelope under depressurization. The

\footnotetext{
7 The term of "SF 6 removal" is used here instead of "air exchange" because the air flowing into the zone of interest from the rest of the house also contains the tracer gas $\mathrm{SF}_{6}$.

8 The average air-exchange rate for the entire house was estimated based on the decay of volume-weighted average $\mathrm{SF}_{6}$ concentration. The $\mathrm{SF}_{6}$ concentrations as a function of time in the six zones were reconstructed according to their linear regression results, since the original data were only available at different times due to the sequential sampling process. A new zone was proposed (the whole house except the kitchen and family room) in calculating the contribution to the average $\mathrm{SF}_{6}$ concentration, because of the similar slopes determined for the living room and the three bedrooms, and the unidentified $\mathrm{SF}_{6}$ concentration in areas such as hallways and the bathroom. The estimated volumes for the family room, the kitchen, and the new zone are 54,48 , and $222 \mathrm{~m}^{3}$, respectively.
} 
air-exchange rates determined for the pressurization and depressurization experiments are summarized in Table 5.2.

\subsubsection{House Air Leakage Characterization}

The air tightness of the study house can be characterized based on the measured air exchange rate and pressure difference across the house envelope. The effective leakage area of the building envelope, which is the aggregate leakage area that would generate the same air infiltration rate at a certain $\Delta \mathrm{P}$, can be approximated according to the following equation (ASHRAE, 1993):

$$
A=\frac{Q}{C_{d}}\left[\frac{\rho}{2 \Delta P}\right]^{1 / 2}
$$

where $A$ is the effective (or equivalent) leakage area $\left(\mathrm{m}^{2}\right), \rho$ is air density $\left(\mathrm{kg} \mathrm{m}^{-3}\right), Q$ is the air flow rate through the test house $\left(\mathrm{m}^{3} \mathrm{~h}^{-1}\right)$, and $C_{d}$ is the discharge coefficient for the leakage openings (dimensionless) ${ }^{9}$.

According to Equation (5.6), the effective leakage area of this study house was estimated to be approximately $620 \mathrm{~cm}^{2}$ at $3 \mathrm{~Pa}$, or $720 \mathrm{~cm}^{2}$ at $4 \mathrm{~Pa}$, the later being a pressure difference commonly reported in building leakage characterization. To compare the relative air tightness of houses, a consistent measure of normalized leakage $\left(L_{n}\right)$ is given by the following equation:

$$
L_{n}=10^{3}\left(\frac{A_{4}}{A_{f}}\right)\left(\frac{H_{c}}{H}\right)^{0.3}
$$

${ }^{9}$ The value of $C_{d}$ usually ranges from 0.6 to 1 depending on the opening configurations; a $C_{d}$ value of one was used for air leakage characterization of this study house. 
where $A_{4}$ is the effective leakage area at reference pressure difference of $4 \mathrm{~Pa}, A_{f}$ is the

floor area $\left(\mathrm{m}^{2}\right), H_{c}$ is the ceiling height of the test house, and $H$ is the reference ceiling height that usually is taken as $2.5 \mathrm{~m}$ (ASHRAE, 1993). From the measured fan pressurization data, the normalized leakage of the study house is approximately 0.67 . For comparison, the average house in U.S. has a normalized leakage of 1.2 (Sherman and Matson, 1997), and a well-sealed new house has an $L_{n}$ value of about 0.5 or lower. This same study house was also characterized more thoroughly by Energy Performance of Buildings Group at Lawrence Berkeley Laboratory. Their measurements found normalized leakage of the house to be 0.65 .

\subsubsection{Particle Deposition Coefficients}

Based on the data obtained during the pressurization experiments, size-resolved particle deposition coefficients were calculated according to Equation (5.4), as shown in Table $5.3^{10}$. Both the time-integrated condition and transient state are included in this data analysis $^{11}$, which assumed no phase transformation of indoor particles. A paired $t$ test was used to compare the size-specific average values of the two particle deposition coefficients, the time-integrated and the combined time-integrated and transient term, for the APS and EAA measurements. The low probability levels $(p<0.005)$ indicate that the transient terms of the particle deposition coefficients are insignificant, suggesting that the

\footnotetext{
${ }^{10}$ The particle deposition coefficients calculated from each pressurization experiment are shown in Figure 5.5. The average outdoor and indoor particle concentrations were computed over the entire sampling duration for each particle size bin to determine the time-integrated particle deposition coefficients. The indoor particle concentrations at beginning and end of each experiment, and the monitoring duration were incorporated in the transient state analysis.

${ }^{11}$ For the APS measurements, the data from the daytime pressurization experiments were excluded in the analysis owing to the high uncertainly resulted from the significant fluctuations of ambient particle concentrations.
} 
time-integrated analysis alone should provide an adequate estimate to characterize particle deposition loss in the experiments. Increased variability of the measured particle deposition coefficients was seen to be associated with larger particle sizes in the APS measurements. This is attributed, in part, to the low ambient particle concentrations in this size range, which in turn reduces the precision because of counting statistics associated with the APS during the sampling intervals.

In addition, the experimental variability of particle deposition onto indoor surfaces tends to be influenced by many environmental conditions, such as air flow intensity (Crump et al., 1983; Okuyama et al., 1986; Cheng, 1997), surface-to-air temperature difference (Thatcher et al., 1996), surface texture (Harrison, 1979; Byrne et al., 1995; Thatcher and Nazaroff, 1997), as well as surface-to-volume ratio and furnishings (Fogh et al., 1997; Thatcher et al., 2002). To illustrate the wide degree of variability, Figure 5.5 presents a comparison of the measured particle deposition coefficients from this work with other field and full-scale laboratory studies. The solid symbols represent the average values of particle deposition coefficients from the pressurization experiments, with the error bars corresponding to one standard deviation based on the data in Table 5.3. Note that the particle deposition coefficients in this study were evaluated under higher turbulence intensity than ordinary indoor environments owing to the use of fans for vigorous air mixing. Nevertheless, the measured deposition results in this study appear reasonably consistent with those reported in other investigations. So far, an understanding of the relative influences among various factors to the deposition measurement variability is incomplete. 


\subsubsection{Particle Penetration Assuming Nonvolatile Composition}

Based on the particle deposition coefficients determined in the pressurization experiments, the size-resolved particle penetration factors, as plotted in Figures 5.6 (a), were computed ${ }^{12}$ for each depressurization experiment according to Equation 5.5. In Figure 5.6 (a), the open symbols represent the average of the time-integrated penetration factors from the EAA and APS measurements. The solid symbols with error bars represent the average penetration factors plus or minus one standard deviation based on the combined transient and time-integrated analysis. Clearly the average values of penetration factors from the time-integrated analysis alone were fairly close to those from the combined time-integrated and transient-state analysis. Also note that the estimated average penetration factor for $0.75 \mu \mathrm{m}$ particles in the EAA measurements agreed moderately well with the one determined from APS measurements, in light of the overlapping error bars, which correspond to sixty-eight percent confidence intervals of measured data. Comparable uncertainty was observed from the time-integrated method and the combined (time-integrated and transient state) analysis in the APS and EAA measurements, as can be seen in Figures 5.6 (a) and (b). The relatively low aerosol concentrations for particles with diameters $>1 \mu \mathrm{m}$ significantly reduced the measurement precision in APS measurements, leading to higher uncertainty associated with the data analysis for larger particles. In contrast, the submicron particles were abundant, which compensated for the fluctuation of PM concentrations.

\footnotetext{
${ }^{12}$ This was done by substituting the average size-specific particle deposition loss coefficients (both the time-integrated and combined time-integrated and transient state) from Table 5.3 into Equation (5.5) for each depressurization experiment. The air-exchange rates obtained in each depressurization test were used in Equation (5.5).
} 
As shown in Figure 5.6, the estimated penetration factors inferred from this analysis were in the range of $0.5-0.9$. This indicates less overall particle penetration than predicted for cracks in Chapter 2, when considering that building leaks consist of various dimensions. Nevertheless, the overall particle penetration would be reduced if a certain fraction of infiltrating air flows through well-insulated wall cavities. As reported in Chapter 2, the fibrous insulation blanket in wall cavities can remove airborne particles effectively if infiltrating air flows through it, thereby lowering the overall particle penetration factors.

Figure 5.7 compares the particle penetration factors determined in this study with other investigations. It is seen that particle penetration factors obtained in this study are relatively consistent with those of Long et al. (2001). Lower experimental particle penetration factors for fine particles have been reported by Vette et al. (2001). Model predictions based on methods presented in Chapter 2 are plotted in Figure 5.7. According to the prediction, if all infiltrating air passed through the building cracks and not through fibrous insulation, then the particle penetration would be expected to be nearly complete with respect to the particle size range studied. However, if 20-30\% of the infiltrating air flowed through the fiberglass materials in wall cavities, the particle penetration results in this study would be largely consistent with the model calculations ${ }^{13}$. Clearly, the relative distribution of infiltrating air flowing through the building cracks and fibrous insulation materials can play an important role in governing the overall particle penetration into the indoor environment.

\footnotetext{
${ }^{13}$ Thus far no direct technique is available to examine the wall cavity insulation without removing the interior walls for inspection, and it was impractical to do so to the rental house in this study.
} 


\subsubsection{Particle Penetration Assuming Semi-Volatile Components}

Another hypothesis to explain the lower penetration factors observed in the experiments is that particles may have undergone chemical transformation upon entry into the house. A significant proportion of ambient particles is made up of ammonium nitrate in the San Joaquin Valley during winter months (Chow et al., 1993; Watson et al., 2000). In winter, as nitrate particles enter buildings, the conditions of higher temperature and lower RH in the indoor environment can favor the dissociation of ammonium nitrate into gaseous ammonia and nitric acid. This would lead to a net loss of particulate matter, which, if not properly accounted for, could be erroneously ascribed to deposition or infiltration loss.

Evidence of this hypothesized aerosol chemical transformation process in the indoor environment is provided by the simultaneous indoor/outdoor measurements on particulate nitrate, sulfate as well as gaseous ammonia in the same Clovis study house (Lunden, et al., 2001). Their preliminary results show that consistently less particulate nitrate was found in the house than outdoors, and consistently elevated indoor gaseous ammonia gas concentrations were observed. These observations indicate that, in addition to particle deposition onto indoor surfaces, additional particle loss as a result of phase transition probably occurred within the study house. Therefore, the apparent penetration factor determined from the altered indoor particle concentrations owing to evaporative loss of certain PM constituents may underestimate the actual fraction of nonvolatile particles that penetrate into the building from the ambient environment.

To provide a quantitative estimate of the expected values of particle penetration factors for nonvolatile constituents for these experiments, an illustrative hypothetical 
calculation was performed accounting for the phase transition process based on available information. In addition to the phase transition of nitrate particles, water evaporation was taken into account since abundant water is present on fine particles at high $\mathrm{RH}$ (Zhang et al., 1993).

First introduced by Junge (1950), the concept of external and internal mixing is used to describe the way in which species are distributed among particles. An externally mixed aerosol is one in which each particle is made up of single species. The overall aerosol chemical composition is governed by the relative amounts of particles, which each has pure composition. An internally mixed aerosol is one in which each particle is a blend of the various chemical species in the same proportion as the overall aerosol. Actual atmospheric aerosols exhibit intermediate states between these two limiting cases. A mathematical representation of the particle size distribution is necessary to permit quantitative estimates as the aerosol size distribution evolves due to phase transitions. A particle size distribution can be characterized using a sum of three lognormal distributions (Jaenicke, 1993):

$$
n^{\mathrm{o}}{ }_{N}\left(\log d_{p}\right)=\sum_{i=1}^{3} \frac{N_{i}}{(2 \pi)^{1 / 2} \log \sigma_{i}} \exp \left(-\frac{\left(\log d_{p}-\log \overline{d_{p i}}\right)^{2}}{2 \log ^{2} \sigma_{i}}\right)
$$

where $n^{\mathrm{o}}{ }_{N}\left(\log d_{p}\right)$ is the particle number distribution as a function of $\log d_{p}, d_{p}$ is particle diameter, and, for the $i^{\text {th }}$ mode, $N_{i}$ is the number concentration, $\overline{d_{p i}}$ is the geometric mean diameter, and $\sigma_{i}$ is the geometric standard deviation.

To construct the simulated particle size distributions, snapshots of the measured indoor and outdoor particle size distributions were taken at noon, January 30. This was when the greatest indoor/outdoor nitrate level difference and the highest outdoor particle 
nitrate level were observed ${ }^{14}$. Figure 5.8 illustrates the measured indoor/outdoor $\mathrm{PM}_{2.5}$ nitrates during the monitoring period (Jan 28-31, 2001). The parameters of the three lognormal modes for the best fit of outdoor and indoor aerosol size distributions at noon, January 30, are listed in Table 5.4, and the best curve fits for indoor and outdoor aerosol size distributions are displayed in Figure 5.9.

The phase transition process occurs as ambient aerosols at higher $\mathrm{RH}$ and lower temperature are transported into indoor environments with lower $\mathrm{RH}$ and higher temperature. Consequently, the measured indoor particle size distribution could reflect conditions in which the semi-volatile species on particles have evaporated. The original indoor particle size distribution without the occurrence of evaporation could be inferred by applying the following two principles. For external mixtures, the evaporation loss of PM semi-volatile species will cause a reduction of particle number concentration but no change in particle size. For internal mixtures, the evaporation of PM volatile species will cause a shrinkage of particle size, resulting in the shift of particle size distribution, but no change in number concentration.

For this study, the following four scenarios were postulated to describe the potential mixing characteristics of nitrate particles: (1) an external mixture with uniform nitrate distribution across particle size; (2) an internal mixture with uniform nitrate distribution across particle size; (3) an external mixture with nitrate non-uniformly distributed with particle size; and (4) an internal mixture with nitrate non-uniformly distributed with particle size. In Scenarios 3 and 4, the fractional nitrate was postulated to distribute as a function of particle size so that it conforms to the best available

\footnotetext{
${ }^{14}$ The evidence of ambient and indoor particulate nitrate concentrations was based on semi-continuous $\mathrm{PM}_{2.5}$ nitrate measurements from an integrated collection and vaporization system (Stolzenburg and Hering, 2000), which was operated concurrently during the study period.
} 
experimental findings (John et al., 1990). Under all scenarios, the overall outdoor aerosol was assumed to consist of $20 \%$ nitrate, based on data on the composition of fine PM in the Fresno area during winter (Chow et al., 1993). It was also assumed that particulate nitrate undergoes complete dissociation upon entry into buildings ${ }^{15}$. The evaporation of water from particles may occur concurrently as the particulate nitrate, a hygroscopic component, disappears from particles. Since the water content of particles greatly depends on the particle chemical composition and RH (Zhang et al., 1993), and the existing information is not sufficient to estimate the extent of water evaporation as a function of particle size, the following simplifying assumption was made. In all scenarios, water was treated as internally mixed with no water evaporation as the base case. Additional cases with water evaporation loss from particles - 5\% and 10\%, respectively — were also included in the simulations to evaluate the impact on the particle size distribution due to a small change of water content.

Figures 5.10 (a)-(d) illustrate the reconstructed indoor particle size distributions accounting for nitrate and different levels of water evaporation for the four idealized scenarios. The measured indoor/outdoor particle size distributions as well as the associated curve fits are also shown for reference. The inserted figures provide better illustrations of the detailed restored particle size distributions — indoor fitting and three different water contents - for $0.02-0.2 \mu \mathrm{m}$ in diameters. The reconstructed particle size distribution is either raised upward or shifted to a larger particle size range depending on the underlying assumptions. According to the newly constructed particle size

\footnotetext{
${ }^{15}$ For a pure water droplet of $20 \mu \mathrm{m}$, it takes $\sim 2.4$ seconds to dry to a $1 \mu \mathrm{m}$ particle at $10^{\circ} \mathrm{C}, 80 \% \mathrm{RH}$ (Hinds, 1999, Chapter 13). Given that droplets contain impurities, the drying rate would be slower than that for pure water as the droplet size becomes close to the nucleus size. Nevertheless, the time scale for droplet drying time is apparently much less than the residence time of air in the study house ( $30 \mathrm{~min})$.
} 
distribution, the indoor/outdoor particle concentration ratios prior to phase change can be evaluated by comparing the area under the curves of interest for a certain particle size range. The revised indoor/outdoor particle concentration ratios are in turn used to estimate the penetration factors from the time-integrated term of Equation (5.5).

The particle deposition loss coefficients determined from the pressurization experiments need as well to be adjusted as a result of the evaporative loss of PM semivolatile constituents. As an illustrative calculation, the particle mixing characteristics were assumed to follow the same four scenarios as stated previously ${ }^{16}$, with $10 \%$ evaporative loss ${ }^{17}$ considered in the analysis. The average indoor and outdoor particle concentrations were taken from the January 30 morning data to formulate the particle size distributions, which were generated from the sum of three lognormal distributions, as shown in Figure 5.11. The parameters for these lognormal distributions are provided in Table 5.5. To evaluate the indoor particle deposition coefficients taking into account particle evaporative loss, the indoor particle concentration has to be compared, on the same particle size basis, to the outdoor particle concentration in which the semi-volatile components have evaporated completely. The outdoor particle size distribution was adjusted by taking out the fraction of the semi-volatile components according to the same principles mentioned in the previous paragraph. The particle deposition coefficients accounting for evaporative loss were then estimated using the indoor particle

\footnotetext{
${ }^{16}$ See page 134. In this case for Scenarios 3 and 4, it was assumed that the semi-volatile components within particles were distributed according to the nitrate fractions assigned in Figures 5.9(c) and (d).

${ }^{17} 10 \%$ evaporative loss is close to the upper bound for the four scenarios so that the indoor particle concentration would not exceed the adjusted size-specific outdoor concentration. No differentiation of chemical compositions within particles was made in this analysis.
} 
concentration and the adjusted outdoor concentration, based on the time-integrated term of Equation (5.4) for the four scenarios.

Figure 5.12 shows the adjusted particle deposition coefficients along with those before adjusting for the four hypothesized scenarios. With a dip in the particle size range of 0.1-1 $\mu \mathrm{m}$, the general pattern of particle deposition coefficients in Scenario 2 presents a reasonable agreement to the expectations from theory and experimental evidence of particle deposition in an enclosure (Crump et al., 1983; Okuyama et al., 1986; Nazaroff and Cass, 1989; Xu et al., 1994; Cheng, 1997; Lai and Nazaroff, 2000; Long et al., 2001; Mosley et al., 2001; Vette et al., 2001). For further exploration, the calculation of particle deposition coefficients was extended to various fractions of evaporation loss for Scenario 2, as seen in Figure 5.13. A more pronounced dip was predicted in the accumulation mode particles as the semi-volatile content within particles increased from 5 to $15 \%$. Although the hypothesized illustration can neither be used to ascertain the true particle mixing characteristics, nor be applied to predict the semi-volatile contents of particles, the deposition coefficients obtained in Scenario 2 provide a reasonable estimate as an input to evaluate particle penetration factors.

Figure 5.14 compares the resulting penetration factors accounting for nitrate and water loss with the apparent penetration factors computed from the January 30 noon data before any adjustments. In Scenarios 3 and 4, the postulated nitrate distribution as a function of particle diameter is also indicated in the figures. Since the true distributions of nitrate and water among particles are unknown, the penetration factors obtained from these four simulated scenarios provide indications of the expected values of penetration factors when volatility is taken into account. In Figure 5.14, the general trend of the 
penetration results clearly shows that the adjusted penetration factors are higher than the "apparent" (nonvolatile) values, except for some that are very close to the original estimates for particle size less than $0.1 \mu \mathrm{m}$ in Scenarios 2-4. In Scenario 1, all adjusted penetration factors are consistently greater than the "apparent" values owing to the assumption of pure external mixtures. For Scenarios 2-4, higher penetration factors are estimated than those in the nonvolatile case, with penetration factors close to unity for particle diameter $>0.2 \mu \mathrm{m}$. If this postulation can be further substantiated by more experimental evidence, the evaporation loss of PM semi-volatile constituents may play a role in contributing to the lower penetration factors measured in Fresno during winter by Vette et al. (2001).

The adjusted particle penetration factors, as indicated in Figure 5.14, agree better with model predictions for particle diameter greater than $0.2 \mu \mathrm{m}$ for Scenarios 2-4. For Scenario 1, the agreement is good for 0.07-0.4 $\mu \mathrm{m}$. The penetration prediction was made assuming a certain crack distribution $(\mathrm{d}=0.05-1 \mathrm{~mm})$ as presented in Chapter 2 . Significant discrepancy, however, occurs for particle sizes less than $0.2 \mu \mathrm{m}$. The information on chemical speciation within ambient particles below this size is scarce. Further investigations on the distribution of semi-volatile constituents (e.g., nitrate, secondary organic materials, water) on ultrafine particles (diameter less than $0.1 \mu \mathrm{m}$ ) will be helpful to gain insights into the expected values of particle penetration factors for this size range. 


\subsubsection{Ozone Penetration}

To capitalize on the effort of the field experiments, the penetration of a reactive gaseous air pollutant, ozone, was examined concurrently with the PM experiments in the study house. An identical experimental protocol was implemented, as described in §5.3.4. Ozone measurements were made with an UV photometric ozone analyzer (Dasibi, Glendale, CA). Particles in the air samples were removed by filtration prior to entering the ozone analyzer to protect the instrument.

Ozone loss due to deposition on indoor surfaces and ozone penetration through the building shell were determined during house pressurization and depressurization, respectively. To compare with previous investigations, the measured ozone deposition coefficient was converted to deposition velocity $\left(v_{d}\right)$ by the following relation:

$$
v_{d}=\frac{k_{d} V}{S}
$$

where $S$ refers to the nominal surface area available for ozone deposition $\left(\mathrm{m}^{2}\right)$. The resulting deposition velocity was in the range of $0.02-0.07 \mathrm{~cm} \mathrm{~s}^{-1}$, which agrees well with previous investigations (Nazaroff et al., 1993). The inferred experimental ozone penetration is nearly unity, suggesting that ambient ozone penetrates completely through building leaks into the residence.

It is unclear how the house is insulated in the wall cavity, and no information is available with respect to how air leakage is distributed in the building envelope. As an estimate, analysis of leakage airflow as a function of crack dimensions for this study house was made assuming that the leakage paths follow the distribution described in 
Chapter 2 when calculating the overall penetration factors ${ }^{18}$. The resulting total leakage airflows for the postulated building crack distribution with crack height range of 0.05-1 $\mathrm{mm}$ and 0.05-2 $\mathrm{mm}$ and a uniform flow path distance of $3 \mathrm{~cm}$ were approximately 350 and $380 \mathrm{~m}^{3} \mathrm{~h}^{-1}$, respectively ${ }^{19}$-nearly $50 \%$ of the infiltrating air was not accounted for ${ }^{20}$. As discussed in Chapter 2, it is not realistic to have leakage paths of small crack heights with extremely long crack width to compensate for the unaccounted leakage airflow. Therefore, it is likely that a significant portion of the total air infiltration arises from air that flowed through orifices or big openings ( $\geq 2 \mathrm{~mm}$ ) in the building shell.

Consider a case in which a certain proportion of ambient air flows through the wall cavity, and the remaining air flows through building cracks. For wall cavities filled with fiberglass insulation, nearly complete ozone penetration would be expected if the fibers previously had accumulated substantial ozone exposure, as summarized by the modeling evidence presented in Chapter 2. For other building leakage paths, ozone penetration through plywood-lined building cracks would range from 0.7 to 1 for crack heights of $0.5-1 \mathrm{~mm}$ and a flow path length of $3 \mathrm{~cm}$. As ozone penetration is governed by the flowrate-weighted penetration from all air leakage paths, small crack heights are expected to have little influence on the overall penetration results. On the other hand, infiltrating air through big openings and orifices would play an important role in bringing ambient ozone into the study house, since ozone removal within such leakage paths is limited by the slow surface kinetics. Thus, nearly complete ozone penetration into this

\footnotetext{
${ }^{18}$ See details on page 37 .

${ }^{19}$ The crack widths as a function of crack heights were bounded by the effective leakage area estimated at $\Delta \mathrm{P}=3 \mathrm{~Pa}$ (page 127).

${ }^{20}$ As a reminder: the house volume is $\sim 332 \mathrm{~m}^{3}$ and the air exchange rate is $\sim 2 \mathrm{~h}^{-1}$.
} 
study house, as determined in the field experiment, is reasonably anticipated from the analysis.

In summary, the observed high ozone penetration through the building envelope of this study house appears to be in good agreement with the above analysis, whether the air infiltrates through the fiberglass insulation or not. As the infiltrating air is dominated by air flowing through orifices and big openings, nearly complete particle penetration would be also expected for this house. From the measurements, however, apparently only $50-90 \%$ particles in the range of $0.02-2 \mu \mathrm{m}$ "penetrate" into the study house. The actual particle penetration might be less than complete as a result of the partial filtration of infiltrating air provided by the fiberglass wall insulation of this study house (§5.4.5). It is also likely that the particle penetration was nearly complete, but appeared less owing to the evaporative loss of PM semi-volatile constituents upon entry of the study house in which the temperature and $\mathrm{RH}$ favored the dissociation, as addressed in §5.4.6. To test these two hypotheses, it would require the inspection of wall insulation by removing the interior walls, as well as more careful experimental work to establish the relationship of phase transformation of semi-volatile species on particles. Some thoughts of how such experiments could proceed will be presented in $§ 6.3 .3$. So far the existing information is not adequate to discern the relative contribution from these two hypotheses to the measured "apparent" penetration factors for this study house.

\subsection{CONCLUSIONS}

Particle penetration factors were quantitatively evaluated for a conventional single-family residence in Clovis, CA during a winter season. A blower door technique 
was applied to sequentially pressurize and depressurize the entire house so that the physical processes of particle penetration and deposition could be studied separately in the experiments. Continuous measurements of indoor and outdoor particle size distributions as well as air exchange rates were performed for four consecutive days, during which the study house was unoccupied, and the doors and windows were all closed. The time-integrated analysis based on a mass-balance equation provides estimates for deposition coefficients and penetration factors. The determined particle deposition coefficients were in a range $\left(0.4-2 \mathrm{~h}^{-1}\right.$ for $\left.0.02-2 \mu \mathrm{m}\right)$ that was consistent with findings of other studies. The apparent resulting whole-house penetration factors were in the range $0.5-0.9$ for $0.02-2 \mu \mathrm{m}$ particles, suggesting that significant penetration loss might have occurred. One plausible explanation for the loss is that a fraction $(\sim 25 \%)$ of the infiltrating air passed through fiberglass insulation in wall cavities, effectively filtering ambient particles. An alternative hypothesis is that the phase transition of volatile species, such as nitrates and water, caused the lower values of "apparent" particle penetration. To consider the second hypothesis, calculations were conducted for four simulated scenarios assuming $20 \%$ nitrate and $0-10 \%$ water content with various mixing characteristics, in order to provide a quantitative estimate of the expected values of penetration factors while accounting for volatilization loss. The results showed that higher particle penetration, close to unity, might have occurred for particle sizes $0.2-2 \mu \mathrm{m}$ when evaporation of nitrate and water in indoor environments is considered.

This winter field study took place in the San Joaquin Valley, with high levels of ambient particulate nitrate. It demonstrates some aspects of the complicated nature of particle transport dynamics from ambient air into the indoor environment. The presence 
of semi-volatile components of ambient particles can cause the apparent particle penetration factor to appear to be less than one if volatilization is not explicitly accounted for. In addition, the evaporation of water on particles may play an important role in the apparent reduction of particle penetration, since abundant water is associated with hygroscopic nitrate and sulfate particles at high RH.

On the other hand, particle penetration might appear unusually high under some circumstances in which significant levels of ambient gaseous ammonia and nitric acid are present during summer. The lower temperature indoors compared to ambient conditions would be expected to shift the equilibrium toward particle formation, potentially resulting in erroneous interpretation of high penetration. Caution should be taken when assessing particle penetration experimentally under conditions where gas-particle conversion can occur.

Additional experimental data pertaining to the size-resolved distribution of volatile constituents (e.g., nitrate, water, and secondary semivolatile organics) associated with fine particles would shed light on the expected values of penetration factors. Moreover, a sophisticated experimental design to accurately measure real-time dynamics of particle nitrate dissociation into gaseous ammonia and nitric acid upon entry of indoor environments would further provide critical insights into the prediction of particle penetration factors, and ultimately, more accurate description of personal exposure indoors to air pollutants of ambient origin. 


\subsection{REFERENCES}

Abt, E., Suh, H.H., Catalano, P., and Koutrakis, P. (2000) Relative contribution of outdoor and indoor particle sources to indoor concentrations, Environmental Science and Technology, 34: 3579-3587.

ASHRAE (1993) ASHRAE Handbook: 1993 Fundamentals, American Society of Heating, Refrigerating, and Air-Conditioning Engineers, Atlanta, Chapter 23.

Byrne, M.A., Goddard, A.J.H., Lange C., and Roed, J. (1995) Stable tracer aerosol deposition measurements in a test chamber, Journal of Aerosol Science, 26: 645-653.

Cheng, Y.S. (1997) Wall deposition of radon progeny and particles in a spherical chamber, Aerosol Science and Technology, 27: 131-146.

Chow, J.C., Watson, J.G., Lowenthal D.H., Solomon, P.A., Magliano, K.L., Ziman, S.D., and Richards, L.W. (1993) $\mathrm{PM}_{10}$ and $\mathrm{PM}_{2.5}$ compositions in California's San Joaquin Valley, Aerosol Science and Technology, 18: 105-128.

Crump J.G., Flagan R.C., and Seinfeld J.H. (1983) Particle wall loss rates in vessels, Aerosol Science And Technology, 2: 303-309.

Fogh C.L., Byrne M.A., Roed J., and Goddard A.J.H. (1997) Size specific indoor aerosol deposition measurements and derived I/O concentrations ratios, Atmospheric Environment, 31: 2193-2203.

Harrison, A.W. (1979) Quiescent boundary layer thickness in aerosol enclosures under convective stirring conditions, Journal of Colloid and Interface Science, 69: 563-570. Hinds, W.C. (1999) Aerosol Technology, $2^{\text {nd }}$ edition, Wiley, New York.

Jaenicke, R. (1993) Tropospheric aerosols, in Aerosol-Cloud-Climate Interactions, edited by P.V. Hobbs, Academic Press, San Diego, CA, pp. 1-31. 
John, W., Wall, S.M., Ondo, J.L., and Winklmayr, W. (1990) Mode in the size distributions of atmospheric inorganic aerosol, Atmospheric Environment, 24A: 23492359.

Junge C. (1950) Das Wachstum der Kondensationskerne mit der relativen Feuchtigkeit, Annalen der Meteorologie, 3: 129-135.

Lai, A.C.K. and Nazaroff, W.W. (2000) Modeling indoor particle deposition from turbulent flow onto smooth surfaces, Journal of Aerosol Science, 31: 463-476.

Long, C.M., Suh, H.H., Catalano, P.J. and Koutrakis, P. (2001) Using time- and sizeresolved particulate data to quantify indoor penetration and deposition behavior, Environmental Scence and Technology, 35: 2089-2099. (See also errata, p. 4584)

Lunden, M.M., Thatcher, T.L., Littlejohn, D., Fisher, M.L., Kirchstetter, T.W., Hering, S.V., Stolzenburg, M., and Brown, N.J. (2001) Building a predictive model of indoor concentrations of outdoor PM-2.5 in homes, Report LBNL-48929, Lawrence Berkeley National Laboratory, Berkeley, CA.

Mosley, R.B., Greenwell, D.J., Sparks, L.E., Guo, Z., Tucker, W.G., Fortmann, R., Whitfield, C., (2001) Penetration of ambient fine particles into the indoor environment, Aerosol Science and Technology, 34: 127-136.

Nazaroff, W.W., and Cass, G.R. (1989) Mass-transport aspects of pollutant removal at indoor surfaces, Environmental International, 15: 567-584.

Nazaroff, W.W., Gadgil, A.J., and Weschler, C.J. (1993) Critique of the use of deposition velocity in modeling indoor air quality, in Nagda, N.L. (ed.), Modeling of Indoor Air Quality and Exposure, ASTM STP 1205, American Society for Testing and Materials, Philadelphia, pp 81-104. 
Okuyama, K., Kousaka, Y., Yamamoto, S., and Hosokawa, T. (1986) Particle loss of aerosols with particle diameters between 6 and $2000 \mathrm{~nm}$ in stirred tank, Journal of Colloid and Interface Science, 110: 214-223.

Özkaynak, H., Xue, J., Spengler, J., Wallace, L., Pellizzari, E., and Jenkins, P. (1996) Personal exposure to airborne particles and metals: Results from the Particle TEAM study in Riverside, California, Journal of Exposure Analysis and Environmental Epidemiology, 6: 57-78.

Pope, C.A., Burnett, R.T., Thun, M.J., Calle, E.E., Krewski, D., Ito, K. and Thurston, G.D. (2002) Lung cancer, cardiopulmonary mortality, and long-term exposure to fine particulate air pollution, Journal of American Medical Association, 287: 11321141.

Schauer, J.J. and Cass, G.R. (2000) Source apportionment of wintertime gas-phase and particle-phase air pollutants using organic compounds as tracers, Environmental Science and Technology, 34: 1821-1832.

Seinfeld, J.H. and Pandis, S.N. (1998) Atmospheric Chemistry and Physics, Wiley, New York.

Sherman, M.H. and Matson, N.E. (1997) Residential ventilation and energy characteristics, ASHRAE Transactions, 103: 717-730; Report LBNL-39036, Lawrence Berkeley National Laboratory, Berkeley, CA.

Stolzenburg, M.R. and Hering, S.V. (2000) Method for the automated measurement of fine particle nitrate in the atmosphere, Environmental Science and Technology, 34: 907-914.

Thatcher, T.L. and Layton, D.W. (1995) Deposition, resuspension, and penetration of 
particles within a residence, Atmospheric Environment, 29: 1487-1497.

Thatcher, T.L., Fairchild, W.A., and Nazaroff, W.W. (1996) Particle deposition from natural convection enclosure flow onto smooth surfaces, Aerosol Science and Technology, 25: 359-374.

Thatcher, T.L. and Nazaroff, W.W. (1997) Effect of small-scale obstructions and surface textures on particle deposition from natural convection flow, Aerosol Science and Technology, 27: 709-725.

Thatcher, T.L., Lai, A.C.K., Moreno-Jackson, R., Sextro, R.G., and Nazaroff, W.W. (2002) Effects of room furnishings and air speed on particle deposition rate indoors, Atmospheric Environment, 36: 1811-1819.

Vette, A.F., Rea, A.W., Lawless, P.A., Rodes, C.E., Evans, G., Highsmith, V.R., and Sheldon, L. (2001) Characterization of indoor-outdoor aerosol concentration relationships during the Fresno PM exposure studies, Aerosol Science and Technology, 34: 118-126.

Watson, J.G., Chow, J.C., Bowen, J. L., Lowenthal, D.H., Hering, S.V., Ouchida, P., and Oslund, W. (2000) Air quality measurements from the Fresno Supersite, Journal of Air and Waste Management Association, 50: 1321-1334.

Xu, M.D., Nematollahi, M., Sextro, R.G., Gadgil, A.J., and Nazaroff, W.W. (1994) Deposition of tobacco smoke particles in a low ventilation room, Aerosol Science and Technology, 20: 194-206.

Zhang, X.Q., McMurry, P.H., Hering, S.V., and Casuccio, G.S. (1993) Mixing characteristics and water content of submicron aerosols measured in Los Angeles and at the Grand Canyon, Atmospheric Environment, 27A: 1593-1607. 
Table 5.1 Summary of previous field studies reporting particle penetration measurements

\begin{tabular}{|c|c|c|c|c|c|c|}
\hline Investigators & $\begin{array}{l}\text { Area } \\
\text { studied }\end{array}$ & $\begin{array}{l}\text { No. houses } \\
\text { studied }\end{array}$ & $\begin{array}{l}\text { Season } \\
\text { studied }\end{array}$ & $\begin{array}{l}\text { Particle size } \\
\text { measured }\end{array}$ & $\begin{array}{l}\text { Penetration } \\
\text { factor }\end{array}$ & $\begin{array}{l}\text { Assumed } \\
\text { steady state? }\end{array}$ \\
\hline $\begin{array}{l}\text { Özkaynak et } \\
\text { al., } 1996\end{array}$ & $\begin{array}{l}\text { Riverside, } \\
\text { CA }\end{array}$ & 178 & fall, 1990 & $\begin{array}{l}\mathrm{PM}_{2.5} \text { and } \\
\mathrm{PM}_{10}\end{array}$ & $\sim 1$ & yes \\
\hline $\begin{array}{l}\text { Long et al., } \\
2001\end{array}$ & Boston, MA & 9 & $\begin{array}{l}\text { all seasons, } \\
1998\end{array}$ & $0.02-10 \mu \mathrm{m}$ & $0.2-1.1$ & yes \\
\hline $\begin{array}{l}\text { Thatcher and } \\
\text { Layton, } 1995\end{array}$ & $\begin{array}{l}\text { Livermore, } \\
\mathrm{CA}\end{array}$ & 1 & $\begin{array}{l}\text { summer, } \\
1993\end{array}$ & $1-25 \mu \mathrm{m}$ & $\sim 1$ & yes \\
\hline $\begin{array}{l}\text { Vette et al., } \\
2001\end{array}$ & Fresno, CA & 1 & $\begin{array}{l}\text { winter and } \\
\text { spring, } \\
1999\end{array}$ & $0.01-2.5 \mu \mathrm{m}$ & $0.5-0.9$ & yes \\
\hline $\begin{array}{l}\text { Lunden, et } \\
\text { al., } 2001\end{array}$ & $\begin{array}{l}\text { Richmond, } \\
\text { CA }\end{array}$ & 1 & $\begin{array}{l}\text { summer, } \\
2001\end{array}$ & $0.1-10 \mu \mathrm{m}$ & $\sim 1$ & no \\
\hline
\end{tabular}


Table 5.2 Summary of the monitoring durations and measured airexchange rates for the pressurization and depressurization experiments in the Clovis study house

\begin{tabular}{|c|c|c|c|c|}
\hline Date & Monitoring duration & $\mathrm{p} / \mathrm{dp}^{\mathrm{a}}$ & Symbol & Air-exchange rate, $\mathrm{h}^{-1}$ \\
\hline 27-Jan & $6: 39 \mathrm{pm} \sim 1: 12 \mathrm{am}$ & $\mathrm{p}$ & jan27p1 & 2.24 \\
\hline 28-Jan & $1: 56 \mathrm{am} \sim 10: 11 \mathrm{am}$ & $\mathrm{dp}$ & jan27dp1 & 2.48 \\
\hline 28-Jan & $11: 24 \mathrm{am} \sim 3: 50 \mathrm{pm}$ & $\mathrm{dp}$ & jan28dp1 & 2.12 \\
\hline 28-Jan & $4: 34 \mathrm{pm} \sim 10: 10 \mathrm{pm}$ & $\mathrm{p}$ & jan28p1 & 2.15 \\
\hline 28-Jan & $10: 34 \mathrm{pm} \sim 3 \mathrm{am}$ & $\mathrm{p}$ & jan28p2 & 2.66 \\
\hline 29-Jan & $3: 30 \mathrm{am} \sim 10 \mathrm{am}$ & $\mathrm{p}$ & jan29p1 & 2.55 \\
\hline 29-Jan & $10: 16 \mathrm{am} \sim 4: 30 \mathrm{pm}$ & $\mathrm{dp}$ & jan29dp1 & 2.70 \\
\hline 29-Jan & $5: 30 \mathrm{pm} \sim 9: 40 \mathrm{pm}$ & $\mathrm{p}$ & jan29p2 & 3.39 \\
\hline 29-Jan & $10: 00 \mathrm{pm} 2: 08 \mathrm{am}$ & $\mathrm{dp}$ & jan29dp2 & 1.78 \\
\hline 30-Jan & 2:20 am 9:00 am & $\mathrm{p}$ & jan30p1 & 2.70 \\
\hline 30-Jan & $10: 22 \mathrm{am} \sim 3: 10 \mathrm{pm}$ & $\mathrm{dp}$ & jan30dp1 & 2.01 \\
\hline 30-Jan & $4: 30 \mathrm{pm} \sim 9 \mathrm{pm}$ & $\mathrm{dp}$ & jan30dp2 & 1.95 \\
\hline 30-Jan & $9: 10 \mathrm{pm} \sim 2 \mathrm{am}$ & $\mathrm{p}$ & jan30p2 & 2.22 \\
\hline 31-Jan & $2: 22 \mathrm{am} \sim 9: 15 \mathrm{am}$ & $\mathrm{p}$ & jan31p1 & 2.17 \\
\hline 31-Jan & $9: 26 \mathrm{am} \sim 4: 06 \mathrm{pm}$ & $\mathrm{dp}$ & jan31dp1 & 2.14 \\
\hline \multicolumn{5}{|c|}{ Summary of statistics } \\
\hline & & $\begin{array}{l}\mathrm{p} \\
\mathrm{dp}\end{array}$ & & $\begin{array}{c}\text { Average } \pm \text { S.D. } \\
2.4 \pm 0.2 \\
2.2 \pm 0.3\end{array}$ \\
\hline & & $t$-test & & $p>0.1^{\mathrm{c}}$ \\
\hline
\end{tabular}

${ }^{\mathrm{a}} \mathrm{p}$ and dp refer to pressurization and depressurization, respectively.

b this data was discarded due to higher air-exchange rate than other experiments.

${ }^{c}$ the air-exchange rates do not appear to be significantly different for pressurization and depressurization according to the $t$-test. 
Table 5.3(a) Particle deposition coefficients, determined from the EAA measurements, as a function of particle size from each pressurization experiment

\begin{tabular}{|c|c|c|c|c|c|c|c|}
\hline Particle diameter, $\mu_{\mathrm{m}}$ & 0.024 & 0.042 & 0.075 & 0.133 & 0.237 & 0.422 & 0.75 \\
\hline Pressurization tests & \multicolumn{7}{|c|}{ Particle deposition loss coefficient $\left(\mathrm{h}^{-1}\right)$, time-integrated+transient terms } \\
\hline $\operatorname{jan} 27 \mathrm{p} 1^{\mathrm{a}}$ & 0.77 & 0.33 & 0.54 & 0.50 & 0.40 & 0.41 & 0.37 \\
\hline $\mathrm{jan} 28 \mathrm{p} 1^{\mathrm{a}}$ & 0.70 & 0.54 & 0.58 & 0.54 & 0.49 & 0.47 & 0.51 \\
\hline $\mathrm{jan} 28 \mathrm{p} 2^{\mathrm{b}}$ & 0.89 & 0.74 & 0.60 & 0.56 & 0.58 & 0.64 & 0.67 \\
\hline jan29p1 & 1.12 & 0.65 & 0.53 & 0.53 & 0.62 & 0.69 & 0.41 \\
\hline $\operatorname{jan} 29 \mathrm{p} 2^{c}$ & 1.48 & 1.56 & 1.64 & 1.38 & 1.27 & 1.28 & 1.08 \\
\hline jan30p1 & 0.89 & 0.81 & 0.62 & 0.75 & 0.70 & 0.68 & 0.43 \\
\hline $\operatorname{jan} 30 \mathrm{p} 2^{\mathrm{b}}$ & 0.43 & 0.40 & 0.24 & 0.22 & 0.29 & 0.40 & 0.37 \\
\hline jan31p1 & 0.82 & 1.12 & 0.48 & 0.54 & 0.57 & 0.59 & 0.46 \\
\hline \multirow[t]{2}{*}{ Average } & $0.80 \pm 0.21$ & $0.65 \pm 0.27$ & $0.51 \pm 0.13$ & $0.52 \pm 0.16$ & $0.52 \pm 0.14$ & $0.55 \pm 0.12$ & $0.46 \pm 0.11$ \\
\hline & \multicolumn{7}{|c|}{ Particle deposition loss coefficient $\left(\mathrm{h}^{-1}\right)$, time-integrated terms } \\
\hline jan27p1 & 0.72 & 0.37 & 0.60 & 0.60 & 0.53 & 0.57 & 0.51 \\
\hline jan28p1 & 0.84 & 0.76 & 0.85 & 0.83 & 0.76 & 0.71 & 0.73 \\
\hline $\mathrm{jan} 28 \mathrm{p} 2^{\mathrm{a}}$ & 0.69 & 0.50 & 0.32 & 0.26 & 0.28 & 0.35 & 0.38 \\
\hline jan29p1 & 1.19 & 0.65 & 0.48 & 0.44 & 0.53 & 0.60 & 0.35 \\
\hline $\operatorname{jan} 29 \mathrm{p} 2^{\mathrm{c}}$ & 1.56 & 1.66 & 1.72 & 1.45 & 1.32 & 4.34 & 4.12 \\
\hline jan30p1 & 0.72 & 0.49 & 0.51 & 0.72 & 0.70 & 0.67 & 0.44 \\
\hline $\operatorname{jan} 30 \mathrm{p} 2^{\mathrm{a}}$ & 0.28 & 0.24 & 0.08 & 0.06 & 0.14 & 0.26 & 0.23 \\
\hline jan31p1 & 0.71 & 0.74 & 0.29 & 0.37 & 0.43 & 0.45 & 0.33 \\
\hline Average & $0.74 \pm 0.27$ & $0.53 \pm 0.19$ & $0.45 \pm 0.25$ & $0.47 \pm 0.27$ & $0.48 \pm 0.22$ & $0.55 \pm 0.17$ & $0.43 \pm 0.16$ \\
\hline
\end{tabular}


Table 5.3(b) Particle deposition coefficients, determined from the APS measurements, as a function of particle size from each pressurization experiment

\begin{tabular}{|c|c|c|c|c|c|c|c|c|c|c|}
\hline \multirow{2}{*}{$\begin{array}{c}\text { Particle } \\
\text { diameter, } \mu_{\mathrm{m}}\end{array}$} & \multicolumn{5}{|c|}{$k_{d}$, time-integrated+transient terms } & \multicolumn{5}{|c|}{$k_{d}$, time-integrated term } \\
\hline & $\operatorname{ian} 27 \mathrm{p} 1^{\mathrm{a}}$ & $\operatorname{jan} 28 \mathrm{p} 1^{\mathrm{a}}$ & $\operatorname{jan} 28 \mathrm{p} 2^{\mathrm{b}}$ & $\operatorname{jan} 30 \mathrm{p} 2^{\mathrm{b}}$ & Average & $\operatorname{jan} 27 \mathrm{p} 1^{\mathrm{a}}$ & $\operatorname{jan} 28 \mathrm{p} 1^{\mathrm{a}}$ & $\operatorname{ian} 28 \mathrm{p} 2^{\mathrm{b}}$ & $\operatorname{ian} 30 \mathrm{p} 2^{\mathrm{b}}$ & Average \\
\hline 0.542 & 0.40 & 0.78 & 1.11 & 0.60 & $0.72 \pm 0.30$ & 0.53 & 1.13 & 0.99 & 0.78 & $0.86 \pm 0.26$ \\
\hline 0.583 & 0.41 & 0.85 & 1.12 & 0.60 & $0.74 \pm 0.31$ & 0.54 & 1.20 & 1.02 & 0.78 & $0.89 \pm 0.29$ \\
\hline 0.626 & 0.41 & 0.94 & 1.12 & 0.61 & $0.77 \pm 0.32$ & 0.54 & 1.29 & 1.06 & 0.79 & $0.92 \pm 0.32$ \\
\hline 0.673 & 0.40 & 0.97 & 1.09 & 0.64 & $0.77 \pm 0.31$ & 0.54 & 1.31 & 1.08 & 0.83 & $0.94 \pm 0.31$ \\
\hline 0.723 & 0.38 & 0.93 & 1.08 & 0.69 & $0.77 \pm 0.30$ & 0.53 & 1.26 & 1.09 & 0.89 & $0.94 \pm 0.31$ \\
\hline 0.777 & 0.35 & 0.88 & 1.05 & 0.78 & $0.72 \pm 0.30$ & 0.51 & 1.19 & 1.08 & 0.97 & $0.94 \pm 0.30$ \\
\hline 0.835 & 0.32 & 0.85 & 1.03 & 0.84 & $0.76 \pm 0.31$ & 0.49 & 1.14 & 1.06 & 1.04 & $0.93 \pm 0.30$ \\
\hline 0.898 & 0.31 & 0.78 & 1.04 & 0.92 & $0.76 \pm 0.32$ & 0.47 & 1.05 & 1.05 & 1.07 & $0.91 \pm 0.29$ \\
\hline 0.965 & 0.30 & 0.75 & 1.08 & 0.91 & $0.76 \pm 0.34$ & 0.46 & 1.02 & 1.07 & 1.06 & $0.90 \pm 0.29$ \\
\hline 1.037 & 0.29 & 0.66 & 1.12 & 0.91 & $0.74 \pm 0.36$ & 0.46 & 0.90 & 1.12 & 1.07 & $0.89 \pm 0.30$ \\
\hline 1.114 & 0.30 & 0.63 & 1.14 & 0.94 & $0.75 \pm 0.37$ & 0.48 & 0.86 & 1.12 & 1.10 & $0.89 \pm 0.30$ \\
\hline 1.197 & 0.26 & 0.53 & 1.14 & 0.97 & $0.72 \pm 0.40$ & 0.43 & 0.73 & 1.11 & 1.14 & $0.85 \pm 0.34$ \\
\hline 1.286 & 0.26 & 0.51 & 1.18 & 0.98 & $0.73 \pm 0.42$ & 0.43 & 0.72 & 1.15 & 1.15 & $0.86 \pm 0.35$ \\
\hline 1.382 & 0.29 & 0.60 & 1.03 & 1.01 & $0.73 \pm 0.36$ & 0.47 & 0.79 & 1.02 & 1.18 & $0.86 \pm 0.31$ \\
\hline 1.486 & 0.19 & 0.60 & 1.16 & 1.22 & $0.79 \pm 0.49$ & 0.38 & 0.78 & 1.18 & 1.40 & $0.93 \pm 0.45$ \\
\hline 1.596 & 0.39 & 0.61 & 1.00 & 1.42 & $0.86 \pm 0.45$ & 0.57 & 0.80 & 1.02 & 1.61 & $1.00 \pm 0.45$ \\
\hline 1.715 & 0.26 & 0.65 & 0.85 & 1.77 & $0.88 \pm 0.64$ & 0.45 & 0.79 & 0.89 & 1.97 & $1.02 \pm 0.66$ \\
\hline 1.843 & 0.30 & 0.74 & 0.87 & 2.00 & $0.98 \pm 0.73$ & 0.53 & 0.90 & 0.91 & 2.19 & $1.13 \pm 0.73$ \\
\hline 1.981 & 0.23 & 0.67 & 0.69 & 2.22 & $0.95 \pm 0.87$ & 0.47 & 0.85 & 0.85 & 2.38 & $1.14 \pm 0.85$ \\
\hline
\end{tabular}


Table 5.4 The parameters of the lognormal distributions used for fitting the outdoor and indoor particle size distributions at noon, January 30, 2001

\begin{tabular}{|c|c|c|c|c|c|c|}
\hline & \multirow[b]{2}{*}{$N_{i}, \mathrm{~cm}^{-3}$} & \multicolumn{2}{|l|}{ Outdoor } & \multirow[b]{2}{*}{$N_{i}, \mathrm{~cm}^{-3}$} & \multicolumn{2}{|l|}{ Indoor } \\
\hline & & ${\overline{d_{p i}}}, \mu \mathrm{m}$ & $\log \sigma_{i}$ & & $\overline{d_{p i}}, \mu \mathrm{m}$ & $\log \sigma$ \\
\hline Mode I & $2.86 \times 10^{3}$ & 0.0082 & 0.225 & $1.71 \times 10^{3}$ & 0.084 & 0.238 \\
\hline Mode II & $2.50 \times 10^{2}$ & 0.238 & 0.233 & $1.05 \times 10^{2}$ & 0.238 & 0.233 \\
\hline Mode III & $2.35 \times 10^{4}$ & 0.0095 & 0.241 & $3.36 \times 10^{3}$ & 0.0142 & 0.185 \\
\hline
\end{tabular}

Table 5.5 The parameters of the lognormal distributions used for fitting the outdoor and indoor particle size distributions determined from January 30 morning data.

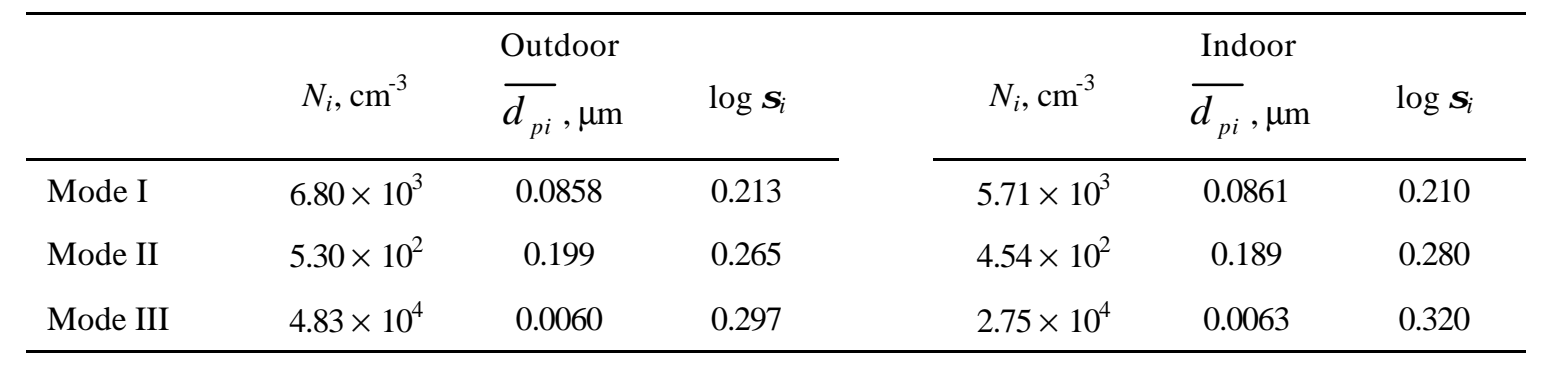




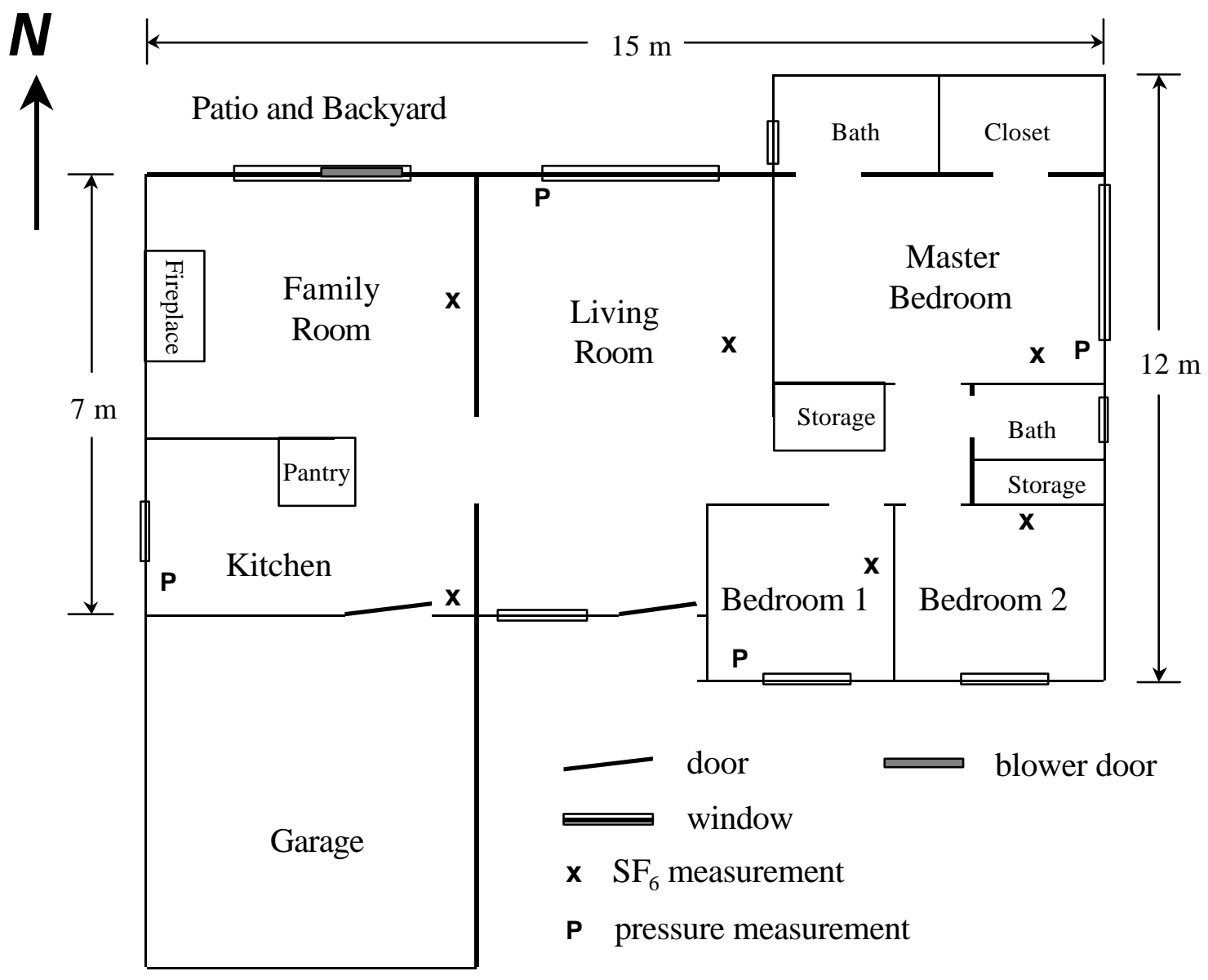

Figure 5.1 Floor plan of the Clovis study residence. 


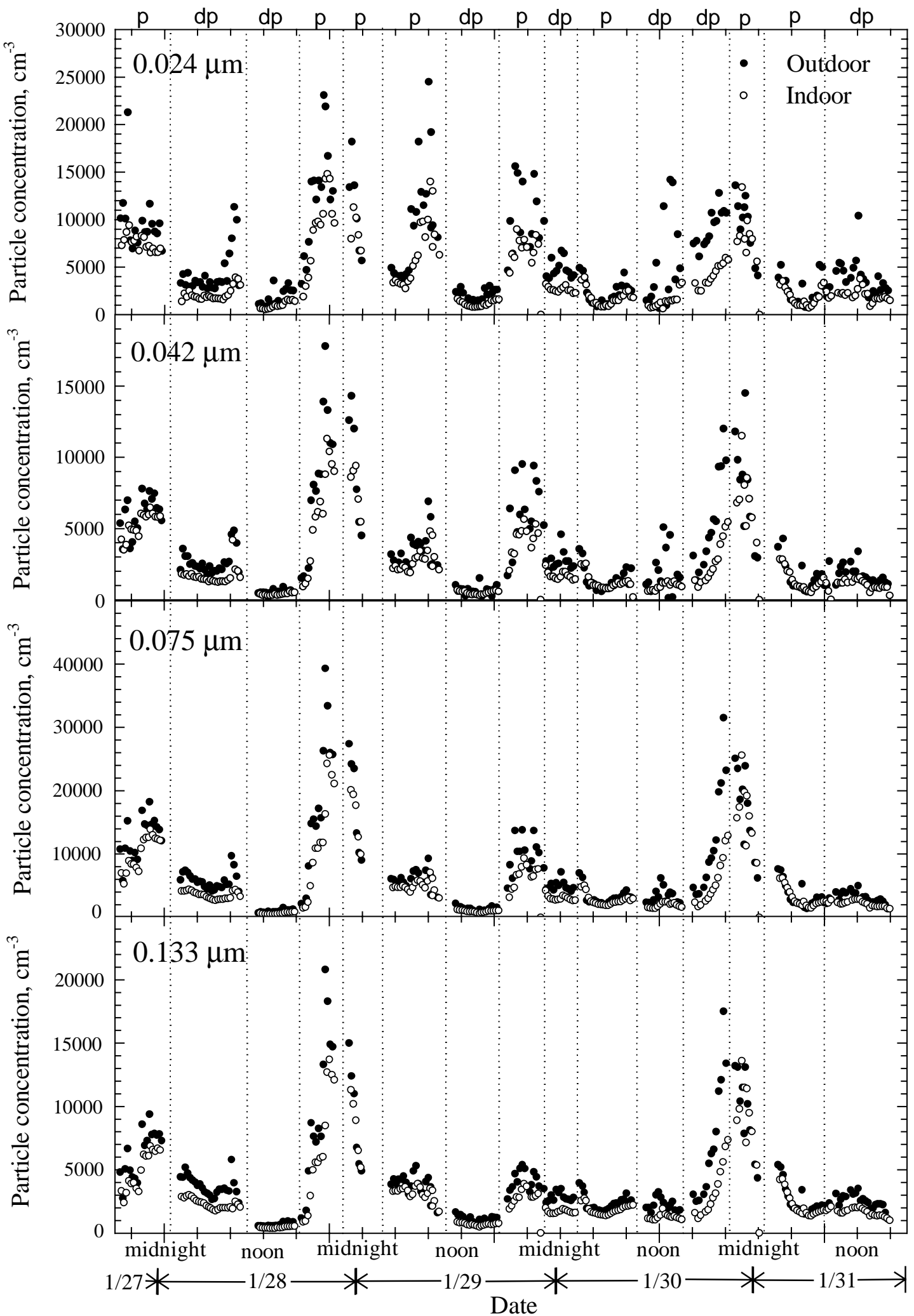

Figure 5.2(a) Outdoor and indoor particle concentration profiles measured by the EAA for mean particle diameters of $0.024,0.042,0.075$, and $0.133 \mu \mathrm{m}$ during the sampling period (Jan. 27 to 31). Periods of pressurization (p) and depressurization $(\mathrm{dp})$ of the house are indicated on the top. 


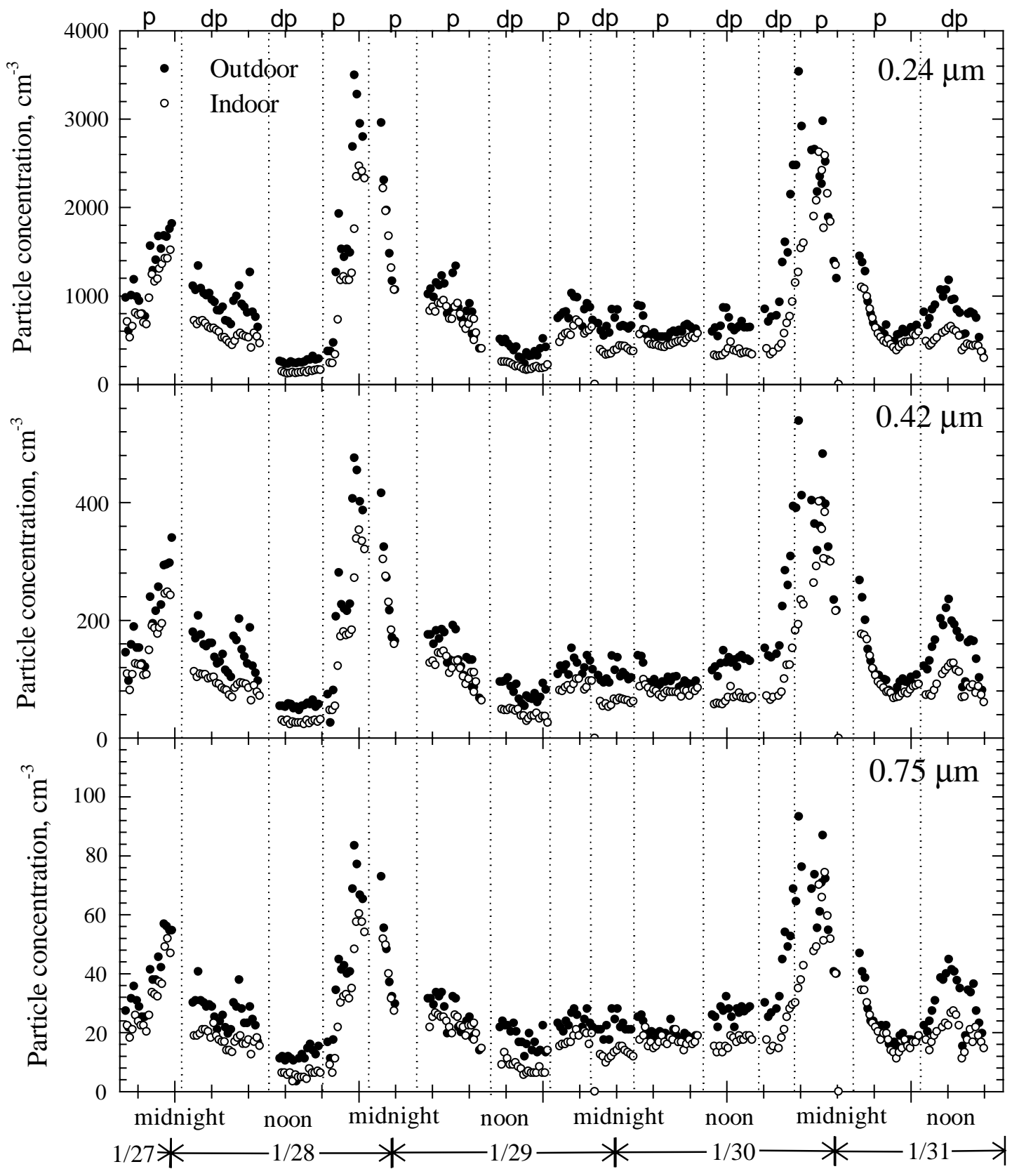

Date

Figure 5.2(b) Outdoor and indoor particle concentration profiles measured by the EAA for mean particle diameters of $0.24,0.42$, and $0.75 \mu \mathrm{m}$ during the sampling period (Jan. 27 to 31). Periods of pressurization (p) and depressurization (dp) of the house are indicated on the top. 


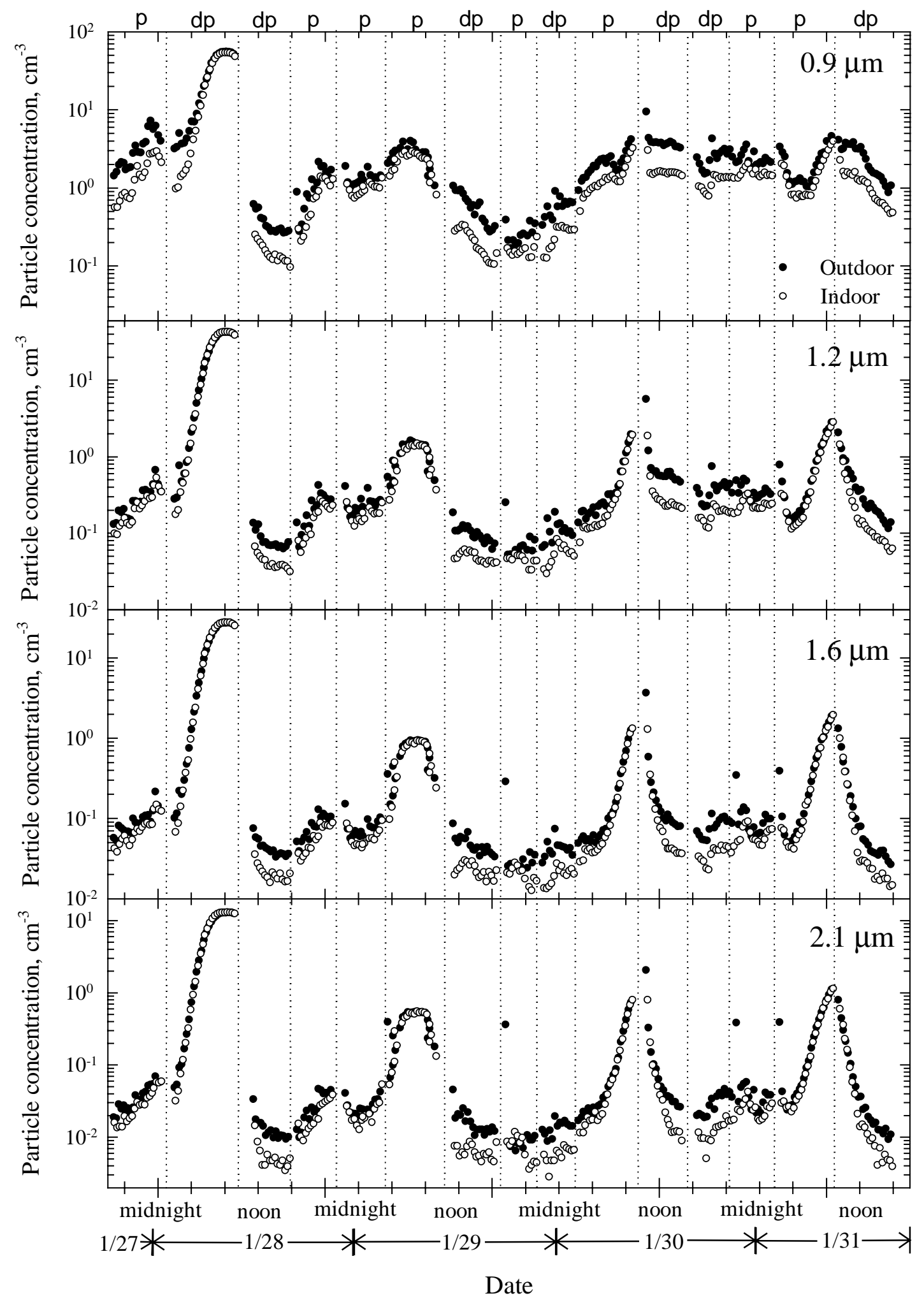

Figure 5.2(c) Outdoor and indoor particle concentration profiles measured by the APS for particle diameters of $0.9,1.2,1.6$, and $2.1 \mu \mathrm{m}$ during the sampling period (Jan. 27 to 31). Periods of pressurization (p) and depressurization (dp) of the house are indicated on the top. 


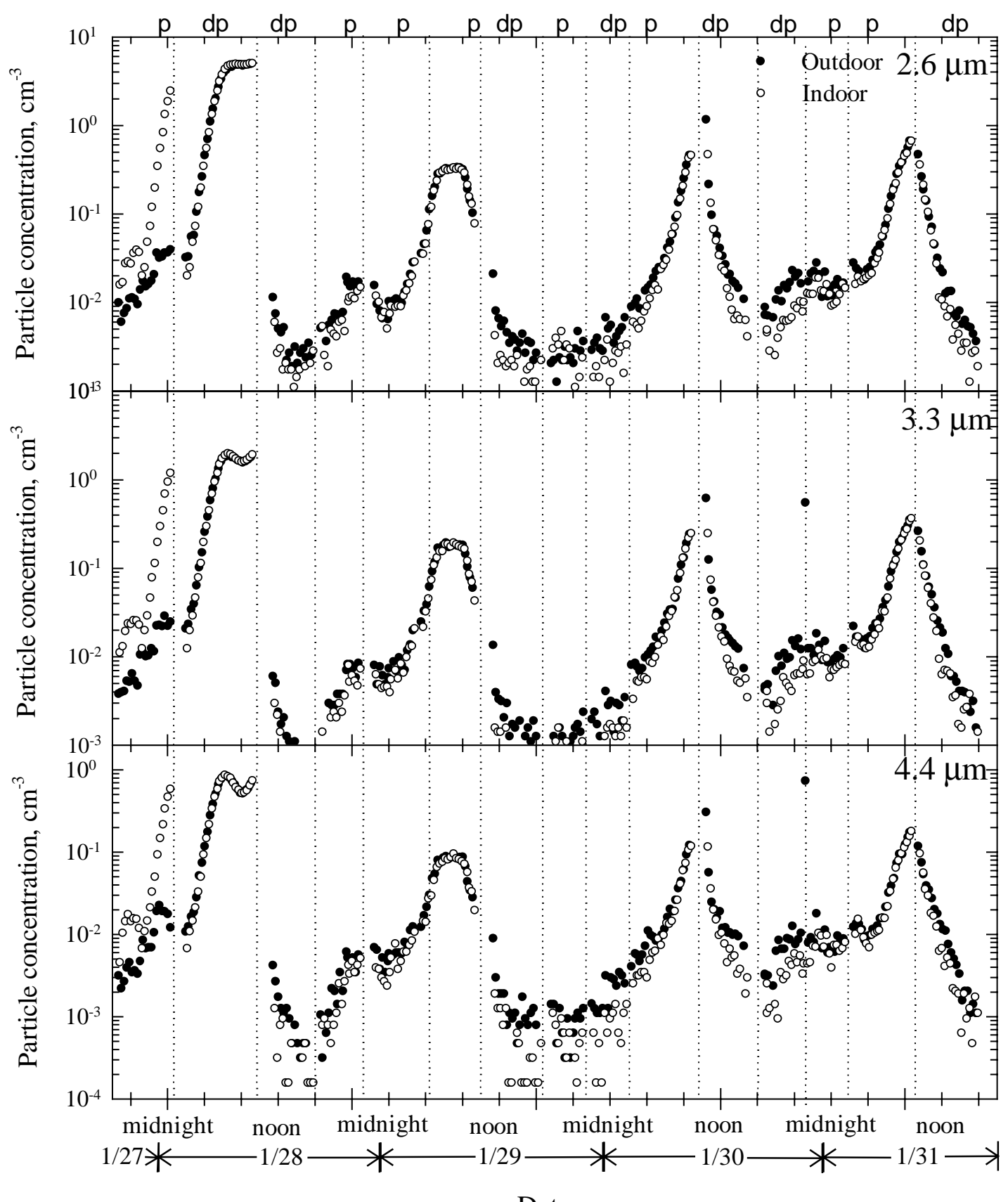

Date

Figure 5.2(d) Outdoor and indoor particle concentration profiles measured by the APS for particle diameters of 2.6, 3.3, and $4.4 \mu \mathrm{m}$ during the sampling period (Jan. 27 to 31). Periods of pressurization (p) and depressurization (dp) of the house are indicated on the top. 
(a)
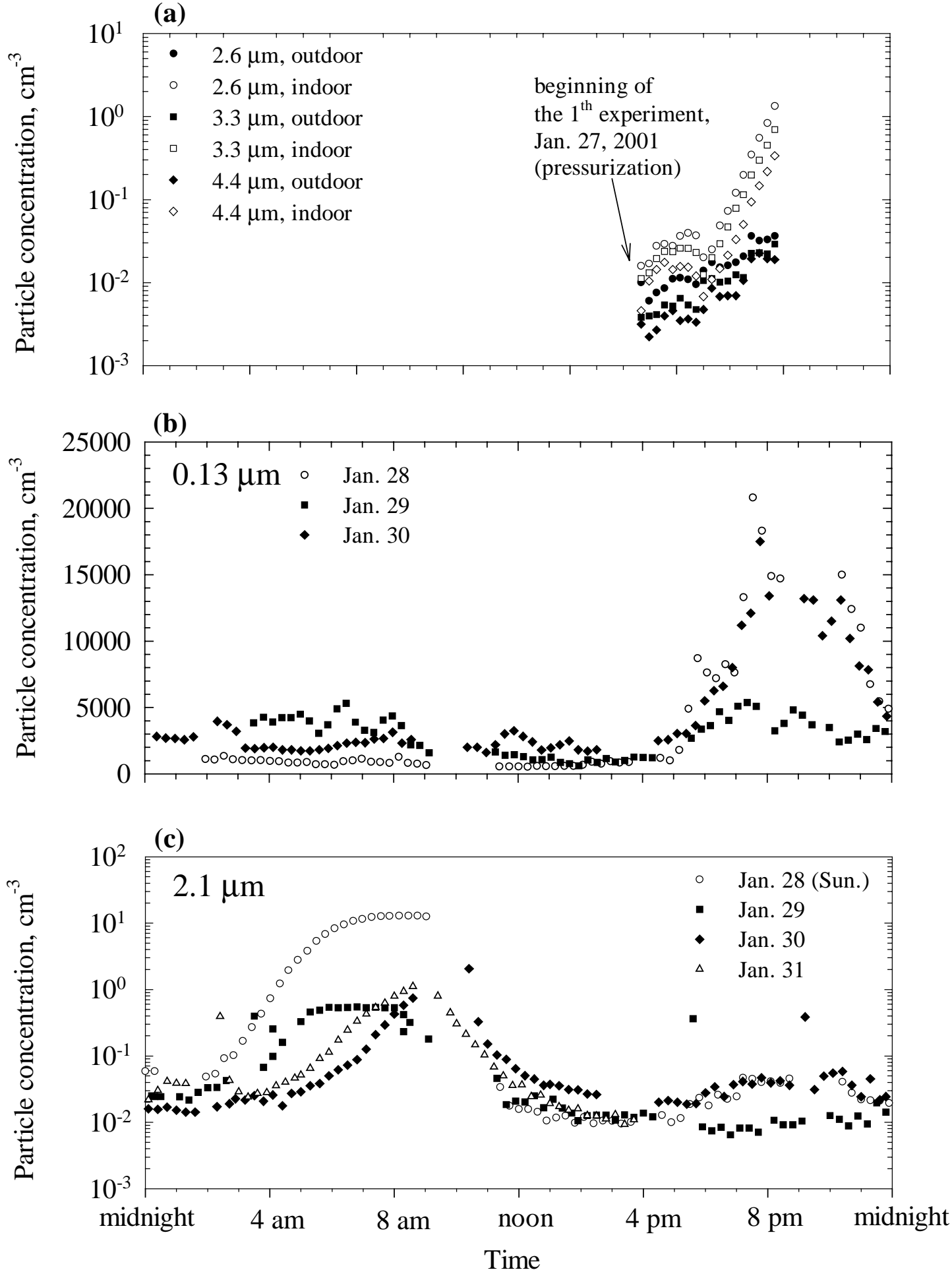

Figure 5.3 Particle concentration profiles for (a) the unusual indoor particle concentration rise at the first pressurization test; (b) the elevated submicron particle concentration outdoors at night; (c) the supermicron outdoor particle concentration peaks during morning rush hours. 
(a)

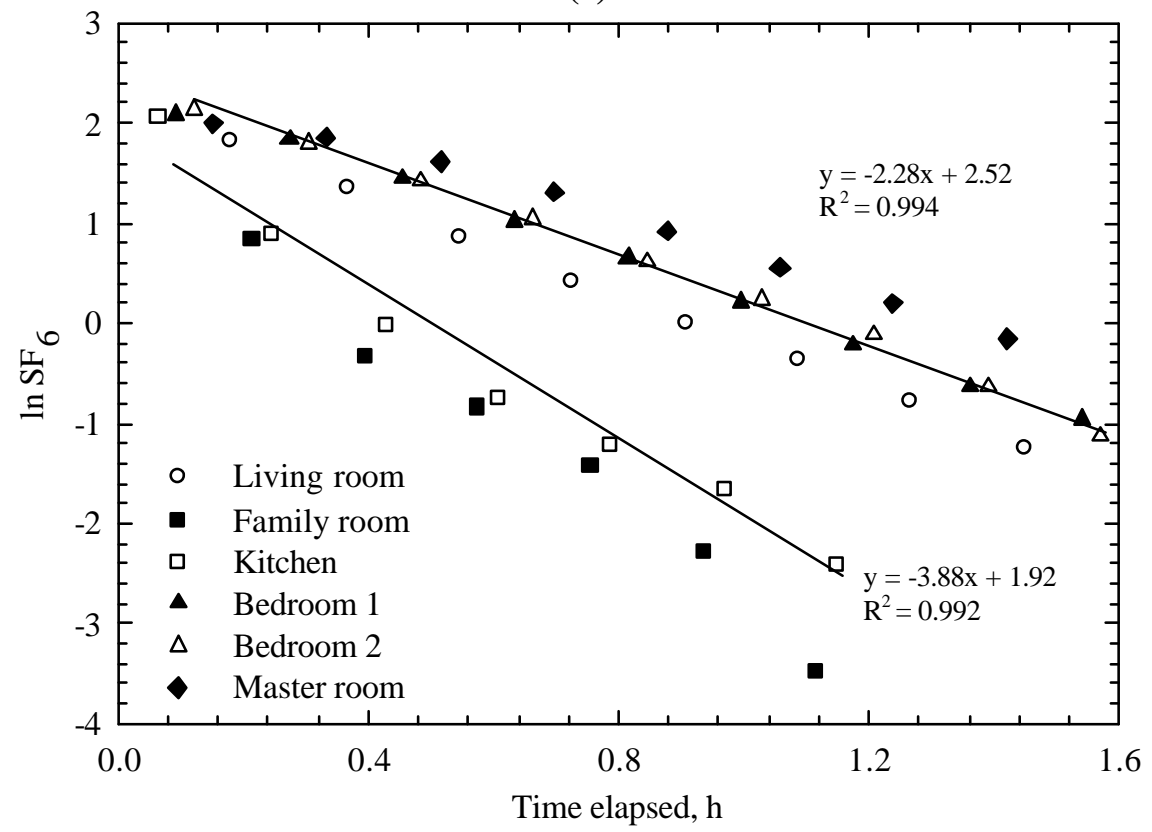

(b)

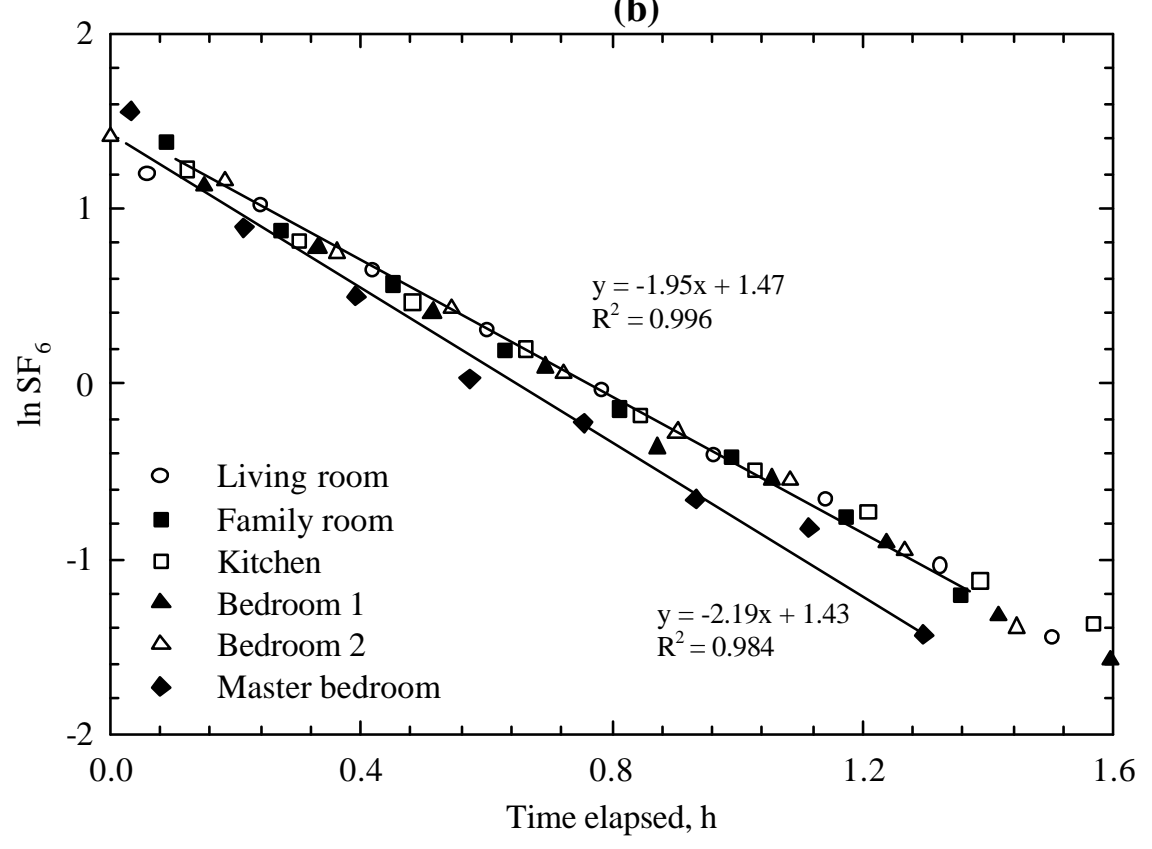

Figure 5.4 The $\mathrm{SF}_{6}$ concentration profiles versus time for various zones in the study house during (a) pressurization and (b) depressurization on January 30, 2001. The $\mathrm{SF}_{6}$ removal rates correspond to the absolute value of the slope and correlation coefficients $\left(\mathrm{R}^{2}\right)$ are indicated. 


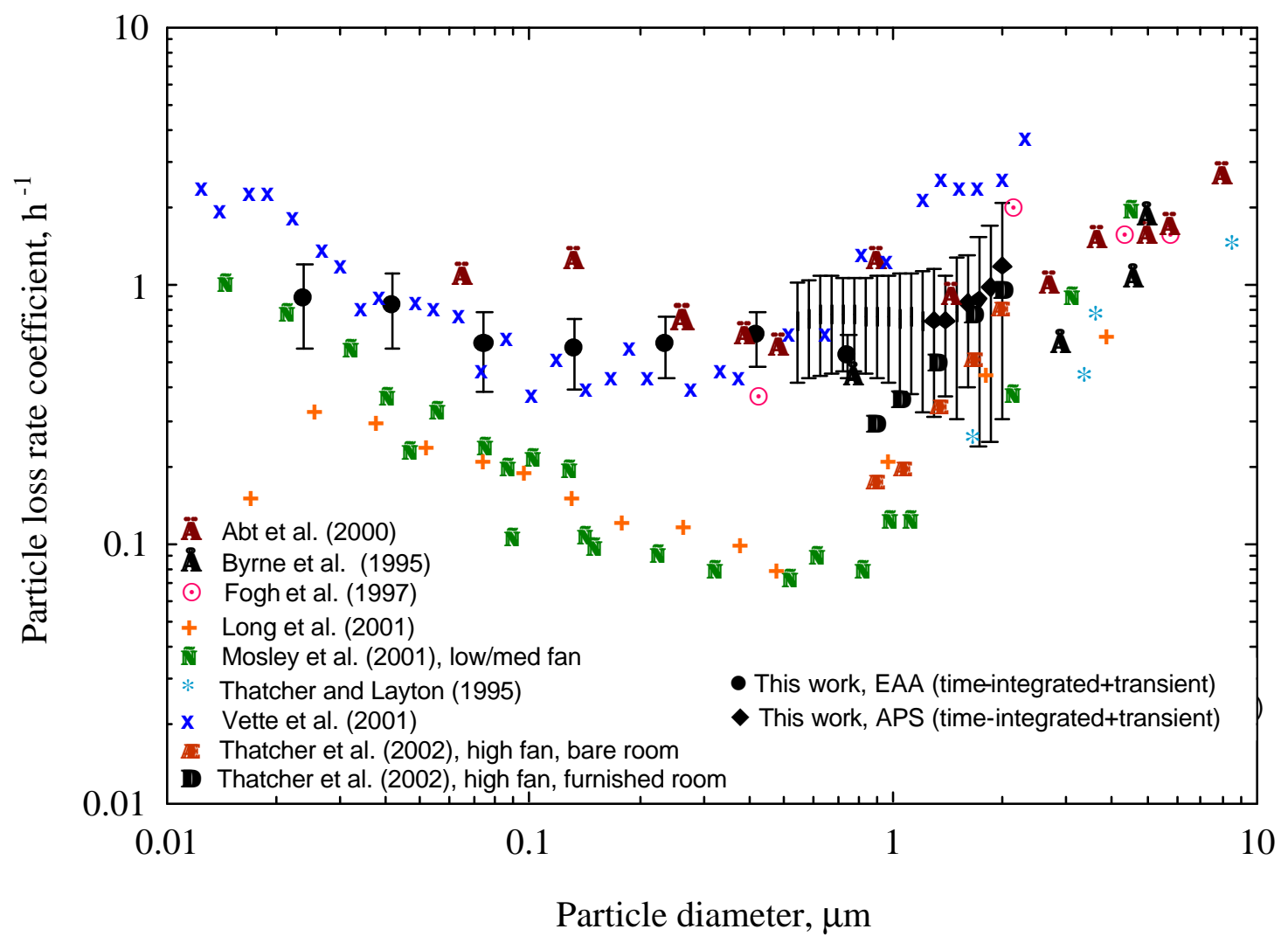

Figure 5.5 Comparison of particle deposition coefficients determined from this study to past investigations, as represented with various symbols in the lower left. 

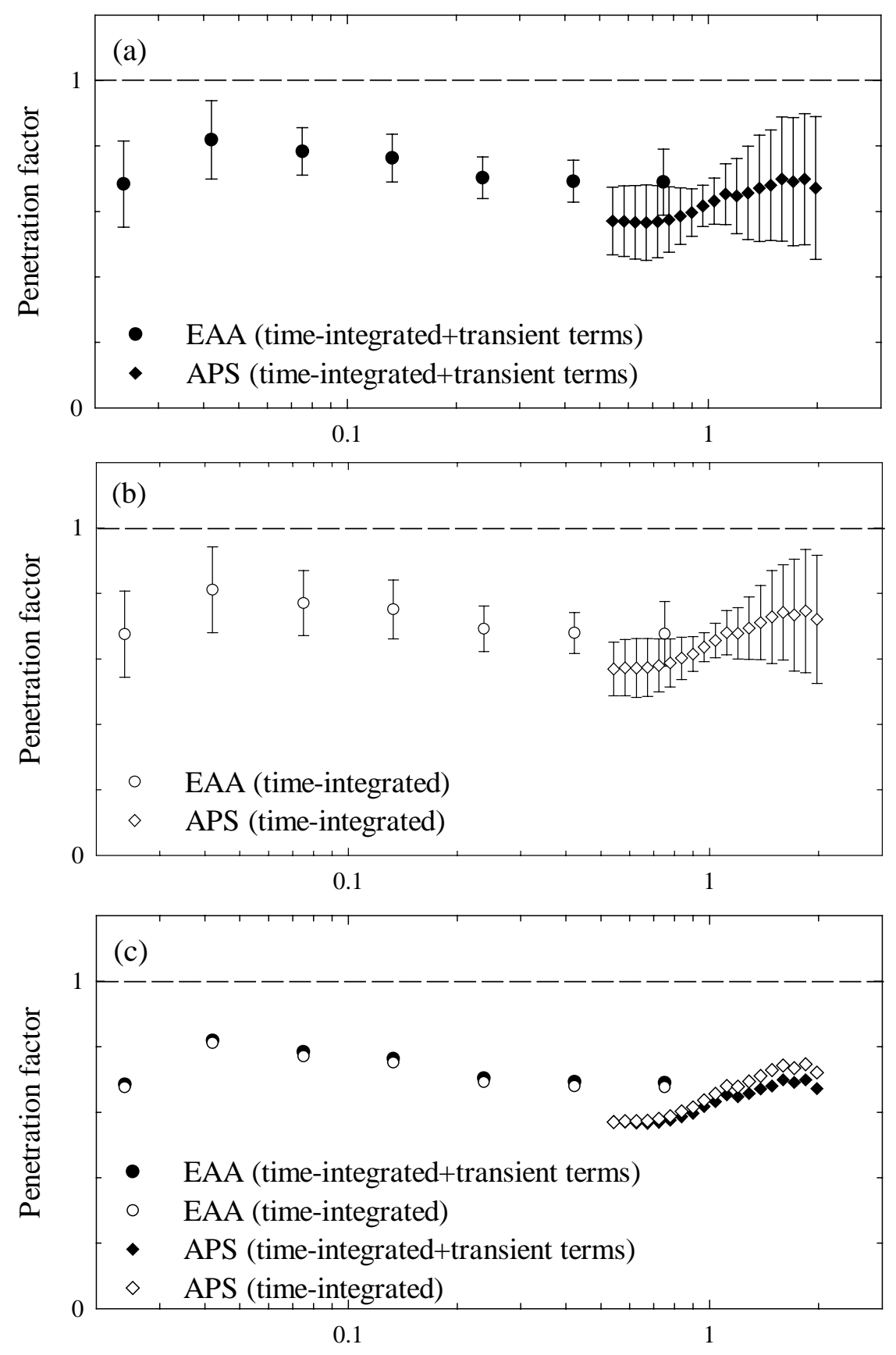

Particle diameter, $\mu \mathrm{m}$

Figure 5.6 Particle penetration factors based on particle deposition coefficients presented in Table 5.3. (a) solid symbols represent average penetration factors from combined time-integrated and transient analysis with error bars of one standard deviation; (b) the open symbols and the error bars represent the average values of penetration factor and one standard deviation from time-integrated analysis; (c) comparison of the average penetration factors from the two approaches. 


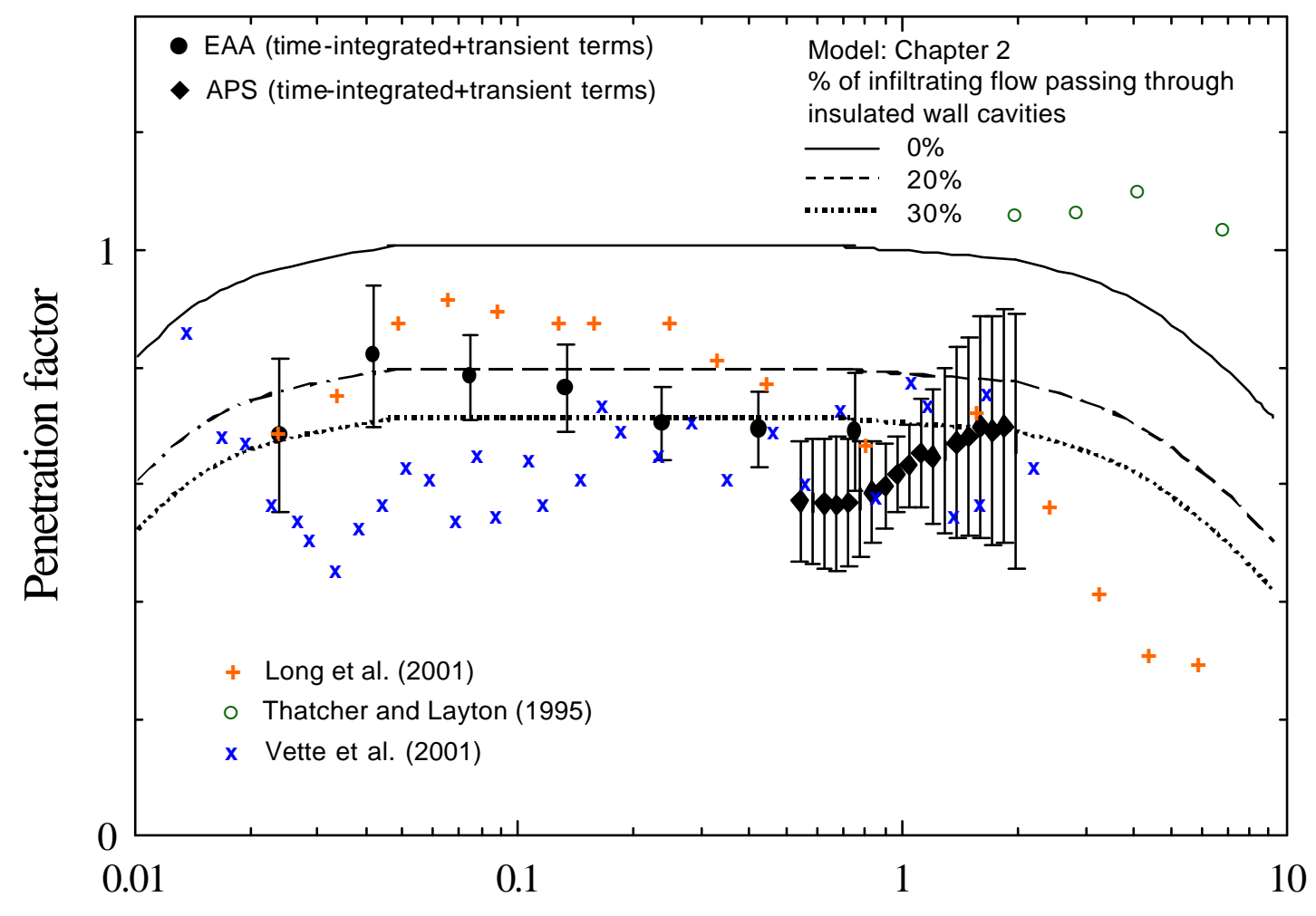

Particle diameter, $\mu \mathrm{m}$

Figure 5.7 Comparison of penetration factors obtained in this study to previous investigations, as indicated with various symbols. The predicted penetration factors from Chapter 2 are also presented for reference. 


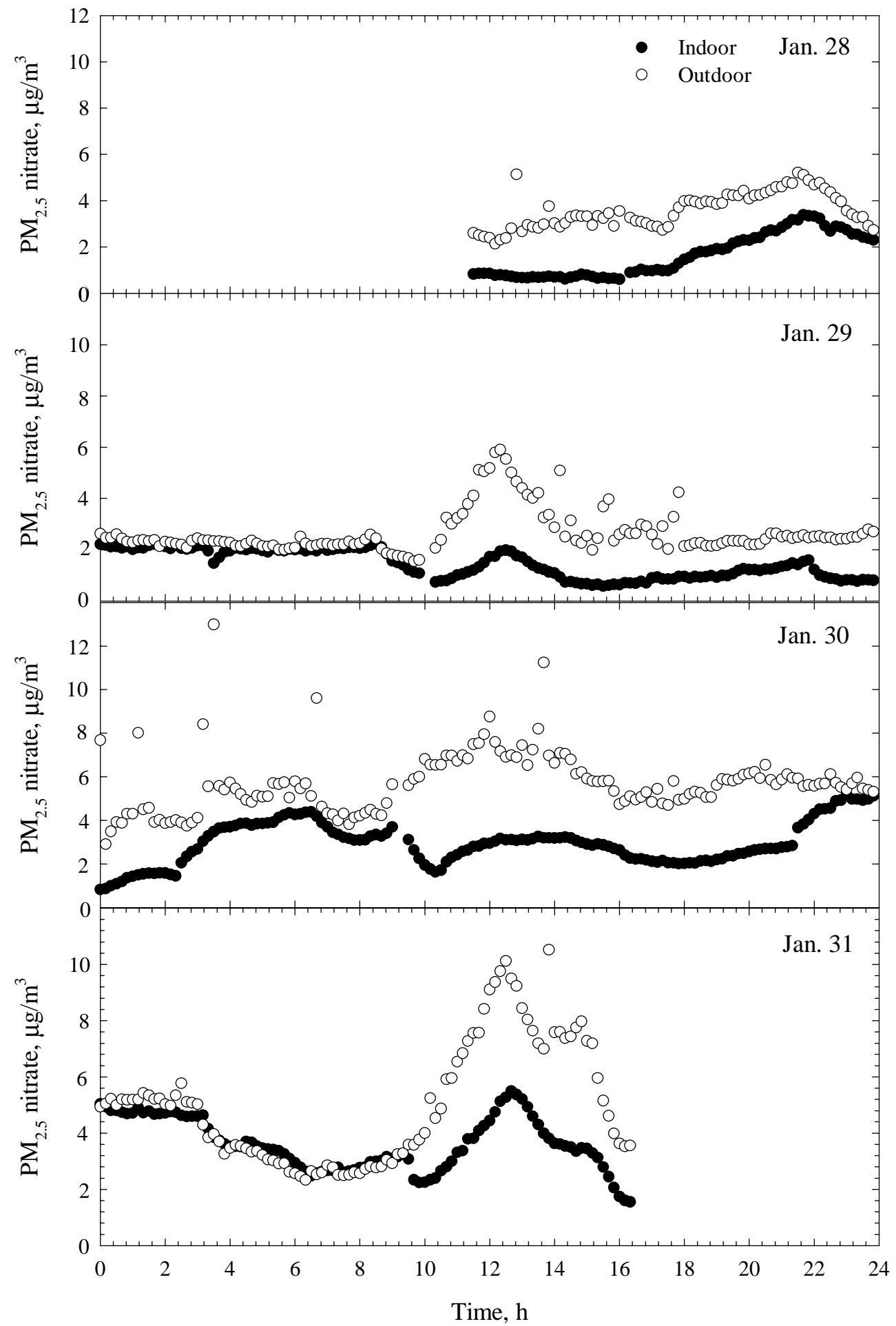

Figure 5.8 Measured indoor/outdoor $\mathrm{PM}_{2.5}$ nitrate concentration profiles from Jan. 28 to Jan. 31, 2001. 


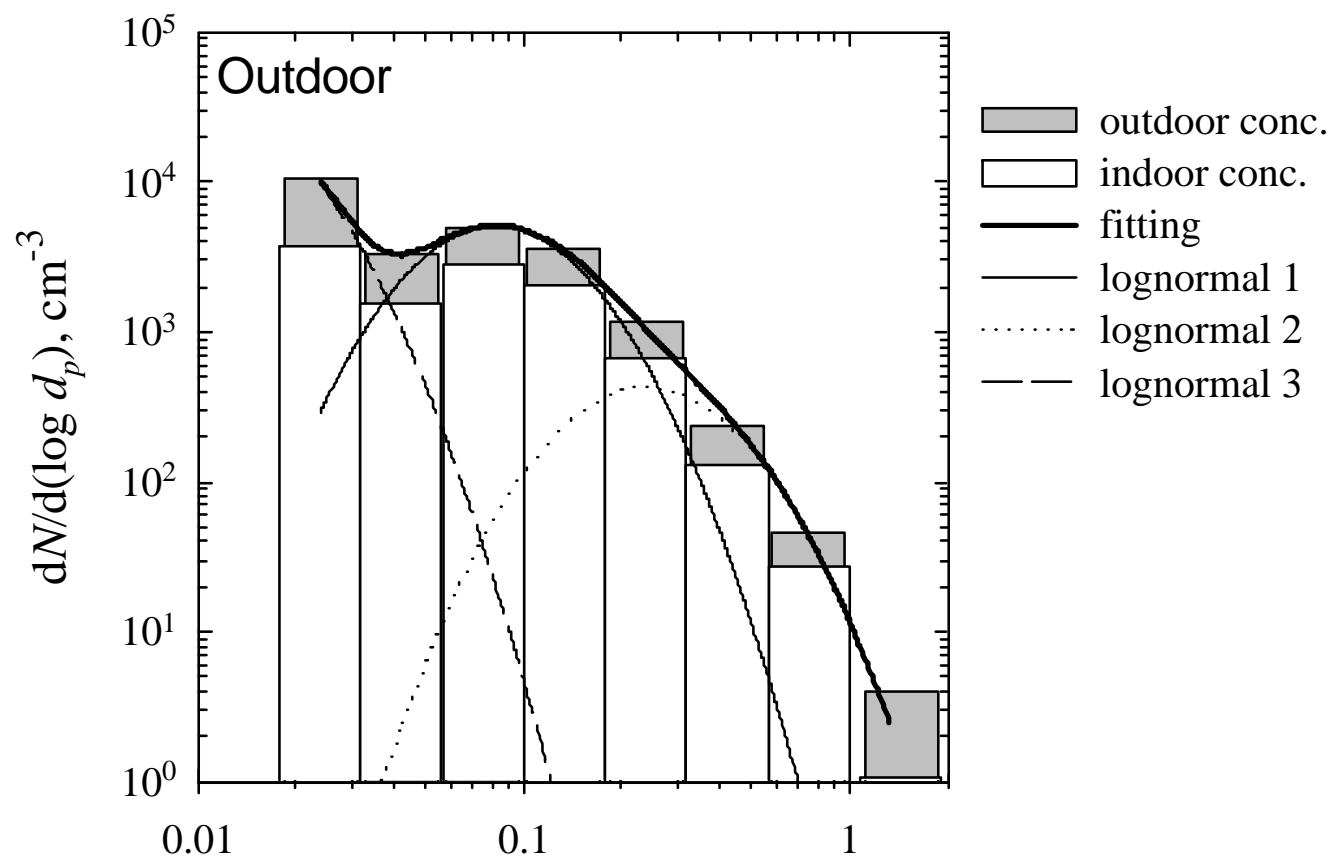

Particle diameter, $\mu \mathrm{m}$

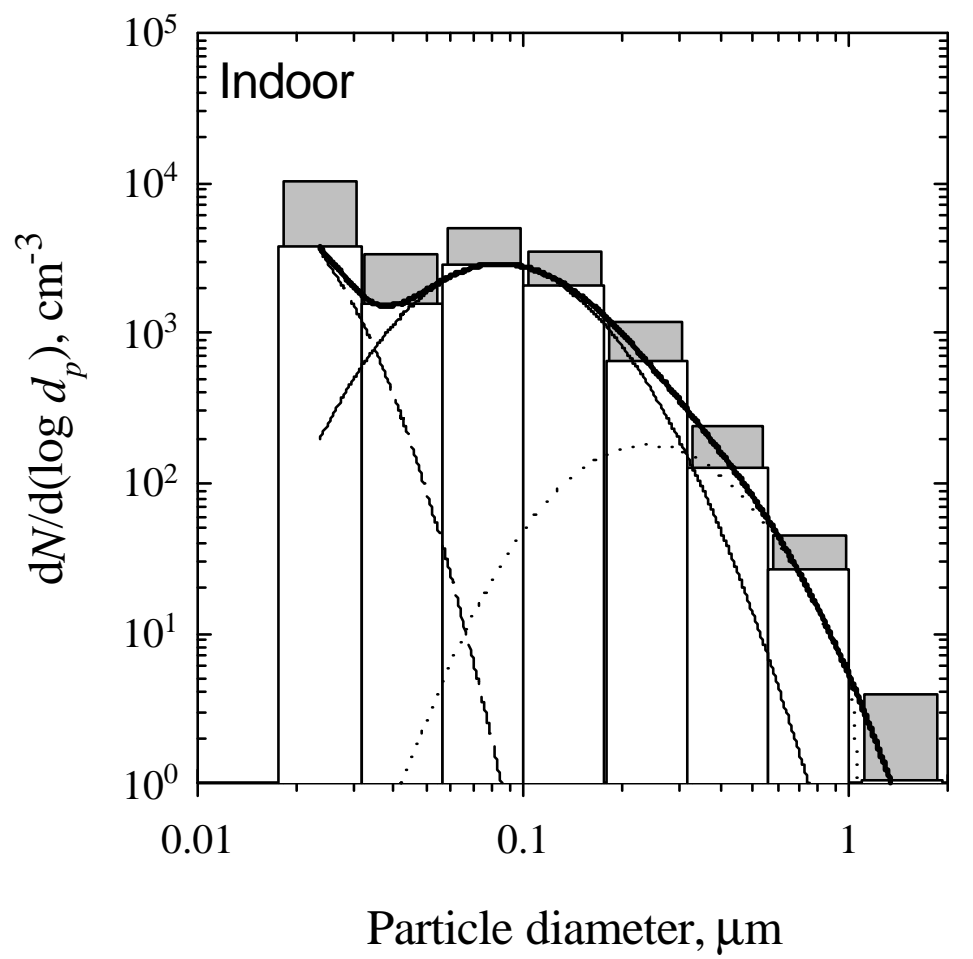

Figure 5.9 Curve fitting from the superposition of three log-normal distributions for outdoor and indoor particles sampled at noon, when outdoor PM nitrate was at its peak concentration on January 30, 2001. 


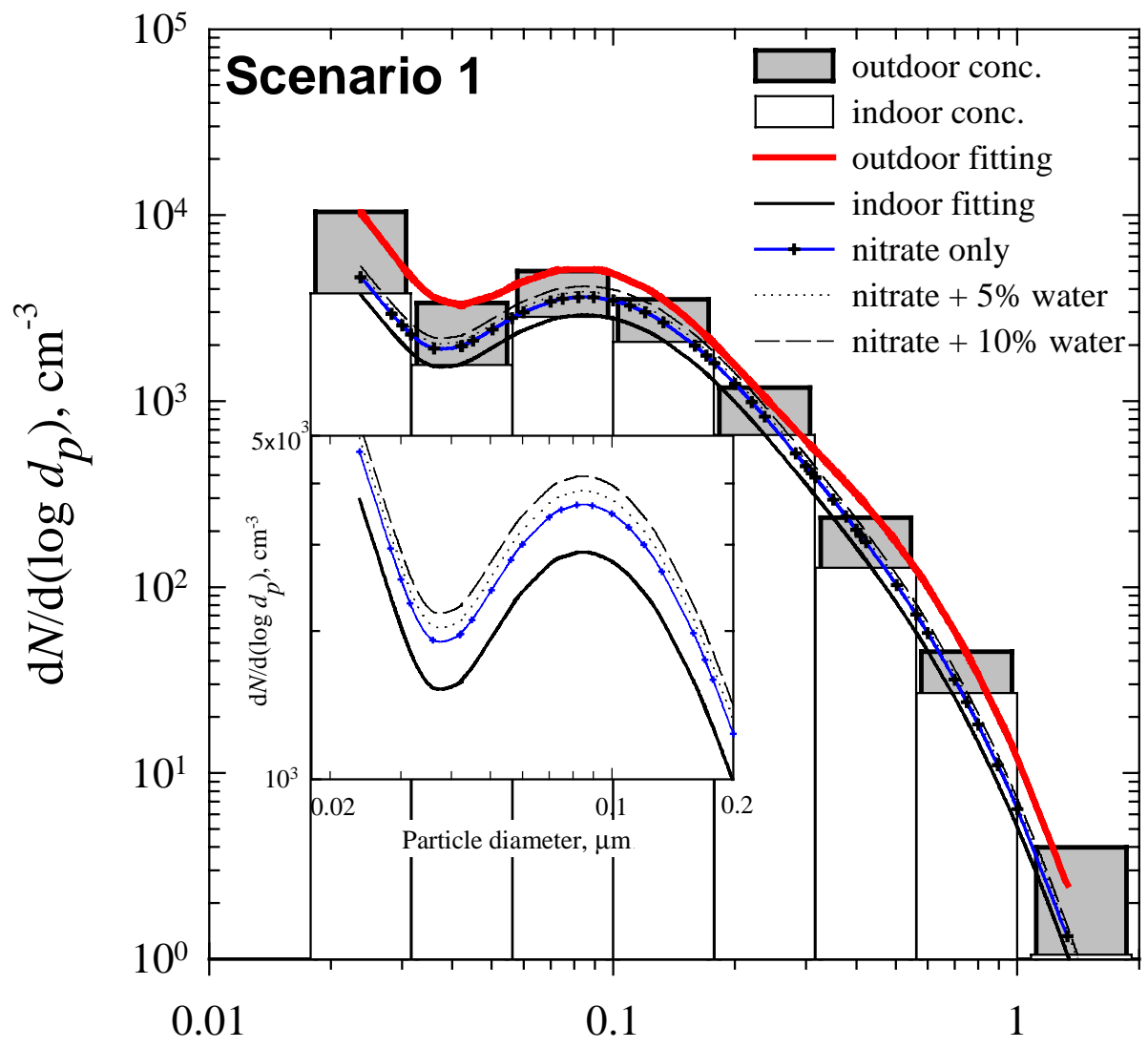

Particle diameter, $\mu \mathrm{m}$

Figure 5.10 The outdoor/indoor particle concentrations were taken from the measurements at noon, January 30, 2001, and the corresponding best indoor/outdoor curve fits were obtained based on the measured particle concentrations. The other three curves, with nitrate only, nitrate + $5 \%$ water, and nitrate $+10 \%$ water, represent the expected indoor particle size distribution assuming no evaporative loss. The insert provides a close-up illustration of the adjusted particle size distribution for indoor fitting and three different water contents in the particle size range of 0.02$0.2 \mu \mathrm{m}$. (a) The simulated indoor PM concentration for Scenario 1, in which the particle size distributions were adjusted assuming complete dissociation of $20 \%$ externally mixed particulate nitrate that is distributed uniformly across particle sizes accompanied by various water content $(0$ $10 \%)$ evaporation. 


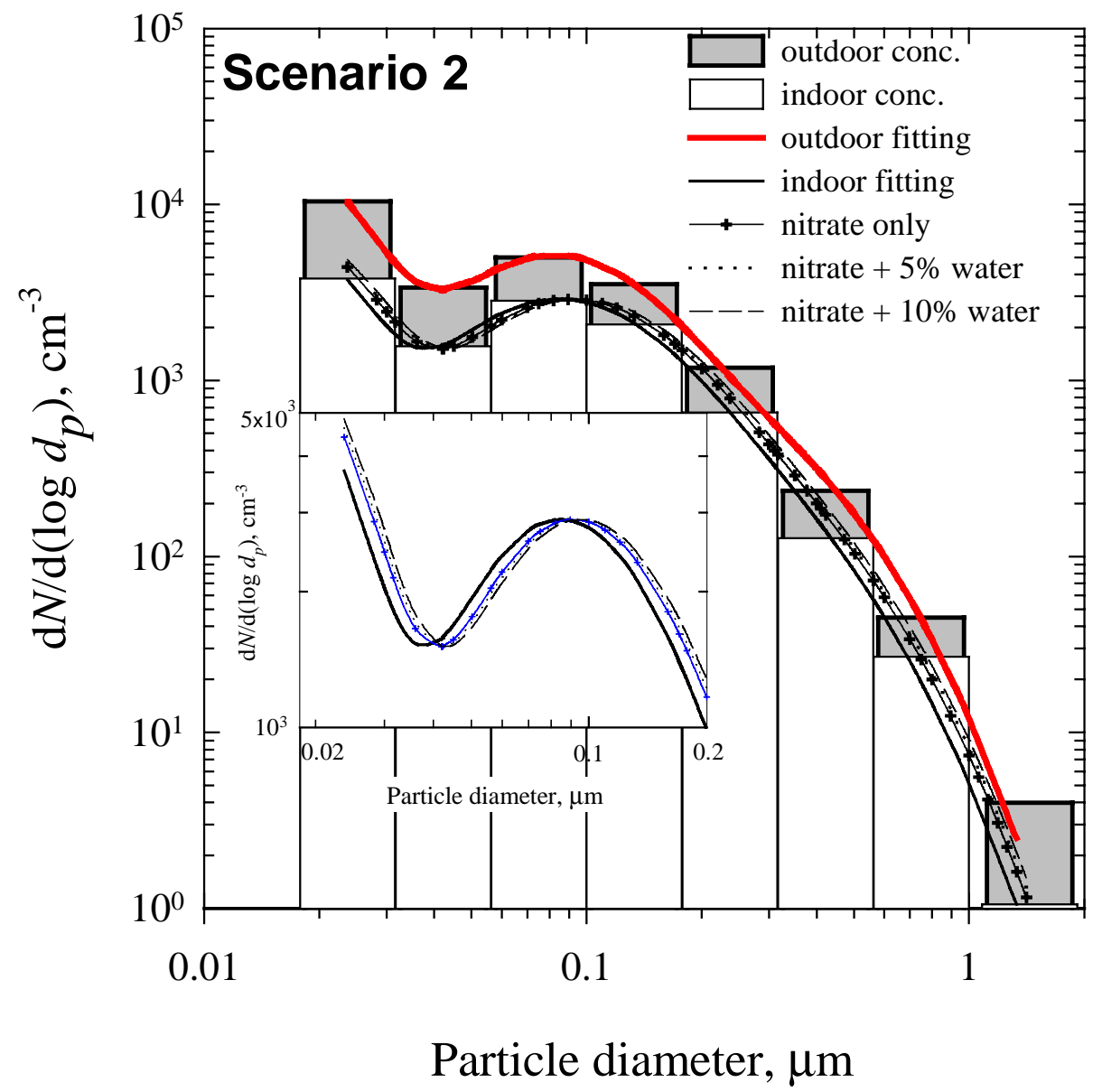

Figure 5.10(b) Simulated indoor PM concentration for Scenario 2, in which the particle size distributions were adjusted assuming complete dissociation of $20 \%$ internally mixed particulate nitrate that is distributed uniformly across particle sizes accompanied by various water content (0-10\%) evaporation. 


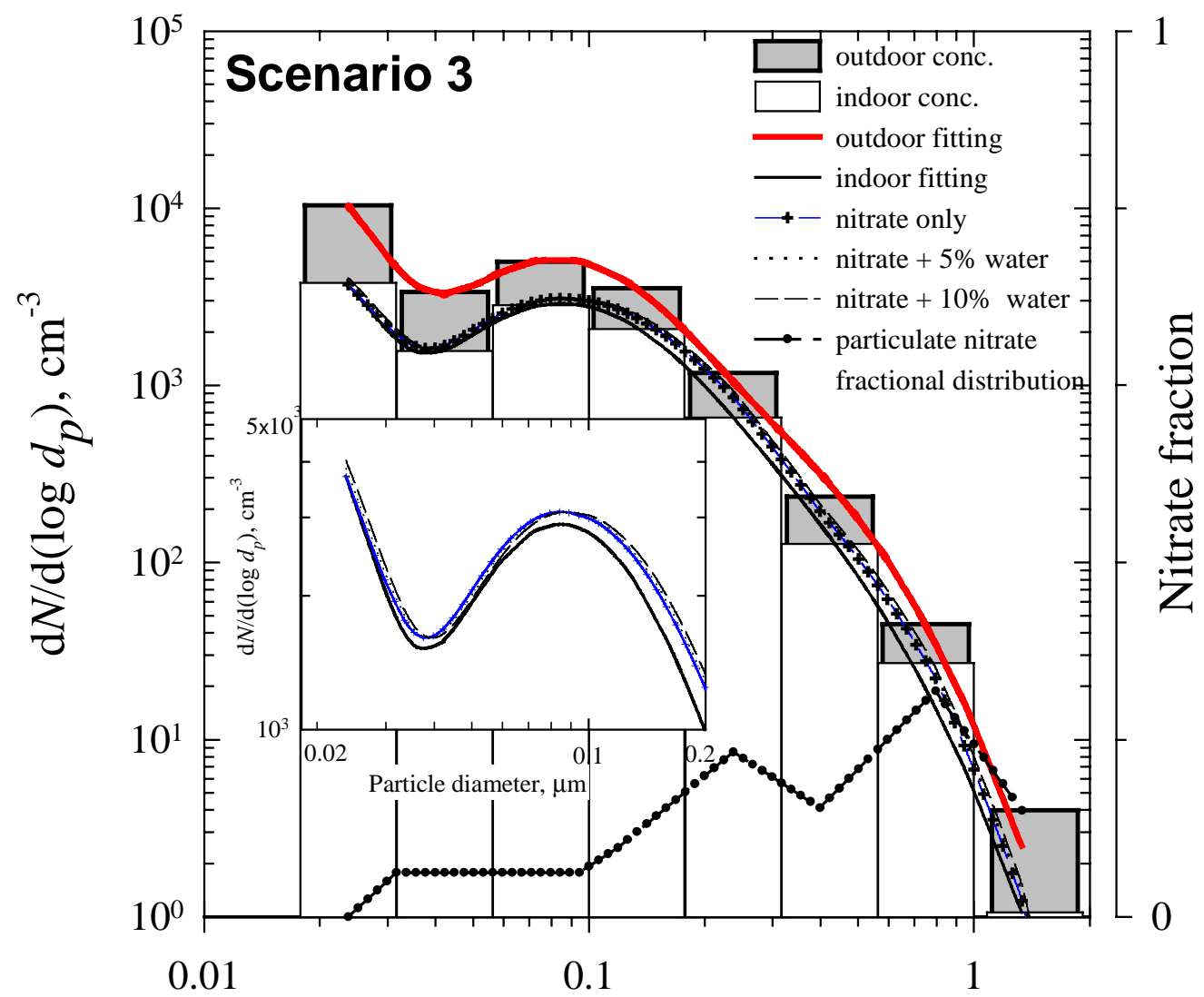

Particle diameter, $\mu \mathrm{m}$

Figure 5.10(c) Simulated indoor PM concentration for Scenario 3, in which the particle size distributions were adjusted assuming complete dissociation of $20 \%$ externally mixed particulate nitrate that was distributed as a function of particle size, as indicated. Various water content $(0-10 \%)$ evaporation was also considered in the analysis. 


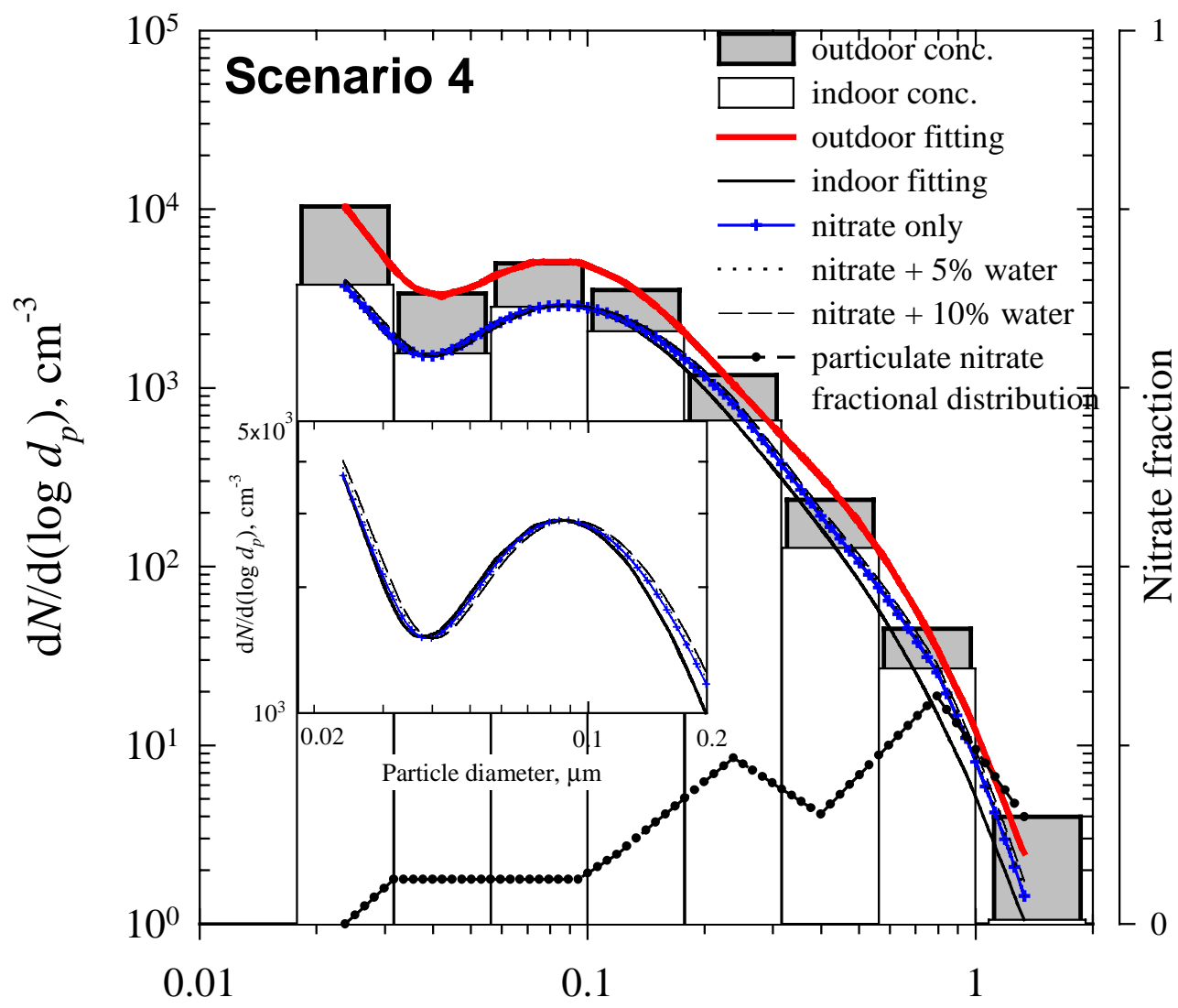

Particle diameter, $\mu \mathrm{m}$

Figure 5.10(d) Simulated indoor PM concentration for Scenario 4, in which the particle size distributions were adjusted assuming complete dissociation of $20 \%$ internally mixed particulate nitrate that was distributed as a function of particle size, as indicated. Various water content (0-10\%) evaporation was also considered in the analysis. 


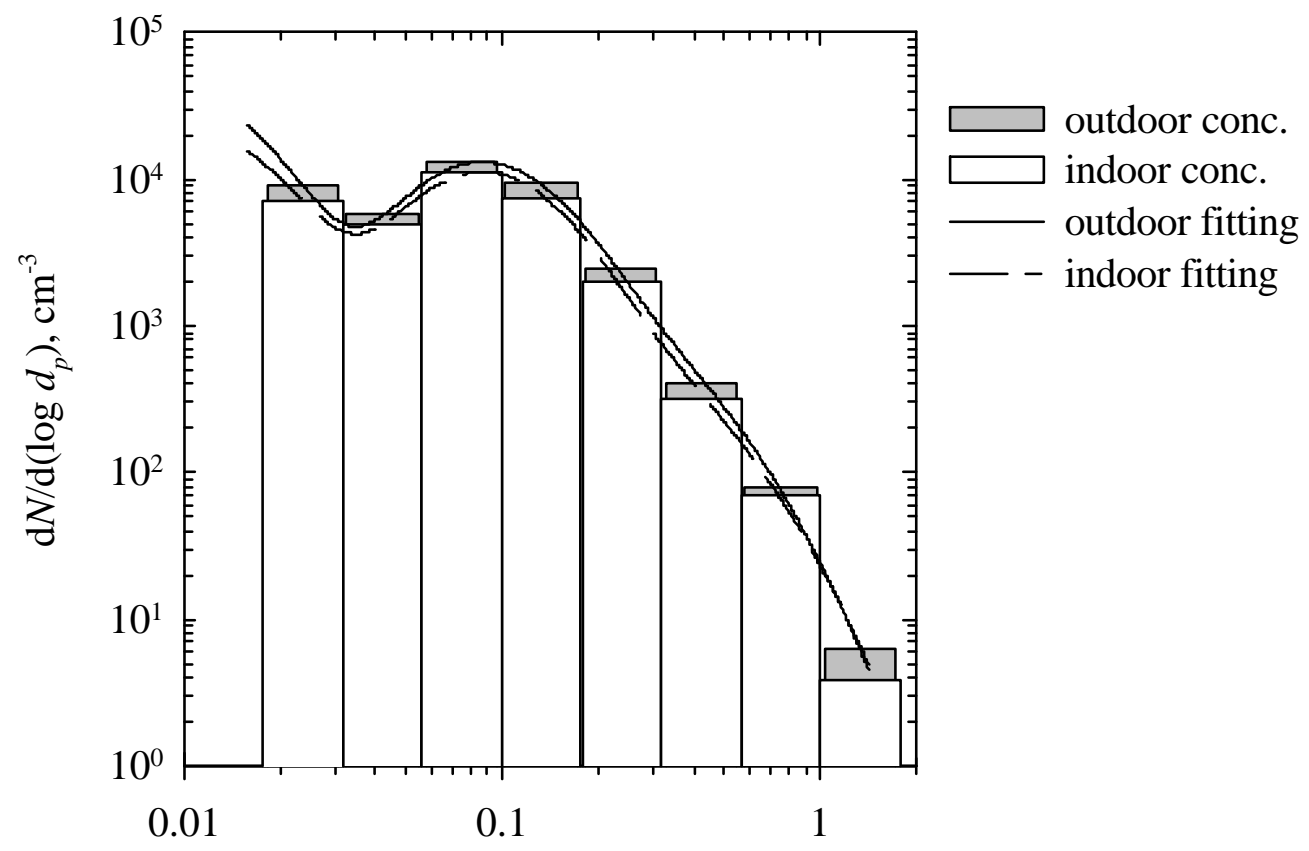

Particle diameter, $\mu \mathrm{m}$

Figure 5.11 Curve fitting from the superposition of three log-normal distributions for outdoor and indoor particles sampled in the morning on January 30, 2001. 

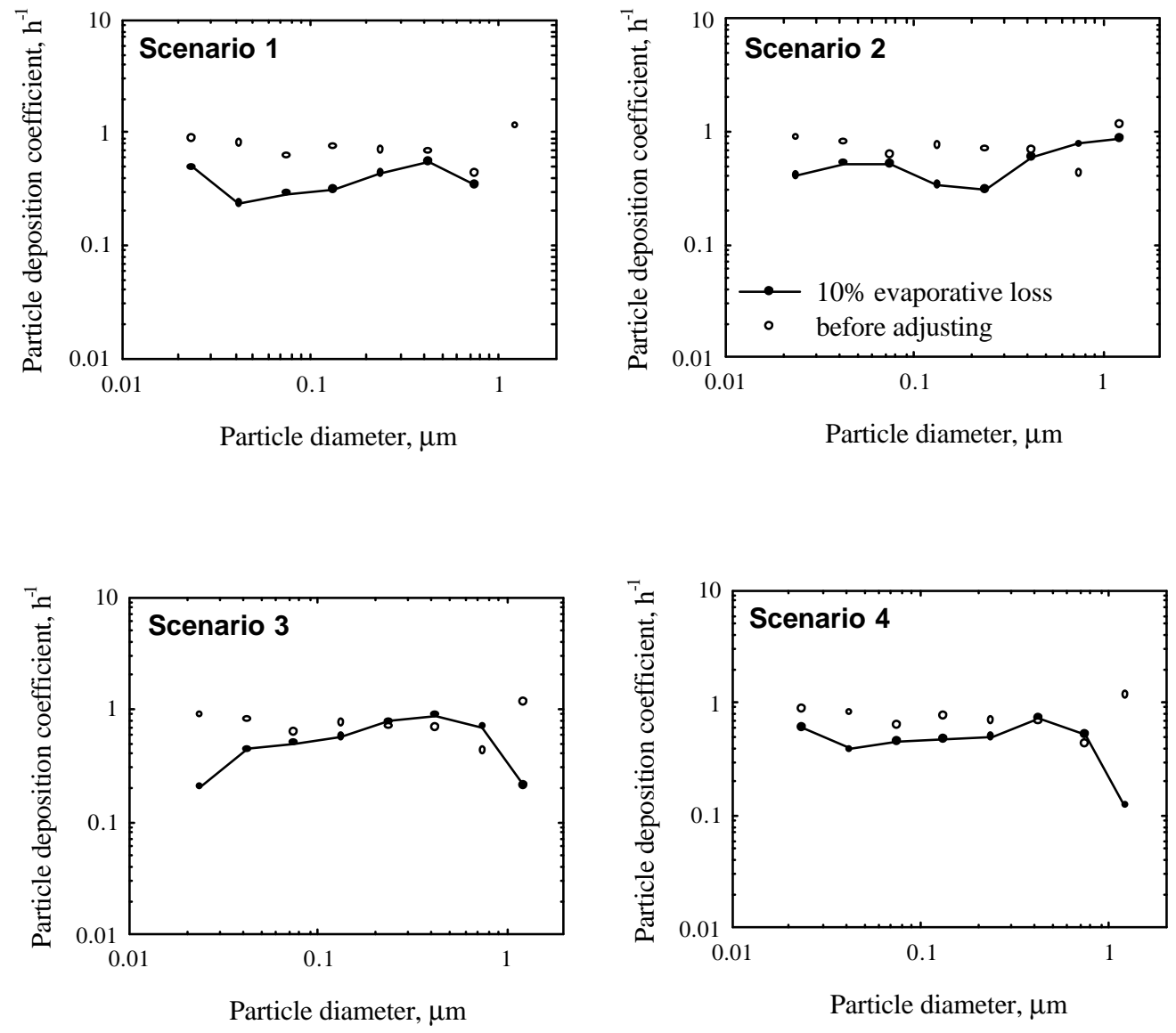

Figure 5.12 Adjusted indoor particle deposition coefficients accounting for the evaporative loss for four hypothesized scenarios, as described in page136. Determined from the January 30 pressurization experiment, the particle deposition coefficients before revision are represented by the open symbols. 


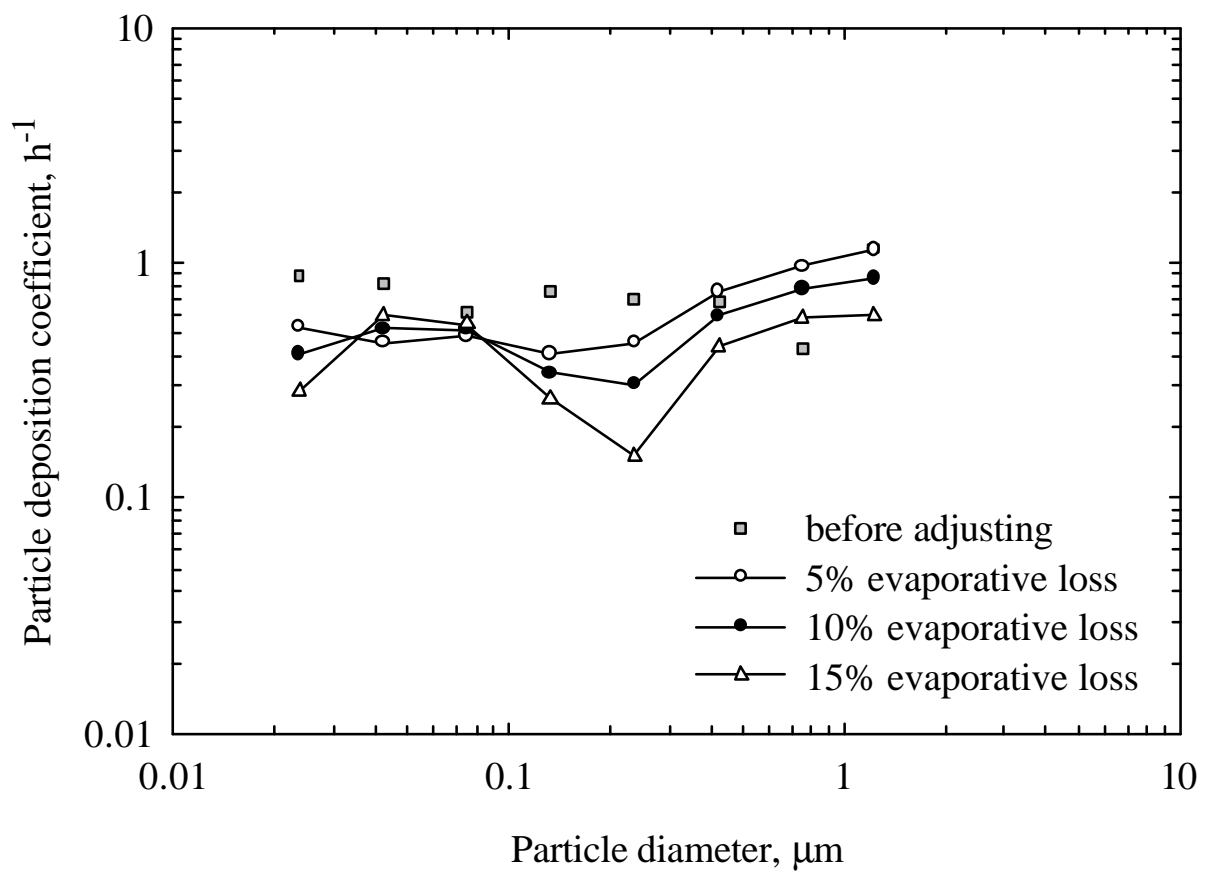

Figure 5.13 Comparison of the particle deposition coefficients before adjustments and those accounting for 5-15\% evaporative loss in Scenario 2, where the volatile constituents within particles were assumed to be internally mixed and uniformly distributed across particle size. 

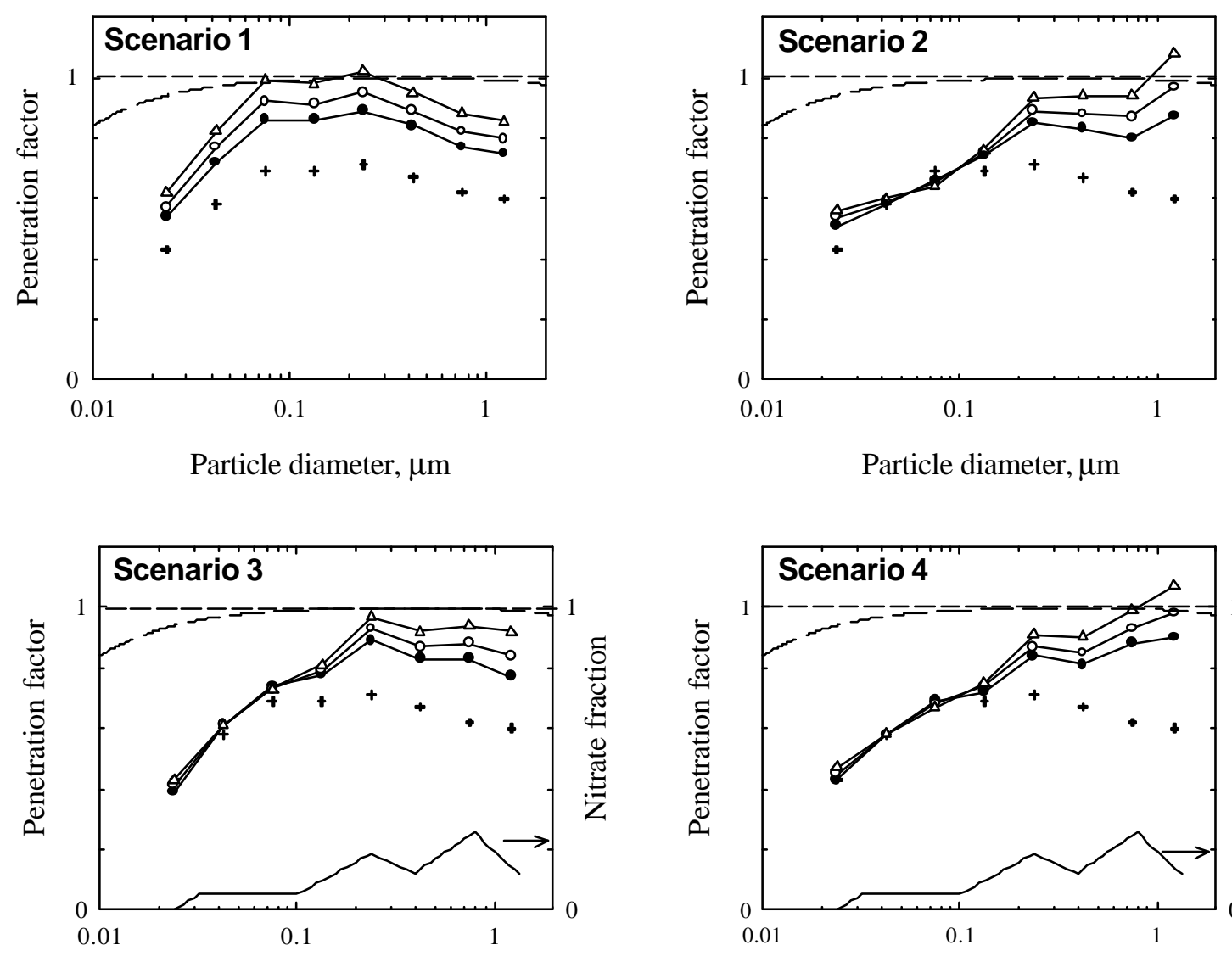

Particle diameter, $\mu \mathrm{m}$

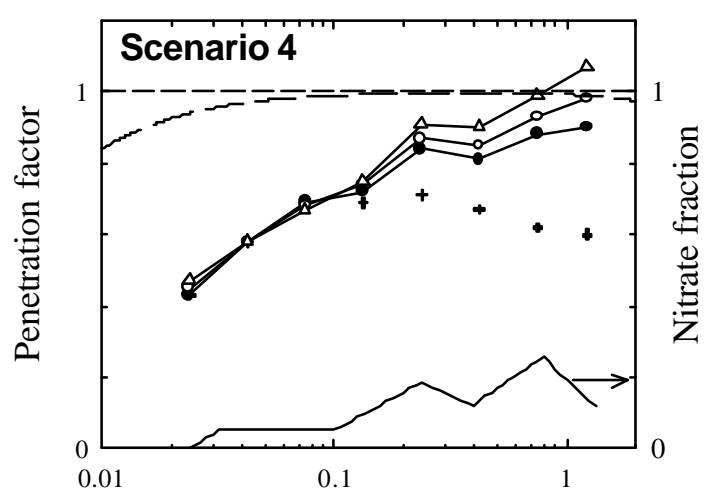

Particle diameter, $\mu \mathrm{m}$

+ before adjusting

$\longrightarrow$ nitrate only

- - nitrate $+5 \%$ water

$\longrightarrow$ nitrate $+10 \%$ water

- particulate nitrate fraction

- - model prediction for $\mathrm{d}=0.05-1 \mathrm{~mm}$

Figure 5.14 Comparison of particle penetration factors for noon on January 30 calculated from the four simulated scenarios, in which $20 \%$ particulate nitrate was assumed to be completely dissociated under various mixing characteristics as well as different levels of water evaporation (0-10\%). 


\section{CONCLUSIONS}

\subsection{SUMMARY}

The goal of this dissertation was to investigate the fraction of ambient air pollutants that infiltrate through building envelopes, particularly airborne particles. The study started with modeling explorations that predict the proportion of particles and reactive gases that penetrate through idealized building cracks and wall cavities. The experimental work involved three distinct systems that represent different scales of air leakage pathways associated with a building envelope. A variety of building-material cracks and two windows of different design were employed to examine particle penetration using nonvolatile particles under well-controlled conditions in the laboratory. A single-family house, in which the experimental parameters were partially controlled, was used to characterize the extent of ambient particles and ozone infiltrating into the indoor environment.

For model development, tools were applied from engineering analysis, incorporating data on building leakage characteristics and information on pollutantsurface interactions, to explore the penetration of particles and reactive gases (e.g., ozone) from outdoors into buildings through cracks and wall cavities, as presented in Chapter 2. Calculations were performed for idealized rectangular cracks, assuming regular geometry, smooth inner crack surface and steady airflow. Particles of $0.1-1.0 \mu \mathrm{m}$ diameter are predicted to have the highest penetration efficiency, nearly unity for crack heights of $0.25 \mathrm{~mm}$ or larger, assuming a pressure difference of $4 \mathrm{~Pa}$ or greater and a flow path length of $3 \mathrm{~cm}$ or less. Supermicron and ultrafine particles are significantly removed 
by means of gravitational settling and Brownian diffusion, respectively. The extent of gaseous pollutant penetration depends on crack geometry as well as on pollutant-surface reaction probability $(\gamma)$. Complete gas penetration is predicted for large cracks $(\sim 1 \mathrm{~mm})$ unless $\gamma$ exceeds $\sim 10^{-5}$. For air that flows through fiberglass insulation in a wall cavity, particle penetration drops to zero and gaseous pollutant penetration is also less than one when the pollutant-surface reaction probability exceeds $\sim 10^{-7}$. The model calculations also suggest that the overall air pollutant penetration, contributed from flow-weighted penetration for each crack, is strongly influenced by larger air leakage paths of building shells.

Since the actual air leakage paths in building envelopes are not comprised of cracks of uniform geometry and smooth inner surfaces, as modeled in Chapter 2, it is essential to examine the particle penetration factors experimentally for various building leakage characteristics. In Chapter 3, an experimental apparatus was designed and built in an attempt to validate the model predictions of particle penetration through cracks, as well as to gain insight into the physical factors that affect penetration. This was achieved by studying rectangular straight-through cracks, which serve as a surrogate for some leakage paths in building envelopes. The test building materials included aluminum, brick, concrete, plywood, redwood lumber, pine lumber, and strand board. The experimental results indicated that particle size and crack height are the two main factors that govern fractional particle penetration. For most cracks with uniform geometry, the experimental particle penetration factors show relatively good agreement with the model predictions presented in Chapter 2, regardless of crack materials. Particle penetration is essentially complete for particles of $0.02-7 \mu \mathrm{m}$ when the crack height is $\geq 1 \mathrm{~mm}$, and for 
particle diameters of $0.1-1 \mu \mathrm{m}$ when the crack height is $\geq 0.25 \mathrm{~mm}$, assuming that the pressure difference is $\geq 4 \mathrm{~Pa}$. The experimental data also suggest that some deviations less particle penetration than predicted — occur for cracks that exhibit significant surface roughness or irregular channel geometries, as illustrated by the results for strand board, concrete, and naturally-broken brick.

Extended from single building cracks, the physical scale of building leakage components was expanded to consider windows, which possess more complicated air leakage geometries and represent important contributors to air infiltration in buildings. It was shown that penetration factors estimated from two different experimental approaches, steady-state and dynamic analyses, produce consistent results. More importantly, more than $80 \%$ of $0.2-3 \mu \mathrm{m}$ particles penetrated through the two windows tested at a $\Delta \mathrm{P}$ of $1 \mathrm{~Pa}$, regardless of the existence of weatherstripping. Also, significantly less penetration was observed for particles smaller or larger than this size range. For instance, $\sim 50 \%$ particle penetration was found for $0.02 \mu \mathrm{m}$ particles for both windows. The two windows tested in the experiments exhibit similar performance in terms of the extent of particle penetration versus particle size, despite different window air leakage rates measured at the same pressure difference across the units. This could be attributable to the fact that the overall particle penetration factor of a window assembly is governed by the distribution of leakage dimensions, as indicated in the modeling reported in Chapter 2. Neither the effective air-leakage area nor the total air-leakage rate that is commonly documented for characterizing window air tightness provides adequate information to predict particle penetration. 
Finally, a house in the San Joaquin Valley was used to conduct penetration experiments, as reported in Chapter 5. The doors and windows were closed and no occupants were present during the experiments. The pressure difference across the building shell was manipulated with a blower door so that the effects of particle penetration and deposition could be examined separately. The penetration factors for the whole house were found to be mostly in the range of $0.5-0.9$ for $0.02-2 \mu \mathrm{m}$ particles, suggesting considerable particle penetration loss through the building envelope. One plausible explanation for the penetration loss is that a fraction $(\sim 25 \%)$ of the infiltrating air passed through fiberglass insulation in wall cavities, effectively filtering ambient particles. An alternative hypothesis is that the phase transition of volatile species, such as nitrates and water, caused the lower values of "apparent" particle penetration, as particles were transported from the conditions of ambient low temperature and high RH into the warmer and lower RH indoor environment. Therefore, four scenarios were simulated, assuming a reasonable percentage of particulate volatile contents with various mixing characteristics, in order to provide a quantitative estimate of the expected values of penetration factors. The simulation results show that nearly complete particle penetration could have occurred for particle sizes of $0.2-2 \mu \mathrm{m}$ when the gas-particle phase transition process is taken into account. The evaporation loss of particles upon entry into indoor environments might explain the low penetration factors reported by other investigators (Vette et al., 2001). Ozone measurements were also performed in this house, and complete penetration into the building was found. These findings were generally consistent with the modeling predictions reported in Chapter 2. 


\subsection{IMPLICATIONS OF THIS RESEARCH}

Air pollutant infiltration into buildings was examined in great detail in this dissertation. The results from model predictions as well as experiments with different building leakage scales — building cracks, windows, and a whole house — have shown consistent findings. These results indicate that particles with diameter of 0.1 to $\sim 2 \mu \mathrm{m}$ in infiltrating air can penetrate effectively into buildings, even with windows and doors all closed. For particles with diameter 0.02-0.1 $\mu \mathrm{m}$ (ultrafine mode), the penetration factors are in the range of 0.4-0.8 and 0.4-0.7 from the window and whole-house measurements, respectively. The experimental data for coarse particles are only available from the window measurements, which indicate the penetration factors could range from 1 to 0.5 for particles of $2 \mu \mathrm{m}$ to $\sim 10 \mu \mathrm{m}$. These results suggest that the penetration of ambient particles (particularly accumulation mode particles) into buildings can play an important role in indoor particle levels, which in turn contributes to personal exposure to particles of outdoor origin, since people spend a majority of their time in indoor environments. This has potentially important implications for public health in terms of short-term exposure to hazardous materials. For example, accidental release from industrial facilities, and chemical/biological agents released from terrorist attacks are of concern. In terms of long-term exposure, many epidemiological studies have shown an association between ambient fine particulate pollution and elevated risks of cardiopulmonary and lung cancer mortality (Thurston et al., 1994; Pope, 2000, Pope et al., 2002). While personal exposure to airborne particles generated from indoor activities can be mitigated through public education and prevention, personal exposure to indoor aerosols of outdoor origin can be consistent, involuntary, and indiscriminate. 


\subsection{FUTURE RESEARCH DIRECTIONS}

\subsubsection{Characterization of Building Leakage Distribution}

This work raises several important issues concerning the distribution of building air leakage and how infiltrating air is distributed with respect to building leakage dimensions and pathways. Existing information about the leakage characteristics of buildings provides important clues, but is not yet sufficient to reliably predict particle penetration into real buildings from models. In this study, results from the whole-house penetration experiments have revealed that significantly lower penetration was consistently observed for particles as compared to the model predictions for straightthrough cracks in Chapter 2. It is not clear yet whether this discrepancy results from different leakage distributions possessed by the house from those assumed in the model. As shown in Chapter 2, a small number of large cracks would produce high penetration factors, while the same total leakage distributed among a large number of small cracks could produce much lower penetration factors. In addition, the extent of particle infiltration can be greatly reduced should a substantial fraction of infiltrating air pass through fibrous materials such as fiberglass insulation rather than around it. Therefore, the characterization of building leakage distribution merits further study to advance our capability in predicting pollutant penetration. A good understanding of infiltrating air distribution with respect to building leakage could yield improvements in innovative building technology in order to minimize air pollutants infiltrating from ambient air. 


\subsubsection{Advances in Building Technology}

The results from the window experiments have shown similar performances with respect to particle penetration for two sliding windows of different design. It also suggests that the installation of weatherstripping is not necessarily helpful in reducing particle penetration, provided that the air leakage paths within the window assembly are distributed toward large crack dimensions. In addition, substantially less penetration was seen for particles smaller than $0.2 \mu \mathrm{m}$ for both windows, and it is unclear whether this a result of the distribution of leakage dimensions, or a result of filtration by the bristles between the sash/frame joint. The bristles might be potentially responsible for removing ultrafine particles effectively by providing a higher surface area for diffusional loss. Moreover, it is likely that the performance of windows exhibits more variation among different window types, such as casement and double-hung windows, than different windows of the same types. Further explorations of the performance on particle penetration for various types of windows may provide insight into the innovative design of fenestration products that aim to offer better protection against infiltrating particles.

Technological advances in this area hold the promise to reduce personal exposure to indoor particles of ambient origin, and to lower the contamination level in certain facilities, such as clean rooms, hospitals, and museums. Such goals can be accomplished by identifying the physical factors that affect particle penetration, and by further incorporating these insights into the design of advanced building technology. For example, air filtration systems have been employed to remove the particulate pollutants that enter buildings via the mechanical ventilation (Hanley, 1994). For reducing the extent of particle penetration in infiltrating air, efforts should be directed to properly 
design fenestration products and wall wrapping techniques so that the smallest dimension of the air leaks in building envelopes can be minimized. In addition, the characteristics of enhanced deposition for $0.1-1 \mu \mathrm{m}$ particles owing to surface roughness and irregular geometry, as presented in Chapter 3, may be exploited to better engineer systems where greater particle mass transfer is desired. For instance, engineering modifications on inner surface roughness or geometry of building air leakage pathways, such as joints in building leakage components, may lead to improvements in building design and operation that reduce particle penetration.

Wind exerts positive pressure on the windward side of a building, which in turn induces pollutant infiltration. Consequently, arranging the large building leaks, such as wiring and plumbing openings, on the leeward side might help minimizing the extent of particle intrusion into the indoor environment, provided that a prevailing wind exists around the building. The effectiveness of this building design strategy may merit exploration by modeling simulations.

\subsubsection{Thermodynamic Aspects of Particle Phase Transformation}

Fine particles often consist of significant fractions of semi-volatile constituents, such as nitrate, ammonia, organic compounds, and water. Such particles can undergo phase transitions in response to certain changes in temperature, $\mathrm{RH}$, and gaseous composition. Therefore, the corresponding physical behavior and the associated constituents could be potentially different from those of purely nonvolatile particles as they travel through building air leakage pathways. Depending on environmental conditions, semi-volatile constituents may change phase, either evaporating from 
particles, or condensing onto existing particles, ultimately altering the concentrations and species of indoor air pollutants. A well-designed experiment that allows accurate measurement of real-time dynamics of gas-to-particle conversion (or vice versa) upon entry into indoor environments will help provide critical insights into better prediction of particle penetration factors, as well as into better assessing personal exposure to indoor air pollutants.

The experimental explorations could start with studying the transport properties of semi-volatile particles (e.g., ammonia nitrate) associated with building leakage components, such as cracks and window assemblies, in a well-controlled laboratory settings. The design of the experimental apparatus reported in this dissertation (Chapters 3 and 4) may be modified to allow better control of the temperature and RH on both sides of the leakage pathways, thus providing detailed information on how these physical factors affect particle penetration. The concentrations of particles and gaseous species (e.g., nitric acid, ammonia) need to be determined as frequently as possible during the experiment in order to elucidate the dynamic aspects of the chemical transformation process, which occurs as semi-volatile particles are transported through the leaks from one compartment to the other under carefully characterized environmental conditions.

In addition, more experimental data pertaining to the size-resolved distribution of volatile constituents on fine particles, particularly ultrafine particles, will shed light on the expected values of penetration factors. The quantification of semi-volatile constituents on ultrafine aerosols remains a challenge owing to a small particulate mass collected to allow chemical analysis accurately as well as the high evaporative loss from the air sampling process. The work by Kim et al. (2001) utilized the concept of a virtual 
impactor to concentrate ultrafine particles, thereby greatly reducing the sampling time for chemical analysis of the filter samples. Nevertheless, this concentration enrichment process, in which the ultrafine particles experience condensation and subsequent evaporation, requires a thorough evaluation with respect to the preservation of particle number concentration and chemical species.

\subsubsection{Pollutant-Surface Interactions}

The penetration factor for reactive gases could be better predicted if more experimental data on their reaction probability were available. A rectangular crack may be utilized to further explore the kinetic aspects of reactive gaseous species associated with a surface reaction. Owing to the well-characterized laminar flow with respect to the straight-through slot of sub-millimeter crack height, the rectangular air leakage path system, as demonstrated in Chapter 3, may be potentially developed to be an effective experimental apparatus for studying physical behavior of reactive gases and aerosols. For instance, the pollutant-surface interaction, as characterized by the reaction probability, could be studied for certain reactive gaseous species and a surface of interest, when the surface uptake kinetics is the rate-limiting process. Under this scenario, the overall pollutant removal from the surface is governed by the species deposition velocity in the limit of control by surface uptake (i.e., $v_{o} \sim v_{s} ;$ p. 30, Chapter 2). The measured penetration factor, which is the ratio of the species concentrations at the inlet and outlet of the crack apparatus, can be used to infer the reaction probability of the reactive gaseous species. 


\subsection{REFERENCES}

Hanley, J.T., Ensor, D.S., Smith, D.D. and Sparks, L.E. (1994) Fractional aerosol filtration efficiency of in-duct ventilation air cleaners, Indoor Air, 4: 169-178.

Kim, S., Jaques, P.A., Chang, M.C., Froines, J.R., and Sioutas, C. (2001) Versatile aerosol concentration enrichment system (VACES) for simultaneous in vivo and in vitro evaluation of toxic effects of ultrafine, fine, and coarse ambient particles. Part I: Development and laboratory characterization, Journal of Aerosol Science, 32: $1281-1297$.

Pope, C.A. (2000) Review: Epidemiological basis for particulate air pollution health standards, Aerosol Science and Technology, 32: 4-14.

Pope, C.A., Burnett, R.T., Thun, M.J., Calle, E.E., Krewski, D., Ito, K. and Thurston, G.D. (2002) Lung cancer, cardiopulmonary mortality, and long-term exposure to fine particulate air pollution, Journal of the American Medicine Association, 287: $1132-1141$.

Thurston, G.D., Ito, K., Hayes, C.G., Bates, D.V., and Lippmann, M. (1994) Respiratory hospital admissions and summertime haze air pollution in Toronto, Ontario: Consideration of the role of acid aerosols, Environmental Research, 65: 271-290.

Vette, A.F., Rea, A.W., Lawless, P.A., Rodes, C.E., Evans, G., Highsmith, V.R., and Sheldon, L. (2001) Characterization of indoor-outdoor aerosol concentration relationships during the Fresno PM exposure studies, Aerosol Science and Technology, 34: 118-126. 


\section{APPENDICES}

\section{APPENDIX A PENETRATION FACTOR DERIVED FROM MASS BALANCE IN A RECTANGULAR CRACK}

The derivation presented in this appendix seeks to evaluate the gaseous pollutant penetration factor, the ratio of pollutant concentration at the outlet to that at the inlet, for a rectangular crack of uniform geometry, as described in $§ 2.3 .1 .4$. This idealized model is used to link the penetration factor to the pollutant deposition velocity. Figure A.1

illustrates a differential slice of a crack, where $\Delta x$ denotes the slice thickness, $d$ the crack height, $W$ the crack width (perpendicular to the airflow direction), $U$ the average airflow velocity, and $v_{\mathrm{o}}$ the overall pollutant deposition velocity. The surface area available for pollutant deposition is $2 W \Delta \mathrm{x}^{1}$.

Assuming that the air flow is uniform, and that surface reaction is the only loss mechanism for reactive gases, then the mass balance within the control volume at steady state is written as follows:

$$
\begin{aligned}
\text { mass in } & =\text { mass out }+ \text { pollutant removal } \\
U \cdot W d \cdot C_{(x)} & =U \cdot W d \cdot C_{(x+\Delta x)}+v_{o} \cdot 2 W \Delta x \cdot C
\end{aligned}
$$

where $C$ is the pollutant concentration. After rearrangement, dividing both sides by $\Delta x$, taking the limit $(\Delta x \rightarrow 0)$, and integrating, equation (A.1) becomes

$$
\int_{C_{\text {in }}}^{C_{\text {out }}} \frac{1}{C} d C=-\int_{0}^{z} \frac{2 v_{o}}{U d} d x
$$

\footnotetext{
${ }^{1}$ approximated from $2(W+d) \Delta x$ since $d \ll W$
} 
where $C_{\text {in }}$ and $C_{\text {out }}$ refer to the pollutant concentrations at crack inlet and outlet, respectively, and $z$ is the flow path length parallel to the airflow direction. As a result, the pollutant penetration factor $p$ is obtained as

$$
p=\frac{C_{\text {out }}}{C_{\text {in }}}=\exp \left(-\frac{2 v_{o}}{U d} z\right)
$$

The overall deposition velocity, $v_{\mathrm{o}}$, is equivalent to the transport-limited deposition velocity, $v_{t}$, when (1) $\gamma$ approaches 1 for a gaseous pollutant, or (2) pollutants are particles.

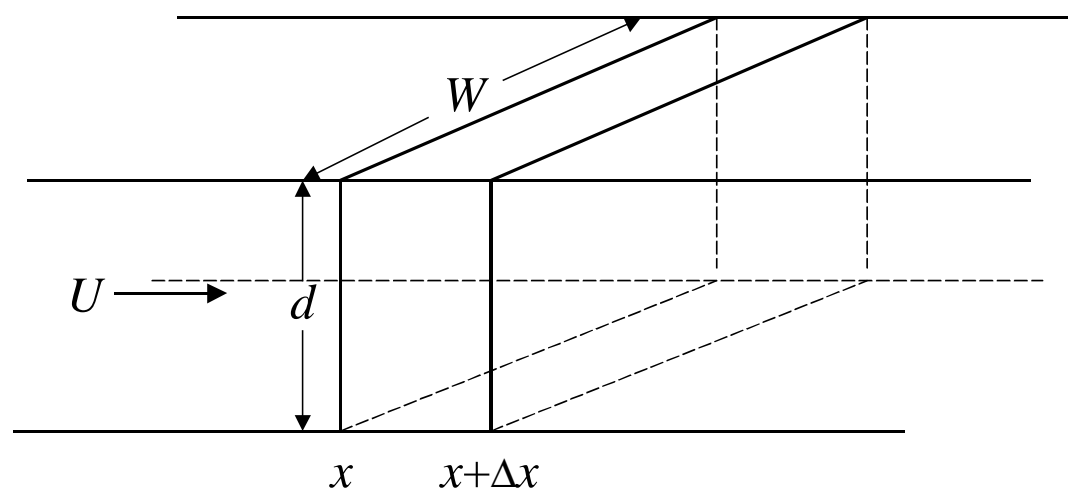

Figure A.1 Illustration of a differential slice within a crack. 


\section{APPENDIX B TRANSPORT-LIMITED DEPOSITION VELOCITY DERIVED FROM PARTICLE FILTRATION THEORY}

This appendix intends to derive the transport-limited deposition velocity for reactive gaseous pollutants (e.g., ozone) as they flow through the fiberglass insulation materials in wall cavities. As a recapitulation, the overall mass transfer process is modeled as two resistances in series:

$$
v_{o}=\left(\frac{1}{v_{s}}+\frac{1}{v_{t}}\right)^{-1}=\frac{v_{s} v_{t}}{v_{s}+v_{t}}
$$

Here, $v_{s}$ and $v_{t}$ refer to the species deposition velocity in the limit of control by surface uptake and control by gas-phase mass transport, respectively. Independent of the pollutant reactivity with the contact surface, the pollutant transport-limited deposition velocity, $v_{t}$, is a function of the air flow field and the species molecular diffusivity. This derivation bridges the concept of particle filtration theory ${ }^{2}$ and the principle of mass conservation.

The transport-limited deposition velocity $v_{t}$ on the fiberglass surface is estimated by assuming

(1) molecular diffusion of ozone is the only mass transport mechanism causing deposition; and

\footnotetext{
${ }^{2}$ See page 33 for details.
} 
(2) ozone molecules behave like particles. Once they collide on surfaces, they are irreversibly removed owing to extremely fast reaction kinetics. In other words, $\gamma$ for ozone and fiberglass materials is assumed to be 1 .

For a differential slice of fiberglass material, as shown in Figure B.1, the mass balance on the volume of $A_{c} \cdot \Delta x$ can be written as follows:

$$
\begin{gathered}
\text { mass in }=\text { mass out }+ \text { ozone removal } \\
C_{(x)} A_{c} U_{o}=C_{(x+\Delta x)} A_{c} U_{o}+v_{t}\left(\frac{A_{c} \cdot \Delta x \cdot \alpha}{\frac{\pi}{4} d_{f}{ }^{2}}\right)\left(\pi \cdot d_{f}\right) \cdot C
\end{gathered}
$$

where $\Delta x$ is the slice thickness, $A_{c}$ is the cross-sectional area (perpendicular to airflow direction), $U_{o}$ is the airflow velocity, $\alpha$ is the solidity of the fiberglass material, $d_{f}$ is the fiber diameter, and $v_{t}$ is the ozone transport-limited deposition velocity.

After rearrangement, dividing both sides by $\Delta x$, and taking the limit $(\Delta x \rightarrow 0)$, (B.1) becomes

$$
\frac{d C}{d x}=-\frac{4 \alpha v_{t}}{d_{f} U_{o}} C
$$

Rearranging Equation (B.2):

$$
\frac{d C}{C}=-\frac{4 \alpha v_{t}}{d_{f} U_{o}} d x
$$

Integrating, the fractional penetration becomes:

$$
p_{f}=\frac{C_{o u t}}{C_{\text {in }}}=\exp \left[-\frac{4 \alpha v_{t} L}{d_{f} U_{o}}\right]
$$


where $C_{\text {in }}$ and $C_{\text {out }}$ are the ozone concentrations at the inlet and outlet, respectively, and $L$ is the flow path length through the fiberglass blanket. Therefore, $v_{t}$ can be evaluated by comparing (B.4) and (2.11):

$$
v_{t}=\frac{\eta_{d}}{\pi} U_{0}
$$

where $\eta_{d}$ is the single fiber efficiency due to diffusion alone. From Equation (2.12), it is seen that the pollutant transport-limited deposition velocity, $v_{t}$, is related to the airflow $\left(U_{o}\right)$ and the molecular diffusivity $\left(\eta_{d}\right)$ only.

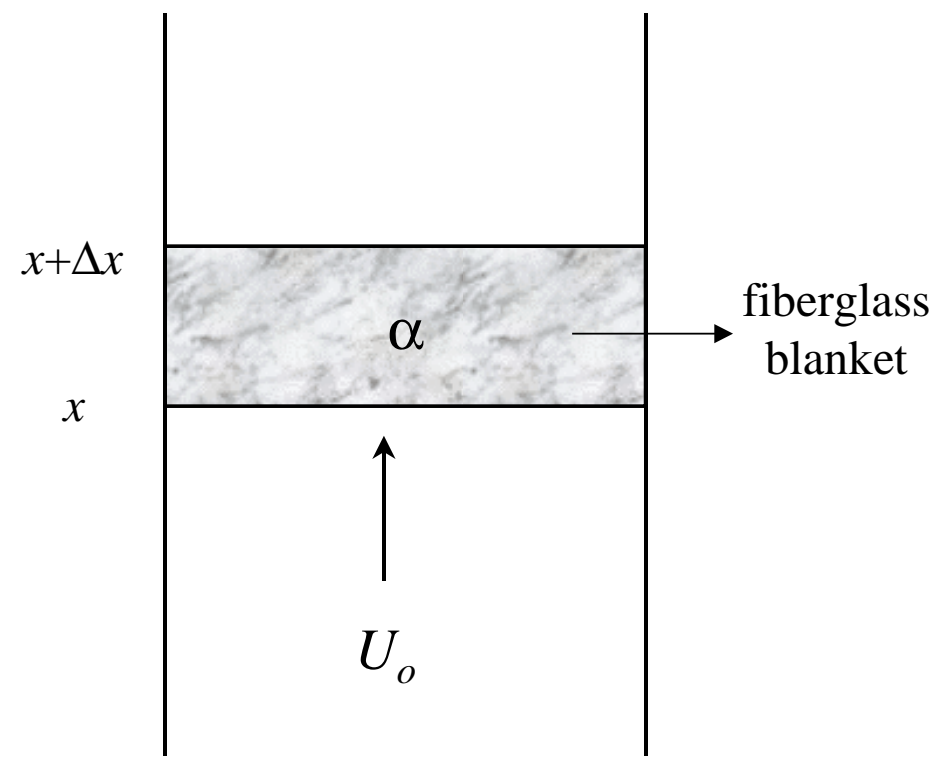

Figure B.1 Configuration of a differential slice of fiberglass blanket within a wall cavity. 


\section{APPENDiX C PARTICle PENETRATION MODELING PROGRAM}

This program was used in Chapter 2 to calculate particle penetration factors through rectangular, straight-through cracks. The underlying assumptions of the model include smooth inner crack surface and steady, uniform airflow. The penetration factors can be expressed as functions of particle size $\left(d_{p}\right)$ based on the following input parameters: crack dimensions (height and flow path distance; $d$ and $z$, respectively), and pressure difference across the crack opening $(\Delta \mathrm{P})$. Assuming that $d$ and $z$ are much less than the crack width $W$ (modeled as a two-dimensional configuration), any input for $W$ will generate the same results. Although particle removal by impaction is not considered in the model due to insufficient particle inertia, the particle Stokes numbers $(S t)$ is calculated for reference. In the following Matlab program, the airflow velocity in the crack is determined based on crack dimensions and $\Delta \mathrm{P}$. The penetration factors associated with particle loss as a result of gravitational settling and Brownian diffusion are computed independently and then combined to determine the overall penetration factors as a function of particle diameter. To evaluate particle penetration factors through L-shaped and double-bend crack configurations, the values of $C$ are replaced with 2.5 and $3.5^{3,4}$ and the particle horizontal path to allow particle deposition by gravity is adjusted appropriately.

${ }^{3}$ Baker, P.H., Sharples, S., and Ward, I.C. (1987) Airflow through cracks, Building and Environment, 22: 293-304.

${ }^{4}$ Chastain, J.P., Colliver, D.G., and Winner, P.W. Jr. (1987) Computation of discharge coefficients for laminar flow in rectangular and circular opening, ASHRAE Transactions, 27: 2259-2283. 


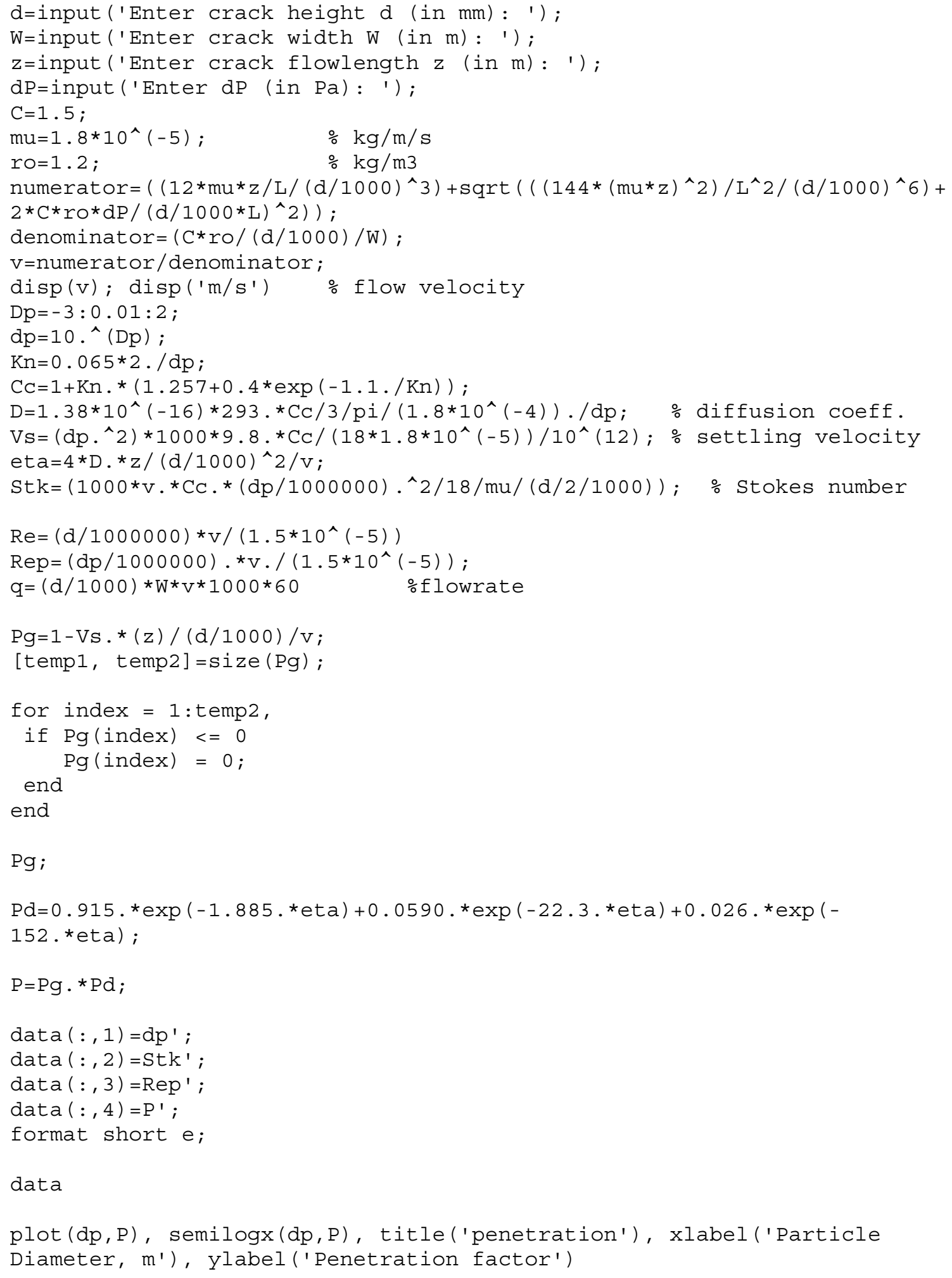




\section{APPENDIX D MAKING THE CONCRETE CRACK SAMPLE}

To simulate the surface roughness of concrete cracks in buildings, a cast was constructed so that the concrete surface resembles plywood grain after concrete is cured. The cast was made of aluminum with the inner surface laminated with a thin layer of plywood veneer.

\section{Materials}

Mix the ingredients according to the following proportions:

$\begin{array}{ll}450 \mathrm{~g} & \text { Portland cement } \\ 450 \mathrm{~g} & \text { sand } \\ 155 \mathrm{ml} & \text { water } \\ \text { multiple } & \text { metal wires }\end{array}$

\section{Procedure}

1. Brush kerosene onto the plywood surface so that the concrete would come out of the cast more easily.

2. Weigh and put above materials together into a bowl, and mix them well.

3. Pour the mixture into the cast to about half height.

4. Put the concrete and the cast on a vibrating machine; adjust the vibration frequency gradually to make the mixture distribute uniformly in the cast.

5. Place metal wires evenly on the surface of the concrete mixture to enhance the structural integrity.

6. Pour more concrete into the cast, and continue vibration only long enough to achieve proper consolidation. Excessive vibration may cause segregation ${ }^{1}$ of water, cement, and sand.

7. Allow to cure until hard, approximately 1 day.

8. Remove the concrete plate from the cast. Two concrete plates are required to assemble the crack apparatus, with two metal shims of appropriate thickness inserted at both ends (see Figure 3.1 for illustration).

${ }^{1}$ Annual Book of ASTM Standards. (2001) C192/C192M, Vol. 04.02, American Society for Testing and Materials, Philadelphia, U.S.A. 


\section{APPENDIX E CONSTRUCTION OF A CUSTOM-BUILT SUPERMICRON AEROSOL ATOMIZER}

A supermicron particle generation device was designed and constructed to meet the experimental needs of research reported in Chapters 3 and 4. This device was needed because most particles generated by the commercial Constant Output Atomizer (TSI 3075. St. Paul, MN) are in the submicron size range. Since large particles have higher tendency of being lost by impaction and gravitational setting in the transport system, the challenge is to minimize the particle loss prior to entering the experimental chamber. This was achieved by avoiding bends in the particle transport system. The custom-built atomizer comprises the following elements: a water and compressed-air mist nozzle (McMaster-Carr, Los Angeles, CA), a particle drying column, a liquid feeding system, and a radioactive charge neutralizer. The unit is illustrated in Figure E.1.

A peristaltic pump (Cole-Palmer, Vernon Hills, IL) was used to feed a saturated $\mathrm{KCl}$ aqueous solution into the nozzle while compressed air was provided simultaneously. The air flowrate and liquid feed rate were $\sim 100 \mathrm{lpm}$ and $0.8 \mathrm{cc} / \mathrm{min}$, respectively. The atomized droplets were desiccated by the upward flow of dry air ( 20 lpm) in the column, and were electrically neutralized by a Kr-85 radioactive source (TSI 3077, St. Paul, MN) before being introduced into the chamber. The drying column $(27 \times 28 \times 51$

$\mathrm{cm}^{3}$ ), made of acrylic plates, was built with the bottom plate detachable so that salt accumulation inside can be easily cleaned after each experiment. The maximum generated particle size can be $\sim 8 \mu \mathrm{m}$.

To prevent salt accumulation in the nozzle, clean water was supplied into the nozzle to flush out the $\mathrm{KCl}$ residue thoroughly with the peristaltic pump after particle 
generation was completed for each experimental run. A burst of compressed air was blown into the nozzle to remove the remaining water.

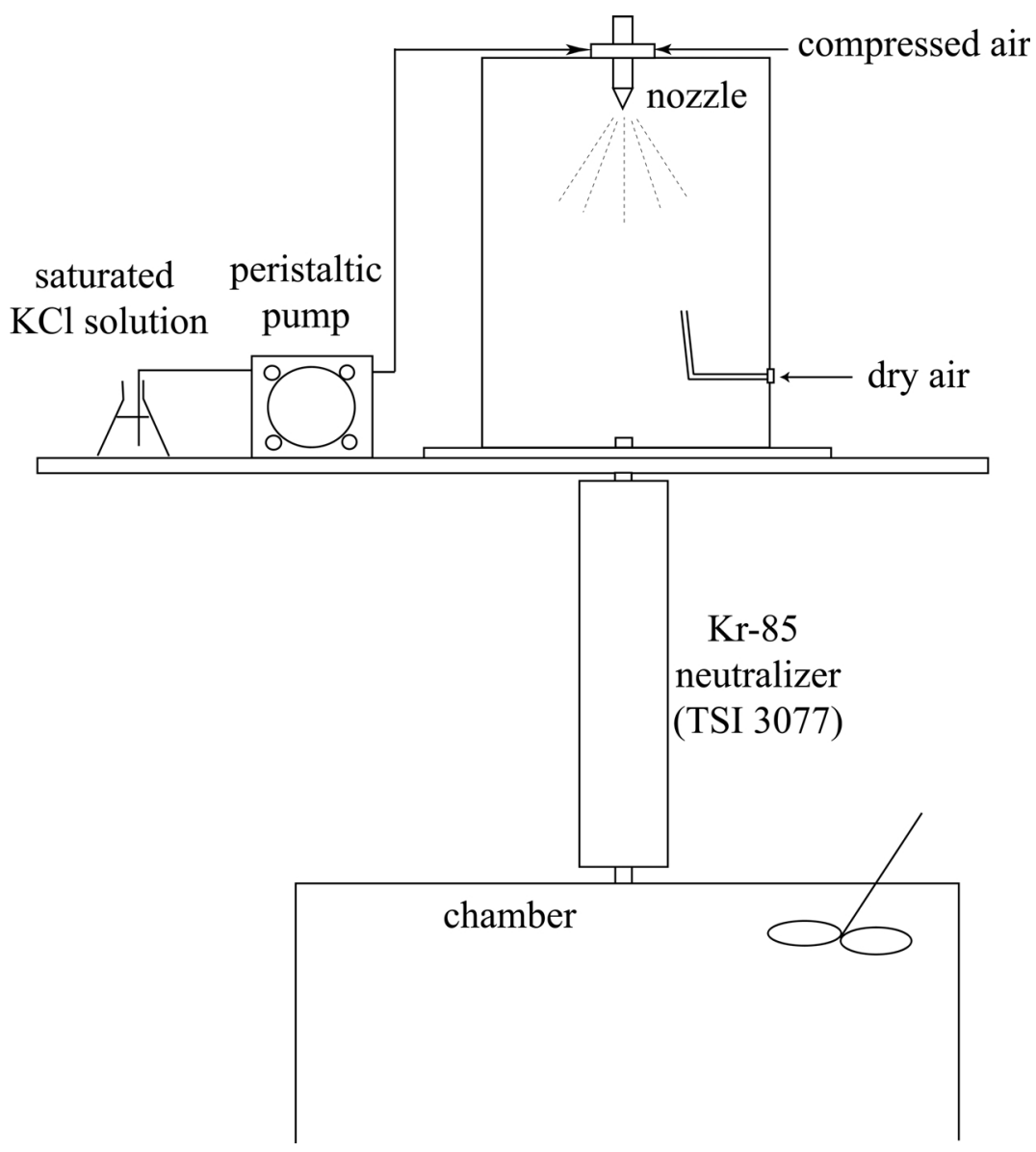

Figure E.1 Schematic illustration of the custom-built supermicron aerosol atomizer. 


\section{APPENDIX F WORKING PRINCIPLES OF AEROSOL INSTRUMENTS USED IN THIS STUDY}

\section{F.1 Differential Mobility Analyzer (DMA)}

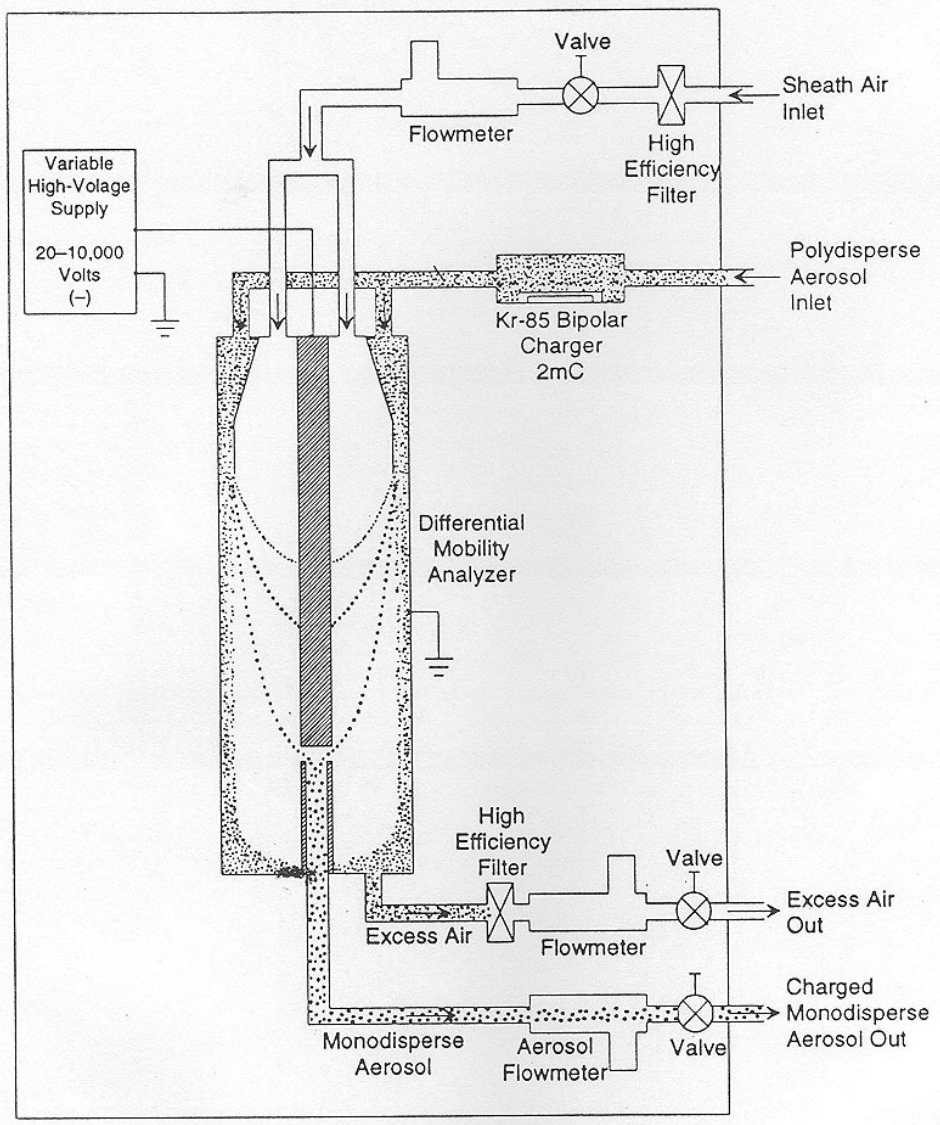

Figure F.1 Schematic of the Differential Mobility Analyzer, Model 3071 (from TSI manual).

In combination with an atomizer, the differential mobility analyzer (DMA) served as a monodisperse submicron particle generator. Before entering the DMA, the input polydisperse aerosols were neutralized to a Boltzmann equilibrium charge distribution, in 
which small particles $(<0.1 \mu \mathrm{m})$ carry either \pm 1 or 0 units of charge ${ }^{1}$. As depicted in Figure F.1, the laminar flow of clean air is surrounded by a thin annular layer of polydisperse aerosols. By adjusting the voltage of the central rod as well as the flow rates of sheath and aerosol-laden air streams, only particles possessing a narrow range of electrical mobilities can exit the monodisperse aerosol outlet. Particles with lower mobility go beyond the exit and pass into the excess air outlet, while particles with greater mobility migrate toward and deposit onto the central rod. The combination of atomizer and DMA can produce particles in the range of 0.01 to $1 \mu \mathrm{m}$. For generating particles larger than $0.1 \mu \mathrm{m}$, multiple particle sizes of the same electrical mobility will be generated thus some additional device, e.g., an impactor, may be needed to remove particles of undesired size.

\section{F.2 Electrical Aerosol Analyzer (EAA)}

With an analogous working principle to the DMA, the electrical aerosol analyzer (EAA) determines particle sizes based on their electrical mobility. The aerosol is introduced into the instrument, as schematically illustrated in Figure F.2, and passes through a unipolar diffusion charger. A laminar flow of clean air is surrounded by a thin annular layer of aerosol as the two streams travel axially between two concentric cylinders. All particles with mobility less than a cutoff mobility, as determined by the central rod voltage, leave the analyzer and subsequently are collected in a high-efficiency electrically conductive filter. An electrometer continuously monitors the current generated by the capture of charged particles in the filter. Because of the monotonic

${ }^{1}$ W.C. Hinds (1999) Aerosol Technology, Wiley, New York, second edition, p. 337. 
relationship between mobility and particle size, the difference in current measured at two analyzer voltage settings can be related to the number of particle in the size (mobility) range, that is defined by the cutoff sizes of the two voltage settings. In automatic operation, the instrument steps through 7 size ranges (with mean particle diameters of $0.024,0.042,0.075,0.13,0.24,0.42$, and $0.75 \mu \mathrm{m})$ in $\sim 76$ seconds.

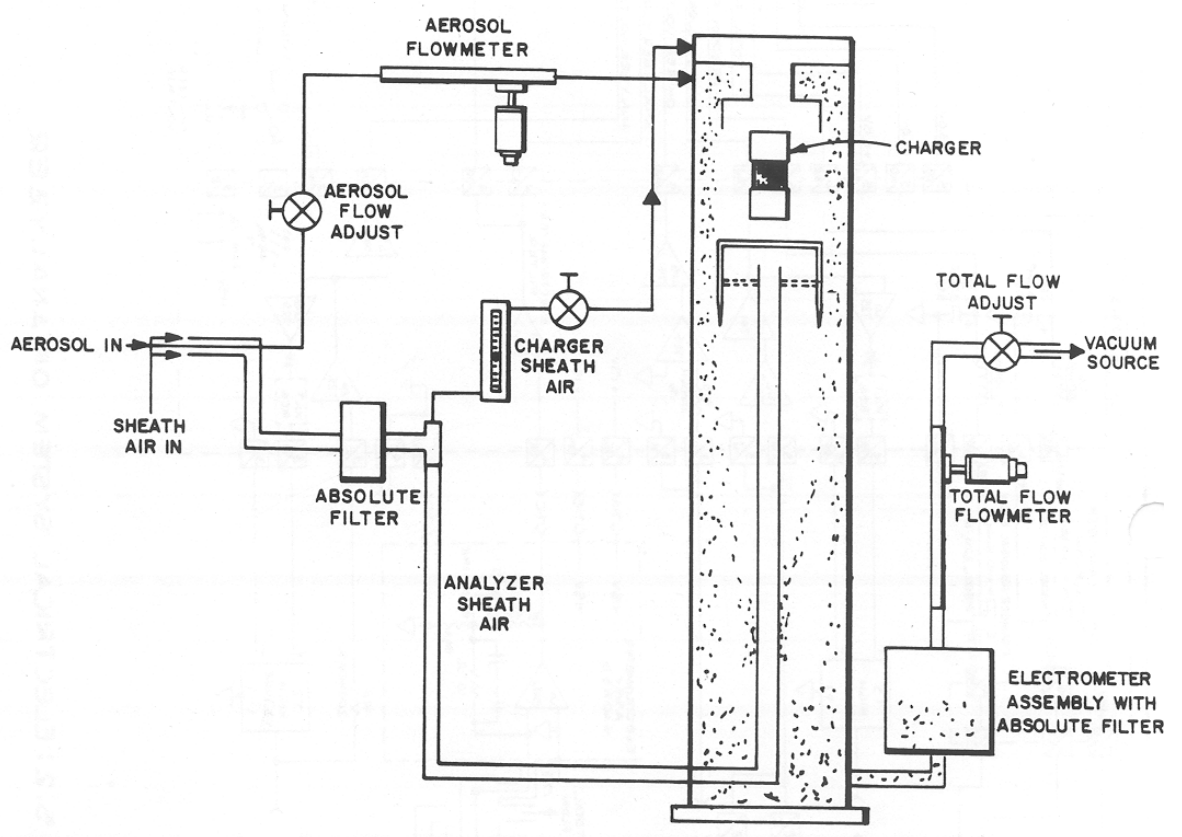

Figure F.2 Schematic diagram of the Electrical Aerosol Analyzer, Model 3030 (from TSI manual). 


\section{F.3 Aerodynamic Particle Sizer (APS)}

As shown schematically in Figure F.3, the Aerodynamic Particle Sizer (APS) is a time-of-flight spectrometer that measures particle sizes by their velocity in an accelerating air flow through a nozzle. The time of flight, which refers to the time interval as a particle passes between two laser beams, can be converted to the particle aerodynamic diameter through previous calibration work with monodisperse spherical particles of known size. The particle number concentration and size distribution $(0.5-20$ $\mu \mathrm{m})$ can be determined in real time.

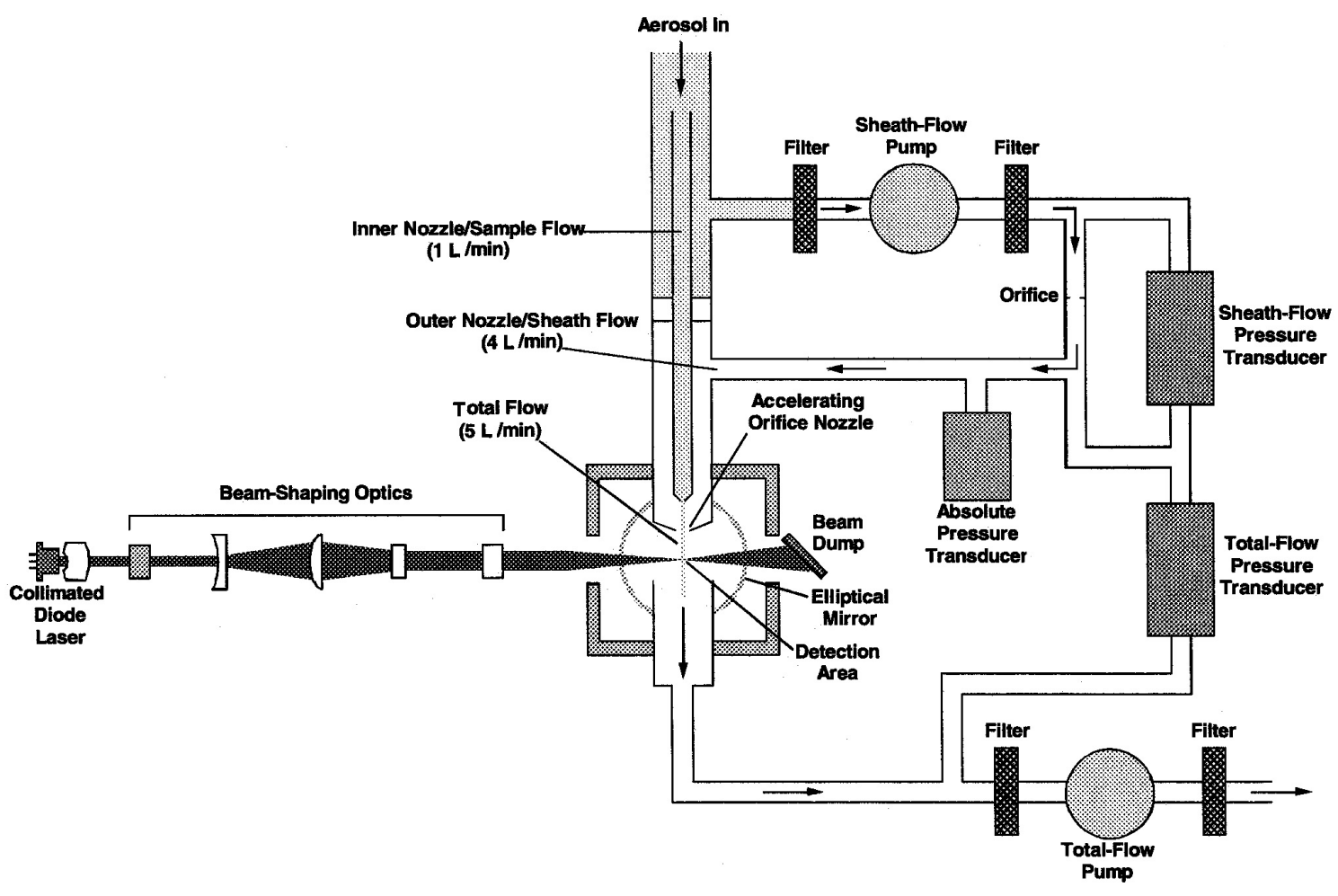

Figure F.3 Schematic illustration of the Aerodynamic Particle Sizer, Model 3320 (from TSI manual). 


\section{F.4 Laser Aerosol Spectrometer (LAS-X)}

As an optical particle counter, the Laser Aerosol Spectrometer (LAS-X) is based on the idea that scattered light intensity is a function of particle size. As a thin stream surrounded by filtered sheath airflow, the aerosol flows through a focused laser beam where a single particle is illuminated and scatters light to the photodetector. The light pulse is converted to an electronic signal and amplified. The electronic pulse is in turn directed to the proper size channel and counted. The particle size distribution is determined from the accumulated counts in each channel. Using laser as the light source, the minimum detectable particle size is $\sim 0.09 \mu \mathrm{m}$. The instrument is designed to measure to a maximum size of $3 \mu \mathrm{m}$. Light scattering depends on a particle's refractive index, so instrument accuracy is improved when used for particles of known, uniform chemical composition.

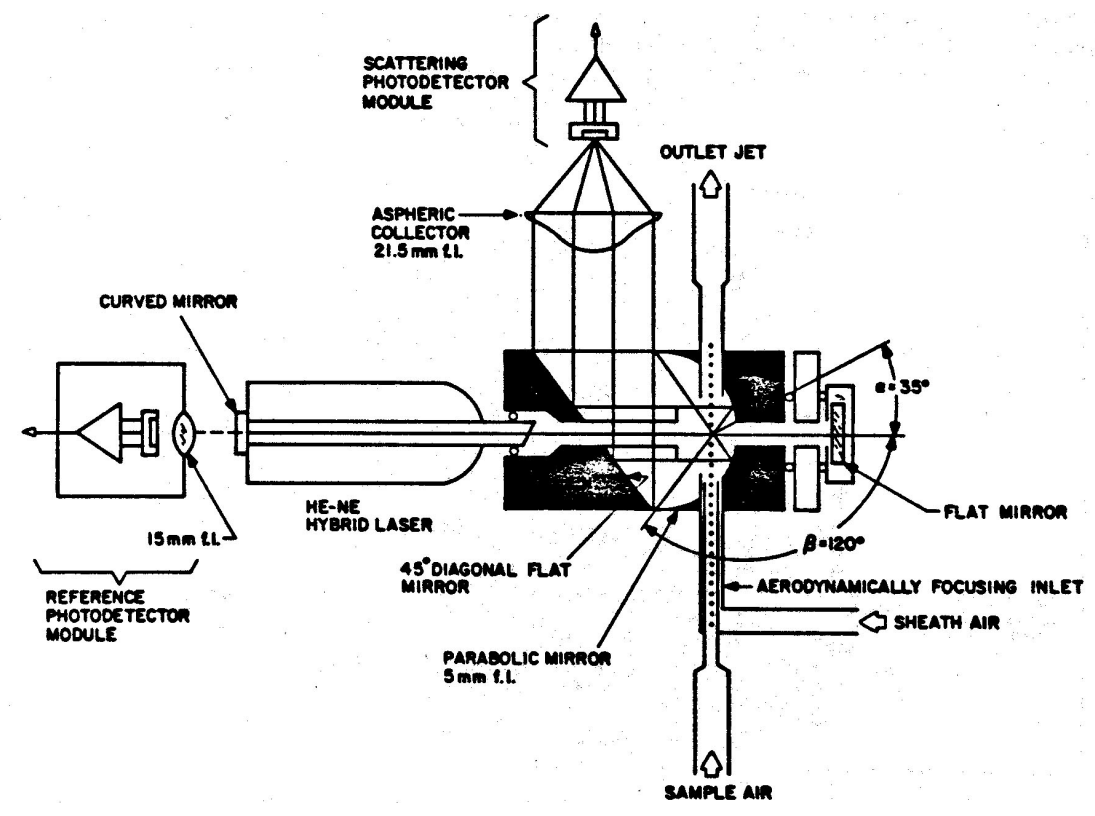

Figure F.4 Schematic of the LAS-X light scattering aerosol optical counter system. 


\section{F.5 Condensation Nucleus Counter (CNC)}

Also called a condensation particle counter (CPC), the condensation nucleus counter $(\mathrm{CNC})$ is used to measure the total number concentration of submicron particles, including those for which the light scattering efficiency is too low to be detected by conventional optical measurement. Thus, the operating principle of the $\mathrm{CNC}$ is to grow particles to a sufficient size so that they can be detected by an optical method. As shown in Figure F.5, the growth of particles is achieved by condensing alcohol vapor on the particle surface from supersaturated vapor. Since each small particle (condensation nucleus) grows to a droplet, the number concentration of droplets and nuclei is the same as long as the nucleus is above a critical minimum size. For example, the smallest nucleus size for growing within the TSI instruments, Model 3022 and 3022A, is 0.02 and $0.03 \mu \mathrm{m}$, respectively.

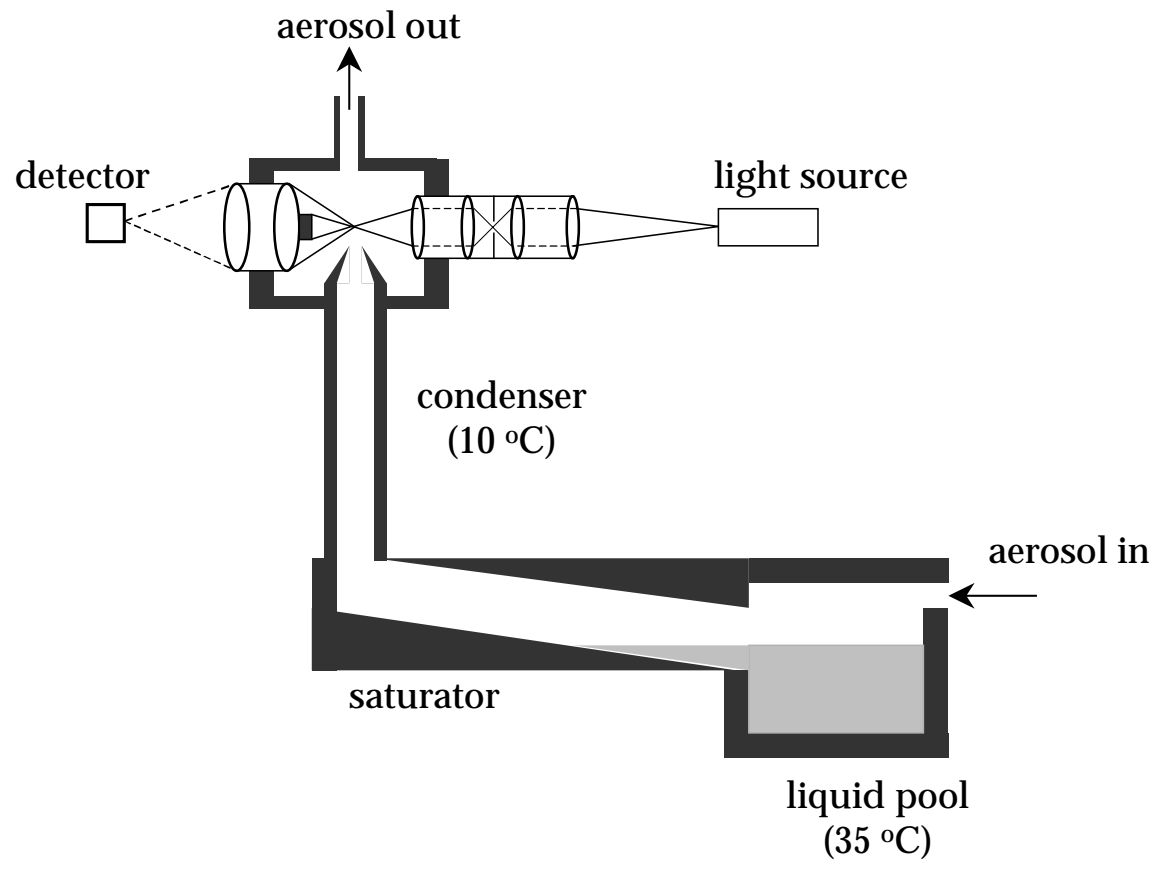

Figure F.5 Schematic drawing of the Condensation Nuclei Counter system. 


\section{APPENDIX G PENETRATION FACTORS MEASURED FOR CRACKS MADE OF ALUMINUM, SIX BUILDING MATERIALS, AND A BROKEN BRICK}

To make the experimental data available for future use, the following tables, categorized by the crack dimensions, pressure difference $(\Delta \mathrm{P})$ across the cracks, and the instrumentation used in the experiments, provide the statistics of the measured penetration factors as a function of particle size for cracks made of different materials in Chapter 3. 
Table G.1 Experimental particle penetration factors for cracks made of aluminum

\begin{tabular}{|c|c|c|c|c|c|c|c|c|c|}
\hline $\begin{array}{c}\text { Particle } \\
\text { diameter } \\
(\mu \mathrm{m})\end{array}$ & mean & $\begin{array}{c}\text { standard } \\
\text { deviation }\end{array}$ & $\begin{array}{c}\text { standard } \\
\text { error }\end{array}$ & $\begin{array}{c}95 \% \\
\text { confidence } \\
\text { interval }\end{array}$ & $\begin{array}{c}\text { Particle } \\
\text { diameter } \\
(\mu \mathrm{m})\end{array}$ & mean & $\begin{array}{l}\text { standard } \\
\text { deviation }\end{array}$ & $\begin{array}{c}\text { standard } \\
\text { error }\end{array}$ & $\begin{array}{c}95 \% \\
\text { confidence } \\
\text { interval }\end{array}$ \\
\hline$\Delta \mathrm{P}=4 \mathrm{~Pa}$ & \multicolumn{9}{|c|}{$\Delta \mathrm{P}=10 \mathrm{~Pa}$} \\
\hline \multirow{2}{*}{\multicolumn{10}{|c|}{${ }_{d=1 n}$}} \\
\hline & & & & & & & & & \\
\hline 0.626 & 1.031 & 0.116 & 0.024 & 0.050 & 0.626 & 1.004 & 0.117 & 0.029 & 0.062 \\
\hline 0.673 & 1.009 & 0.059 & 0.012 & 0.026 & 0.673 & 1.019 & 0.081 & 0.020 & 0.043 \\
\hline 0.723 & 1.018 & 0.061 & 0.013 & 0.026 & 0.723 & 1.023 & 0.075 & 0.019 & 0.040 \\
\hline 0.777 & 1.007 & 0.045 & 0.009 & 0.019 & 0.777 & 0.999 & 0.049 & 0.012 & 0.026 \\
\hline 0.835 & 1.020 & 0.057 & 0.012 & 0.024 & 0.835 & 0.987 & 0.037 & 0.009 & 0.020 \\
\hline 0.898 & 1.017 & 0.048 & 0.010 & 0.021 & 0.898 & 0.992 & 0.038 & 0.010 & 0.020 \\
\hline 0.965 & 1.010 & 0.052 & 0.011 & 0.022 & 0.965 & 1.004 & 0.027 & 0.007 & 0.014 \\
\hline 1.037 & 1.005 & 0.057 & 0.012 & 0.025 & 1.037 & 0.995 & 0.033 & 0.008 & 0.018 \\
\hline 1.114 & 1.005 & 0.055 & 0.011 & 0.024 & 1.114 & 0.982 & 0.043 & 0.011 & 0.023 \\
\hline 1.197 & 0.990 & 0.061 & 0.013 & 0.026 & 1.197 & 0.996 & 0.034 & 0.009 & 0.018 \\
\hline 1.286 & 0.998 & 0.075 & 0.016 & 0.032 & 1.286 & 0.983 & 0.032 & 0.008 & 0.017 \\
\hline 1.382 & 0.987 & 0.065 & 0.014 & 0.028 & 1.382 & 0.988 & 0.040 & 0.010 & 0.021 \\
\hline 1.486 & 0.980 & 0.077 & 0.016 & 0.033 & 1.486 & 0.974 & 0.034 & 0.009 & 0.018 \\
\hline 1.596 & 0.963 & 0.065 & 0.014 & 0.028 & 1.596 & 0.984 & 0.035 & 0.009 & 0.019 \\
\hline 1.715 & 0.956 & 0.081 & 0.017 & 0.035 & 1.715 & 0.979 & 0.039 & 0.010 & 0.021 \\
\hline 1.843 & 0.941 & 0.079 & 0.016 & 0.034 & 1.843 & 0.985 & 0.032 & 0.008 & 0.017 \\
\hline 1.981 & 0.912 & 0.109 & 0.023 & 0.047 & 1.981 & 0.958 & 0.028 & 0.007 & 0.015 \\
\hline 2.129 & 0.897 & 0.100 & 0.021 & 0.043 & 2.129 & 0.965 & 0.032 & 0.008 & 0.017 \\
\hline 2.288 & 0.882 & 0.091 & 0.019 & 0.039 & 2.288 & 0.949 & 0.034 & 0.008 & 0.018 \\
\hline 2.458 & 0.875 & 0.105 & 0.022 & 0.045 & 2.458 & 0.941 & 0.040 & 0.010 & 0.021 \\
\hline 2.642 & 0.866 & 0.109 & 0.023 & 0.047 & 2.642 & 0.926 & 0.028 & 0.007 & 0.015 \\
\hline 2.839 & 0.844 & 0.094 & 0.020 & 0.041 & 2.839 & 0.899 & 0.048 & 0.012 & 0.026 \\
\hline 3.051 & 0.830 & 0.113 & 0.024 & 0.049 & 3.051 & 0.926 & 0.049 & 0.012 & 0.026 \\
\hline 3.278 & 0.831 & 0.126 & 0.026 & 0.055 & 3.278 & 0.871 & 0.050 & 0.013 & 0.027 \\
\hline 3.523 & 0.795 & 0.105 & 0.022 & 0.046 & 3.523 & 0.872 & 0.073 & 0.018 & 0.039 \\
\hline 3.786 & 0.762 & 0.084 & 0.018 & 0.036 & 3.786 & 0.853 & 0.077 & 0.019 & 0.041 \\
\hline 4.068 & 0.714 & 0.161 & 0.034 & 0.070 & 4.068 & 0.834 & 0.106 & 0.026 & 0.056 \\
\hline 4.371 & 0.667 & 0.133 & 0.028 & 0.057 & 4.371 & 0.820 & 0.075 & 0.019 & 0.040 \\
\hline 4.698 & 0.646 & 0.134 & 0.028 & 0.058 & 4.698 & 0.774 & 0.097 & 0.024 & 0.052 \\
\hline 5.048 & 0.537 & 0.091 & 0.019 & 0.040 & 5.048 & 0.766 & 0.105 & 0.026 & 0.056 \\
\hline 5.425 & 0.500 & 0.158 & 0.033 & 0.068 & & & & & \\
\hline \multicolumn{10}{|c|}{$d=1 \mathrm{~mm}, z=4.3 \mathrm{~cm}$} \\
\hline 0.626 & 0.975 & 0.157 & 0.032 & 0.066 & 0.626 & 1.029 & 0.160 & 0.030 & 0.062 \\
\hline 0.673 & 0.957 & 0.071 & 0.014 & 0.030 & 0.673 & 0.977 & 0.103 & 0.019 & 0.040 \\
\hline 0.723 & 0.981 & 0.064 & 0.013 & 0.027 & 0.723 & 0.989 & 0.080 & 0.015 & 0.031 \\
\hline 0.777 & 0.962 & 0.055 & 0.011 & 0.023 & 0.777 & 0.988 & 0.071 & 0.013 & 0.028 \\
\hline 0.835 & 0.994 & 0.057 & 0.012 & 0.024 & 0.835 & 0.989 & 0.067 & 0.013 & 0.026 \\
\hline 0.898 & 0.989 & 0.053 & 0.011 & 0.022 & 0.898 & 0.985 & 0.069 & 0.013 & 0.027 \\
\hline 0.965 & 0.993 & 0.045 & 0.009 & 0.019 & 0.965 & 0.994 & 0.062 & 0.012 & 0.024 \\
\hline 1.037 & 0.991 & 0.058 & 0.012 & 0.024 & 1.037 & 0.983 & 0.065 & 0.012 & 0.025 \\
\hline 1.114 & 1.000 & 0.048 & 0.010 & 0.020 & 1.114 & 0.991 & 0.059 & 0.011 & 0.023 \\
\hline 1.197 & 0.988 & 0.041 & 0.008 & 0.017 & 1.197 & 0.987 & 0.059 & 0.011 & 0.023 \\
\hline 1.286 & 0.999 & 0.059 & 0.012 & 0.025 & 1.286 & 0.993 & 0.060 & 0.011 & 0.023 \\
\hline 1.382 & 0.985 & 0.051 & 0.010 & 0.021 & 1.382 & 1.000 & 0.068 & 0.013 & 0.026 \\
\hline 1.486 & 0.993 & 0.055 & 0.011 & 0.023 & 1.486 & 0.993 & 0.059 & 0.011 & 0.023 \\
\hline 1.596 & 0.993 & 0.044 & 0.009 & 0.019 & 1.596 & 0.999 & 0.071 & 0.013 & 0.027 \\
\hline 1.715 & 0.992 & 0.045 & 0.009 & 0.019 & 1.715 & 0.994 & 0.061 & 0.011 & 0.024 \\
\hline 1.843 & 0.981 & 0.057 & 0.012 & 0.024 & 1.843 & 0.994 & 0.066 & 0.012 & 0.026 \\
\hline 1.981 & 0.980 & 0.054 & 0.011 & 0.023 & 1.981 & 1.012 & 0.065 & 0.012 & 0.025 \\
\hline 2.129 & 0.982 & 0.073 & 0.015 & 0.031 & 2.129 & 1.001 & 0.064 & 0.012 & 0.025 \\
\hline 2.288 & 0.985 & 0.080 & 0.016 & 0.034 & 2.288 & 0.994 & 0.070 & 0.013 & 0.027 \\
\hline 2.458 & 0.984 & 0.065 & 0.013 & 0.027 & 2.458 & 0.975 & 0.082 & 0.016 & 0.032 \\
\hline 2.642 & 0.978 & 0.079 & 0.016 & 0.033 & 2.642 & 0.980 & 0.075 & 0.014 & 0.029 \\
\hline 2.839 & 0.978 & 0.108 & 0.022 & 0.046 & 2.839 & 0.977 & 0.076 & 0.014 & 0.029 \\
\hline
\end{tabular}


Table G.1 (cont.)

\begin{tabular}{|c|c|c|c|c|c|c|c|c|c|}
\hline $\begin{array}{c}\text { Particle } \\
\text { diameter } \\
(\mu \mathrm{m})\end{array}$ & mean & $\begin{array}{c}\text { standard } \\
\text { deviation }\end{array}$ & $\begin{array}{l}\text { standard } \\
\text { error }\end{array}$ & $\begin{array}{c}95 \% \\
\text { confidence } \\
\text { interval }\end{array}$ & $\begin{array}{l}\text { Particle } \\
\text { diameter } \\
(\mu \mathrm{m})\end{array}$ & mean & $\begin{array}{c}\text { standard } \\
\text { deviation }\end{array}$ & $\begin{array}{l}\text { standard } \\
\text { error }\end{array}$ & $\begin{array}{c}95 \% \\
\text { confidence } \\
\text { interval }\end{array}$ \\
\hline$\Delta \mathrm{P}=4 \mathrm{~Pa}$ & & & & & $\Delta \mathrm{P}=10 \mathrm{~Pa}$ & & & & \\
\hline 3.051 & 0.965 & 0.091 & 0.018 & 0.038 & 3.051 & 0.966 & 0.095 & 0.018 & 0.037 \\
\hline 3.278 & 0.982 & 0.105 & 0.021 & 0.044 & 3.278 & 0.993 & 0.112 & 0.021 & 0.043 \\
\hline 3.523 & 0.961 & 0.081 & 0.017 & 0.034 & 3.523 & 0.985 & 0.106 & 0.020 & 0.041 \\
\hline 3.786 & 0.991 & 0.138 & 0.028 & 0.058 & 3.786 & 0.940 & 0.106 & 0.020 & 0.041 \\
\hline 4.068 & 0.948 & 0.130 & 0.026 & 0.055 & 4.068 & 0.963 & 0.132 & 0.025 & 0.051 \\
\hline 4.371 & 0.979 & 0.183 & 0.037 & 0.077 & 4.371 & 0.973 & 0.149 & 0.028 & 0.058 \\
\hline 4.698 & 0.981 & 0.114 & 0.023 & 0.048 & 4.698 & 0.984 & 0.181 & 0.034 & 0.070 \\
\hline 5.048 & 1.078 & 0.219 & 0.045 & 0.092 & 5.048 & 0.911 & 0.218 & 0.041 & 0.084 \\
\hline 5.425 & 1.039 & 0.226 & 0.046 & 0.096 & & & & & \\
\hline \multicolumn{10}{|c|}{$d=0.25 \mathrm{~mm}, z=9.4 \mathrm{~cm}$} \\
\hline 0.542 & 0.518 & 0.120 & 0.027 & 0.056 & 0.626 & 0.848 & 0.075 & 0.017 & 0.035 \\
\hline 0.583 & 0.522 & 0.106 & 0.023 & 0.048 & 0.673 & 0.867 & 0.064 & 0.014 & 0.030 \\
\hline 0.626 & 0.490 & 0.089 & 0.019 & 0.040 & 0.723 & 0.824 & 0.033 & 0.007 & 0.015 \\
\hline 0.673 & 0.470 & 0.131 & 0.029 & 0.060 & 0.777 & 0.786 & 0.041 & 0.009 & 0.019 \\
\hline 0.723 & 0.396 & 0.114 & 0.025 & 0.052 & 0.835 & 0.712 & 0.052 & 0.012 & 0.025 \\
\hline 0.777 & 0.304 & 0.116 & 0.025 & 0.053 & 0.898 & 0.697 & 0.066 & 0.015 & 0.031 \\
\hline 0.835 & 0.283 & 0.170 & 0.037 & 0.078 & 0.965 & 0.620 & 0.062 & 0.014 & 0.029 \\
\hline 0.898 & 0.225 & 0.121 & 0.027 & 0.057 & 1.037 & 0.553 & 0.048 & 0.011 & 0.022 \\
\hline 0.965 & 0.186 & 0.112 & 0.024 & 0.051 & 1.114 & 0.526 & 0.067 & 0.015 & 0.031 \\
\hline 1.037 & 0.122 & 0.101 & 0.022 & 0.046 & 1.197 & 0.438 & 0.045 & 0.010 & 0.021 \\
\hline 1.114 & 0.134 & 0.106 & 0.024 & 0.049 & 1.286 & 0.325 & 0.041 & 0.009 & 0.019 \\
\hline 1.197 & 0.078 & 0.083 & 0.018 & 0.038 & 1.382 & 0.199 & 0.044 & 0.010 & 0.021 \\
\hline 1.286 & 0.037 & 0.063 & 0.014 & 0.029 & 1.486 & 0.096 & 0.028 & 0.006 & 0.013 \\
\hline 1.382 & 0.033 & 0.055 & 0.012 & 0.026 & 1.596 & 0.038 & 0.024 & 0.005 & 0.011 \\
\hline 1.486 & 0.011 & 0.035 & 0.011 & 0.025 & 1.715 & 0.014 & 0.017 & 0.004 & 0.008 \\
\hline 1.596 & 0.000 & 0.000 & 0.000 & 0.000 & 1.843 & 0.002 & 0.006 & 0.001 & 0.003 \\
\hline 1.715 & 0.000 & 0.000 & 0.000 & 0.000 & 1.981 & 0.001 & 0.005 & 0.001 & 0.002 \\
\hline 1.843 & 0.000 & 0.000 & 0.000 & 0.000 & 2.129 & 0.000 & 0.000 & 0.000 & 0.000 \\
\hline \multicolumn{10}{|c|}{$d=0.25 \mathrm{~mm}, z=4.3 \mathrm{~cm}$} \\
\hline 0.626 & 0.963 & 0.062 & 0.016 & 0.035 & 0.626 & 1.012 & 0.038 & 0.009 & 0.019 \\
\hline 0.673 & 0.967 & 0.050 & 0.013 & 0.028 & 0.673 & 1.025 & 0.034 & 0.008 & 0.017 \\
\hline 0.723 & 0.920 & 0.070 & 0.018 & 0.039 & 0.723 & 1.013 & 0.032 & 0.008 & 0.016 \\
\hline 0.777 & 0.860 & 0.068 & 0.018 & 0.038 & 0.777 & 0.986 & 0.045 & 0.011 & 0.023 \\
\hline 0.835 & 0.857 & 0.094 & 0.024 & 0.052 & 0.835 & 0.980 & 0.036 & 0.009 & 0.019 \\
\hline 0.898 & 0.826 & 0.083 & 0.021 & 0.046 & 0.898 & 0.949 & 0.051 & 0.012 & 0.026 \\
\hline 0.965 & 0.809 & 0.085 & 0.022 & 0.047 & 0.965 & 0.915 & 0.041 & 0.010 & 0.021 \\
\hline 1.037 & 0.771 & 0.124 & 0.032 & 0.069 & 1.037 & 0.930 & 0.039 & 0.009 & 0.020 \\
\hline 1.114 & 0.744 & 0.107 & 0.028 & 0.059 & 1.114 & 0.921 & 0.051 & 0.012 & 0.026 \\
\hline 1.197 & 0.692 & 0.085 & 0.022 & 0.047 & 1.197 & 0.878 & 0.063 & 0.015 & 0.032 \\
\hline 1.286 & 0.611 & 0.079 & 0.020 & 0.044 & 1.286 & 0.861 & 0.075 & 0.018 & 0.038 \\
\hline 1.382 & 0.532 & 0.085 & 0.022 & 0.047 & 1.382 & 0.807 & 0.056 & 0.014 & 0.029 \\
\hline 1.486 & 0.504 & 0.076 & 0.020 & 0.042 & 1.486 & 0.772 & 0.059 & 0.014 & 0.030 \\
\hline 1.715 & 0.315 & 0.087 & 0.022 & 0.048 & 1.596 & 0.738 & 0.044 & 0.011 & 0.022 \\
\hline 1.84 & 0.227 & 0.129 & 0.033 & 0.072 & 1.715 & 0.715 & 0.062 & 0.015 & 0.032 \\
\hline 1.98 & 0.112 & 0.066 & 0.017 & 0.037 & 1.843 & 0.619 & 0.068 & 0.017 & 0.035 \\
\hline 2.13 & 0.087 & 0.078 & 0.020 & 0.043 & 1.981 & 0.617 & 0.097 & 0.024 & 0.050 \\
\hline \multirow[t]{7}{*}{2.29} & 0.062 & 0.074 & 0.019 & 0.041 & 2.129 & 0.524 & 0.082 & 0.020 & 0.042 \\
\hline & & & & & 2.288 & 0.494 & 0.105 & 0.025 & 0.054 \\
\hline & & & & & 2.458 & 0.388 & 0.100 & 0.024 & 0.051 \\
\hline & & & & & 2.642 & 0.275 & 0.139 & 0.034 & 0.071 \\
\hline & & & & & 2.839 & 0.298 & 0.186 & 0.045 & 0.096 \\
\hline & & & & & 3.051 & 0.258 & 0.254 & 0.062 & 0.131 \\
\hline & & & & & 3.278 & 0.106 & 0.131 & 0.032 & 0.067 \\
\hline
\end{tabular}


Table G.1 (cont.)

\begin{tabular}{|c|c|c|c|c|c|c|c|c|c|}
\hline $\begin{array}{c}\text { Particle } \\
\text { diameter } \\
(\mu \mathrm{m})\end{array}$ & mean & $\begin{array}{c}\text { standard } \\
\text { deviation }\end{array}$ & $\begin{array}{l}\text { standard } \\
\text { error }\end{array}$ & $\begin{array}{c}95 \% \\
\text { confidence } \\
\text { interval }\end{array}$ & $\begin{array}{c}\text { Particle } \\
\text { diameter } \\
(\mu \mathrm{m})\end{array}$ & mean & $\begin{array}{c}\text { standard } \\
\text { deviation }\end{array}$ & $\begin{array}{l}\text { standard } \\
\text { error }\end{array}$ & $\begin{array}{c}95 \% \\
\text { confidence } \\
\text { interval }\end{array}$ \\
\hline$\Delta \mathrm{P}=4 \mathrm{~Pa}$ & & & & & $\Delta \mathrm{P}=10 \mathrm{~Pa}$ & & & & \\
\hline \multicolumn{10}{|l|}{ EAA } \\
\hline \multicolumn{10}{|c|}{$d=1 \mathrm{~mm}, z=9.4 \mathrm{~cm}$} \\
\hline 0.024 & 0.817 & 0.102 & 0.019 & 0.039 & 0.024 & 0.949 & 0.056 & 0.010 & 0.021 \\
\hline 0.042 & 0.967 & 0.098 & 0.018 & 0.037 & 0.042 & 0.980 & 0.083 & 0.015 & 0.032 \\
\hline 0.075 & 0.927 & 0.038 & 0.007 & 0.014 & 0.075 & 0.972 & 0.042 & 0.008 & 0.016 \\
\hline 0.133 & 0.971 & 0.026 & 0.005 & 0.010 & 0.133 & 0.994 & 0.023 & 0.004 & 0.009 \\
\hline 0.237 & 0.986 & 0.015 & 0.003 & 0.006 & 0.237 & 0.992 & 0.022 & 0.004 & 0.008 \\
\hline 0.422 & 0.988 & 0.031 & 0.006 & 0.012 & 0.422 & 0.984 & 0.034 & 0.006 & 0.013 \\
\hline 0.75 & 0.981 & 0.035 & 0.007 & 0.013 & 0.75 & 1.003 & 0.031 & 0.006 & 0.012 \\
\hline \multicolumn{10}{|c|}{$d=1 \mathrm{~mm}, z=4.3 \mathrm{~cm}$} \\
\hline 0.024 & 0.910 & 0.159 & 0.030 & 0.061 & 0.024 & 0.918 & 0.089 & 0.017 & 0.034 \\
\hline 0.042 & 0.860 & 0.114 & 0.022 & 0.045 & 0.042 & 0.954 & 0.060 & 0.011 & 0.023 \\
\hline 0.075 & 0.957 & 0.033 & 0.006 & 0.013 & 0.075 & 0.989 & 0.027 & 0.005 & 0.010 \\
\hline 0.133 & 0.963 & 0.038 & 0.007 & 0.014 & 0.133 & 0.990 & 0.025 & 0.005 & 0.010 \\
\hline 0.237 & 0.979 & 0.035 & 0.006 & 0.013 & 0.237 & 0.979 & 0.029 & 0.005 & 0.011 \\
\hline 0.422 & 1.004 & 0.042 & 0.008 & 0.016 & 0.422 & 0.979 & 0.052 & 0.010 & 0.020 \\
\hline 0.75 & 0.976 & 0.054 & 0.010 & 0.021 & 0.75 & 1.012 & 0.071 & 0.013 & 0.028 \\
\hline \multicolumn{10}{|c|}{$d=0.25 \mathrm{~mm}, z=9.4 \mathrm{~cm}$} \\
\hline 0.024 & 0.310 & 0.108 & 0.019 & 0.038 & 0.024 & 0.365 & 0.156 & 0.028 & 0.056 \\
\hline 0.042 & 0.349 & 0.115 & 0.020 & 0.041 & 0.042 & 0.461 & 0.159 & 0.029 & 0.058 \\
\hline 0.075 & 0.500 & 0.113 & 0.020 & 0.041 & 0.075 & 0.559 & 0.121 & 0.020 & 0.041 \\
\hline 0.133 & 0.666 & 0.112 & 0.018 & 0.037 & 0.133 & 0.712 & 0.111 & 0.018 & 0.037 \\
\hline 0.237 & 0.728 & 0.132 & 0.022 & 0.044 & 0.237 & 0.783 & 0.107 & 0.018 & 0.036 \\
\hline 0.422 & 0.779 & 0.159 & 0.027 & 0.055 & 0.422 & 0.846 & 0.158 & 0.026 & 0.054 \\
\hline 0.75 & 0.725 & 0.230 & 0.041 & 0.083 & 0.75 & 0.805 & 0.161 & 0.027 & 0.054 \\
\hline \multicolumn{10}{|c|}{$d=0.25 \mathrm{~mm}, z=4.3 \mathrm{~cm}$} \\
\hline 0.024 & 0.528 & 0.229 & 0.040 & 0.081 & 0.024 & 0.602 & 0.151 & 0.026 & 0.052 \\
\hline 0.042 & 0.622 & 0.200 & 0.035 & 0.071 & 0.042 & 0.703 & 0.098 & 0.017 & 0.034 \\
\hline 0.075 & 0.691 & 0.122 & 0.021 & 0.042 & 0.075 & 0.775 & 0.079 & 0.013 & 0.027 \\
\hline 0.133 & 0.780 & 0.106 & 0.018 & 0.037 & 0.133 & 0.867 & 0.047 & 0.008 & 0.016 \\
\hline 0.237 & 0.849 & 0.107 & 0.018 & 0.037 & 0.237 & 0.888 & 0.053 & 0.009 & 0.018 \\
\hline 0.422 & 0.873 & 0.136 & 0.023 & 0.047 & 0.422 & 0.919 & 0.085 & 0.014 & 0.029 \\
\hline 0.75 & 0.891 & 0.226 & 0.038 & 0.078 & 0.75 & 0.929 & 0.120 & 0.020 & 0.041 \\
\hline \multicolumn{10}{|l|}{ DMA+CNC } \\
\hline \multicolumn{10}{|c|}{$d=1 \mathrm{~mm}, z=9.4 \mathrm{~cm}$} \\
\hline 0.02 & 0.868 & 0.019 & 0.004 & 0.009 & 0.02 & 0.868 & 0.130 & 0.028 & 0.058 \\
\hline 0.03 & 0.903 & 0.051 & 0.011 & 0.023 & 0.03 & 0.925 & 0.041 & 0.009 & 0.018 \\
\hline 0.09 & 0.944 & 0.032 & 0.008 & 0.018 & 0.09 & 0.947 & 0.031 & 0.007 & 0.015 \\
\hline \multicolumn{10}{|c|}{$d=1 \mathrm{~mm}, z=4.3 \mathrm{~cm}$} \\
\hline 0.02 & 0.909 & 0.029 & 0.007 & 0.016 & 0.03 & 0.933 & 0.023 & 0.005 & 0.010 \\
\hline 0.03 & 0.919 & 0.030 & 0.007 & 0.014 & 0.04 & 0.932 & 0.021 & 0.005 & 0.009 \\
\hline 0.09 & 0.927 & 0.027 & 0.006 & 0.013 & 0.09 & 0.946 & 0.031 & 0.007 & 0.015 \\
\hline \multicolumn{10}{|c|}{$d=0.25 \mathrm{~mm}, z=9.4 \mathrm{~cm}$} \\
\hline 0.04 & 0.083 & 0.017 & 0.004 & 0.007 & 0.03 & 0.215 & 0.036 & 0.007 & 0.015 \\
\hline 0.06 & 0.269 & 0.093 & 0.019 & 0.039 & 0.04 & 0.316 & 0.047 & 0.009 & 0.018 \\
\hline 0.09 & 0.347 & 0.063 & 0.013 & 0.027 & 0.09 & 0.654 & 0.036 & 0.007 & 0.014 \\
\hline \multicolumn{10}{|c|}{$d=0.25 \mathrm{~mm}, z=4.3 \mathrm{~cm}$} \\
\hline 0.03 & 0.436 & 0.023 & 0.005 & 0.011 & 0.03 & 0.561 & 0.028 & 0.006 & 0.012 \\
\hline 0.04 & 0.589 & 0.044 & 0.013 & 0.028 & 0.04 & 0.792 & 0.023 & 0.005 & 0.010 \\
\hline 0.09 & 0.754 & 0.048 & 0.011 & 0.023 & 0.09 & 0.765 & 0.015 & 0.003 & 0.007 \\
\hline
\end{tabular}


Table G.2 Experimental particle penetration factors for cracks made of six building materials $(z=4.5 \mathrm{~cm}, \Delta \mathrm{P}=4 \mathrm{~Pa})$

\begin{tabular}{|c|c|c|c|c|c|c|c|c|c|c|}
\hline & $\begin{array}{c}\text { Particle } \\
\text { diameter } \\
\quad(\mu \mathrm{m})\end{array}$ & mean & $\begin{array}{c}\text { standard } \\
\text { deviation }\end{array}$ & $\begin{array}{c}\text { standard } \\
\text { error }\end{array}$ & $\begin{array}{c}95 \% \\
\text { confidence } \\
\text { interval }\end{array}$ & $\begin{array}{l}\text { Particle } \\
\text { diameter } \\
\quad(\mu \mathrm{m})\end{array}$ & mean & $\begin{array}{c}\text { standard } \\
\text { deviation }\end{array}$ & $\begin{array}{c}\text { standard } \\
\text { error }\end{array}$ & $\begin{array}{c}95 \% \\
\text { confidence } \\
\text { interval }\end{array}$ \\
\hline$\overline{\text { Plywood }}$ & & \multirow{2}{*}{\multicolumn{9}{|c|}{ Pine lumber }} \\
\hline $\mathrm{mm}$ & & & & & & & & & & \\
\hline \multirow[t]{7}{*}{ EAA } & 0.024 & 0.383 & 0.195 & 0.039 & 0.081 & 0.542 & 0.619 & 0.284 & 0.046 & 0.092 \\
\hline & 0.042 & 0.456 & 0.238 & 0.046 & 0.094 & 0.583 & 0.741 & 0.228 & 0.034 & 0.068 \\
\hline & 0.075 & 0.710 & 0.135 & 0.023 & 0.048 & 0.626 & 0.821 & 0.191 & 0.027 & 0.055 \\
\hline & 0.133 & 0.779 & 0.112 & 0.019 & 0.040 & 0.673 & 0.862 & 0.202 & 0.030 & 0.060 \\
\hline & 0.237 & 0.821 & 0.133 & 0.024 & 0.048 & 0.723 & 0.826 & 0.170 & 0.024 & 0.049 \\
\hline & 0.422 & 0.857 & 0.147 & 0.026 & 0.054 & 0.777 & 0.827 & 0.173 & 0.027 & 0.054 \\
\hline & 0.75 & 0.771 & 0.242 & 0.043 & 0.089 & & & & & \\
\hline \multirow[t]{4}{*}{$\mathrm{DMA}+\mathrm{CNC}$} & 0.02 & 0.270 & 0.017 & 0.002 & 0.005 & 0.02 & 0.318 & 0.023 & 0.003 & 0.007 \\
\hline & 0.03 & 0.469 & 0.037 & 0.005 & 0.010 & 0.03 & 0.473 & 0.022 & 0.003 & 0.006 \\
\hline & 0.04 & 0.602 & 0.039 & 0.006 & 0.012 & 0.04 & 0.657 & 0.026 & 0.004 & 0.008 \\
\hline & 0.09 & 0.725 & 0.058 & 0.009 & 0.018 & 0.09 & 0.733 & 0.071 & 0.013 & 0.027 \\
\hline \multirow[t]{25}{*}{ APS } & 0.542 & 0.823 & 0.152 & 0.024 & 0.048 & 0.835 & 0.808 & 0.142 & 0.027 & 0.056 \\
\hline & 0.583 & 0.826 & 0.103 & 0.016 & 0.033 & 0.898 & 0.787 & 0.117 & 0.023 & 0.046 \\
\hline & 0.626 & 0.825 & 0.101 & 0.016 & 0.032 & 0.965 & 0.768 & 0.123 & 0.024 & 0.049 \\
\hline & 0.673 & 0.822 & 0.111 & 0.017 & 0.035 & 1.037 & 0.767 & 0.105 & 0.020 & 0.042 \\
\hline & 0.723 & 0.801 & 0.085 & 0.013 & 0.027 & 1.114 & 0.736 & 0.094 & 0.018 & 0.037 \\
\hline & 0.777 & 0.778 & 0.095 & 0.015 & 0.030 & 1.197 & 0.739 & 0.096 & 0.018 & 0.038 \\
\hline & 0.835 & 0.760 & 0.098 & 0.015 & 0.031 & 1.286 & 0.702 & 0.085 & 0.016 & 0.034 \\
\hline & 0.898 & 0.728 & 0.094 & 0.015 & 0.030 & 1.382 & 0.688 & 0.080 & 0.015 & 0.032 \\
\hline & 0.965 & 0.698 & 0.082 & 0.013 & 0.026 & 1.486 & 0.668 & 0.095 & 0.018 & 0.038 \\
\hline & 1.037 & 0.677 & 0.098 & 0.015 & 0.031 & 1.596 & 0.652 & 0.088 & 0.017 & 0.035 \\
\hline & 1.114 & 0.628 & 0.079 & 0.012 & 0.025 & 1.715 & 0.582 & 0.081 & 0.016 & 0.032 \\
\hline & 1.197 & 0.584 & 0.087 & 0.014 & 0.028 & 1.843 & 0.510 & 0.069 & 0.013 & 0.027 \\
\hline & 1.286 & 0.534 & 0.086 & 0.014 & 0.027 & 1.981 & 0.436 & 0.097 & 0.019 & 0.038 \\
\hline & 1.382 & 0.478 & 0.090 & 0.014 & 0.028 & 2.129 & 0.341 & 0.069 & 0.013 & 0.027 \\
\hline & 1.486 & 0.419 & 0.091 & 0.014 & 0.029 & 2.288 & 0.254 & 0.053 & 0.010 & 0.021 \\
\hline & 1.596 & 0.359 & 0.085 & 0.013 & 0.027 & 2.458 & 0.188 & 0.043 & 0.008 & 0.017 \\
\hline & 1.715 & 0.300 & 0.061 & 0.010 & 0.019 & 2.642 & 0.119 & 0.050 & 0.010 & 0.020 \\
\hline & 1.843 & 0.226 & 0.053 & 0.008 & 0.017 & 2.839 & 0.046 & 0.026 & 0.005 & 0.010 \\
\hline & 1.981 & 0.160 & 0.042 & 0.007 & 0.013 & 3.051 & 0.016 & 0.017 & 0.003 & 0.007 \\
\hline & 2.129 & 0.086 & 0.031 & 0.005 & 0.010 & 3.278 & 0.006 & 0.007 & 0.001 & 0.003 \\
\hline & 2.288 & 0.039 & 0.016 & 0.002 & 0.005 & 3.523 & 0.003 & 0.006 & 0.001 & 0.002 \\
\hline & 2.458 & 0.013 & 0.008 & 0.001 & 0.003 & 3.786 & 0.004 & 0.007 & 0.001 & 0.003 \\
\hline & 2.642 & 0.007 & 0.005 & 0.001 & 0.001 & & & & & \\
\hline & 2.839 & 0.008 & 0.009 & 0.001 & 0.003 & & & & & \\
\hline & 3.051 & 0.008 & 0.008 & 0.001 & 0.002 & & & & & \\
\hline \multicolumn{11}{|l|}{$d=1.0 \mathrm{~mm}$} \\
\hline \multirow[t]{7}{*}{ EAA } & 0.024 & 0.936 & 0.061 & 0.013 & 0.027 & 0.024 & 0.962 & 0.106 & 0.022 & 0.045 \\
\hline & 0.042 & 0.983 & 0.090 & 0.019 & 0.040 & 0.042 & 0.999 & 0.135 & 0.028 & 0.057 \\
\hline & 0.075 & 0.980 & 0.037 & 0.008 & 0.016 & 0.075 & 0.965 & 0.054 & 0.011 & 0.023 \\
\hline & 0.133 & 0.993 & 0.035 & 0.007 & 0.016 & 0.133 & 0.989 & 0.029 & 0.006 & 0.012 \\
\hline & 0.237 & 0.972 & 0.039 & 0.008 & 0.017 & 0.237 & 0.994 & 0.032 & 0.007 & 0.014 \\
\hline & 0.422 & 0.995 & 0.104 & 0.022 & 0.046 & 0.422 & 0.987 & 0.076 & 0.015 & 0.032 \\
\hline & 0.75 & 1.015 & 0.144 & 0.031 & 0.064 & & & & & \\
\hline
\end{tabular}


Table G.2 (cont.)

\begin{tabular}{|c|c|c|c|c|c|c|c|c|c|c|}
\hline & $\begin{array}{c}\text { Particle } \\
\text { diameter } \\
\quad(\mu \mathrm{m})\end{array}$ & mean & $\begin{array}{c}\text { standard } \\
\text { deviation }\end{array}$ & $\begin{array}{c}\text { standard } \\
\text { error }\end{array}$ & $\begin{array}{c}95 \% \\
\text { confidence } \\
\text { interval }\end{array}$ & $\begin{array}{l}\text { Particle } \\
\text { diameter } \\
(\mu \mathrm{m})\end{array}$ & mean & $\begin{array}{c}\text { standard } \\
\text { deviation }\end{array}$ & $\begin{array}{c}\text { standard } \\
\text { error }\end{array}$ & $\begin{array}{c}95 \% \\
\text { confidence } \\
\text { interval }\end{array}$ \\
\hline \multirow[t]{37}{*}{ APS } & 0.542 & 0.992 & 0.112 & 0.014 & 0.027 & 0.542 & 0.989 & 0.132 & 0.017 & 0.034 \\
\hline & 0.583 & 0.989 & 0.102 & 0.013 & 0.025 & 0.583 & 0.993 & 0.133 & 0.017 & 0.034 \\
\hline & 0.626 & 0.995 & 0.108 & 0.013 & 0.026 & 0.626 & 0.997 & 0.136 & 0.017 & 0.034 \\
\hline & 0.673 & 0.994 & 0.108 & 0.013 & 0.026 & 0.673 & 0.997 & 0.143 & 0.018 & 0.036 \\
\hline & 0.723 & 0.993 & 0.111 & 0.014 & 0.027 & 0.723 & 0.996 & 0.146 & 0.018 & 0.037 \\
\hline & 0.777 & 0.993 & 0.112 & 0.014 & 0.027 & 0.777 & 0.994 & 0.148 & 0.019 & 0.038 \\
\hline & 0.835 & 0.999 & 0.112 & 0.014 & 0.027 & 0.835 & 0.996 & 0.151 & 0.019 & 0.038 \\
\hline & 0.898 & 0.997 & 0.111 & 0.014 & 0.027 & 0.898 & 0.990 & 0.151 & 0.019 & 0.038 \\
\hline & 0.965 & 0.994 & 0.111 & 0.014 & 0.027 & 0.965 & 0.992 & 0.149 & 0.019 & 0.038 \\
\hline & 1.037 & 0.995 & 0.111 & 0.014 & 0.027 & 1.037 & 0.991 & 0.148 & 0.019 & 0.038 \\
\hline & 1.114 & 0.997 & 0.112 & 0.014 & 0.027 & 1.114 & 0.991 & 0.146 & 0.019 & 0.037 \\
\hline & 1.197 & 0.995 & 0.112 & 0.014 & 0.027 & 1.197 & 0.987 & 0.142 & 0.018 & 0.036 \\
\hline & 1.286 & 0.998 & 0.112 & 0.014 & 0.027 & 1.286 & 0.987 & 0.143 & 0.018 & 0.036 \\
\hline & 1.382 & 0.993 & 0.112 & 0.014 & 0.028 & 1.382 & 0.985 & 0.144 & 0.018 & 0.037 \\
\hline & 1.486 & 0.990 & 0.109 & 0.013 & 0.027 & 1.486 & 0.981 & 0.143 & 0.018 & 0.036 \\
\hline & 1.596 & 0.991 & 0.112 & 0.014 & 0.028 & 1.596 & 0.983 & 0.139 & 0.018 & 0.035 \\
\hline & 1.715 & 0.992 & 0.111 & 0.014 & 0.027 & 1.715 & 0.981 & 0.138 & 0.018 & 0.035 \\
\hline & 1.843 & 0.988 & 0.109 & 0.013 & 0.027 & 1.843 & 0.980 & 0.140 & 0.018 & 0.036 \\
\hline & 1.981 & 0.992 & 0.107 & 0.013 & 0.026 & 1.981 & 0.978 & 0.141 & 0.018 & 0.036 \\
\hline & 2.129 & 0.998 & 0.110 & 0.014 & 0.027 & 2.129 & 0.977 & 0.136 & 0.017 & 0.034 \\
\hline & 2.288 & 0.985 & 0.112 & 0.014 & 0.028 & 2.288 & 0.978 & 0.136 & 0.017 & 0.035 \\
\hline & 2.458 & 0.983 & 0.121 & 0.015 & 0.030 & 2.458 & 0.974 & 0.139 & 0.018 & 0.035 \\
\hline & 2.642 & 0.990 & 0.121 & 0.015 & 0.030 & 2.642 & 0.976 & 0.141 & 0.018 & 0.036 \\
\hline & 2.839 & 0.988 & 0.126 & 0.016 & 0.031 & 2.839 & 0.971 & 0.139 & 0.018 & 0.035 \\
\hline & 3.051 & 0.988 & 0.130 & 0.016 & 0.032 & 3.051 & 0.977 & 0.156 & 0.020 & 0.040 \\
\hline & 3.278 & 0.976 & 0.131 & 0.016 & 0.032 & 3.278 & 0.966 & 0.147 & 0.019 & 0.037 \\
\hline & 3.523 & 0.977 & 0.153 & 0.019 & 0.037 & 3.523 & 0.978 & 0.140 & 0.018 & 0.036 \\
\hline & 3.786 & 0.978 & 0.168 & 0.021 & 0.041 & 3.786 & 0.990 & 0.176 & 0.022 & 0.045 \\
\hline & 4.068 & 0.958 & 0.197 & 0.024 & 0.048 & 4.068 & 0.970 & 0.181 & 0.023 & 0.046 \\
\hline & 4.371 & 0.989 & 0.228 & 0.028 & 0.056 & 4.371 & 0.949 & 0.166 & 0.021 & 0.042 \\
\hline & 4.698 & 0.935 & 0.261 & 0.032 & 0.064 & 4.698 & 0.974 & 0.227 & 0.029 & 0.058 \\
\hline & 5.048 & 1.006 & 0.330 & 0.042 & 0.083 & 5.048 & 0.962 & 0.241 & 0.031 & 0.061 \\
\hline & 5.425 & 0.948 & 0.288 & 0.036 & 0.072 & 5.425 & 0.896 & 0.216 & 0.027 & 0.055 \\
\hline & 5.829 & 1.032 & 0.340 & 0.043 & 0.086 & 5.829 & 0.879 & 0.287 & 0.037 & 0.075 \\
\hline & 6.264 & 0.899 & 0.308 & 0.040 & 0.080 & 6.264 & 0.923 & 0.335 & 0.044 & 0.087 \\
\hline & 6.732 & 0.929 & 0.360 & 0.048 & 0.096 & 6.732 & 0.880 & 0.287 & 0.038 & 0.075 \\
\hline & 7.234 & 0.813 & 0.252 & 0.061 & 0.130 & 7.234 & 0.845 & 0.355 & 0.045 & 0.090 \\
\hline \multirow{8}{*}{$\begin{array}{r}\text { Strand board } \\
d=0.25 \mathrm{~mm} \\
\text { EAA }\end{array}$} & \multicolumn{10}{|c|}{ Redwood lumber } \\
\hline & 0.024 & 0.383 & 0.195 & 0.039 & 0.081 & 0.024 & 0.298 & 0.196 & 0.020 & 0.040 \\
\hline & 0.042 & 0.456 & 0.238 & 0.046 & 0.094 & 0.042 & 0.495 & 0.230 & 0.023 & 0.046 \\
\hline & 0.075 & 0.710 & 0.135 & 0.023 & 0.048 & 0.075 & 0.545 & 0.141 & 0.013 & 0.026 \\
\hline & 0.133 & 0.779 & 0.112 & 0.019 & 0.040 & 0.133 & 0.682 & 0.141 & 0.013 & 0.027 \\
\hline & 0.237 & 0.821 & 0.133 & 0.024 & 0.048 & 0.237 & 0.756 & 0.144 & 0.013 & 0.027 \\
\hline & 0.422 & 0.857 & 0.147 & 0.026 & 0.054 & 0.422 & 0.778 & 0.229 & 0.021 & 0.042 \\
\hline & 0.75 & 0.771 & 0.242 & 0.043 & 0.089 & & & & & \\
\hline \multirow[t]{4}{*}{$\mathrm{DMA}+\mathrm{CNC}$} & 0.02 & 0.270 & 0.017 & 0.002 & 0.005 & 0.02 & 0.496 & 0.043 & 0.006 & 0.013 \\
\hline & 0.03 & 0.469 & 0.037 & 0.005 & 0.010 & 0.03 & 0.594 & 0.039 & 0.006 & 0.012 \\
\hline & 0.04 & 0.602 & 0.039 & 0.006 & 0.012 & 0.04 & 0.678 & 0.056 & 0.008 & 0.017 \\
\hline & 0.09 & 0.725 & 0.058 & 0.009 & 0.018 & 0.09 & 0.822 & 0.097 & 0.015 & 0.029 \\
\hline
\end{tabular}


Table G.2 (cont.)

\begin{tabular}{|c|c|c|c|c|c|c|c|c|c|c|}
\hline & $\begin{array}{c}\text { Particle } \\
\text { diameter } \\
\quad(\mu \mathrm{m})\end{array}$ & mean & $\begin{array}{c}\text { standard } \\
\text { deviation }\end{array}$ & $\begin{array}{l}\text { standard } \\
\text { error }\end{array}$ & $\begin{array}{c}95 \% \\
\text { confidence } \\
\text { interval }\end{array}$ & $\begin{array}{c}\text { Particle } \\
\text { diameter } \\
\quad(\mu \mathrm{m})\end{array}$ & mean & $\begin{array}{c}\text { standard } \\
\text { deviation }\end{array}$ & $\begin{array}{l}\text { standard } \\
\text { error }\end{array}$ & $\begin{array}{c}95 \% \\
\text { confidence } \\
\text { interval }\end{array}$ \\
\hline \multirow[t]{25}{*}{ APS } & 0.542 & 0.823 & 0.152 & 0.024 & 0.048 & 0.542 & 0.788 & 0.102 & 0.018 & 0.036 \\
\hline & 0.583 & 0.826 & 0.103 & 0.016 & 0.033 & 0.583 & 0.774 & 0.090 & 0.016 & 0.032 \\
\hline & 0.626 & 0.825 & 0.101 & 0.016 & 0.032 & 0.626 & 0.771 & 0.074 & 0.013 & 0.026 \\
\hline & 0.673 & 0.822 & 0.111 & 0.017 & 0.035 & 0.673 & 0.766 & 0.075 & 0.013 & 0.027 \\
\hline & 0.723 & 0.801 & 0.085 & 0.013 & 0.027 & 0.723 & 0.757 & 0.078 & 0.014 & 0.028 \\
\hline & 0.777 & 0.778 & 0.095 & 0.015 & 0.030 & 0.777 & 0.741 & 0.074 & 0.013 & 0.026 \\
\hline & 0.835 & 0.760 & 0.098 & 0.015 & 0.031 & 0.835 & 0.738 & 0.072 & 0.012 & 0.025 \\
\hline & 0.898 & 0.728 & 0.094 & 0.015 & 0.030 & 0.898 & 0.718 & 0.075 & 0.013 & 0.027 \\
\hline & 0.965 & 0.698 & 0.082 & 0.013 & 0.026 & 0.965 & 0.708 & 0.075 & 0.013 & 0.027 \\
\hline & 1.037 & 0.677 & 0.098 & 0.015 & 0.031 & 1.037 & 0.688 & 0.086 & 0.015 & 0.030 \\
\hline & 1.114 & 0.628 & 0.079 & 0.012 & 0.025 & 1.114 & 0.641 & 0.085 & 0.015 & 0.030 \\
\hline & 1.197 & 0.584 & 0.087 & 0.014 & 0.028 & 1.197 & 0.596 & 0.095 & 0.016 & 0.033 \\
\hline & 1.286 & 0.534 & 0.086 & 0.014 & 0.027 & 1.286 & 0.542 & 0.104 & 0.018 & 0.036 \\
\hline & 1.382 & 0.478 & 0.090 & 0.014 & 0.028 & 1.382 & 0.461 & 0.082 & 0.014 & 0.028 \\
\hline & 1.486 & 0.419 & 0.091 & 0.014 & 0.029 & 1.486 & 0.394 & 0.087 & 0.015 & 0.030 \\
\hline & 1.596 & 0.359 & 0.085 & 0.013 & 0.027 & 1.596 & 0.346 & 0.114 & 0.019 & 0.039 \\
\hline & 1.715 & 0.300 & 0.061 & 0.010 & 0.019 & 1.715 & 0.271 & 0.099 & 0.017 & 0.034 \\
\hline & 1.843 & 0.226 & 0.053 & 0.008 & 0.017 & 1.843 & 0.206 & 0.089 & 0.015 & 0.030 \\
\hline & 1.981 & 0.160 & 0.042 & 0.007 & 0.013 & 1.981 & 0.130 & 0.079 & 0.013 & 0.027 \\
\hline & 2.129 & 0.086 & 0.031 & 0.005 & 0.010 & 2.129 & 0.079 & 0.068 & 0.011 & 0.023 \\
\hline & 2.288 & 0.039 & 0.016 & 0.002 & 0.005 & 2.288 & 0.048 & 0.044 & 0.007 & 0.015 \\
\hline & 2.458 & 0.013 & 0.008 & 0.001 & 0.003 & 2.458 & 0.005 & 0.007 & 0.001 & 0.003 \\
\hline & 2.642 & 0.007 & 0.005 & 0.001 & 0.001 & 2.642 & 0.018 & 0.022 & 0.004 & 0.008 \\
\hline & 2.839 & 0.008 & 0.009 & 0.001 & 0.003 & 2.839 & 0.013 & 0.019 & 0.003 & 0.007 \\
\hline & 3.051 & 0.008 & 0.008 & 0.001 & 0.002 & 3.051 & 0.008 & 0.015 & 0.002 & 0.005 \\
\hline \multicolumn{11}{|l|}{$d=1.0 \mathrm{~mm}$} \\
\hline \multirow[t]{7}{*}{ EAA } & 0.024 & 0.936 & 0.061 & 0.013 & 0.027 & 0.024 & 0.953 & 0.088 & 0.018 & 0.036 \\
\hline & 0.042 & 0.983 & 0.090 & 0.019 & 0.040 & 0.042 & 1.019 & 0.126 & 0.025 & 0.051 \\
\hline & 0.075 & 0.980 & 0.037 & 0.008 & 0.016 & 0.075 & 0.964 & 0.055 & 0.011 & 0.022 \\
\hline & 0.133 & 0.993 & 0.035 & 0.007 & 0.016 & 0.133 & 0.983 & 0.088 & 0.017 & 0.035 \\
\hline & 0.237 & 0.972 & 0.039 & 0.008 & 0.017 & 0.237 & 0.998 & 0.090 & 0.017 & 0.036 \\
\hline & 0.422 & 0.995 & 0.104 & 0.022 & 0.046 & 0.422 & 0.999 & 0.089 & 0.017 & 0.035 \\
\hline & 0.75 & 1.015 & 0.144 & 0.031 & 0.064 & & & & & \\
\hline \multirow[t]{18}{*}{ APS } & 0.542 & 0.992 & 0.112 & 0.014 & 0.027 & 0.542 & 0.900 & 0.151 & 0.023 & 0.046 \\
\hline & 0.583 & 0.989 & 0.102 & 0.013 & 0.025 & 0.583 & 0.937 & 0.177 & 0.027 & 0.054 \\
\hline & 0.626 & 0.995 & 0.108 & 0.013 & 0.026 & 0.626 & 0.954 & 0.177 & 0.027 & 0.054 \\
\hline & 0.673 & 0.994 & 0.108 & 0.013 & 0.026 & 0.673 & 0.968 & 0.178 & 0.027 & 0.054 \\
\hline & 0.723 & 0.993 & 0.111 & 0.014 & 0.027 & 0.723 & 0.972 & 0.193 & 0.029 & 0.059 \\
\hline & 0.777 & 0.993 & 0.112 & 0.014 & 0.027 & 0.777 & 0.983 & 0.189 & 0.029 & 0.058 \\
\hline & 0.835 & 0.999 & 0.112 & 0.014 & 0.027 & 0.835 & 0.979 & 0.188 & 0.028 & 0.057 \\
\hline & 0.898 & 0.997 & 0.111 & 0.014 & 0.027 & 0.898 & 0.977 & 0.186 & 0.028 & 0.057 \\
\hline & 0.965 & 0.994 & 0.111 & 0.014 & 0.027 & 0.965 & 0.982 & 0.181 & 0.027 & 0.055 \\
\hline & 1.037 & 0.995 & 0.111 & 0.014 & 0.027 & 1.037 & 0.986 & 0.187 & 0.028 & 0.057 \\
\hline & 1.114 & 0.997 & 0.112 & 0.014 & 0.027 & 1.114 & 0.978 & 0.187 & 0.028 & 0.057 \\
\hline & 1.197 & 0.995 & 0.112 & 0.014 & 0.027 & 1.197 & 0.978 & 0.190 & 0.029 & 0.058 \\
\hline & 1.286 & 0.998 & 0.112 & 0.014 & 0.027 & 1.286 & 0.974 & 0.186 & 0.028 & 0.057 \\
\hline & 1.382 & 0.993 & 0.112 & 0.014 & 0.028 & 1.382 & 0.971 & 0.197 & 0.030 & 0.060 \\
\hline & 1.486 & 0.990 & 0.109 & 0.013 & 0.027 & 1.486 & 0.977 & 0.199 & 0.030 & 0.061 \\
\hline & 1.596 & 0.991 & 0.112 & 0.014 & 0.028 & 1.596 & 0.974 & 0.209 & 0.032 & 0.064 \\
\hline & 1.715 & 0.992 & 0.111 & 0.014 & 0.027 & 1.715 & 0.973 & 0.218 & 0.033 & 0.066 \\
\hline & 1.843 & 0.988 & 0.109 & 0.013 & 0.027 & 1.843 & 0.963 & 0.198 & 0.030 & 0.060 \\
\hline
\end{tabular}


Table G.2 (cont.)

\begin{tabular}{|c|c|c|c|c|c|c|c|c|c|c|}
\hline & $\begin{array}{l}\text { Particle } \\
\text { diameter } \\
\quad(\mu \mathrm{m})\end{array}$ & mean & $\begin{array}{l}\text { standard } \\
\text { deviation }\end{array}$ & $\begin{array}{l}\text { standard } \\
\text { error }\end{array}$ & $\begin{array}{c}95 \% \\
\text { confidence } \\
\text { interval }\end{array}$ & $\begin{array}{l}\text { Particle } \\
\text { diameter } \\
\quad(\mu \mathrm{m})\end{array}$ & mean & $\begin{array}{c}\text { standard } \\
\text { deviation }\end{array}$ & $\begin{array}{l}\text { standard } \\
\text { error }\end{array}$ & $\begin{array}{c}95 \% \\
\text { confidence } \\
\text { interval }\end{array}$ \\
\hline & 1.981 & 0.992 & 0.107 & 0.013 & 0.026 & 1.981 & 0.955 & 0.195 & 0.029 & 0.059 \\
\hline & 2.129 & 0.998 & 0.110 & 0.014 & 0.027 & 2.129 & 0.967 & 0.217 & 0.033 & 0.066 \\
\hline & 2.288 & 0.985 & 0.112 & 0.014 & 0.028 & 2.288 & 0.970 & 0.224 & 0.034 & 0.068 \\
\hline & 2.458 & 0.983 & 0.121 & 0.015 & 0.030 & 2.458 & 0.971 & 0.242 & 0.036 & 0.073 \\
\hline & 2.642 & 0.990 & 0.121 & 0.015 & 0.030 & 2.642 & 0.956 & 0.234 & 0.035 & 0.071 \\
\hline & 2.839 & 0.988 & 0.126 & 0.016 & 0.031 & 2.839 & 0.955 & 0.252 & 0.038 & 0.077 \\
\hline & 3.051 & 0.988 & 0.130 & 0.016 & 0.032 & 3.051 & 0.963 & 0.236 & 0.036 & 0.072 \\
\hline & 3.278 & 0.976 & 0.131 & 0.016 & 0.032 & 3.278 & 0.937 & 0.268 & 0.040 & 0.082 \\
\hline & 3.523 & 0.977 & 0.153 & 0.019 & 0.037 & 3.523 & 0.935 & 0.257 & 0.039 & 0.078 \\
\hline & 3.786 & 0.978 & 0.168 & 0.021 & 0.041 & 3.786 & 0.910 & 0.275 & 0.041 & 0.084 \\
\hline & 4.068 & 0.958 & 0.197 & 0.024 & 0.048 & 4.068 & 0.896 & 0.286 & 0.043 & 0.087 \\
\hline & 4.371 & 0.989 & 0.228 & 0.028 & 0.056 & 4.371 & 0.852 & 0.278 & 0.042 & 0.085 \\
\hline & 4.698 & 0.935 & 0.261 & 0.032 & 0.064 & 4.698 & 0.773 & 0.251 & 0.038 & 0.077 \\
\hline & 5.048 & 1.006 & 0.330 & 0.042 & 0.083 & 5.048 & 0.833 & 0.372 & 0.056 & 0.113 \\
\hline & 5.425 & 0.948 & 0.288 & 0.036 & 0.072 & 5.425 & 0.820 & 0.334 & 0.051 & 0.103 \\
\hline & 5.829 & 1.032 & 0.340 & 0.043 & 0.086 & 5.829 & 0.721 & 0.371 & 0.058 & 0.117 \\
\hline & 6.264 & 0.899 & 0.308 & 0.040 & 0.080 & 6.264 & 0.694 & 0.386 & 0.060 & 0.120 \\
\hline & 6.732 & 0.929 & 0.360 & 0.048 & 0.096 & 6.732 & 0.940 & 0.956 & 0.153 & 0.310 \\
\hline & 7.234 & 0.813 & 0.252 & 0.061 & 0.130 & 7.234 & 8.769 & 19.166 & 0.856 & 1.682 \\
\hline \multirow[t]{7}{*}{$\begin{array}{l}\text { Brick } \\
d=0.25 \mathrm{~mm}\end{array}$} & & & & & & Concrete & & & & \\
\hline & 0.024 & 0.329 & 0.317 & 0.043 & 0.086 & 0.024 & 0.342 & 0.198 & 0.032 & 0.064 \\
\hline & 0.042 & 0.550 & 0.260 & 0.043 & 0.088 & 0.042 & 0.466 & 0.198 & 0.031 & 0.062 \\
\hline & 0.075 & 0.769 & 0.237 & 0.028 & 0.055 & 0.075 & 0.623 & 0.268 & 0.035 & 0.070 \\
\hline & 0.133 & 0.849 & 0.151 & 0.017 & 0.034 & 0.133 & 0.669 & 0.236 & 0.031 & 0.061 \\
\hline & 0.237 & 0.911 & 0.174 & 0.020 & 0.040 & 0.237 & 0.739 & 0.202 & 0.026 & 0.053 \\
\hline & 0.422 & 0.863 & 0.177 & 0.020 & 0.040 & 0.422 & 0.777 & 0.195 & 0.025 & 0.051 \\
\hline \multirow[t]{4}{*}{$\mathrm{DMA}+\mathrm{CNC}$} & 0.02 & 0.383 & 0.028 & 0.004 & 0.008 & 0.02 & 0.551 & 0.031 & 0.005 & 0.009 \\
\hline & 0.03 & 0.502 & 0.038 & 0.006 & 0.011 & 0.03 & 0.597 & 0.035 & 0.005 & 0.009 \\
\hline & 0.04 & 0.670 & 0.037 & 0.006 & 0.011 & 0.04 & 0.684 & 0.025 & 0.004 & 0.008 \\
\hline & 0.09 & 0.773 & 0.066 & 0.010 & 0.020 & 0.09 & 0.772 & 0.059 & 0.011 & 0.022 \\
\hline \multirow[t]{19}{*}{ APS } & 0.542 & 0.834 & 0.148 & 0.028 & 0.057 & 0.542 & 0.782 & 0.141 & 0.023 & 0.046 \\
\hline & 0.583 & 0.848 & 0.096 & 0.018 & 0.037 & 0.583 & 0.761 & 0.104 & 0.017 & 0.034 \\
\hline & 0.626 & 0.835 & 0.115 & 0.021 & 0.044 & 0.626 & 0.736 & 0.063 & 0.010 & 0.020 \\
\hline & 0.673 & 0.813 & 0.097 & 0.018 & 0.037 & 0.673 & 0.724 & 0.056 & 0.009 & 0.018 \\
\hline & 0.723 & 0.804 & 0.088 & 0.016 & 0.033 & 0.723 & 0.696 & 0.053 & 0.008 & 0.017 \\
\hline & 0.777 & 0.795 & 0.096 & 0.018 & 0.037 & 0.777 & 0.667 & 0.056 & 0.009 & 0.018 \\
\hline & 0.835 & 0.773 & 0.092 & 0.017 & 0.035 & 0.835 & 0.645 & 0.054 & 0.009 & 0.017 \\
\hline & 0.898 & 0.747 & 0.079 & 0.015 & 0.030 & 0.898 & 0.602 & 0.051 & 0.008 & 0.016 \\
\hline & 0.965 & 0.690 & 0.094 & 0.017 & 0.036 & 0.965 & 0.574 & 0.057 & 0.009 & 0.018 \\
\hline & 1.037 & 0.678 & 0.077 & 0.014 & 0.029 & 1.037 & 0.535 & 0.056 & 0.009 & 0.018 \\
\hline & 1.114 & 0.643 & 0.090 & 0.017 & 0.034 & 1.114 & 0.487 & 0.050 & 0.008 & 0.016 \\
\hline & 1.197 & 0.584 & 0.093 & 0.017 & 0.035 & 1.197 & 0.448 & 0.045 & 0.007 & 0.015 \\
\hline & 1.286 & 0.533 & 0.081 & 0.015 & 0.031 & 1.286 & 0.412 & 0.045 & 0.007 & 0.014 \\
\hline & 1.382 & 0.469 & 0.085 & 0.016 & 0.032 & 1.382 & 0.365 & 0.038 & 0.006 & 0.012 \\
\hline & 1.486 & 0.379 & 0.086 & 0.016 & 0.033 & 1.486 & 0.328 & 0.039 & 0.006 & 0.013 \\
\hline & 1.596 & 0.321 & 0.080 & 0.015 & 0.031 & 1.596 & 0.275 & 0.034 & 0.005 & 0.011 \\
\hline & 1.715 & 0.246 & 0.064 & 0.012 & 0.024 & 1.715 & 0.227 & 0.033 & 0.005 & 0.011 \\
\hline & 1.843 & 0.170 & 0.070 & 0.013 & 0.027 & 1.843 & 0.186 & 0.030 & 0.005 & 0.010 \\
\hline & 1.981 & 0.097 & 0.032 & 0.006 & 0.012 & 1.981 & 0.145 & 0.027 & 0.004 & 0.009 \\
\hline
\end{tabular}


Table G.2 (cont.)

\begin{tabular}{|c|c|c|c|c|c|c|c|c|c|c|}
\hline & $\begin{array}{l}\text { Particle } \\
\text { diameter } \\
\quad(\mu \mathrm{m})\end{array}$ & mean & $\begin{array}{l}\text { standard } \\
\text { deviation }\end{array}$ & $\begin{array}{c}\text { standard } \\
\text { error }\end{array}$ & $\begin{array}{c}95 \% \\
\text { confidence } \\
\text { interval }\end{array}$ & $\begin{array}{l}\text { Particle } \\
\text { diameter } \\
\quad(\mu \mathrm{m})\end{array}$ & mean & $\begin{array}{c}\text { standard } \\
\text { deviation }\end{array}$ & $\begin{array}{l}\text { standard } \\
\text { error }\end{array}$ & $\begin{array}{c}95 \% \\
\text { confidence } \\
\text { interval }\end{array}$ \\
\hline & 2.129 & 0.057 & 0.043 & 0.008 & 0.016 & 2.129 & 0.105 & 0.026 & 0.004 & 0.008 \\
\hline & 2.288 & 0.017 & 0.009 & 0.002 & 0.003 & 2.288 & 0.070 & 0.021 & 0.003 & 0.007 \\
\hline & 2.458 & 0.007 & 0.009 & 0.002 & 0.004 & 2.458 & 0.040 & 0.020 & 0.003 & 0.007 \\
\hline & & & & & & 2.642 & 0.016 & 0.010 & 0.002 & 0.003 \\
\hline \multicolumn{11}{|l|}{$d=1.0 \mathrm{~mm}$} \\
\hline \multirow[t]{6}{*}{ EAA } & 0.024 & 0.961 & 0.075 & 0.011 & 0.021 & 0.024 & 0.941 & 0.063 & 0.012 & 0.025 \\
\hline & 0.042 & 0.979 & 0.089 & 0.013 & 0.026 & 0.042 & 0.961 & 0.085 & 0.016 & 0.032 \\
\hline & 0.075 & 0.972 & 0.034 & 0.005 & 0.010 & 0.075 & 0.976 & 0.030 & 0.005 & 0.011 \\
\hline & 0.133 & 0.987 & 0.020 & 0.003 & 0.006 & 0.133 & 0.992 & 0.029 & 0.005 & 0.011 \\
\hline & 0.237 & 0.986 & 0.022 & 0.003 & 0.006 & 0.237 & 0.994 & 0.043 & 0.008 & 0.015 \\
\hline & 0.422 & 0.980 & 0.026 & 0.004 & 0.007 & 0.422 & 0.985 & 0.032 & 0.006 & 0.012 \\
\hline \multirow[t]{36}{*}{ APS } & 0.542 & 0.992 & 0.074 & 0.013 & 0.026 & 0.542 & 0.998 & 0.102 & 0.015 & 0.031 \\
\hline & 0.583 & 0.991 & 0.076 & 0.013 & 0.026 & 0.583 & 0.999 & 0.106 & 0.016 & 0.032 \\
\hline & 0.626 & 0.985 & 0.077 & 0.013 & 0.027 & 0.626 & 1.000 & 0.107 & 0.016 & 0.032 \\
\hline & 0.673 & 0.987 & 0.076 & 0.013 & 0.027 & 0.673 & 1.001 & 0.108 & 0.016 & 0.033 \\
\hline & 0.723 & 0.988 & 0.080 & 0.014 & 0.028 & 0.723 & 1.001 & 0.109 & 0.016 & 0.033 \\
\hline & 0.777 & 0.987 & 0.076 & 0.013 & 0.027 & 0.777 & 1.004 & 0.109 & 0.016 & 0.033 \\
\hline & 0.835 & 0.987 & 0.078 & 0.013 & 0.027 & 0.835 & 1.002 & 0.107 & 0.016 & 0.033 \\
\hline & 0.898 & 0.987 & 0.077 & 0.013 & 0.027 & 0.898 & 1.003 & 0.104 & 0.016 & 0.031 \\
\hline & 0.965 & 0.988 & 0.078 & 0.013 & 0.027 & 0.965 & 1.002 & 0.106 & 0.016 & 0.032 \\
\hline & 1.037 & 0.987 & 0.079 & 0.013 & 0.027 & 1.037 & 1.000 & 0.103 & 0.016 & 0.031 \\
\hline & 1.114 & 0.986 & 0.078 & 0.013 & 0.027 & 1.114 & 1.002 & 0.100 & 0.015 & 0.031 \\
\hline & 1.197 & 0.990 & 0.079 & 0.014 & 0.028 & 1.197 & 1.002 & 0.103 & 0.016 & 0.031 \\
\hline & 1.286 & 0.992 & 0.080 & 0.014 & 0.028 & 1.286 & 1.003 & 0.103 & 0.016 & 0.031 \\
\hline & 1.382 & 0.991 & 0.078 & 0.013 & 0.027 & 1.382 & 1.001 & 0.102 & 0.015 & 0.031 \\
\hline & 1.486 & 0.991 & 0.082 & 0.014 & 0.029 & 1.486 & 0.997 & 0.098 & 0.015 & 0.030 \\
\hline & 1.596 & 0.984 & 0.083 & 0.014 & 0.029 & 1.596 & 0.990 & 0.100 & 0.015 & 0.030 \\
\hline & 1.715 & 0.983 & 0.080 & 0.014 & 0.029 & 1.715 & 0.990 & 0.101 & 0.015 & 0.031 \\
\hline & 1.843 & 0.986 & 0.083 & 0.014 & 0.029 & 1.843 & 0.990 & 0.099 & 0.015 & 0.030 \\
\hline & 1.981 & 0.984 & 0.085 & 0.015 & 0.030 & 1.981 & 0.980 & 0.103 & 0.015 & 0.031 \\
\hline & 2.129 & 0.980 & 0.084 & 0.014 & 0.029 & 2.129 & 0.977 & 0.100 & 0.015 & 0.030 \\
\hline & 2.288 & 0.975 & 0.082 & 0.014 & 0.029 & 2.288 & 0.978 & 0.102 & 0.015 & 0.031 \\
\hline & 2.458 & 0.975 & 0.086 & 0.015 & 0.030 & 2.458 & 0.968 & 0.104 & 0.016 & 0.032 \\
\hline & 2.642 & 0.966 & 0.087 & 0.015 & 0.030 & 2.642 & 0.973 & 0.101 & 0.015 & 0.031 \\
\hline & 2.839 & 0.966 & 0.090 & 0.015 & 0.031 & 2.839 & 0.957 & 0.097 & 0.015 & 0.030 \\
\hline & 3.051 & 0.962 & 0.093 & 0.016 & 0.033 & 3.051 & 0.958 & 0.099 & 0.015 & 0.030 \\
\hline & 3.278 & 0.949 & 0.090 & 0.015 & 0.031 & 3.278 & 0.942 & 0.099 & 0.015 & 0.030 \\
\hline & 3.523 & 0.932 & 0.088 & 0.015 & 0.031 & 3.523 & 0.922 & 0.105 & 0.016 & 0.032 \\
\hline & 3.786 & 0.916 & 0.092 & 0.016 & 0.032 & 3.786 & 0.933 & 0.131 & 0.020 & 0.040 \\
\hline & 4.068 & 0.909 & 0.084 & 0.014 & 0.029 & 4.068 & 0.882 & 0.138 & 0.021 & 0.042 \\
\hline & 4.371 & 0.888 & 0.092 & 0.016 & 0.032 & 4.371 & 0.863 & 0.133 & 0.020 & 0.040 \\
\hline & 4.698 & 0.855 & 0.102 & 0.017 & 0.035 & 4.698 & 0.809 & 0.159 & 0.024 & 0.048 \\
\hline & 5.048 & 0.847 & 0.126 & 0.021 & 0.043 & 5.048 & 0.842 & 0.203 & 0.031 & 0.062 \\
\hline & 5.425 & 0.825 & 0.127 & 0.021 & 0.044 & 5.425 & 0.839 & 0.201 & 0.031 & 0.063 \\
\hline & 5.829 & 0.816 & 0.159 & 0.027 & 0.054 & 5.829 & 0.745 & 0.195 & 0.030 & 0.061 \\
\hline & 6.264 & 0.762 & 0.159 & 0.025 & 0.051 & 6.264 & 0.851 & 0.201 & 0.031 & 0.063 \\
\hline & 6.732 & 0.731 & 0.132 & 0.021 & 0.042 & 6.732 & 0.878 & 0.239 & 0.039 & 0.080 \\
\hline
\end{tabular}


Table G.3 Experimental particle penetration factors for cracks created by naturally broken bricks $(\Delta \mathrm{P}=4 \mathrm{~Pa}$ and the nominal flow path length $z=4.5 \mathrm{~cm}$ )

\begin{tabular}{|c|c|c|c|c|c|}
\hline & $\begin{array}{c}\text { Particle } \\
\text { diameter }(\mu \mathrm{m})\end{array}$ & mean & $\begin{array}{c}\text { standard } \\
\text { deviation }\end{array}$ & $\begin{array}{c}\text { standard } \\
\text { error } \\
\end{array}$ & $\begin{array}{c}95 \% \text { confidence } \\
\text { interval }\end{array}$ \\
\hline \multicolumn{6}{|l|}{$d=0.25 \mathrm{~mm}$} \\
\hline \multirow[t]{4}{*}{$\mathrm{DMA}+\mathrm{CNC}$} & 0.02 & 0.161 & 0.215 & 0.030 & 0.061 \\
\hline & 0.03 & 0.211 & 0.013 & 0.002 & 0.003 \\
\hline & 0.04 & 0.446 & 0.032 & 0.006 & 0.012 \\
\hline & 0.09 & 0.645 & 0.069 & 0.017 & 0.035 \\
\hline \multirow[t]{27}{*}{ APS } & 0.542 & 0.680 & 0.128 & 0.037 & 0.082 \\
\hline & 0.583 & 0.694 & 0.128 & 0.035 & 0.077 \\
\hline & 0.626 & 0.702 & 0.133 & 0.033 & 0.071 \\
\hline & 0.673 & 0.690 & 0.109 & 0.027 & 0.058 \\
\hline & 0.723 & 0.668 & 0.097 & 0.026 & 0.056 \\
\hline & 0.777 & 0.616 & 0.158 & 0.037 & 0.079 \\
\hline & 0.835 & 0.626 & 0.119 & 0.032 & 0.069 \\
\hline & 0.898 & 0.603 & 0.169 & 0.044 & 0.094 \\
\hline & 0.965 & 0.550 & 0.165 & 0.037 & 0.077 \\
\hline & 1.037 & 0.509 & 0.198 & 0.047 & 0.098 \\
\hline & 1.114 & 0.441 & 0.156 & 0.028 & 0.057 \\
\hline & 1.197 & 0.396 & 0.162 & 0.029 & 0.059 \\
\hline & 1.286 & 0.354 & 0.168 & 0.030 & 0.062 \\
\hline & 1.382 & 0.312 & 0.180 & 0.032 & 0.066 \\
\hline & 1.486 & 0.285 & 0.168 & 0.030 & 0.062 \\
\hline & 1.596 & 0.236 & 0.174 & 0.031 & 0.064 \\
\hline & 1.715 & 0.195 & 0.167 & 0.030 & 0.061 \\
\hline & 1.843 & 0.165 & 0.167 & 0.030 & 0.061 \\
\hline & 1.981 & 0.142 & 0.165 & 0.030 & 0.060 \\
\hline & 2.129 & 0.106 & 0.156 & 0.028 & 0.057 \\
\hline & 2.288 & 0.081 & 0.149 & 0.027 & 0.055 \\
\hline & 2.458 & 0.060 & 0.128 & 0.023 & 0.047 \\
\hline & 2.642 & 0.047 & 0.113 & 0.020 & 0.041 \\
\hline & 2.839 & 0.037 & 0.083 & 0.015 & 0.030 \\
\hline & 3.051 & 0.030 & 0.061 & 0.011 & 0.022 \\
\hline & 3.278 & 0.020 & 0.041 & 0.007 & 0.015 \\
\hline & 3.523 & 0.023 & 0.027 & 0.005 & 0.010 \\
\hline \multirow[t]{11}{*}{ LAS-X } & 0.1 & 0.898 & 0.034 & 0.006 & 0.011 \\
\hline & 0.125 & 0.905 & 0.025 & 0.004 & 0.008 \\
\hline & 0.175 & 0.911 & 0.030 & 0.005 & 0.010 \\
\hline & 0.225 & 0.915 & 0.058 & 0.010 & 0.019 \\
\hline & 0.275 & 0.884 & 0.062 & 0.010 & 0.021 \\
\hline & 0.35 & 0.841 & 0.069 & 0.011 & 0.023 \\
\hline & 0.45 & 0.768 & 0.093 & 0.015 & 0.031 \\
\hline & 0.575 & 0.679 & 0.099 & 0.016 & 0.033 \\
\hline & 0.725 & 0.545 & 0.100 & 0.017 & 0.033 \\
\hline & 0.9 & 0.423 & 0.129 & 0.021 & 0.043 \\
\hline & 1.125 & 0.271 & 0.171 & 0.028 & 0.057 \\
\hline $\mathrm{VOAG}+\mathrm{CNC}$ & 0.94 & 0.354 & 0.035 & 0.006 & 0.013 \\
\hline
\end{tabular}


Table G.3 (cont.)

\begin{tabular}{|c|c|c|c|c|c|}
\hline & $\begin{array}{c}\text { Particle } \\
\text { diameter }(\mu \mathrm{m})\end{array}$ & mean & $\begin{array}{c}\text { standard } \\
\text { deviation }\end{array}$ & $\begin{array}{c}\text { standard } \\
\text { error }\end{array}$ & $\begin{array}{c}95 \% \text { confidence } \\
\text { interval }\end{array}$ \\
\hline \multicolumn{6}{|l|}{$d=1 \mathrm{~mm}$} \\
\hline \multirow[t]{4}{*}{$\mathrm{DMA}+\mathrm{CNC}$} & 0.02 & 0.920 & 0.906 & 0.971 & 0.988 \\
\hline & 0.03 & 0.046 & 0.036 & 0.033 & 0.045 \\
\hline & 0.04 & 0.007 & 0.005 & 0.005 & 0.007 \\
\hline & 0.09 & 0.014 & 0.011 & 0.010 & 0.013 \\
\hline \multirow[t]{7}{*}{ EAA } & 0.024 & 0.962 & 0.051 & 0.009 & 0.019 \\
\hline & 0.042 & 0.939 & 0.078 & 0.014 & 0.029 \\
\hline & 0.075 & 0.979 & 0.022 & 0.004 & 0.008 \\
\hline & 0.133 & 0.979 & 0.013 & 0.002 & 0.005 \\
\hline & 0.237 & 0.977 & 0.014 & 0.002 & 0.005 \\
\hline & 0.422 & 0.989 & 0.026 & 0.005 & 0.010 \\
\hline & 0.75 & 0.984 & 0.035 & 0.006 & 0.013 \\
\hline \multirow[t]{37}{*}{ APS } & 0.542 & 0.909 & 0.096 & 0.021 & 0.045 \\
\hline & 0.583 & 0.923 & 0.085 & 0.019 & 0.040 \\
\hline & 0.626 & 0.903 & 0.070 & 0.016 & 0.033 \\
\hline & 0.673 & 0.913 & 0.061 & 0.014 & 0.029 \\
\hline & 0.723 & 0.917 & 0.055 & 0.012 & 0.026 \\
\hline & 0.777 & 0.926 & 0.054 & 0.012 & 0.025 \\
\hline & 0.835 & 0.924 & 0.052 & 0.012 & 0.024 \\
\hline & 0.898 & 0.924 & 0.049 & 0.011 & 0.023 \\
\hline & 0.965 & 0.921 & 0.052 & 0.012 & 0.024 \\
\hline & 1.037 & 0.926 & 0.052 & 0.012 & 0.024 \\
\hline & 1.114 & 0.921 & 0.050 & 0.011 & 0.023 \\
\hline & 1.197 & 0.925 & 0.046 & 0.010 & 0.021 \\
\hline & 1.286 & 0.923 & 0.053 & 0.012 & 0.025 \\
\hline & 1.382 & 0.919 & 0.048 & 0.011 & 0.023 \\
\hline & 1.486 & 0.908 & 0.056 & 0.012 & 0.026 \\
\hline & 1.596 & 0.914 & 0.053 & 0.012 & 0.025 \\
\hline & 1.715 & 0.901 & 0.059 & 0.013 & 0.028 \\
\hline & 1.843 & 0.898 & 0.062 & 0.014 & 0.029 \\
\hline & 1.981 & 0.892 & 0.053 & 0.012 & 0.025 \\
\hline & 2.129 & 0.883 & 0.044 & 0.010 & 0.021 \\
\hline & 2.288 & 0.865 & 0.052 & 0.012 & 0.024 \\
\hline & 2.458 & 0.842 & 0.054 & 0.012 & 0.025 \\
\hline & 2.642 & 0.832 & 0.048 & 0.011 & 0.022 \\
\hline & 2.839 & 0.818 & 0.038 & 0.008 & 0.018 \\
\hline & 3.051 & 0.793 & 0.054 & 0.012 & 0.025 \\
\hline & 3.278 & 0.758 & 0.046 & 0.010 & 0.022 \\
\hline & 3.523 & 0.742 & 0.054 & 0.012 & 0.025 \\
\hline & 3.786 & 0.696 & 0.071 & 0.016 & 0.033 \\
\hline & 4.068 & 0.658 & 0.051 & 0.011 & 0.024 \\
\hline & 4.371 & 0.645 & 0.076 & 0.017 & 0.035 \\
\hline & 4.698 & 0.614 & 0.097 & 0.022 & 0.046 \\
\hline & 5.048 & 0.554 & 0.078 & 0.018 & 0.037 \\
\hline & 5.425 & 0.510 & 0.098 & 0.022 & 0.046 \\
\hline & 5.829 & 0.468 & 0.072 & 0.016 & 0.034 \\
\hline & 6.264 & 0.476 & 0.090 & 0.020 & 0.042 \\
\hline & 7.234 & 0.454 & 0.117 & 0.026 & 0.055 \\
\hline & 7.774 & 0.467 & 0.133 & 0.030 & 0.062 \\
\hline
\end{tabular}




\section{APPENDIX H SURFACE ROUGHNESS MEASUREMENT FOR TWO CRACK SAMPLES}

Strand board and brass, representing the roughest and smoothest materials used in the single crack experiments, were selected for surface roughness characterization. The measurement was performed with an optical phase-shift profiling instrument (Micromap Model 570) in the Optical Metrology Laboratory at Lawrence Berkeley National Laboratory. Because only a thin and small sample can be measured by the instrument, the aluminum plate was replaced by a brass shim that is believed to exhibit similar surface roughness. The roughness measurement results are presented in Table H.1.

The brass was fairly easy to measure, and showed good agreement between the $5 \times$ and $20 \times$ measurements. The strand board, however, was difficult to set up. This is due to its irregular surfaces with poor reflectivity. The Micromap assumes the complex reflectivity is constant over the entire measuring surface. If there is a difference in reflectivity between adjacent surfaces, the reflected phase difference is interpreted as a height difference. Thus a perfectly flat surface with different chemical makeup along the surface will be measured as a rough surface. However, the misinterpreted height variation should not exceed $0.5 \mu \mathrm{m}$. Therefore, the measurement data presented here are expected to be accurate within to $0.5 \mu \mathrm{m}$. 
Table H.1. Results of surface roughness measurement for brass (surrogate for aluminum) and strand board

\begin{tabular}{lcccc}
\hline Sample & Objective & Area measured, $\mu \mathrm{m}^{2}$ & $\mathrm{rms}^{\mathrm{a}}, \mu \mathrm{m}$ & $\mathrm{PV}^{\mathrm{b}}, \mu \mathrm{m}$ \\
\hline Brass & $5 \times$ & $784 \times 784$ & 0.13 & 5.41 \\
& $20 \times$ & $196 \times 196$ & 0.21 & 4.18 \\
Strand board & $5 \times$ & $784 \times 784$ & 9.7 & 85.4 \\
& $20 \times$ & $196 \times 196$ & 14.6 & 68.0 \\
\hline
\end{tabular}

${ }^{a}$ root mean square (rms) height variation from a best-fit plane over the $400 \times 400$ pixel area.

b peak to valley difference for the best-fit plane. 


\section{APPENDIX I DERIVATION OF PARTICLE DEPOSITION COEFFICIENTS AND PENETRATION FACTORS IN THE TIME-INTEGRATED AND TRANSIENT ANALYSIS}

This appendix provides the detailed derivation of Equations (5.4) and (5.5) for solving particle deposition coefficients and penetration factors in Chapter 5. Assuming that ambient particle infiltration is the only source and that there is no indoor particle generation in the house, the mass balance equation for describing indoor particle concentration $C_{i}$ is written

$$
\frac{d C_{i}}{d t}=\lambda_{v} C_{o}-\left(\lambda_{v}+k_{d}\right) C_{i}
$$

The first step in the basic analysis scheme involves evaluating particle deposition coefficients for a pressurized house. Integrating Equation (5.3) from $t=0$ to $t$ yields

$$
\int_{t=0}^{t} d\left(C_{i} \cdot V\right)=\int_{t=0}^{t}\left(Q \cdot C_{o}-Q \cdot C_{i}-k_{d} \cdot V \cdot C_{i}\right) d t
$$

where $Q$ is the ventilation supply rate into the house $\left(=\lambda_{v} \times V ; \mathrm{m}^{3} \mathrm{~h}^{-1}\right)$. As $Q$ and $V$ can be reasonably treated as constants during the experiment, evaluation of Equation (I.1) leads to

$$
V\left(C_{i}(t)-C_{i}(0)\right)=\tau_{\text {exp }}\left[Q \cdot \bar{C}_{o}-Q \cdot \bar{C}_{i}-k_{d} \cdot V \cdot \bar{C}_{i}\right]
$$

where $\bar{C}_{i}$ and $\bar{C}_{o}$ are the time-average concentrations of indoor and outdoor particles throughout the experiment, $\tau_{\mathrm{exp}}$ is the duration of experiment, and $C_{i}(0)$ and $C_{i}(t)$ are the indoor particle concentrations at beginning and end of the experiment, respectively. After rearrangement of Equation (I.2), $k_{d}$ is obtained as 


$$
k_{d}=\frac{\lambda_{v}}{\bar{C}_{i}}\left(\bar{C}_{o}-\bar{C}_{i}\right)-\frac{1}{\tau_{\exp } \bar{C}_{i}}\left[C_{i}(t)-C_{i}(0)\right]
$$

Particle deposition coefficients can be assessed based on Equation (5.4) when the house is pressurized.

When the house undergoes depressurization, on the other hand, the mass balance equation for indoor particle concentration $C_{i}$ becomes

$$
\frac{d C_{i}}{d t}=p \lambda_{v} C_{o}-\left(\lambda_{v}+k_{d}\right) C_{i}
$$

Integrating Equation (5.2) from $t=0$ to $t$ leads to

$$
V\left(C_{i}(t)-C_{i}(0)\right)=\tau_{\exp }\left[p \cdot Q \cdot \bar{C}_{o}-Q \cdot \bar{C}_{i}-k_{d} \cdot V \cdot \bar{C}_{i}\right]
$$

With the particle deposition coefficient obtained in Equation (5.4), the particle penetration factor can be solved by rearranging Equation (I.3):

$$
p=\left(\frac{k_{d}}{\lambda_{v}}+1\right) \frac{\bar{C}_{i}}{\bar{C}_{o}}+\frac{1}{\lambda_{v} \tau_{\exp }} \frac{C_{i}(t)-C_{i}(0)}{\bar{C}_{o}}
$$

Note that the first and second terms on the right hand side of Equations (5.4) and (5.5) represent the time-averaged and transient terms, respectively. The time-averaged terms tend to remain consistent in magnitude with increasing experimental duration. The transient terms, on the other hand, decrease inversely with $\tau_{\text {exp }}$. Given a sufficient experimental time interval, the transient terms are expected to become negligible in comparison to the time-averaged terms. 